Cochrane Database of Systematic Reviews

\title{
Lifestyle interventions for the treatment of women with gestational diabetes (Review)
}

Brown J, Alwan NA, West J, Brown S, McKinlay CJD, Farrar D, Crowther CA

Brown J, Alwan NA, West J, Brown S, McKinlay CJD, Farrar D, Crowther CA.

Lifestyle interventions for the treatment of women with gestational diabetes.

Cochrane Database of Systematic Reviews 2017, Issue 5. Art. No.: CD011970.

DOI: 10.1002/14651858.CD011970.pub2.

www.cochranelibrary.com 
TABLE OF CONTENTS

HEADER

ABSTRACT

PLAIN LANGUAGE SUMMARY

SUMMARY OF FINDINGS

BACKGROUND

OBJECTIVES

METHODS

RESULTS

Figure 1.

Figure 2.

Figure 3.

Figure 4.

DISCUSSION

AUTHORS' CONCLUSIONS

ACKNOWLEDGEMENTS

REFERENCES

CHARACTERISTICS OF STUDIES

DATA AND ANALYSES

Analysis 1.1. Comparison 1 Lifestyle intervention versus usual care/control, Outcome 1 Hypertensive disorders of pregnancy (including pre-eclampsia, pregnancy-induced hypertension, eclampsia).

Analysis 1.2. Comparison 1 Lifestyle intervention versus usual care/control, Outcome 2 Caesarean section.

Analysis 1.3. Comparison 1 Lifestyle intervention versus usual care/control, Outcome 3 Development of type 2 diabetes. .......

Analysis 1.4. Comparison 1 Lifestyle intervention versus usual care/control, Outcome 4 Perinatal (fetal and neonatal death) and later infant mortality.

Analysis 1.5. Comparison 1 Lifestyle intervention versus usual care/control, Outcome 5 Large-for-gestational age. ................. Analysis 1.6. Comparison 1 Lifestyle intervention versus usual care/control, Outcome 6 Death or serious morbidity composite (variously defined by trials, e.g. perinatal or infant death, shoulder dystocia, bone fracture or nerve palsy).

Analysis 1.7. Comparison 1 Lifestyle intervention versus usual care/control, Outcome 7 Use of additional pharmacotherapy. ...

Analysis 1.8. Comparison 1 Lifestyle intervention versus usual care/control, Outcome 8 Maternal hypoglycaemia.

Analysis 1.9. Comparison 1 Lifestyle intervention versus usual care/control, Outcome 9 Glycaemic control during/end treatment.

Analysis 1.10. Comparison 1 Lifestyle intervention versus usual care/control, Outcome 10 Weight gain in pregnancy (kg). ...... Analysis 1.11. Comparison 1 Lifestyle intervention versus usual care/control, Outcome 11 Induction of labour. ....................... Analysis 1.12. Comparison 1 Lifestyle intervention versus usual care/control, Outcome 12 Postpartum haemorrhage. ............ Analysis 1.13. Comparison 1 Lifestyle intervention versus usual care/control, Outcome 13 Postnatal infection/pyrexia. .......... Analysis 1.14. Comparison 1 Lifestyle intervention versus usual care/control, Outcome 14 Perineal trauma/tear. ................... Analysis 1.15. Comparison 1 Lifestyle intervention versus usual care/control, Outcome 15 Breastfeeding at discharge, six weeks postpartum, six months or longer.

Analysis 1.16. Comparison 1 Lifestyle intervention versus usual care/control, Outcome 16 Sense of well-being and quality of lifeduring treatment.

Analysis 1.17. Comparison 1 Lifestyle intervention versus usual care/control, Outcome 17 Sense of well-being and quality of life three months postpartum.

Analysis 1.18. Comparison 1 Lifestyle intervention versus usual care/control, Outcome 18 Postnatal depression.

Analysis 1.19. Comparison 1 Lifestyle intervention versus usual care/control, Outcome 19 Postnatal weight retention or return to pre-pregnancy weight.

Analysis 1.20. Comparison 1 Lifestyle intervention versus usual care/control, Outcome 20 Fasting plasma glucose 3 months postpartum $\mathrm{mmol} / \mathrm{L}$.

Analysis 1.21. Comparison 1 Lifestyle intervention versus usual care/control, Outcome 21 Maternal postnatal impaired glucose tolerance.

Analysis 1.22. Comparison 1 Lifestyle intervention versus usual care/control, Outcome 22 Maternal metabolic syndrome (follow-up)

Analysis 1.23. Comparison 1 Lifestyle intervention versus usual care/control, Outcome 23 Stillbirth.

Analysis 1.24. Comparison 1 Lifestyle intervention versus usual care/control, Outcome 24 Neonatal death. 
Analysis 1.25. Comparison 1 Lifestyle intervention versus usual care/control, Outcome 25 Macrosomia.

Analysis 1.26. Comparison 1 Lifestyle intervention versus usual care/control, Outcome 26 Small-for-gestational age. ............. Analysis 1.27. Comparison 1 Lifestyle intervention versus usual care/control, Outcome 27 Birth trauma (shoulder dystocia, bone fracture, nerve palsy).

Analysis 1.28. Comparison 1 Lifestyle intervention versus usual care/control, Outcome 28 Gestational age at birth (weeks). .... Analysis 1.29. Comparison 1 Lifestyle intervention versus usual care/control, Outcome 29 Preterm birth (<37 weeks' gestation; and $<32$ weeks' gestation).

Analysis 1.30. Comparison 1 Lifestyle intervention versus usual care/control, Outcome 30 Five-minute Apgar less than seven. . Analysis 1.31. Comparison 1 Lifestyle intervention versus usual care/control, Outcome 31 Birthweight (grams).

Analysis 1.32. Comparison 1 Lifestyle intervention versus usual care/control, Outcome 32 Length (cm).

Analysis 1.33. Comparison 1 Lifestyle intervention versus usual care/control, Outcome 33 Adiposity (Neonatal fat mass (g)). ... Analysis 1.34. Comparison 1 Lifestyle intervention versus usual care/control, Outcome 34 Neonatal hypoglycaemia. ............... Analysis 1.35. Comparison 1 Lifestyle intervention versus usual care/control, Outcome 35 Respiratory distress syndrome. ...... Analysis 1.36. Comparison 1 Lifestyle intervention versus usual care/control, Outcome 36 Neonatal jaundice (hyperbilirubinaemia).

Analysis 1.37. Comparison 1 Lifestyle intervention versus usual care/control, Outcome 37 Hypocalcaemia. ............................

Analysis 1.38. Comparison 1 Lifestyle intervention versus usual care/control, Outcome 38 Polycythemia.

Analysis 1.39. Comparison 1 Lifestyle intervention versus usual care/control, Outcome 39 Childhood weight (kg).

Analysis 1.40. Comparison 1 Lifestyle intervention versus usual care/control, Outcome 40 Childhood height (cm). .................. Analysis 1.41. Comparison 1 Lifestyle intervention versus usual care/control, Outcome 41 Adiposity (Childhood BMI > 85th percentile).

Analysis 1.42. Comparison 1 Lifestyle intervention versus usual care/control, Outcome 42 Adiposity (BMI Z score childhood). .. Analysis 1.43. Comparison 1 Lifestyle intervention versus usual care/control, Outcome 43 Childhood glycaemic control (mmol/ L).

Analysis 1.44. Comparison 1 Lifestyle intervention versus usual care/control, Outcome 44 Dyslipidaemia or metabolic syndrome (Childhood cholesterol (mg/dL)).

Analysis 1.45. Comparison 1 Lifestyle intervention versus usual care/control, Outcome 45 Number of antenatal visits or admissions.

Analysis 1.46. Comparison 1 Lifestyle intervention versus usual care/control, Outcome 46 Number of hospital or health professional visits (including midwife, obstetrician, physician, dietician, diabetic nurse).

Analysis 1.47. Comparison 1 Lifestyle intervention versus usual care/control, Outcome 47 Number of hospital or health professional visits (including midwife, obstetrician, physician, dietician, diabetic nurse)l.

Analysis 1.48. Comparison 1 Lifestyle intervention versus usual care/control, Outcome 48 Admission to neonatal intensive care unit/nursery.

ADDITIONAL TABLES 
[Intervention Review]

\section{Lifestyle interventions for the treatment of women with gestational diabetes}

Julie Brown ${ }^{1}$, Nisreen A Alwan², Jane West ${ }^{3}$, Stephen Brown ${ }^{4}$, Christopher JD McKinlay ${ }^{1}$, Diane Farrar ${ }^{5}$, Caroline A Crowther ${ }^{1}$

1Liggins Institute, The University of Auckland, Auckland, New Zealand. 2Academic Unit of Primary Care and Population Sciences, Faculty of Medicine, University of Southampton, Southampton, UK. ${ }^{3}$ Bradford Institute for Health Research, Bradford Teaching Hospitals NHS Foundation Trust, Bradford, UK. ${ }^{4}$ School of Interprofessional Health Studies, Auckland University of Technology, Auckland, New Zealand. 5 Maternal and Child Health, Bradford Institute for Health Research, Bradford, UK

Contact address: Julie Brown, Liggins Institute, The University of Auckland, Park Rd, Grafton, Auckland, 1142, New Zealand. j.brown@auckland.ac.nz.

Editorial group: Cochrane Pregnancy and Childbirth Group.

Publication status and date: New, published in Issue 5, 2017.

Citation: Brown J, Alwan NA, West J, Brown S, McKinlay CJD, Farrar D, Crowther CA. Lifestyle interventions for the treatment of women with gestational diabetes. Cochrane Database of Systematic Reviews 2017, Issue 5. Art. No.: CD011970. DOI: 10.1002/14651858.CD011970.pub2.

Copyright @ 2017 The Cochrane Collaboration. Published by John Wiley \& Sons, Ltd.

\section{A B S T R A C T}

\section{Background}

Gestational diabetes (GDM) is glucose intolerance, first recognised in pregnancy and usually resolving after birth. GDM is associated with both short- and long-term adverse effects for the mother and her infant. Lifestyle interventions are the primary therapeutic strategy for many women with GDM.

\section{Objectives}

To evaluate the effects of combined lifestyle interventions with or without pharmacotherapy in treating women with gestational diabetes.

\section{Search methods}

We searched the Pregnancy and Childbirth Group's Trials Register (14 May 2016), ClinicalTrials.gov, WHO International Clinical Trials Registry Platform (ICTRP) (14th May 2016) and reference lists of retrieved studies.

\section{Selection criteria}

We included only randomised controlled trials comparing a lifestyle intervention with usual care or another intervention for the treatment of pregnant women with GDM. Quasi-randomised trials were excluded. Cross-over trials were not eligible for inclusion. Women with preexisting type 1 or type 2 diabetes were excluded.

\section{Data collection and analysis}

We used standard methodological procedures expected by the Cochrane Collaboration. All selection of studies, data extraction was conducted independently by two review authors.

\section{Main results}

Fifteen trials (in 45 reports) are included in this review (4501 women, 3768 infants). None of the trials were funded by a conditional grant from a pharmaceutical company. The lifestyle interventions included a wide variety of components such as education, diet, exercise and self-monitoring of blood glucose. The control group included usual antenatal care or diet alone. Using GRADE methodology, the quality of the evidence ranged from high to very low quality. The main reasons for downgrading evidence were inconsistency and risk of bias. We summarised the following data from the important outcomes of this review. 


\section{Lifestyle intervention versus control group}

For the mother:

There was no clear evidence of a difference between lifestyle intervention and control groups for the risk of hypertensive disorders of

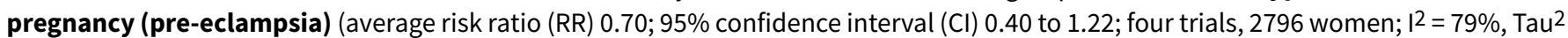
= 0.23; low-quality evidence); caesarean section (average RR 0.90; 95\% Cl 0.78 to $1.05 ; 10$ trials, 3545 women; $\left.\right|^{2}=48 \%$, Tau ${ }^{2}=0.02 ;$ lowquality evidence); development of type 2 diabetes (up to a maximum of 10 years follow-up) (RR $0.98,95 \% \mathrm{Cl} 0.54$ to 1.76 ; two trials, 486 women; $1^{2}=16 \%$; low-quality evidence); perineal trauma/tearing ( $\mathrm{RR} 1.04,95 \% \mathrm{Cl} 0.93$ to 1.18; one trial, $\mathrm{n}=1000$ women; moderate-quality evidence) or induction of labour (average RR $1.20,95 \% \mathrm{Cl} 0.99$ to 1.46 ; four trials, $\mathrm{n}=2699$ women; 12 = 37\%; high-quality evidence).

More women in the lifestyle intervention group had met postpartum weight goals one year after birth than in the control group (RR $1.75,95 \% \mathrm{Cl} 1.05$ to $2.90 ; 156$ women; one trial, low-quality evidence). Lifestyle interventions were associated with a decrease in the risk of postnatal depression compared with the control group ( $\mathrm{RR} 0.49,95 \% \mathrm{Cl} 0.31$ to 0.78 ; one trial, $\mathrm{n}=573$ women; low-quality evidence).

For the infant/child/adult:

Lifestyle interventions were associated with a reduction in the risk of being born large-for-gestational age (LGA) (RR $0.60,95 \% \mathrm{Cl} 0.50$ to 0.71 ; six trials, 2994 infants; $I^{2}=4 \%$; moderate-quality evidence). Birthweight and the incidence of macrosomia were lower in the lifestyle intervention group.

Exposure to the lifestyle intervention was associated with decreased neonatal fat mass compared with the control group (mean difference (MD) $-37.30 \mathrm{~g}, 95 \% \mathrm{Cl}-63.97$ to -10.63 ; one trial, 958 infants; low-quality evidence). In childhood, there was no clear evidence of a difference between groups for body mass index (BMI) $\geq 85$ th percentile (RR 0.91, 95\% Cl 0.75 to 1.11 ; three trials, $767 \mathrm{children} ; \mathrm{I}^{2}=4 \%$; moderate-quality evidence).

There was no clear evidence of a difference between lifestyle intervention and control groups for the risk of perinatal death (RR $0.09,95 \%$ $\mathrm{Cl} 0.01$ to 1.70; two trials, 1988 infants; low-quality evidence). Of 1988 infants, only five events were reported in total in the control group and there were no events in the lifestyle group. There was no clear evidence of a difference between lifestyle intervention and control groups for a composite of serious infant outcome/s (average RR $0.57,95 \% \mathrm{Cl} 0.21$ to 1.55 ; two trials, 1930 infants; $\left.\right|^{2}=82 \%$, Tau ${ }^{2}=0.44$;

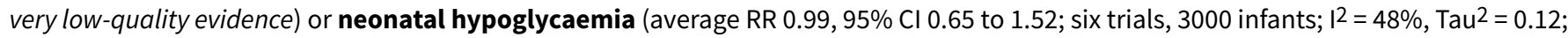
moderate-quality evidence).

Diabetes and adiposity in adulthood and neurosensory disability in later childhoodwere not prespecified or reported as outcomes for any of the trials included in this review.

\section{Authors' conclusions}

Lifestyle interventions are the primary therapeutic strategy for women with GDM. Women receiving lifestyle interventions were less likely to have postnatal depression and were more likely to achieve postpartum weight goals. Exposure to lifestyle interventions was associated with a decreased risk of the baby being born LGA and decreased neonatal adiposity. Long-term maternal and childhood/adulthood outcomes were poorly reported.

The value of lifestyle interventions in low-and middle-income countries or for different ethnicities remains unclear. The longer-term benefits or harms of lifestyle interventions remains unclear due to limited reporting.

The contribution of individual components of lifestyle interventions could not be assessed. Ten per cent of participants also received some form of pharmacological therapy. Lifestyle interventions are useful as the primary therapeutic strategy and most commonly include healthy eating, physical activity and self-monitoring of blood glucose concentrations.

Future research could focus on which specific interventions are most useful (as the sole intervention without pharmacological treatment), which health professionals should give them and the optimal format for providing the information. Evaluation of long-term outcomes for the mother and her child should be a priority when planning future trials. There has been no in-depth exploration of the costs 'saved' from reduction in risk of $L G A /$ macrosomia and potential longer-term risks for the infants.

\section{PLAIN LANGUAGE SUMMARY}

\section{Lifestyle interventions for treating women with gestational diabetes (or diabetes in pregnancy)}

\section{What is the issue?}

Gestational diabetes (GDM), is a glucose intolerance leading to high blood glucose levels that is first recognised during pregnancy and which usually normalises after giving birth. Diabetes during pregnancy has been linked to many short-term and long-term health problems for the mother and her baby. The main way to treat GDM is through lifestyle changes such as diet, exercise and checking blood glucose levels. 


\section{Why is this important?}

Women with GDM have an increased risk of developing high blood pressure during pregnancy (pre-eclampsia) and are more likely to have their labour induced. The babies of women with GDM are more likely to be large when born and this can be linked to babies having birth trauma (bones broken or nerves damaged during the birth) and the need for giving birth by caesarean section. Lifestyle interventions that include two or more components of dietary advice, physical activity, education, and self-monitoring of blood glucose are the first-line treatment for most women diagnosed with GDM. Interventions such as healthy eating and physical activity aim to help women maintain their blood glucose levels within a target range and to improve health outcomes for the mother and baby.

\section{What evidence did we find?}

We searched the literature (May 2016) for controlled trials comparing lifestyle intervention with a control group of women receiving usual care or another intervention. Fifteen randomised controlled trials ( 45 publications) are included in this review, involving 4501 women and 3768 infants. None of the trials were funded by a conditional grant from a pharmaceutical company.

For the baby, lifestyle interventions were associated with a reduction in the risk of being born large-for-gestational age (six trials, 2994 infants). The number of babies with birthweight over $4000 \mathrm{~g}$ (macrosomia) was lower with the lifestyle intervention, with no clear difference in the number of newborn babies experiencing low blood glucose levels (six trials, 3000 infants). The evidence was of moderate quality for these findings. Birthweight was also lower in the lifestyle intervention group.

For the mothers, introducing lifestyle interventions made no clear difference in the number of women with pregnancy-induced high blood pressure (four trials, 2796 women) or having a caesarean section (10 trials, 3545 women) based on low-quality evidence or on induction of labour (four trials, 2699 women, high-quality evidence). Similar numbers of women experienced perineal trauma or tearing (one trial, 1000 women) or developed type 2 diabetes at a maximum of 10 years after giving birth (two trials, 486 women). These findings were supported by low- to moderate-quality evidence.

More women in the lifestyle group had met their weight goals one year after giving birth, and lifestyle interventions were associated with a decrease in the risk of depression after birth, from single trials. These findings were supported by low quality evidence.

\section{What does this mean?}

Lifestyle interventions provide benefits to women with GDM and their babies. The interventions are useful as the primary therapeutic strategy and generally include, as a minimum, healthy eating, physical activity and self-monitoring of blood sugar levels.

Furture research could focus on the effective components of lifestyle interventions and the use of lifestyle interventions as the sole intervention without pharmacological treatment. Future studies also need to consider long-term outcomes for the mother and her child as a priority when planning future trials. 


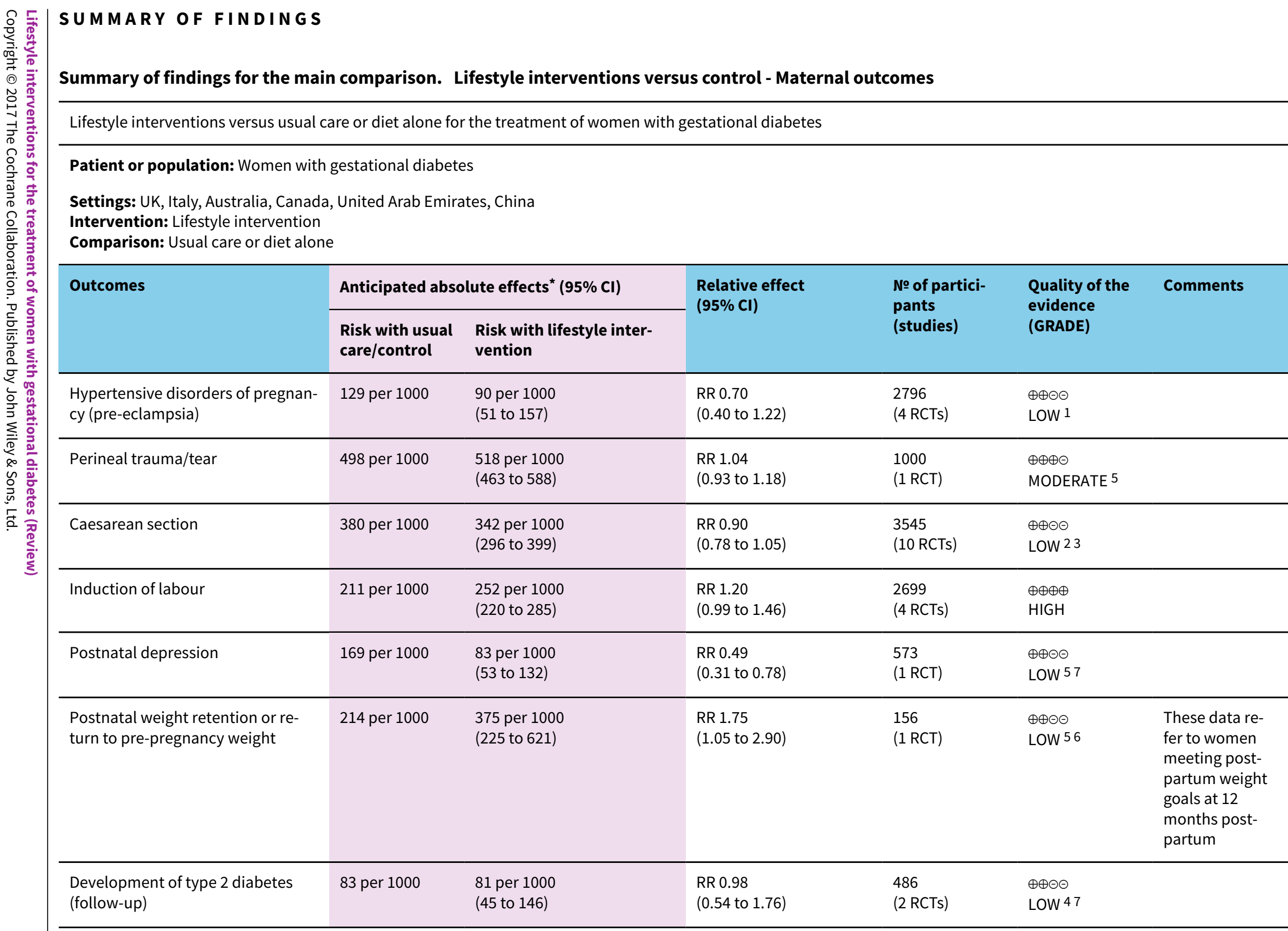

Settings: UK, Italy, Australia, Canada, United Arab Emirates, China 
*The risk in the intervention group (and its $95 \%$ confidence interval) is based on the assumed risk in the comparison group and the relative effect of the intervention (and its $95 \% \mathrm{Cl})$.

\section{Cl: Confidence interval; RR: Risk ratio}

\section{GRADE Working Group grades of evidence}

High quality: We are very confident that the true effect lies close to that of the estimate of the effect

Moderate quality: We are moderately confident in the effect estimate: The true effect is likely to be close to the estimate of the effect, but there is a possibility that it is substantially different

Low quality: Our confidence in the effect estimate is limited: The true effect may be substantially different from the estimate of the effect

Very low quality: We have very little confidence in the effect estimate: The true effect is likely to be substantially different from the estimate of effect

1 Evidence of inconsistency with $12>70 \%$, downgraded 2 levels

2 Evidence of selective reporting in more than half of the trials reporting this outcome - downgraded 1 level

3 Evidence of inconsistency with $\mathrm{I}^{2}=>50 \%$ but $<70 \%$, downgraded 1 level

4 Evidence of risk of bias with one of the two studies not blinding participants/researchers, downgraded 1 level

5 Imprecision - Evidence is based on a single trial, downgraded 1 level

6 Evidence of risk of bias - Allocation concealment unclear and no blinding of participants/researchers, downgraded 1 level

7 Evidence of risk of bias - attrition bias, downgraded 1 level

\section{Summary of findings 2 . Lifestyle versus control - Neonatal and later outcomes}

Lifestyle interventions versus usual care or diet alone for the treatment of women with gestational diabetes

Patient or population: Women with gestational diabetes

Settings: UK, Italy, Australia, United Arab Emirates, Canada, China, USA

Intervention: Lifestyle intervention

Comparison: Usual care or diet alone

\begin{tabular}{|c|c|c|c|c|c|c|}
\hline \multirow[t]{2}{*}{ Outcomes } & \multicolumn{2}{|c|}{ Anticipated absolute effects ${ }^{\star}(95 \% \mathrm{Cl})$} & \multirow{2}{*}{$\begin{array}{l}\text { Relative effect } \\
(95 \% \mathrm{Cl})\end{array}$} & \multirow{2}{*}{$\begin{array}{l}\text { № of partici- } \\
\text { pants } \\
\text { (studies) }\end{array}$} & \multirow{2}{*}{$\begin{array}{l}\text { Quality of the } \\
\text { evidence } \\
\text { (GRADE) }\end{array}$} & \multirow[t]{2}{*}{ Comments } \\
\hline & $\begin{array}{l}\text { Risk with usual } \\
\text { care/control }\end{array}$ & $\begin{array}{l}\text { Risk with lifestyle } \\
\text { intervention }\end{array}$ & & & & \\
\hline Large-for-gestational age & 189 per 1000 & $\begin{array}{l}113 \text { per } 1000 \\
\text { (95 to } 134 \text { ) }\end{array}$ & $\begin{array}{l}\text { RR } 0.60 \\
\text { (0.50 to } 0.71)\end{array}$ & $\begin{array}{l}2994 \\
\text { (6 RCTs) }\end{array}$ & $\begin{array}{l}\oplus \oplus \oplus \ominus \\
\text { MODERATE } 9\end{array}$ & \\
\hline $\begin{array}{l}\text { Perinatal (fetal and neonatal } \\
\text { death) and later infant mortali- } \\
\text { ty }\end{array}$ & 5 per 1000 & $\begin{array}{l}0 \text { per } 1000 \\
(0 \text { to } 9)\end{array}$ & $\begin{array}{l}\text { RR } 0.09 \\
\text { (0.01 to } 1.70)\end{array}$ & $\begin{array}{l}1988 \\
\text { (2 RCTs) }\end{array}$ & $\begin{array}{l}\oplus \oplus \odot \ominus \\
\text { LOW } 24\end{array}$ & $\begin{array}{l}\text { Analysis refers to perinatal death } \\
\text { only. No data were reported for lat- } \\
\text { er infant mortality }\end{array}$ \\
\hline
\end{tabular}




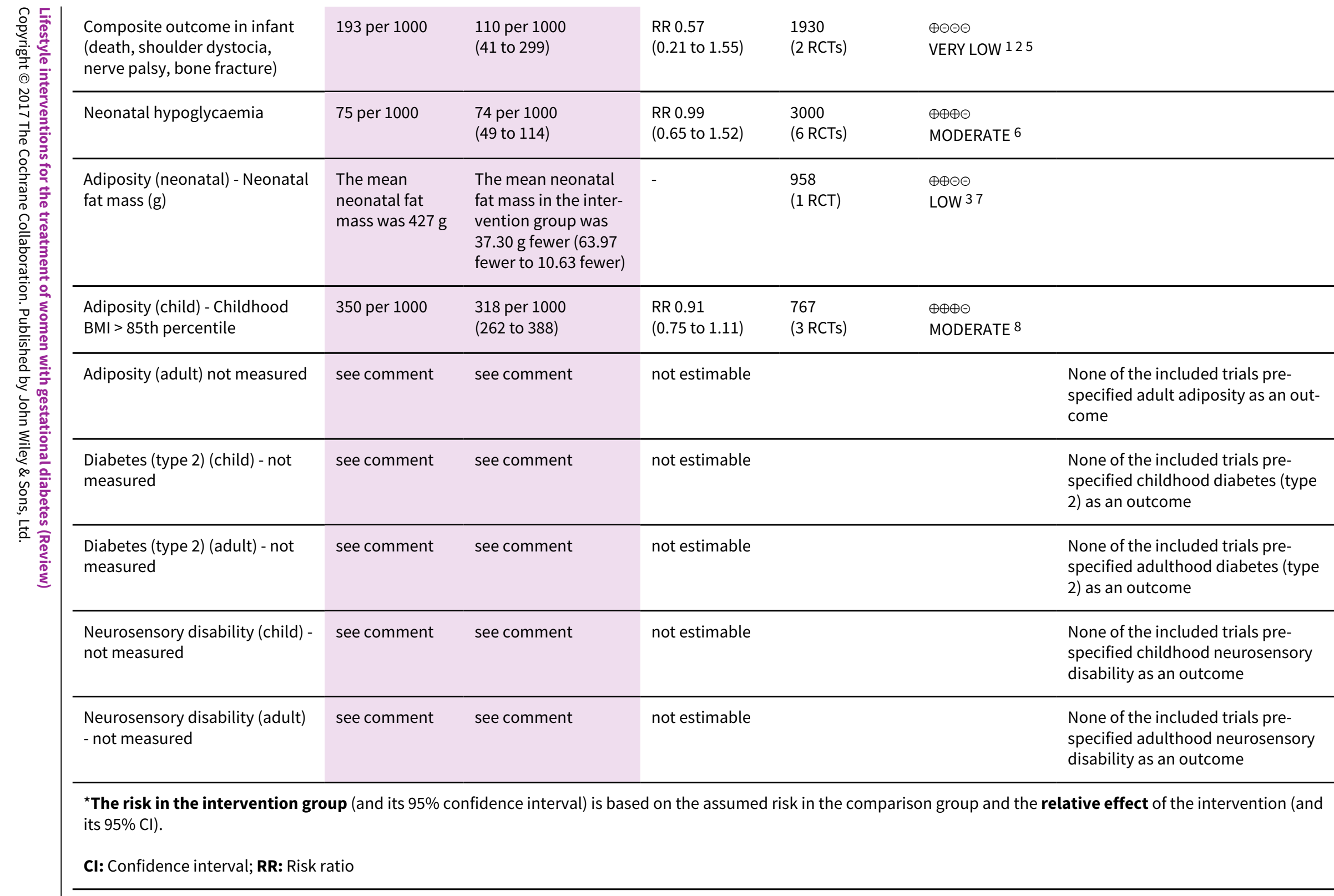

\section{GRADE Working Group grades of evidence}

High quality: We are very confident that the true effect lies close to that of the estimate of the effect

Moderate quality: We are moderately confident in the effect estimate: The true effect is likely to be close to the estimate of the effect, but there is a possibility that it is sub- 
1 Evidence of inconsistency with $12>70 \%$, downgraded 2 levels

21 of the 2 studies did not blind participants/researchers, downgraded 1 level

3 Imprecision. Evidence is based on a single trial, downgraded 1 level

4 There is evidence of imprecision with wide confidence intervals and low event rates, downgraded 1 level

5 Evidence of imprecision with wide confidence intervals crossing the line of no effect, downgraded 1 level

6 Allocation concealment was unclear in 2/6 trials and blinding was not undertaken in 2/6 trials, downgraded 1 level

7 There was no blinding of researchers/participants in this single trial, downgraded 1 level

8 Allocation concealment and randomisation was unclear in $1 / 3$ trials and $1 / 3$ trials did not blind participants/researchers, downgraded 1 level

9 Several of the included studies had high risk of bias for lack of blinding, incomplete outcome data and selective reporting, allocation concealment was unclear in 2 of the 6 studies. Downgraded 1 level. 


\section{B A C K G R O U N D}

The original review on Treatments for gestational diabetes (Alwan 2009) has been split into three new reviews due to the complexity of the included interventions. The following new review protocols are published.

Lifestyle interventions for the treatment of women with gestational diabetes (this review) (Brown 2015)

Oral anti-diabetic pharmacological therapies for the treatment of women with gestational diabetes (Brown 2015b)

Insulin for the treatment of women with gestational diabetes (Brown 2016)

There will be similarities in the background, methods and outcomes between these three systematic reviews. Portions of the methods section of this protocol are based on a standard template used by the Cochrane Pregnancy and Childbirth Review Group.

\section{Description of the condition}

Gestational diabetes mellitus (GDM), often referred to as gestational diabetes can be defined as 'glucose intolerance or hyperglycaemia (high blood glucose concentration) with onset or first recognition during pregnancy' (WHO 1999). GDM occurs when the body is unable to make enough insulin to meet the extra needs in pregnancy. The high blood sugars associated with GDM will usually return to normal after the birth of the baby. However, there is currently no universally accepted diagnostic criteria (ACOG 2013; Coustan 2010; HAPO 2008; Hoffman 1998; IADPSG 2010; Metzger 1998; NICE 2015). GDM may include previously undetected glucose intolerance (IADPSG 2010; Nankervis 2014; WHO 2013). In an attempt to distinguish women with diabetes mellitus in pregnancy from women with gestational diabetes, WHO 2013 provides separate diagnostic criteria. Some countries such as New Zealand have recommended early screening in the first trimester using glycated or glycosylated haemoglobin - HbA1C (glycated or glycosylated haemoglobin is a form of haemoglobin measured primarily to identify the average plasma glucose concentration over a period of time), with the aim that more women with overt diabetes will be diagnosed and treated appropriately (Ministry of Health 2014 - New Zealand). It should be noted that this screening is not used globally.

GDM is one of the most common pregnancy complications and the prevalence is rising worldwide with $1 \%$ to $36 \%$ of pregnancies being affected (Bottalico 2007; Cundy 2014; Duran 2014; Ferrara 2007; Kleinwechter 2014; NICE 2015; Tran 2013). The prevalence of GDM is likely to continue to increase along with the increasing prevalence of maternal obesity and associated type 2 diabetes mellitus (Bottalico 2007; Mulla 2010).

\section{Screening and diagnosis of GDM}

There are global variations in screening for GDM with some countries, such as the UK, using an assessment of risk for GDM based on maternal characteristics (NICE 2015), some countries, such as the USA, use either an assessment based on maternal risk factors or a $50 \mathrm{~g}$ oral glucose challenge test. In New Zealand all women with an $\mathrm{HbAlC}$ value in the normal range at the time of booking are offered the $50 \mathrm{~g}$ oral glucose challenge test at 24 to 28 weeks' gestation (Ministry of Health 2014).
Diagnosis of GDM is usually based on either a $75 \mathrm{~g}$ two-hour oral glucose tolerance test (OGTT) or a $100 \mathrm{~g}$ three-hour OGTT (ADA 2013; IADPSG 2010; Nankervis 2014; NICE 2015; WHO 1999; WHO 2013). Recommendations regarding diagnostic criteria vary nationally and internationally (Table 1), and these diagnostic criteria have changed over time, sometimes due to changing understanding about the effects of hyperglycaemia on pregnancy and infant outcomes (Coustan 2010), but also because of a lack of evidence clearly demonstrating the clinical and cost-effectiveness of one criterion over another.

The Hyperglycaemia and Adverse Pregnancy Outcomes (HAPO) study (HAPO 2008) was a large, international observational study that reported graded linear associations in the odds of several GDM-associated adverse outcomes and glucose concentrations at OGTT, with no clear threshold identified at which risk increased substantially. The International Association of the Diabetes and Pregnancy Study Groups (IADPSG) recommended diagnostic criteria using data from the HAPO study (IADPSG 2010) (Table 1). Applying the IADPSG criteria in most health environments will increase the number of women diagnosed with GDM. A study conducted in Vietnam showed that depending on the criteria used, the diagnosis of GDM varied between 5.9\% (American Diabetes Association - ADA), 20.4\% (IADPSG), 20.8\% (Australasian Diabetes in Pregnancy Society - ADIPS), and up to $24.3 \%$ (World Health Organization - WHO) (Tran 2013). A Bulgarian study also reported differences in prevalence based on the different diagnostic criteria used ranging from 10.8\% (European Association for the Study of Diabetes - EASD), $13.5 \%$ (ADA), $16.2 \%$ (New Zealand Society for the Study of Diabetes - NZSSD), 17.1\% (WHO), 21.2\% (ADIPS), 31.6\% (IADPSG) (Boyadzhieva 2012).

\section{Pathophysiology of GDM}

Normal pregnancy is associated with significant changes in maternal metabolism (Lain 2007). In early pregnancy, oestrogen and progesterone stimulate maternal beta-cell hyperplasia and insulin secretion, which promotes maternal nutrient storage (adipose and hepatic glycogen) to support later fetal growth. At this stage, insulin sensitivity is maintained or may even increase. However, as pregnancy progresses, whole-body insulin sensitivity steadily decreases, such that by the third trimester it is reduced by almost half (Barbour 2007). Several factors contribute to this, including placental hormones (human placental lactogen and placental growth hormone), cytokines released from adipocytes (e.g. IL-6, TNF-alpha), increased free fatty acids and lower adiponectin concentrations (Clapp 2006; Devlieger 2008). This results in decreased post-prandial peripheral glucose disposal by up to $40 \%$ to $60 \%$ (Barbour 2007). Because glucose is transported across the placenta to the fetus by facilitated diffusion, this state of physiological insulin resistance promotes fetal glucose uptake, a principal oxidative fuel and carbon source for the growing fetus. In normal pregnancy, maternal glycaemia is maintained by a significant increase in insulin secretion of up to $200 \%$ to $250 \%$ (Barbour 2007; Lain 2007; Suman Rao 2013).

Women who develop GDM have greater reductions in insulin sensitivity in pregnancy and are unable to increase insulin secretion sufficiently to maintain euglycaemia, especially after meals. Glucose intolerance results from both reduced insulin action in skeletal muscle, leading to decreased peripheral glucose disposal, and in the liver, resulting in inadequate suppression of endogenous glucose production. GDM is associated with impaired 
insulin signalling, with disruption of several components of the signalling cascade. Subclinical inflammation (TNF-alpha) and decreased secretion of adiponectin from adipocytes contribute to altered insulin signalling in women with GDM (Barbour 2007). The net effect in skeletal muscle is reduced insulin-mediated glucose uptake due to decrease translocation of the glucose transporter GLUT4 to the cell membrane.

In GDM, the steeper maternal-fetal glucose gradient, especially post-prandial, leads to increased fetal glucose uptake, which stimulates fetal insulin secretion. Insulin is a key fetal anabolic hormone and hyperinsulinaemia promotes fetal overgrowth, especially of fat, leading to large-for-gestational age (LGA) infants, macrosomia (larger than average baby), and possible organ damage (Catalano 2003; Ju 2008; Metzger 2008; Reece 2009).

Women with GDM have increased circulating inflammatory cytokines and lower adiponectin concentrations which can lead to insulin resistance in adipose tissue, which in turn results in increased lipolysis and fatty acid concentrations. Placental transfer of free fatty acids contributes to increased fetal adiposity, independent of glucose uptake (Knopp 1985). Thus, even women with well-controlled GDM still have an increased risk of fetal macrosomia (Langer 2005).

\section{Risk factors associated with GDM}

A variety of factors have been associated with an increased risk of developing GDM. Non-modifiable risk factors include advanced maternal age (Chamberlain 2013; Morisset 2010), high parity, nonCaucasian race or ethnicity (in particular South Asian, Middle Eastern), family history of diabetes mellitus, maternal high or low birthweight, polycystic ovarian syndrome (Cypryk 2008; Petry 2010; Solomon 1997), a history of having a previous macrosomic infant (birthweight $4000 \mathrm{~g}$ or more) and previous history of GDM (Petry 2010).

Modifiable risk factors include physical inactivity (Chasan-Taber 2008), having a low-fibre and high-glycaemic load diet (Zhang 2006), maternal overweight (body mass index (BMI) equal to or greater than $25 \mathrm{~kg} / \mathrm{m}^{2}$ ) or obesity (BMI equal to or greater than $30 \mathrm{~kg} / \mathrm{m}^{2}$ ) (Kim 2010a), and excessive weight gain during pregnancy, especially for those who are already overweight or obese (Hedderson 2010).

\section{Clinical outcomes for women with pregnancy hyperglycaemia}

Adverse outcomes have been consistently reported at higher rates in women diagnosed with GDM, and their infants, compared with women without GDM (Crowther 2005; Landon 2009; Metzger 2008; Reece 2009).

Women with GDM have an increased risk of developing preeclampsia, are more likely to have their labour induced (Anderberg 2010; Crowther 2005; Ju 2008; Landon 2009; Metzger 2008), and to give birth by caesarean section (Landon 2009; Metzger 2008). The incidence of uterine rupture, shoulder dystocia and perineal lacerations is increased in women with GDM due to the increased likelihood of having a LGA or macrosomic baby (Jastrow 2010). Women who have experienced GDM are at a greater risk of metabolic dysfunction in later life (Shah 2008; Vohr 2008), with a crude cumulative incidence of type 2 diabetes of $10 \%$ to $20 \%$ within 10 years (Bellamy 2009; Kim 2002), but up to $50 \%$ when adjusted for retention and length of follow-up (Kim 2002).

\section{Neonatal, infant and later outcomes related to pregnancy hyperglycaemia}

A significant adverse health outcome for babies born to mothers with GDM is being born LGA or macrosomic (Catalano 2003; Crowther 2005; Landon 2009; Metzger 2008; Reece 2009), which increases the risk of birth injury, including shoulder dystocia, perinatal asphyxia, bone fractures and nerve palsies (Esakoff 2009; Henriksen 2008; Langer 2005; Metzger 2008). Other adverse outcomes which are increased for babies born to women with GDM include respiratory distress syndrome, hypoglycaemia (which if prolonged can cause brain injury), hyperbilirubinaemia, hypertrophic cardiomyopathy, hypocalcaemia, hypomagnesaemia, polycythaemia and admission to the neonatal nursery (Metzger 2008; Reece 2009).

Babies born to women with GDM, compared with babies born to women without GDM, have significantly greater skinfold measures and fat mass (Catalano 2003), have greater adiposity (Pettitt 1985; Pettitt 1993), and are more likely to develop early overweight or obesity, type 2 diabetes (Hillier 2007; Pettitt 1993; Whincup 2008), and metabolic syndrome in childhood, adolescence or adulthood. Metabolic syndrome is a cluster of risk factors defined by the occurrence of three of the following: obesity, hypertension, hypertriglyceridaemia and low concentration of high-density lipoprotein (HDL) cholesterol (Guerrero-Romero 2010; Harder 2009).

The development of the metabolic syndrome during childhood is a risk factor for the development of adult type 2 diabetes at 25 to 30 years of age (Morrison 2008). These health problems repeat across generations (Dabelea 2005; Mulla 2010) and are important from a public health perspective, because with each generation the prevalence of diabetes increases.

\section{Description of the intervention}

GDM management aims to optimise glycaemic control and consequently improve pregnancy outcomes (Kim 2010b). Providing dietary and lifestyle advice is usually recommended as the primary therapeutic strategy for women with GDM (ACOG 2013; ADA 2015a; Hoffman 1998; NICE 2015). If diet and lifestyle management alone are insufficient to achieve targets for maternal glycaemic control, insulin therapy or oral anti-diabetic pharmacological therapies such as glibenclamide and metformin can be added (ACOG 2013; ADA 2013; Hoffman 1998; NICE 2015; Silva 2010; Simmons 2004). As part of GDM management, maternal glucose monitoring and ultrasonography are advised to monitor the effectiveness of treatment and to guide care for birth (ACOG 2013; Hoffman 1998; NICE 2015). However, treatment recommendations differ across countries, for example, serial ultrasonography is not recommended to guide treatment management in the New Zealand Ministry of Health guidelines (Ministry of Health 2014).

\section{Dietary intervention for managing GDM}

Diet therapy is the primary strategy for managing GDM. Elevated blood glucose concentrations, in particular elevations in postprandial glucose are associated with adverse pregnancy outcomes in GDM (de Veciana 1995). The role of different dietary interventions for treatment of women with GDM, assessed by head-to-head trials, has been described in the Cochrane systematic review by Han 2013 and will not be included in this systematic review. 
Carbohydrate-containing foods are important sources of energy, vitamins, minerals and fibre and are the main nutrient affecting blood glucose concentrations (Reader 2007). Blood glucose concentrations are affected by both total amount and type of carbohydrates consumed (Reader 2007). Glycaemic index (GI) is a ranking of the effects of carbohydrates on blood glucose concentrations (Jenkins 1981). Foods with a low GI (less than 55) produce a lower post-prandial glucose elevation and area under the glucose curve; foods with a high GI (more than 70) produce a rapid increase in post-prandial blood glucose concentrations (Jenkins 1981). Outside of pregnancy, consumption of low-GI diets by people with diabetes seems to help lower glycated or glycosylated haemoglobin - HbA1C (Thomas 2010). Use of low-Gl diets in GDM management seems to be beneficial in reducing the need for insulin, though the evidence is limited (Moses 2009). Polyunsaturated fatty acids may be protective against impaired glucose tolerance, while saturated fatty acids can increase glucose and insulin concentrations in women with GDM (Ilic 1999). Reducing blood lipid concentrations may improve glycaemic control and pregnancy outcomes in GDM (Barrett 2014). However, the specific amount and sources of fat that are beneficial for GDM management are not clear (Kim 2010b). Therefore, recommendations on the fat intake for women with GDM have not yet been promulgated (ACOG 2013; Hoffman 1998; Metzger 2007; (New Zealand) Ministry of Health 2014; NICE 2015). Recommendations on the intake of other nutrients for women with GDM are usually based on the general recommendations for people with diabetes mellitus outside pregnancy (Cheung 2009).

\section{Physical activity during pregnancy for managing GDM}

The role of supplementary physical activity interventions for the management of glycaemic control in women with diabetes in pregnancy (including GDM) was one of the comparisons described in the Cochrane review by Ceysens 2006. In non-pregnant women with type 2 diabetes, physical activity (in addition to diet and insulin) helped to normalise blood glucose levels (Tuomilehto 2001). Caution is required when generalising this evidence to pregnant women, but it potentially suggests that during pregnancy mild exercise could reduce the risk of complications related to high blood glucose and high insulin levels, including macrosomia, birth trauma, respiratory distress, neonatal hypoglycaemia and hypocalcaemia. Exercise interventions alone for treating women with gestational diabetes will not be included in this systematic review.

\section{Appropriate weight gain during pregnancy}

Interventions for preventing excessive weight gain in pregnancy (diet or exercise or both) have been described in the Cochrane systematic review by Muktabhant 2015, which included 65 randomised controlled trials, of which seven recruited women who were at high risk of gestational diabetes. Given the high prevalence of overweight and obesity in women with GDM, dietary interventions for appropriate pregnancy weight gain are routinely included as a part of nutritional management of GDM (Kim 2010b). Small reductions in weight improve glycaemic control (ACOG 2005), but the implications in pregnancy for the mother and fetus are unclear.

In 2009, the American Institute of Medicine updated their guidelines for weight gain during pregnancy. Guidance is stratified by prepregnancy BMI, i.e. women with a pre-pregnancy BMI between 25 $\mathrm{kg} / \mathrm{m}^{2}$ and $29.9 \mathrm{~kg} / \mathrm{m}^{2}$ should aim for $6.8 \mathrm{~kg}$ to $11.4 \mathrm{~kg}$ weight gain and those with pre-pregnancy BMI of $30 \mathrm{~kg} / \mathrm{m}^{2}$ or more should aim for $5 \mathrm{~kg}$ to $9 \mathrm{~kg}$ weight gain (IOM 2009). However, the degree of energy restriction for pre-pregnancy overweight and obese women to achieve these weight gain goals is unknown and based on observational data (Kim 2010b).

Dietary interventions provided for women with GDM should ensure adequate nutrients for normal fetal growth and maternal health, but not induce weight loss or excessive weight gain during pregnancy; the main aim however is to promote optimal glycaemic control (ACOG 2013; Hoffman 1998; Metzger 2007; NICE 2015).

\section{Combined dietary intervention and physical activity during pregnancy for managing GDM}

Some interventions may involve a combination of dietary and physical activity modalities. Regular physical activity may help normalise maternal blood glucose for pregnant women with gestational diabetes and in combination with dietary interventions may reduce the need for oral anti-diabetic agents or insulin. As women with gestational diabetes are at increased risk of developing type 2 diabetes in the future, regular physical activity may also help reduce the risk of this long-term complications (Tuomilehto 2011).

\section{Other interventions during pregnancy for managing GDM}

There may be other interventions, including psychological approaches that could be used independently or alongside physical activity or dietary modalities such as mindfulness eating, yoga or spiritual support.

\section{How the intervention might work}

\section{Role of diet}

A carbohydrate-controlled diet (with carbohydrates distributed evenly throughout the day) that provides adequate nutrition, alongside glycaemic control and avoids ketonuria (ketones are produced when stored fat is utilised to produce energy in the absence of glucose) is thought to be optimal to reduce complications associated with gestational diabetes (Dornhorst 2002). Other elements of diet such as fat and fibre are also thought to influence maternal blood glucose concentrations (Zhang 2006). Excess fetal growth is most effectively limited by normal post-prandial maternal glucose concentrations (de Veciana 1995; Dornhorst 2002; Harmon 2011; Rowan 2011; Weisz 2005). Dietary advice in the second trimester, when insulin resistance is increasing, may help reduce the risk of adverse outcomes associated with GDM (Dornhorst 2002).

\section{Role of physical activity}

Insulin sensitivity in skeletal muscle is related to the degree of physical activity, and therefore, physical activity interventions may improve insulin sensitivity and glucose control in individuals with diabetes (Asano 2014).

Glucose enters skeletal muscle cells via facilitated diffusion through a glucose transporter (GLUT4). Peripheral clearance of glucose in skeletal muscle depends on blood flow to muscle, expression of GLUT4 transporters and intracellular utilisation of glucose through glycolysis and glycogenesis. Translocation of the GLUT4 transporter is induced by insulin and insulin-independent mechanisms (Richter 
2001). Exercise increases glucose uptake in skeletal muscle (Asano 2014), and improves glucose homeostasis and insulin sensitivity in skeletal muscle. Exercise potentiates most of the insulinmediated post-receptor events that lead to an increased expression of GLUT4, and GLUT4 translocation from intracellular stores to the muscle membrane. These exercise-induced improvements in glucose uptake, however, are not limited to changes in GLUT4 expression. The improvements in insulin sensitivity after regular exercise may be related to changes in expression and/or activity of proteins involved in insulin signal transduction in skeletal muscle. As such, the enhanced glucose uptake in skeletal muscle attributed to exercise might be related to an increased expression and activity of key proteins for insulin signalling such as insulin receptor, insulin receptor substrate, and phosphatidylinositol 3-kinase (Chibalin 2000; Dela 1993; Hjeltnes 1998). Physical activity improves blood supply to the active skeletal muscles (Jensen 2004), counteracts the ability of lipids to induce insulin resistance (Schenk 2005), and modifies the hormonal regulation of hepatic glucose output. These exercise-induced alterations in muscle glucose handling explain most of the insulin-sensitising and diabetes-preventing effects of exercise, and partly explain why the many defects of insulin action observed in type 2 diabetes and insulin resistance are reversed by the effects of exercise (Zierath 2002).

\section{Self-monitoring of blood glucose}

Self-monitoring of blood glucose is performed by most women with GDM. Evidence has suggested that self-monitoring between four and seven times per day (including fasting and post-prandial measurements) can contribute to improved maternal and perinatal outcomes (ADA 2015a), and is likely to be most effective when combined with effective treatment.

\section{Why it is important to do this review}

GDM affects a significant proportion of pregnant women and the prevalence is increasing worldwide (Bottalico 2007; Dabelea 2005; Mulla 2010). GDM is associated with an increased risk of a range of adverse pregnancy outcomes and these adverse health outcomes repeat across generations (Metzger 2008; Mulla 2010), which has important implications for the future. Providing dietary and lifestyle advice is usually recommended as the primary therapeutic strategy for women with GDM (ACOG 2013; Hoffman 1998; (New Zealand) Ministry of Health 2014; NICE 2015).

Two other Cochrane reviews cover comparisons of individual lifestyle components (diet and exercise) 'Different types of dietary advice for women with gestational diabetes mellitus' (Han 2013). This review examined the effects of two or more modalities of dietary interventions compared with each other for treating women with GDM, i.e. standard dietary advice compared with individualised dietary advice, individual dietary education sessions compared with group dietary education sessions, single dietary counselling session compared with multiple dietary counselling sessions. 'Exercise for diabetic pregnant women' (Ceysens 2006). This review evaluated the effects of physical activity interventions with or without dietary interventions compared with no additional physical activity intervention for women with diabetes in pregnancy and the trials included in the review recruited women with gestational diabetes.

\section{O B JECTIVES}

To evaluate the effects of combined lifestyle interventions with or without pharmacotherapy in treating women with gestational diabetes.

\section{METHODS}

\section{Criteria for considering studies for this review Types of studies}

We included published or unpublished randomised controlled trials in full text or abstract format. If identified, we planned to include cluster-randomised trials. Quasi-randomised trials were excluded. Cross-over trials were not eligible for inclusion. Conference abstracts were handled in the same way as full-text publications.

\section{Types of participants}

Participants were pregnant women diagnosed with gestational diabetes (diagnosis as defined by the individual trial). Women with known type 1 or type 2 diabetes were excluded.

\section{Types of interventions}

We included randomised trials comparing lifestyle interventions (as defined by trialists) with:

- expectant management, standard care;

- other lifestyle intervention or combination of lifestyle interventions not described below.

The aim of the interventions was to maintain maternal glycaemic targets during pregnancy in women with gestational diabetes.

Lifestyle interventions could include a combination of at least two or more of the following interventions:

- diet;

- physical activity;

- education;

- behavioural change techniques;

- regimens of self-monitoring of blood glucose;

- other intervention not previously specified.

These interventions may or may not require adjunctive pharmacotherapy (oral anti-diabetic pharmacological therapies, insulin) used to treat women with gestational diabetes.

Interventions examining the comparison of different dietary interventions or the effects of exercise alone are not be included in this review as they are already included in other Cochrane systematic reviews (Han 2013 and Ceysens 2006, respectively).

\section{Types of outcome measures}

The following standardised outcomes have been developed through a process involving authors of Cochrane reviews for treatment interventions for women with gestational diabetes mellitus (GDM).

This review focuses on the potential effectiveness of multicomponent lifestyle interventions. 


\section{Primary outcomes}

\section{Maternal}

- Hypertensive disorders of pregnancy (including pre-eclampsia, pregnancy-induced hypertension, eclampsia as defined by trialists)

- Caesarean section

- Development of type 2 diabetes

\section{Neonatal}

- Perinatal (fetal and neonatal death) and later infant mortality

- Large-for-gestational age (LGA) (as defined by trialists)

- Death or serious morbidity composite (variously defined by trials, e.g. perinatal or infant death, shoulder dystocia, bone fracture or nerve palsy)

- Neurosensory disability in later childhood (as defined by trialists)

\section{Secondary outcomes}

\section{Maternal}

- Use of additional pharmacotherapy

- Maternal hypoglycaemia (as defined by trialists)

- Glycaemic control during/end of treatment (as defined by trialists)

- Weight gain in pregnancy

- Adherence to the intervention

- Induction of labour

- Placental abruption

- Postpartum haemorrhage (as defined by trialists)

- Postpartum infection

- Perineal trauma/tear

- Breastfeeding at discharge, six weeks postpartum, six months or longer

- Maternal mortality

- Sense of well-being and quality of life

- Behavioural changes associated with the intervention

- Views of the intervention

- Relevant biomarker changes associated with the intervention (including adiponectin, free fatty acids, triglycerides, highdensity lipoproteins (HDL), low-density lipoproteins (LDL), insulin)

\section{Long-term outcomes for mother}

- Postnatal depression

- Body mass index (BMI)

- Postnatal weight retention or return to pre-pregnancy weight

- Type 1 diabetes

- Impaired glucose tolerance

- Subsequent gestational diabetes

- Cardiovascular health (as defined by trialists including blood pressure, hypertension, cardiovascular disease, metabolic syndrome)

\section{Fetal/neonatal outcomes}

- Stillbirth
- Neonatal death

- Macrosomia (greater than $4000 \mathrm{~g}$; or as defined by individual study)

- Small-for-gestational (SGA) age (as defined by trialists)

- Birth trauma (shoulder dystocia, bone fracture, nerve palsy)

- Gestational age at birth

- Preterm birth (<37 weeks' gestation; and < 32 weeks' gestation)

- Five-minute Apgar less than seven

- Birthweight and z score

- Head circumference and z score

- Length and z score

- Ponderal index

- Adiposity (including skinfold thickness measurements (mm); fat mass as defined by trialists)

- Neonatal hypoglycaemia (as defined by trialists)

- Respiratory distress syndrome

- Neonatal jaundice (hyperbilirubinaemia) (as defined by trialists)

- Hypocalcaemia (as defined by trialists)

- Polycythaemia (as defined by trialists)

- Relevant biomarker changes associated with the intervention (including insulin, cord c-peptide)

\section{Later infant/childhood outcomes}

- Weight and z score

- Height and z score

- Head circumference and z score

- Adiposity (including BMI, skinfold thickness, fat mass)

- Educational attainment

- Blood pressure

- Type 1 diabetes

- Type 2 diabetes

- Impaired glucose tolerance

- Dyslipidaemia or metabolic syndrome

\section{Child as an adult outcomes}

- Weight

- Height

- Adiposity (including BMI, skinfold thickness, fat mass)

- Employment, education and social status/achievement

- Dyslipidaemia or metabolic syndrome

- Type 1 diabetes

- Type 2 diabetes

- Impaired glucose tolerance

- Cardiovascular health (as defined by trialists including blood pressure, hypertension, cardiovascular disease, metabolic syndrome)

\section{Health service use}

- Number of antenatal visits or admissions

- Number of hospital or health professional visits (including midwife, obstetrician, physician, dietician, diabetic nurse)

- Admission to neonatal intensive care unit/nursery

- Duration of stay in neonatal intensive care unit or special care baby unit 
- Length of antenatal stay

- Length of postnatal stay (maternal)

- Length of postnatal stay (baby)

- Cost of maternal care

- Cost of offspring care

- Costs associated with the intervention

- Costs to families associated with the management provided

- Cost of dietary monitoring (e.g. diet journals, dietician, nurse visits, etc)

- Costs to families - change of diet, extra antenatal visits

- Extra use of healthcare services (consultations, blood glucose monitoring, length and number of antenatal visits)

- Women's view of treatment advice

\section{Search methods for identification of studies}

The following methods section of this review is based on a standard template used by Cochrane Pregnancy and Childbirth.

\section{Electronic searches}

We searched Cochrane Pregnancy and Childbirth's Trials Register by contacting their Information Specialist (14 May 2016).

The Register is a database containing over 23,000 reports of controlled trials in the field of pregnancy and childbirth. For full search methods used to populate Pregnancy and Childbirth's Trials Register including the detailed search strategies for CENTRAL, MEDLINE, Embase and CINAHL; the list of handsearched journals and conference proceedings, and the list of journals reviewed via the current awareness service, please follow this link to the editorial information about the Cochrane Pregnancy and Childbirth in the Cochrane Library and select the 'Specialized Register' section from the options on the left side of the screen.

Briefly, Cochrane Pregnancy and Childbirth's Trials Register is maintained by their Information Specialist and contains trials identified from:

1. monthly searches of the Cochrane Central Register of Controlled Trials (CENTRAL);

2. weekly searches of MEDLINE (Ovid);

3. weekly searches of Embase (Ovid);

4. monthly searches of CINAHL (EBSCO);

5. handsearches of 30 journals and the proceedings of major conferences;

6. weekly current awareness alerts for a further 44 journals plus monthly BioMed Central email alerts.

Search results are screened by two people and the full text of all relevant trial reports identified through the searching activities described above is reviewed. Based on the intervention described, each trial report is assigned a number that corresponds to a specific Pregnancy and Childbirth review topic (or topics), and is then added to the Register. The Information Specialist searches the Register for each review using this topic number rather than keywords. This results in a more specific search set which has been fully accounted for in the relevant review sections (Included studies; Excluded studies; Studies awaiting classification; Ongoing studies).
In addition, we searched ClinicalTrials.gov and the WHO International Clinical Trials Registry Platform (ICTRP) (14 May 2016) for unpublished, planned and ongoing trial reports. The search terms we used are given in (Appendix 1).

\section{Searching other resources}

We searched the reference lists of retrieved studies. We did not apply any language or date restrictions.

\section{Data collection and analysis}

The following methods section of this review is based on a standard template used by Cochrane Pregnancy and Childbirth.

\section{Selection of studies}

Two review authors independently assessed for inclusion all the potential studies we identified as a result of the search strategy. We resolved any disagreement through discussion or, if required, consulted a third person.

We created a study flow diagram to map out the number of records identified, included and excluded.

\section{Data extraction and management}

We designed a form to extract data. For eligible studies, two review authors extracted the data using the agreed form. We resolved discrepancies through discussion or, if required, we consulted a third person. We entered data into Review Manager software (RevMan 2014) and checked for accuracy. When information regarding any of the above was unclear, we attempted to contact authors of the original reports to provide further details.

\section{Assessment of risk of bias in included studies}

Two review authors independently assessed risk of bias for each randomised study using the criteria outlined in the Cochrane Handbook for Systematic Reviews of Interventions (Higgins 2011). We resolved any disagreement by discussion or by involving a third assessor. For cluster-randomised trials, we planned to refer to the Handbook sections 16.3.2 and 16.4.3 for assessing bias. No clusterrandomised trials were identified in this version of the review.

\section{(1) Random sequence generation (checking for possible selection bias)}

We described for each included study the method used to generate the allocation sequence in sufficient detail to allow an assessment of whether it should produce comparable groups.

We assessed the method as:

- low risk of bias (any truly random process, e.g. random number table; computer random number generator);

- high risk of bias (any non-random process, e.g. odd or even date of birth; hospital or clinic record number);

- unclear risk of bias.

\section{(2) Allocation concealment (checking for possible selection bias)}

We described for each included study the method used to conceal allocation to interventions prior to assignment and will assess whether intervention allocation could have been foreseen in advance of, or during recruitment, or changed after assignment. 
We assessed the methods as:

- low risk of bias (e.g. telephone or central randomisation; consecutively numbered sealed opaque envelopes);

- high risk of bias (open random allocation; unsealed or nonopaque envelopes, alternation; date of birth);

- unclear risk of bias.

\section{(3.1) Blinding of participants and personnel (checking for} possible performance bias)

We described for each included study the methods used, if any, to blind study participants and personnel from knowledge of which intervention a participant received. We considered that studies were at low risk of bias if they were blinded, or if we judged that the lack of blinding was unlikely to affect results. We assessed blinding separately for different outcomes or classes of outcomes.

We assessed the methods as:

- low, high or unclear risk of bias for participants;

- low, high or unclear risk of bias for personnel.

\section{(3.2) Blinding of outcome assessment (checking for possible detection bias)}

We described for each included study the methods used, if any, to blind outcome assessors from knowledge of which intervention a participant received. We assessed blinding separately for different outcomes or classes of outcomes.

We assessed methods used to blind outcome assessment as:

- low, high or unclear risk of bias.

(4) Incomplete outcome data (checking for possible attrition bias due to the amount, nature and handling of incomplete outcome data)

We described for each included study, and for each outcome or class of outcomes, the completeness of data including attrition and exclusions from the analysis. We stated whether attrition and exclusions were reported and the numbers included in the analysis at each stage (compared with the total randomised participants), reasons for attrition or exclusion where reported, and whether missing data were balanced across groups or were related to outcomes. Where sufficient information was reported, or could be supplied by the trial authors, we re-included missing data in the analyses which we undertook.

We assessed methods as:

- low risk of bias (e.g. no missing outcome data; missing outcome data balanced across groups);

- high risk of bias (e.g. numbers or reasons for missing data imbalanced across groups; 'as treated' analysis done with substantial departure of intervention received from that assigned at randomisation);

- unclear risk of bias.

\section{(5) Selective reporting (checking for reporting bias)}

We described for each included study how we investigated the possibility of selective outcome reporting bias and what we found.
We assessed the methods as:

- low risk of bias (where it was clear that all of the study's prespecified outcomes and all expected outcomes of interest to the review had been reported);

- high risk of bias (where not all the study's pre-specified outcomes had been reported; one or more reported primary outcomes were not pre-specified; outcomes of interest were reported incompletely and so could be used; study failed to include results of a key outcome that would have been expected to have been reported);

- unclear risk of bias.

(6) Other bias (checking for bias due to problems not covered by (1) to (5) above)

We described for each included study any important concerns we have about other possible sources of bias.

We assessed whether each study was free of other problems that could put it at risk of bias:

- low risk of other bias;

- high risk of other bias;

- unclear whether there is risk of other bias.

\section{(7) Overall risk of bias}

We made explicit judgements about whether studies were at high risk of bias, according to the criteria given in the Handbook (Higgins 2011). With reference to (1) to (6) above, we assessed the likely magnitude and direction of the bias and whether we considered it was likely to impact on the findings. We explored the impact of the level of bias through undertaking sensitivity analyses - see Sensitivity analysis.

\section{Assessment of the quality of the evidence using the GRADE approach}

We assessed the quality of the evidence using the GRADE approach as outlined in the GRADE handbook in order to assess the quality of the body of evidence relating to the following outcomes. We selected up to a maximum of seven outcomes for the mother and seven for the infant covering both short- and long-term outcomes for the main comparisons.

\section{Maternal outcomes}

- Hypertensive disorders of pregnancy (including pre-eclampsia, pregnancy-induced hypertension, eclampsia)

- Perineal trauma/tear

- Induction of labour

- Caesarean section

- Postnatal depression

- Return to pre-pregnancy weight

- Development of type 2 diabetes

Neonatal/child/adult outcomes

- LGA (neonatal)

- Perinatal mortality (neonatal)

- Death or serious morbidity composite (variously defined by trials, e.g. perinatal or infant death, shoulder dystocia, bone fracture or nerve palsy) (neonatal) 
- Neonatal hypoglycaemia (neonatal)

- Adiposity (neonatal, child, adult)

- Diabetes (type 2) (child or adult)

- Neurosensory disability (child, adult)

We used the GRADEpro Guideline Development Tool to import data from Review Manager 5.3 (RevMan 2014) in order to create 'Summary of findings' tables. A summary of the intervention effect and a measure of quality for each of the above outcomes was produced using the GRADE approach. The GRADE approach uses five considerations (study limitations, consistency of effect, imprecision, indirectness and publication bias) to assess the quality of the body of evidence for each outcome. The evidence can be downgraded from 'high quality' by one level for serious (or by two levels for very serious) limitations, depending on assessments for risk of bias, indirectness of evidence, serious inconsistency, imprecision of effect estimates or potential publication bias.

\section{Measures of treatment effect}

\section{Dichotomous data}

For dichotomous data, we presented results as summary risk ratio with $95 \%$ confidence intervals.

\section{Continuous data}

For continuous data, we used the mean difference if outcomes are measured in the same way between trials. We planned to use the standardised mean difference to combine trials that measured the same outcome, but used different methods.

\section{Unit of analysis issues}

\section{Cluster-randomised trials}

No cluster-randomised trials were identified in this version of the review. In future updates, if identified, we will include cluster-randomised trials in the analyses along with individuallyrandomised trials. We will make adjustments using the methods described in the Handbook [Section 16.3.4 or 16.3.6] using an estimate of the intra-cluster correlation co-efficient (ICC) derived from the trial (if possible), from a similar trial or from a study of a similar population. If we use ICCs from other sources, we will report this and conduct sensitivity analyses to investigate the effect of variation in the ICC. We will consider it reasonable to combine the results from both cluster-randomised trials and individuallyrandomised trials if there is little heterogeneity between the study designs and the interaction between the effect of intervention and the choice of randomisation unit is considered to be unlikely. If cluster-randomised trials are included, we will seek statistical advice on appropriate analysis to enable inclusion of data in the meta-analyses.

\section{Other unit of analysis issues}

\section{Multiple pregnancy}

We presented maternal data as per woman randomised and neonatal data per infant.

\section{Multiple-arm studies}

If in future versions of the review a trial has multiple intervention arms we will avoid 'double counting' of participants by combining groups to create a single pair-wise comparison if possible. Where this is not possible, we will split the 'shared' group into two or more groups with smaller sample size and include two or more (reasonably independent) comparisons.

\section{Dealing with missing data}

For included studies, we noted levels of attrition. We planned to explore the impact of including studies with high levels of missing data (> 20\%) in the overall assessment of treatment effect by using sensitivity analysis.

For all outcomes, we carried out analyses, as far as possible, on an intention-to-treat basis, i.e. we attempted to include all participants randomised to each group in the analyses, and all participants were analysed in the group to which they were allocated, regardless of whether or not they received the allocated intervention. The denominator for each outcome in each trial was the number randomised minus any participants whose outcomes are known to be missing.

\section{Assessment of heterogeneity}

We assessed statistical heterogeneity in each meta-analysis using the $\mathrm{Tau}^{2}, \mathrm{I}^{2}$ and $\mathrm{Chi}^{2}$ statistics. We regarded heterogeneity as substantial if an $\mathrm{I}^{2}$ was greater than $30 \%$ and either a $\mathrm{Tau}^{2}$ was greater than zero, or there was a low $P$ value (less than 0.10 ) in the $\mathrm{Chi}^{2}$ test for heterogeneity.

\section{Assessment of reporting biases}

Where there were 10 or more studies in the meta-analysis, we investigated reporting biases (such as publication bias) using funnel plots. We assessed funnel plot asymmetry visually. If asymmetry was suggested by a visual assessment, we performed exploratory analyses to investigate it.

\section{Data synthesis}

We carried out statistical analysis using the Review Manager software (RevMan 2014). We used fixed-effect meta-analysis for combining data where it was reasonable to assume that studies were estimating the same underlying treatment effect: i.e. where trials examined the same intervention, and the trials' populations and methods were judged sufficiently similar. If clinical heterogeneity was sufficient to expect that the underlying treatment effects differed between trials, or if substantial statistical heterogeneity was detected, we used random-effects metaanalysis to produce an overall summary, if an average treatment effect across trials was considered clinically meaningful. The random-effects summary was treated as the average of the range of possible treatment effects and we discussed the clinical implications of treatment effects differing between trials. If the average treatment effect was not clinically meaningful, we did not combine trials.

Where we used random-effects analyses, the results were presented as the average treatment effect with 95\% confidence intervals, and the estimates of $\mathrm{Tau}^{2}$ and $\mathrm{I}^{2}$.

\section{Subgroup analysis and investigation of heterogeneity}

If we identified substantial heterogeneity, we investigated it using subgroup analyses and sensitivity analyses. We considered whether an overall summary was meaningful, and if it was, used random-effects analysis to produce it. 
- Diagnostic test used: ADA 2013, IADPSG 2010, Nankervis 2014 versus ACOG 2013 versus NICE 2015 versus NICE 2008; WHO 1999; WHO 2013 or Hoffman 1998 versus New Zealand Ministry of Health 2014 versus other not previously specified

- Timing of diagnosis: early ( $<28$ weeks' gestation) versus late $(\geq$ 28 weeks' gestation)

The following outcomes were used in subgroup analysis.

\section{Maternal outcomes}

- Pre-eclampsia

- Caesarean section

- Development of type 2 diabetes

\section{Neonatal outcomes}

- LGA

- Perinatal mortality

- Death or morbidity composite (variously defined by trials, e.g. infant death, shoulder dystocia, bone fracture or nerve palsy)

- Neurosensory disability in later childhood (as defined by trialists)

We assessed subgroup differences by interaction tests available within RevMan (RevMan 2014). We reported the results of subgroup analyses quoting the $\mathrm{Chi}^{2}$ statistic and $\mathrm{P}$ value, and the interaction test $I^{2}$ value.

\section{Sensitivity analysis}

If there was evidence of significant heterogeneity, we explored this by using the quality of the included trials for the primary outcomes. We compared trials that have low risk of bias for allocation concealment with those judged to be of unclear or high risk of bias, and conference abstracts were excluded from the metaanalysis.

We planned to investigate the effect of the randomisation unit (i.e. if we had included cluster-randomised trials along with individuallyrandomised trials).

\section{RE S U L T S}

\section{Description of studies}

\section{Results of the search}

We assessed 253 abstracts from the electronic search and an additional 21 potential studies from other sources. Two hundred and one of these abstracts were excluded due to lack of relevance and 73 publications were viewed in full-text format. Of these, 23 studies ( 28 reports) were excluded. Twenty-five studies ( 45 reports) were included in the qualitative synthesis (Figure 1). 
Figure 1. Study flow diagram.

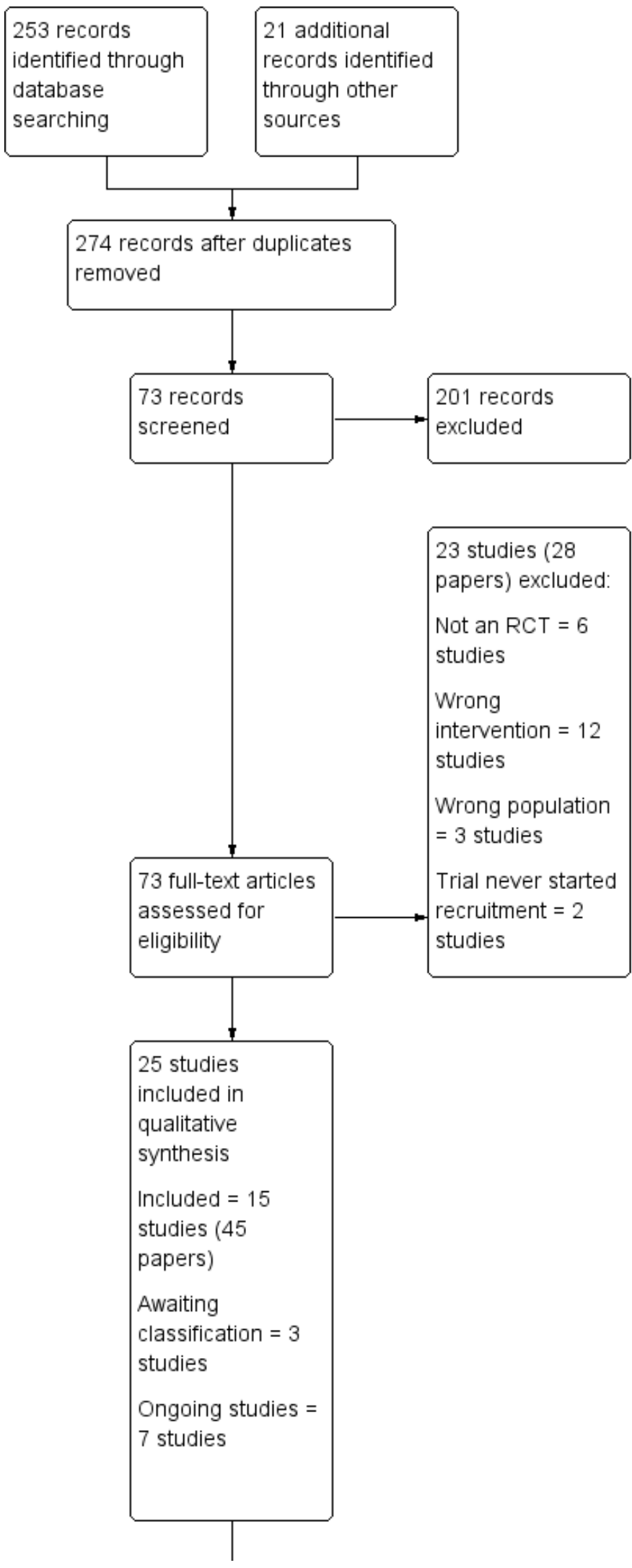


Figure 1. (Continued)

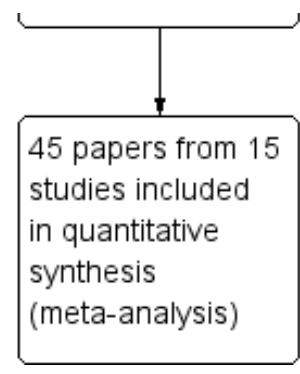

Three studies are awaiting classification as methodological queries need to be answered or translations into English are required. Where necessary authors have been contacted (Cao 2012; Kaveh 2012; Zhang 2012), See Characteristics of studies awaiting classification.

There are seven studies that are currently ongoing and would appear to meet the inclusion criteria for the review (See Characteristics of ongoing studies). For the next update of this review we will see if any data from these trials have been published.

\section{Included studies}

Forty-five publications associated with 15 trials are included in this review (Bancroft 2000; Bo 2014; Crowther 2005; Elnour 2008; Ferrara 2011; Garner 1997; Gillen 2004; Jovanovic-Peterson 1989; Kaviani 2014; Landon 2009; Mendelson 2008; Rahimikian 2014; Yang 2003; Yang 2014; Youngwanichsetha 2014). The 15 trials included a total of 4501 women and 3768 infants. Four trials did not report any neonatal data (Kaviani 2014; Rahimikian 2014; Yang 2003; Youngwanichsetha 2014).

\section{Design}

All of the included studies used a parallel design in a randomised controlled trial.

\section{Sample sizes}

Sample sizes ranged from 19 (Jovanovic-Peterson 1989) to 1000 (Crowther 2005) women. Twelve studies had a sample size of 300 women or fewer (Bancroft 2000; Bo 2014; Elnour 2008; Ferrara 2011; Garner 1997; Gillen 2004; Jovanovic-Peterson 1989; Kaviani 2014; Mendelson 2008; Rahimikian 2014; Yang 2003; Youngwanichsetha 2014).

\section{Settings}

Four studies were conducted in the USA (Ferrara 2011; Landon 2009; Mendelson 2008; Jovanovic-Peterson 1989), two in China (Yang 2003; Yang 2014), two in Iran (Kaviani 2014; Rahimikian 2014), two in Canada (Garner 1997; Gillen 2004), one each in the UK (Bancroft 2000), Italy (Bo 2014), United Arab Emirates (Elnour 2008), Thailand (Youngwanichsetha 2014), and one in Australia and the UK (Crowther 2005).

\section{Population}

Eleven trials reported data for maternal age (see Table 2 In the intervention groups the mean age ranged from a minimum of $29.2 \pm$ 5.7 years (Landon 2009) to maximum of $35.9 \pm 4.8$ years (Bo 2014). In the control groups, the mean age ranged from a minimum of $28.9 \pm$ 5.6 (Landon 2009) to $33.9 \pm 5.3$ years (Bo 2014). Details on maternal
BMI $\left(\mathrm{kg} / \mathrm{m}^{2}\right)$ at trial entry, reported in seven trials and ethnicity reported in nine of 15 trials are summarised in Table 3 and Table 4 , respectively. Gestational age at trial entry and treatment targets are described in Table 5 and Table 6, respectively.

\section{Details of diagnostic criteria used}

Criteria used to diagnose the women with gestational diabetes were variable. Six different diagnostic criteria were used in the nine trials that provided details (Table 7).

- World Health Organization (1999) Bancroft 2000; Crowther 2005; Yang 2003

- Carpenter and Coustan criteria Elnour 2008; Landon 2009

- American Diabetes Association (2000) Ferrara 2011

- ADIPS (Hofman 1998) Gillen 2004

- IADPSG criteria Yang 2014

- Hatem (1988) $75 \mathrm{~g}$ OGTT $>7.5 \mathrm{mmol}$ (second trimester) and $>9.6$ $\mathrm{mmol} / \mathrm{L}$ (third trimester) (no other details) (Garner 1997)

Six trials did not provide details on the criteria used to diagnose the women with gestational diabetes (Bo 2014; JovanovicPeterson 1989; Kaviani 2014; Mendelson 2008; Rahimikian 2014; Youngwanichsetha 2014).

\section{Interventions}

The types of interventions used varied, as can be seen below.

Bancroft 2000: Intensive intervention (standard dietary advice, glucose monitoring five days a week, HbAlc monthly, serial ultrasound, Doppler studies, cardiotocography (CTG monitoring) compared with usual care (dietary advice, HbAlc monthly).

Bo 2014: Reported on a multiple-arm trial that included a) Individualised-dietary advice alone, b) Exercise alone, c) Behavioural intervention and d) Behavioural intervention and exercise. We used the combined behavioural and exercise group as the intervention arm for this review and the Individualised-dietary advice alone as the control group.

Crowther 2005: Intensive intervention (individualised-dietary advice, advice on self-monitoring of blood glucose) compared with usual care (women and caregivers unaware of diagnosis).

Elnour 2008: Intensive intervention (structured pharmaceutical care, structured education, self-monitoring of blood glucose) compared with usual care (no additional education or pharmacist counselling). 
Ferrara 2011: Intensive intervention (individualised advice on diet, exercise and breastfeeding) compared with usual care (printed material only in prenatal and postnatal period).

Garner 1997: Intensive intervention (dietary counselling, selfglucose monitoring, biweekly review, monitoring of fetal growth, amniotic volume and cardiac size) versus usual care (no dietary counselling).

Gillen 2004: Group session on education and diet followed by specific dietary advice compared with group session on education and diet followed by standard clinical care and advice.

Jovanovic-Peterson 1989: Diet alone compared with diet plus supervised exercise.

Kaviani 2014: Relaxation training (education, breathing, muscle relaxation, mental imagery, and contacted by telephone by the researcher three times per week) compared with usual care (no details).

Landon 2009: Nutritional counselling and diet therapy $+/$ - insulin plus self-monitoring of blood glucose compared with usual care $+/-$ insulin plus self-monitoring of blood glucose.

Mendelson 2008: Intensive education and spiritual intervention compared with standard education.

Rahimikian 2014: Face-to-face education (risks of GDM, training on glycaemic control, exercise, diet, medication and follow-up) compared with usual care (no details).

Yang 2003: Intensive intervention (including diet and exercise advice, self-monitoring of blood glucose, insulin if required, fortnightly specialist review) versus usual care (no details).

Yang 2014: Shared care protocol adapted from Crowther 2005. Individualised and group dietary and physical activity counselling, self-monitoring blood glucose compared with usual care (group education on exercise and physical activity, not specifically taught blood glucose self-monitoring).

Youngwanichsetha 2014: Mindfulness eating and yoga compared with standard diabetes care (no details).

\section{Outcomes}

For the maternal primary outcomes: pregnancy-induced hypertension was reported in four trials (Crowther 2005; Elnour 2008; Landon 2009; Yang 2014), and caesarean section in 10 trials (Bancroft 2000; Bo 2014; Crowther 2005; Elnour 2008; Garner 1997; Gillen 2004; Landon 2009; Mendelson 2008; Yang 2003; Yang 2014). Development of type 2 diabetes was reported in two trials (Bancroft 2000; Landon 2009).

For the neonatal primary outcomes: Perinatal death was reported in two trials (Crowther 2005; Landon 2009); large-for-gestational age (LGA) in six trials (Bancroft 2000; Bo 2014; Crowther 2005; Elnour 2008; Landon 2009; Yang 2014), and a composite of serious neonatal outcomes in two trials (Crowther 2005; Landon 2009). Neurosensory disability in later childhood was not a pre-specified outcome, nor reported for any of the included trials.

Data were available for the following maternal secondary outcomes: need for supplementary medication, maternal hypoglycaemia, fasting plasma glucose concentration, postprandial glucose concentration, $\mathrm{HbAlc}$, weight gain in pregnancy, induction of labour, postpartum haemorrhage, postnatal infection/pyrexia, perineal trauma/tear, breastfeeding, postnatal depression, quality of life, impaired glucose tolerance, metabolic syndrome and return to prepregnancy weight.

Data were available for the following neonatal secondary outcomes: stillbirth, neonatal death, macrosomia, smallfor-gestational age (SGA), birth trauma (shoulder dystocia, bone fracture, nerve palsy), gestational age at birth, preterm birth, congenital anomaly, five-minute Apgar less than seven, birthweight, length, neonatal fat mass, neonatal hypoglycaemia, respiratory distress syndrome, hyperbilirubinaemia, hypocalcaemia, polycythaemia, childhood growth, childhood cholesterol and childhood impaired glucose tolerance.

Data were available for the following health service outcomes: visits to health professionals, antenatal hospital admissions and admission to neonatal intensive care unit.

\section{Funding sources}

Funding sources were reported in seven trials (Bo 2014; Crowther 2005; Ferrara 2011; Kaviani 2014; Landon 2009; Mendelson 2008; Yang 2014). None of the sources were conditional grants from pharmaceutical companies. The remaining trials did not detail the sources of funding (if any) in the published manuscript (Bancroft 2000; Elnour 2008; Garner 1997; Gillen 2004; Jovanovic-Peterson 1989; Rahimikian 2014; Yang 2003; Youngwanichsetha 2014).

\section{Declarations of interest}

Declarations of conflicts of interest were made in four trials (Bo 2014; Ferrara 2011; Landon 2009; Yang 2014). Three reported that there were no conflicts of interest for any of the authors (Bo 2014; Ferrara 2011; Landon 2009). One trial (Yang 2014) reported that there was a conflict of interest for one of the 12 authors. The conflict states that the authors institution had received research funding from Eli Lilly and the author is a member of advisory committee and speaker forum sponsored by Eli Lilly. The remaining trials did not provide any statements about conflicts of interest (Bancroft 2000; Crowther 2005; Elnour 2008; Garner 1997; Gillen 2004; JovanovicPeterson 1989; Kaviani 2014; Mendelson 2008; Rahimikian 2014; Yang 2003; Youngwanichsetha 2014).

\section{Excluded studies}

Twenty-three trials (28 reports) were excluded. Six studies were not randomised (Abirami 2014; O'Sullivan 1980; Reader 2006) or were quasi-randomised trials (O'Sullivan 1971; O'Sullivan 1974; Perichart-Perera 2009).

Twelve trials did not use an intervention/comparison included in this review (Adam 2014; Bastani 2015; Berry 2013; Fadl 2015; Ford 1997; Grant 2011; Homko 2002; Holmes 2012; Langer 1989; Li 1987; Mirzamoradi 2015; Rey 1997).

Three trials included women not meeting the diagnosis of gestational diabetes and representing the wrong population for this review (Bevier 1999; Bonomo 2005; Osmundson 2015). 
One trial, although registered, never started recruitment due to insufficient funding (Branch 2010), and a second trial did not start recruitment, although no reason could be found (Kitzmiller 1990).

\section{Risk of bias in included studies}

Refer to Figure 2; Figure 3.

Figure 2. Risk of bias graph: review authors' judgements about each risk of bias item presented as percentages across all included studies.

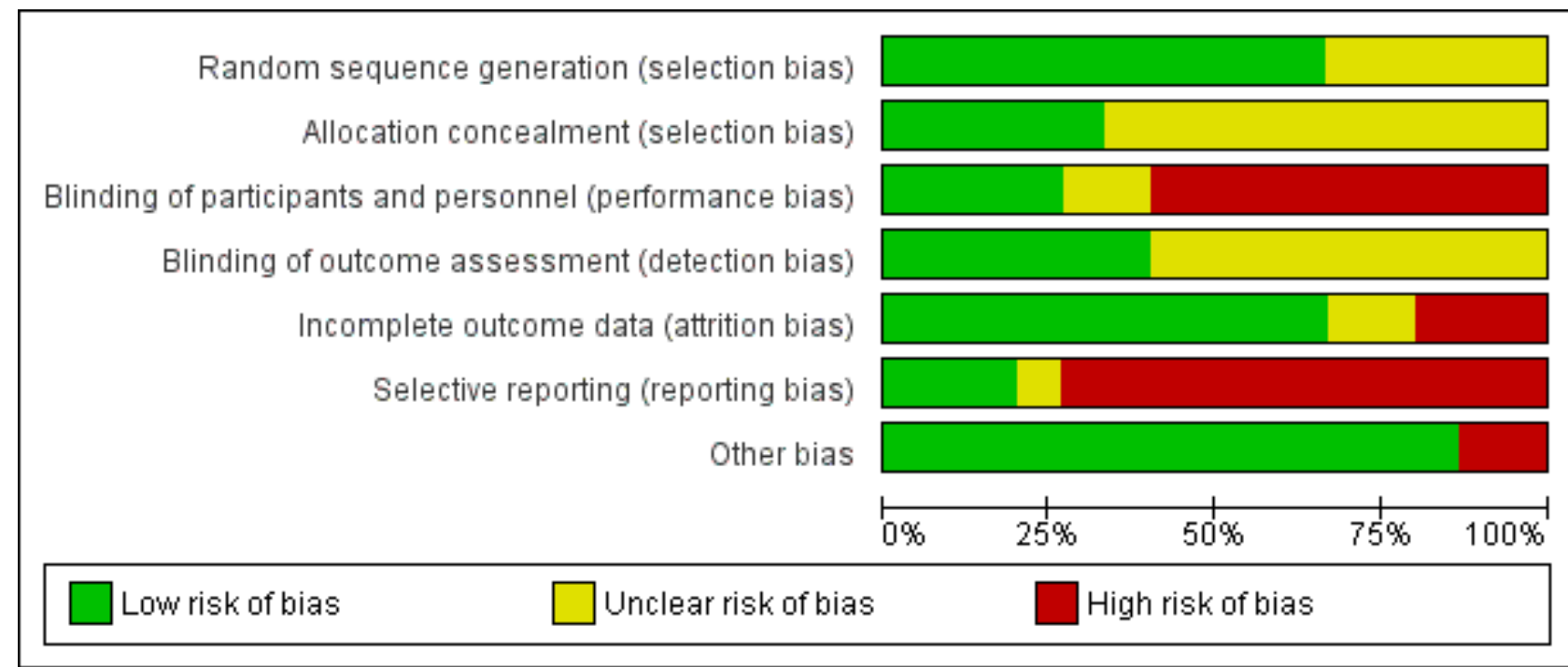


Figure 3. Risk of bias summary: review authors' judgements about each risk of bias item for each included study.

\begin{tabular}{|c|c|c|c|c|c|c|c|}
\hline & 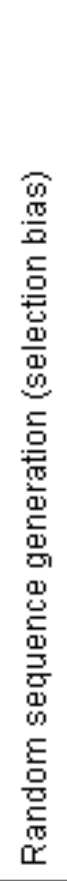 & 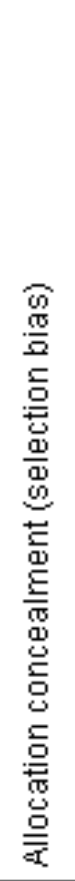 & 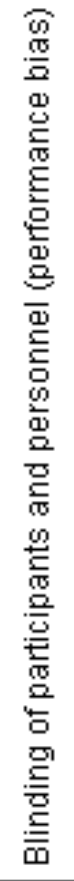 & 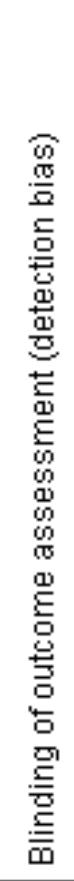 & 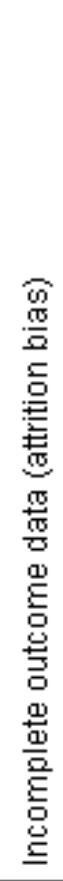 & 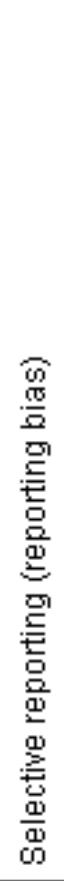 & 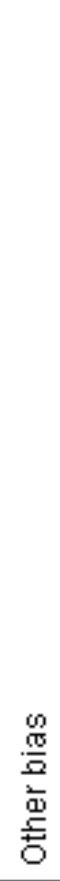 \\
\hline Bancroft 2000 & + & 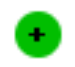 & 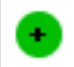 & $?$ & $?$ & ) & + \\
\hline Bo 2014 & $?$ & $\odot$ & - & $\odot$ & $\odot$ & - & + \\
\hline Crowther 2005 & + & 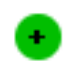 & 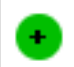 & $?$ & + & 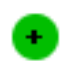 & + \\
\hline Elnour 2008 & + & $?$ & $\odot$ & $\oplus$ & + & + & + \\
\hline Ferrara 2011 & 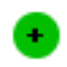 & $?$ & - & $\odot$ & + & & $\odot$ \\
\hline Garner 1997 & $?$ & $?$ & + & $?$ & + & & + \\
\hline Gillen 2004 & + & + & $?$ & $?$ & + & & + \\
\hline Jovanovic-Peterson 1989 & + & $?$ & - & $?$ & + & & \\
\hline Kaviani 2014 & + & $?$ & - & $?$ & + & - & $\odot$ \\
\hline Landon 2009 & + & + & - & + & + & + & + \\
\hline Mendelson 2008 & + & $?$ & $?$ & $?$ & & $?$ & + \\
\hline Rahimikian 2014 & $?$ & $?$ & - & $?$ & $?$ & & + \\
\hline Yang 2003 & $?$ & $?$ & - & $?$ & & & \\
\hline Yang 2014 & 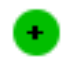 & $?$ & + & + & & & + \\
\hline Youngwanichsetha 2014 & $?$ & $?$ & - & + & + & - & + \\
\hline
\end{tabular}




\section{Allocation}

Randomisation - 10 of the trials were considered to be of low risk of bias for randomisation (Bancroft 2000; Crowther 2005; Elnour 2008; Ferrara 2011; Gillen 2004; Jovanovic-Peterson 1989; Kaviani 2014; Landon 2009; Mendelson 2008; Yang 2014). Seven of these trials (Bancroft 2000; Crowther 2005; Ferrara 2011; Gillen 2004; Kaviani 2014; Mendelson 2008; Yang 2014) used computer-generated randomisation. Elnour 2008 used a restricted randomisation method; Jovanovic-Peterson 1989 randomised by drawing a number; and Landon 2009 used a simple urn method. Method of randomisation was judged as unclear in five trials due to lack of sufficient details (Bo 2014; Garner 1997; Rahimikian 2014; Yang 2003; Youngwanichsetha 2014).

Allocation concealment - five trials were considered to be of low risk of bias for allocation concealment (Bancroft 2000; Bo 2014; Crowther 2005; Gillen 2004; Landon 2009). Bancroft 2000 used a telephone randomisation service that was controlled by a trial centre and Bo 2014 used a website (third person); Crowther 2005; Gillen 2004; Landon 2009 performed randomisation centrally. Allocation concealment was judged as unclear in 10 trials due to lack of sufficient details (Elnour 2008; Ferrara 2011; Garner 1997; Jovanovic-Peterson 1989; Kaviani 2014; Mendelson 2008; Rahimikian 2014; Yang 2003; Yang 2014; Youngwanichsetha 2014).

\section{Blinding}

\section{Performance bias}

Four trials were judged to be of low risk of bias. Bancroft 2000 reported that the obstetrician was blinded to randomisation. Yang 2014 reported that the women with GDM were masked to the allocation although the research staff were not. Crowther 2005 reported women and caregivers were unaware of diagnosis in the control group and Garner 1997 reported that healthcare workers in the control group were blinded to allocation.

In two trials the risk of bias was judged to be unclear: in Gillen 2004 participants were unaware of differences in advice between the intervention and control groups but the researchers were aware and in Mendelson 2008 the women were not blinded to allocation but the diabetes educators were blinded to allocation (personal communication). Nine trials were judged to be of high risk of bias, including six trials (Bo 2014; Jovanovic-Peterson 1989; Kaviani 2014; Rahimikian 2014; Yang 2003; Youngwanichsetha 2014) that provided no details of blinding for participants or researchers. Due to the types of interventions blinding is unlikely. Three trials clearly stated that the researchers and participants were not blinded (Elnour 2008; Ferrara 2011; Landon 2009).

\section{Detection bias}

Six trials were considered to be of low risk of detection bias. Bo 2014 reported that dieticians and obstetricians who reported maternal/neonatal complications and laboratory personnel were blinded to allocation. Elnour 2008 reported that nursing and pharmacy staff who assisted with questionnaire administration were blinded to allocation. Ferrara 2011 provided details in the trials registration document that outcome assessors were blinded. Yang 2014 reported that outcome assessors for pregnancy-induced hypertension were blinded to allocation and Youngwanichsetha 2014 reported that $\mathrm{HbA1c}$ testing was conducted in a laboratory and the personnel there are likely to have been blinded (no further details). Landon 2009 reported that outcome assessors were blinded for some relevant outcomes (no details).

Nine trials (Bancroft 2000; Crowther 2005; Garner 1997; Gillen 2004; Jovanovic-Peterson 1989; Kaviani 2014; Mendelson 2008; Rahimikian 2014; Yang 2003) provided no details of blinding of outcome assessors and were judged as having an unclear risk of bias.

\section{Incomplete outcome data}

Ten trials were judged to be of low risk for attrition bias. Bo 2014; Crowther 2005; Jovanovic-Peterson 1989; Kaviani 2014 reported that all women who were randomised were analysed or that there were no losses to follow-up. Attrition of less than 10\% was reported by Elnour 2008 (9\%); Ferrara 2011 (4\%); Garner 1997 (< 1\%); Gillen 2004 (6\%); Landon 2009 (6\%) and Youngwanichsetha 2014 (6\%). The Crowther 2005 trial, although reporting low attrition levels for clinical data, reported that only $68 \%$ of women provided data for maternal health status.

Two trials were judged to be of unclear risk of bias. In the Rahimikian 2014 trial, data appear to be missing for one of the intervention groups but no reasons are provided. Bancroft 2000 reported that $18 \%$ of women failed to return for postnatal measurements.

Three trials were judged to be at high risk for attrition bias. Mendelson 2008 reported that only 27\% (27/100) of women had an $\mathrm{HbA1C}$ value recorded at birth; there is no explanation as to why the remaining women did not have results. Yang 2003 reported that only $51 \%(48 / 95)$ of women in the intervention group completed the management plan. Yang 2014 reported that due to construction work in the building where the intervention took place during the trial, 242 women did not receive the intended intervention and they excluded these women from the analysis.

\section{Selective reporting}

Three trials were judged to be of low risk for reporting bias (Crowther 2005; Elnour 2008; Landon 2009).

One trial was judged to be of unclear risk for reporting bias. Mendelson 2008 reported one additional outcome of caesarean section that was not prespecified in the methods section; all of the other outcomes listed a priori were reported.

Eleven trials were judged to be of high risk for reporting bias. Bancroft 2000; Bo 2014; Jovanovic-Peterson 1989 and Yang 2014 reported additional outcomes in the results section that were not prespecified in the methods. Ferrara 2011 reported data for a pilot study and the full trial is yet to be reported on; the primary trial outcome was postpartum weight gain and there were very limited neonatal outcomes. Garner 1997 did not pre-specify any outcomes; Gillen 2004 did not clearly pre-specify trial outcomes, the trial authors report no differences in pregnancy outcomes or mode of birth but these data are not reported in the paper. Kaviani 2014 reported very limited maternal outcome and no neonatal outcomes were reported. Rahimikian 2014 did not provide any numeric data for any of the specified trial outcomes. Yang 2003 reported the trial as a letter and only data for caesarean section and rupture of membranes were reported. Youngwanichsetha 2014 reported on the effects of glycaemic control but no other neonatal or maternal outcomes were reported. 


\section{Other potential sources of bias}

Two trials were judged to be at high risk of other bias. Yang 2003 published findings in a letter and we were unable to find a full publication. The sample size was estimated at 200 but only 100 women were randomised. Jovanovic-Peterson 1989 reported that the women in the exercise plus diet group had a significantly higher one-hour plasma glucose in the diagnostic test at baseline, the treatment and control groups are therefore not balanced for an important baseline prognostic variable.

There was no evidence of other risk of bias reported by Bancroft 2000; Bo 2014; Crowther 2005; Elnour 2008; Ferrara 2011; Garner 1997; Gillen 2004; Kaviani 2014; Landon 2009; Mendelson 2008; Rahimikian 2014; Yang 2014; Youngwanichsetha 2014. These studies were judged to be of low risk of other potential sources of bias.

\section{Effects of interventions}

See: Summary of findings for the main comparison Lifestyle interventions versus control - Maternal outcomes; Summary of findings 2 Lifestyle versus control - Neonatal and later outcomes

\subsection{Lifestyle intervention versus usual care or control Maternal primary outcomes}

1.1 Hypertensive disorders of pregnancy (including pre-eclampsia, pregnancy-induced hypertension, eclampsia)

There was no evidence of a difference between lifestyle intervention and control groups forrisk of pre-eclampsia (average risk ratio (RR) 0.70; 95\% confidence interval $(\mathrm{Cl}) 0.40$ to 1.22 ; four trials, 2796 women; $1^{2}=79 \%$, Tau ${ }^{2}=0.23$; low-quality of evidence) (Analysis 1.1). The evidence was downgraded (-2) for inconsistency.

We explored the heterogeneity by looking at the diagnostic criteria used and the definitions used in the individual trials. Three different diagnostic criteria were used by studies reporting data for pregnancy-induced hypertension: (i) World Health Organization WHO (1999) Crowther 2005; (ii) American Diabetes Association - ADA (2013) Elnour 2008; Landon 2009 and (iii) International Association for the Study of Diabetes in Pregnancy - IADPSG (2010) Yang 2014. Subgroup analysis identified a significant differential effect on the risk for pre-eclampsia based on diagnostic criteria $\left(\mathrm{Chi}^{2}=9.94, \mathrm{df}\right.$ $=2, P=0.007,12=79.9 \%$ ). Interpretation of these data remains unclear due to the limited number of trials reporting data for each diagnostic criteria.

\subsection{Caesarean section}

Caesarean section was reported in 10 trials (Bancroft 2000; Bo 2014; Crowther 2005; Elnour 2008; Garner 1997; Gillen 2004; Landon 2009; Mendelson 2008; Yang 2003; Yang 2014). There was no evidence of a difference between lifestyle intervention and control groups forrisk of birth by caesarean section (average RR 0.90; $95 \% \mathrm{Cl}$ 0.78 to $1.05 ; 10$ trials, 3545 women; $1^{2}=48 \%$, Tau $^{2}=0.02$; lowquality evidence) (Analysis 1.2). The evidence was downgraded for selective reporting and inconsistency. There is some suggestion of asymmetry observed in the funnel plot (Figure 4). 
Figure 4. Funnel plot of comparison: 1 Lifestyle intervention versus usual care/control, outcome: 1.2 Caesarean section.

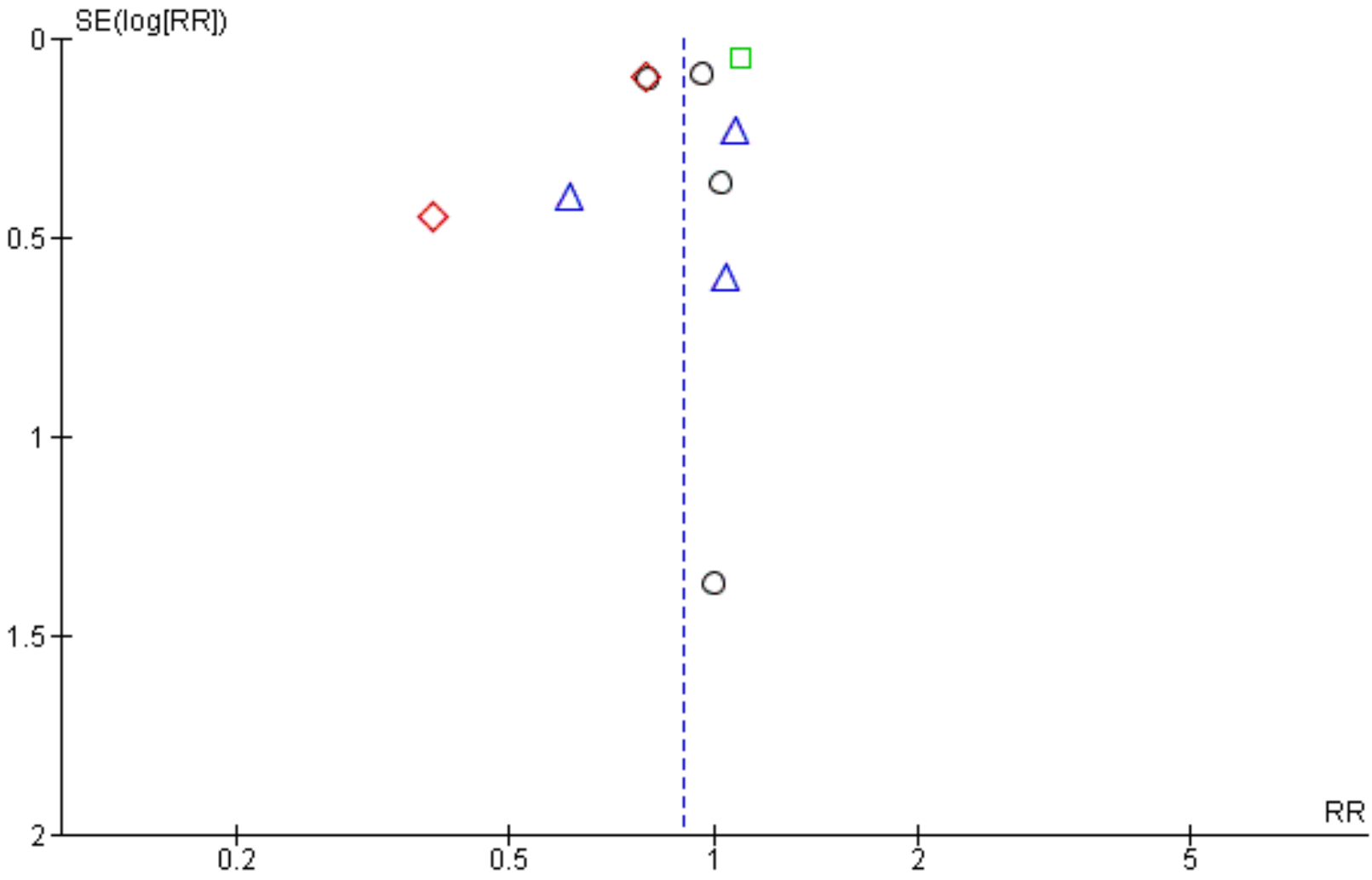

\subsection{Development of type 2 diabetes}

Two trials (Bancroft 2000; Landon 2009) reported no evidence of a difference between lifestyle interventions and control groups for development of type 2 diabetes (RR $0.98,95 \% \mathrm{Cl} 0.54$ to 1.76 ; two trials, 486 women; $1^{2}=16 \%$; Analysis 1.3; low-quality evidence). The evidence was downgraded for risk of bias and attrition bias. Bancroft 2000 only states that diagnosis was postnatally. Bancroft 2000 reports data for postnatal glucose metabolism, but there are no details at what time point the test was conducted. Landon 2009 reported follow-up at 4.5 to 10 years.

\section{Neonatal primary outcomes}

\subsection{Perinatal (fetal and neonatal death) and later infant mortality}

There is substantial uncertainty about the size and he direction of the effect for the outcome of perinatal death between lifestyle intervention and control groups reported in two trials (Crowther 2005; Landon 2009) (RR 0.09, 95\% Cl 0.01 to 1.70; two trials, 1988 infants; Analysis 1.4; low-quality evidence). The evidence was downgraded for risk of bias and imprecision. The evidence should be interpreted with caution as no perinatal deaths were reported in either intervention or control group in the Landon 2009 trial. No data were reported for later infant mortality.

\subsection{Large-for-gestational age (LGA) (as defined by the trialists)}

Lifestyle interventions were associated with a reduction in the risk of being born large-for-gestational age reported in six trials (Bancroft 2000; Bo 2014; Crowther 2005; Elnour 2008; Landon 2009; Yang 2014) (RR 0.60, 95\% Cl 0.50 to 0.71; six trials, 2994 infants; $\left.\right|^{2}$ $=4 \%$; Analysis 1.5; moderate-quality evidence). The evidence was downgraded due to unclear and high risk of bias for allocation concealment, lack of blinding and selective reporting.

1.6 Death of serious morbidity composite (variously defined by trials, e.g. perinatal or infant death, should dystocia, bone fracture or nerve palsy)

A composite of serious infant outcome was reported in two trials (Crowther 2005; Landon 2009). There was no evidence of a difference between lifestyle intervention and control groups for risk of a composite of serious infant outcome (average RR $0.57,95 \% \mathrm{Cl}$ 0.21 to 1.55 ; two trials, 1930 infants; $I^{2}=82 \%$, Tau $^{2}=0.44$; Analysis 1.6; very low-quality of evidence). The evidence was downgraded for inconsistency, risk of bias and imprecision. In the Crowther 2005 trial, the composite included one or more of: death, shoulder dystocia, bone fracture and nerve palsy. In the Landon 2009 trial the composite included: stillbirth, neonatal death, hypoglycaemia, hyperbilirubinaemia, elevated cord-blood C-peptide level and birth 
trauma. We decided to include the meta-analysis as the direction of the treatment effect is the same in both trials.

\section{Primary outcomes not reported in the included studies}

None of the included trials prespecified or reported neurosensory disability in later childhood as a trial outcome.

\section{Maternal secondary outcomes}

\subsection{Use of additional pharmacotherapy}

Use of additional pharmacotherapy was reported in eight trials. One trial (Ferrara 2011) found no evidence of a difference between women who had received lifestyle interventions and those in the control groups for the use of additional oral anti-diabetic agents which were required by $28 \%$ (27/96) women in the intervention group and $36 \%(36 / 101)$ in the control group (RR 0.79, 95\% Cl 0.52 to 1.19; one trial, $n=197$ women; Analysis 1.7). Eight trials reported on the need for additional insulin (Bancroft 2000; Bo 2014; Crowther 2005; Elnour 2008; Ferrara 2011; Gillen 2004; Landon 2009; Yang 2014). Lifestyle interventions were associated with an increase in the use of supplementary insulin $(214 / 1626 ; 13 \%)$ compared with control interventions (62/1628; 4\%) (average RR 2.54; 95\% Cl 1.19 to 5.42 ; nine trials, $\mathrm{n}=3254$ women; $\mathrm{I}^{2}=80 \%$, $\mathrm{Tau}^{2}=0.77$; Analysis 1.7). We advise caution when interpreting these results due to the observed heterogeneity (inconsistency). The data suggest a wide spread of treatment effects and incidence of the outcome (Analysis 1.7).

\subsection{Maternal hypoglycaemia}

One small trial of 19 women (Jovanovic-Peterson 1989) reported no events of maternal hypoglycaemia in either the lifestyle intervention or the control groups (Analysis 1.8).

\subsection{Glycaemic control during/after treatment}

Glycaemic control during/after treatment was reported in seven trials that provided data suitable for meta-analysis. Data from the Kaviani 2014 trial were not suitable for inclusion in the metaanalysis for fasting blood glucose concentration or postprandial blood glucose concentration. Further information has been requested from the authors.

1.9.1 Six trials reported on fasting blood glucose concentrations (Bancroft 2000; Bo 2014; Elnour 2008; Garner 1997; Mendelson 2008; Youngwanichsetha 2014). There was no clear evidence of a difference between lifestyle interventions and control groups in fasting blood glucose concentrations during/at the end of treatment (average standardised mean difference (SMD) -0.32; 95\% $\mathrm{Cl}-0.72$ to 0.07 ; six trials; 853 women; $\mathrm{I}^{2}=85 \%$, $\mathrm{Tau}^{2}=0.18$; data not shown). Bancroft 2000 reported on median and range for postnatal fasting blood glucose concentrations (Table 6). There was no evidence of a difference between the intervention and control group.

1.9.2 Postprandial blood glucose concentration was reported at one hour in two trials (Garner 1997; Jovanovic-Peterson 1989) and at two hours in two trials (Bancroft 2000; Youngwanichsetha 2014); one trial did not provide details of the timing of the postprandial test (Bo 2014). The data from the Bancroft 2000 trial are median and range which could not be included in a meta-analysis and are summarised in Table 6 . Lifestyle interventions were associated with a decrease in postprandial blood glucose concentration at the end of treatment (average mean difference (MD) $-27.11 \mathrm{mg} /$
$\mathrm{dL} ; 95 \% \mathrm{Cl}-44.62$ to -9.61 ; four trials, $\mathrm{n}=588$ women; $\mathrm{I}^{2}=97 \%$, $\left.\mathrm{Tau}^{2}=300.13\right)$. Visual inspection of the forest plot suggests that the Jovanovic-Peterson 1989 trial is an outlier. This is a very small trial of just 19 women in which the treatment effect suggests very large benefit. The removal of this trial from the meta-analysis does not substantially alter the estimate of treatment effect or benefit (MD $-10.95 \mathrm{mg} / \mathrm{dL}, 95 \% \mathrm{Cl}-13.50$ to -8.40 - analysis not shown), but observed heterogeneity is reduced to $\mathrm{L}^{2}=0 \%$ (Analysis 1.9 ).

1.9.3 $\mathrm{HbA1C}$ was reported at the end of treatment in six trials (Bancroft 2000; Bo 2014; Elnour 2008; Jovanovic-Peterson 1989; Mendelson 2008; Youngwanichsetha 2014). Lifestyle interventions were associated with a reduction in $\mathrm{HbAlc}$ values at the end of treatment (average MD $-0.33 \mathrm{mmol} / \mathrm{mol} ; 95 \% \mathrm{Cl}-0.47$ to -0.19 ; six trials, $\mathrm{n}=532$ women; $\mathrm{I}^{2}=66 \%$, $\mathrm{Tau}^{2}=0.02$; Analysis 1.9 ).

\subsection{Weight gain in pregnancy}

Weight gain in pregnancy was reported in four trials (Crowther 2005; Garner 1997; Landon 2009; Yang 2014). Lifestyle interventions were associated with a decrease in weight gain in pregnancy (average MD $-1.30 \mathrm{~kg}, 95 \% \mathrm{Cl}-2.26$ to -0.35 ; four trials, $\mathrm{n}=2930$ women; $\mathrm{I}^{2}$ $=80 \%$, Tau $^{2}=0.75 ;$ Analysis 1.10). The largest difference between groups was observed in the Landon 2009 trial $(2 \mathrm{~kg}$ in the lifestyle intervention group versus $5 \mathrm{~kg}$ in the control group), whereas the Yang 2014 trial found no evidence of a difference between groups but also reported a mean increase in weight during pregnancy of approximately $15 \mathrm{~kg}$.

\subsection{Induction of labour}

Induction of labour was reported in four trials (Bancroft 2000; Crowther 2005; Landon 2009; Yang 2014). There was no evidence of a difference between the lifestyle intervention groups and the control groups (average RR 1.20, 95\% Cl 0.99 to 1.46; four trials, $\mathrm{n}$ = 2699 women; $\left.\right|^{2}=37 \%, T^{2}=0.01$; high-quality evidence; Analysis 1.11).

\subsection{Postpartum haemorrhage (as defined by trialists)}

Two trials reported on postpartum haemorrhage (Crowther 2005; Elnour 2008). There was no evidence of a difference for postpartum haemorrhage between women in the lifestyle intervention or the control groups (average RR $0.61,95 \% \mathrm{Cl} 0.20$ to 1.89 ; two trials, $\mathrm{n}=$ 1165 women; $\left.\right|^{2}=64 \%$, Tau $^{2}=0.46$; Analysis 1.12).

\subsection{Postpartum infection}

Postpartum infection was reported in the Crowther 2005 trial only. There was no evidence of a difference for postpartum infection between women in the lifestyle intervention or the control groups ( $\mathrm{RR} 0.61,95 \% \mathrm{Cl} 0.34$ to 1.10 ; one trial, $\mathrm{n}=1000$ women; Analysis 1.13).

\subsection{Perineal trauma/tearing}

Perineal trauma/tearing was reported in the Crowther 2005 trial only. There was no evidence of a difference for perineal trauma/ tearing between women in the lifestyle intervention or the control groups (RR 1.04, 95\% Cl 0.93 to 1.18; one trial, $\mathrm{n}=1000$ women; moderate-quality evidence; Analysis 1.14). Evidence was downgraded due to imprecision as it is based on a single trial. 
1.15 Breastfeeding at discharge, six weeks postpartum, six months or longer

Breastfeeding was reported in two trials (Crowther 2005; Ferrara 2011). Crowther 2005 reported no clear difference for rates of breastfeeding at discharge between the lifestyle intervention or the control groups ( $\mathrm{RR} 1.04,95 \% \mathrm{Cl} 0.99$ to 1.10 ; one trial, $\mathrm{n}$ $=1000$ women). Ferrara 2011 reported on breastfeeding at six weeks' postpartum (RR $0.97,95 \% \mathrm{Cl} 0.87$ to 1.07 ; one trial, $\mathrm{n}=$ 188 women) and six months or longer (RR $1.31,95 \% \mathrm{Cl} 0.99$ to 1.74; one trial, $\mathrm{n}=161$ women). At neither six weeks' postpartum nor six months postpartum was there evidence of a difference in breastfeeding rates between lifestyle intervention and control groups. See Analysis 1.15.

\subsection{6 and 1.17 Sense of well-being and quality of life}

Quality of life was reported in two trials (Crowther 2005; Elnour 2008) both during the treatment and at three months postpartum using the SF36 questionnaire. Maternal quality of life was improved during treatment for physical functioning, role physical, bodily pain, general health, vitality, social functioning, role emotional, health state utility and overall physical component for women receiving a lifestyle intervention compared with the control group (Analysis 1.16). There were no clear differences between intervention and control groups for mental health, overall mental component or anxiety. At three months follow-up, only social functioning remained different between intervention and control groups. No other differences between groups were found for quality of life (Analysis 1.17).

No data were reported for adherence to the intervention, placental abruption, maternal mortality, behavioural changes associated with the intervention, views of the intervention or relevant biomarker changes associated with the intervention (including adiponectin, free fatty acids, triglycerides, high-density lipoproteins, (HDL) low-density lipoproteins (LDL), insulin).

\section{Long-term outcomes for mother}

\subsection{Postnatal depression}

Postnatal depression was reported in the Crowther 2005 trial only and defined as a Edinburgh Postnatal Depression Score $>12$. Lifestyle interventions were associated with a decrease in the risk of postnatal depression compared with the control group (RR 0.49, $95 \% \mathrm{Cl} 0.31$ to 0.78 ; one trial, $\mathrm{n}=573$ women; low-quality evidence; Analysis 1.18). The evidence was downgraded for imprecision as it is based on a single trial and risk of attrition bias as only $68 \%$ of randomised women responded to the questionnaire.

\subsection{Postnatal weight retention or return to pre-pregnancy weight}

Ability to meet postpartum weight goals was reported in one study (Ferrara 2011). At six weeks and seven months postpartum there was no evidence of a difference between the lifestyle and control groups for this outcome (RR $1.20,95 \% \mathrm{Cl} 0.67$ to $2.17 ; \mathrm{n}=189$ women; RR $1.59,95 \% \mathrm{Cl} 0.99$ to $2.57, \mathrm{n}=159$ women, respectively; Analysis 1.19). At 12 months postpartum more women in the lifestyle group had met postpartum weight goals than in the control group (RR 1.75, 95\% Cl 1.05 to 2.90; participants = 156; low-quality evidence; Analysis 1.19). The evidence was downgraded due to imprecision and risk of bias.

\subsection{0 and 1.21 Impaired glucose intolerance}

Fasting plasma glucose concentration at three months postpartum was reported by Elnour 2008. There was a non-significant trend towards lower fasting glucose concentrations in the women who had received a lifestyle intervention compared with the control group (MD $-0.08 \mathrm{mmol} / \mathrm{L}, 95 \% \mathrm{Cl}-0.16$ to 0.00 ; one trial, $\mathrm{n}=165$ women; Analysis 1.20). At six months postpartum, there was a reduction in fasting blood glucose concentrations in the lifestyle intervention group compared with the control group (MD $-0.14 \mathrm{mmol} / \mathrm{L}, 95 \% \mathrm{Cl}-0.22$ to -0.06 ; one trial $\mathrm{n}=$ 165 women; Analysis 1.20). Data from Kaviani 2014 were not suitable for inclusion in the meta-analysis for postnatal glycaemic blood glucose concentrations. The authors have been contacted for further information. Bancroft 2000 found no evidence of a difference between lifestyle intervention and control groups for diagnosis of postnatal impaired glucose tolerance (RR $0.67,95 \% \mathrm{Cl}$ 0.12 to 3.69; one trial, $\mathrm{n}=56$ women; Analysis 1.21).

1.22 Cardiovascular health (as defined by the trialists including blood pressure, hypertension, cardiovascular disease, metabolic syndrome)

Landon 2009 reported no evidence of a difference between lifestyle and interventions groups for the risk of maternal metabolic syndrome at follow-up at between 4.5 to 10 years after diagnosis of gestational diabetes mellitus (GDM) (RR 0.93, 95\% Cl 0.71 to 1.22 ; $\mathrm{n}$ $=430$ women; Analysis 1.22).

There was no evidence of a difference between lifestyle and control groups for body mass index (BMI) at the follow-up. Landon 2009 reported data for maternal BMI at long-term follow-up, 4.5 and 10 years after diagnosis of GDM. The trial by Garner 1997 followed up mothers and infants at nine to 11 years. The data in both trials were not in a format suitable for inclusion in a meta-analysis and are summarised in Table 8.

No data were reported for type 1 diabetes, subsequent gestational diabetes, cardiovascular health (blood pressure, hypertension or cardiovascular disease).

\section{Neonatal secondary outcomes}

\subsection{Stillbirth}

Stillbirth was reported in four trials (Bancroft 2000; Crowther 2005; Garner 1997; Landon 2009). There was no evidence of a difference in the risk of stillbirth between the lifestyle and the control groups (RR $0.15,9 \% \mathrm{Cl} 0.01$ to 2.86 ; four trials, $\mathrm{n}=2355$ infants). There were no events of stillbirth reported in the lifestyle intervention group (0/1172) and three events in the control group (3/1183). All three stillbirths were reported from a single trial (Crowther 2005) (Analysis 1.23).

\subsection{Neonatal death}

Neonatal death was reported in five trials (Bancroft 2000; Crowther 2005; Garner 1997; Landon 2009; Yang 2014). There was no evidence of a difference in the risk for neonatal death between the lifestyle and the control groups (RR $0.73,95 \% \mathrm{Cl} 0.22$ to 2.42 ; five trials, $\mathrm{n}$ $=3055$ infants; $12=0 \%)$. Event rates were low with $4 / 1511(0.3 \%)$ neonatal deaths in the lifestyle intervention group and 6/1544 $(0.4 \%)$ in the control group (Analysis 1.24$)$. 


\subsection{Macrosomia (greater than $4000 \mathrm{~g}$; or as defined by individual} study)

Macrosomia was reported in seven trials (Crowther 2005; Elnour 2008; Ferrara 2011; Garner 1997; Landon 2009; Mendelson 2008; Yang 2014). The Crowther 2005 and Yang 2014 trials defined macrosomia as $\geq 4 \mathrm{~kg}$, the remaining trials used a definition of $>4 \mathrm{~kg}$. Lifestyle interventions were associated with a significant reduction in the risk of macrosomia compared with the control group (average RR $0.64,95 \% \mathrm{Cl} 0.48$ to 0.87 ; seven trials, $\mathrm{n}=3422$ infants; $1^{2}=65 \%$, Tau ${ }^{2}=0.10$; Analysis 1.25$)$. Sensitivity analyses were used to explore the heterogeneity by looking at those trials that were judged to be low risk of bias for allocation concealment (Crowther 2005; Landon 2009). The direction of the treatment effect was unchanged and heterogeneity was reduced to $12=0 \%$ (RR 0.44, $95 \% \mathrm{Cl} 0.34$ to 0.57 ; participants = 1961; studies = two).

\subsection{Small-for-gestational (SGA) age (as defined by trialists)}

There was no evidence of a difference in the risk of the infant being born SGA between the lifestyle or the control group (RR 0.98, 95\% $\mathrm{Cl} 0.73$ to $1.31 ; \mathrm{n}=2324$ infants; four trials; $\left.\right|^{2}=0 \%$; Analysis 1.26 ).

\subsection{Birth trauma (shoulder dystocia, bone fracture, nerve palsy)}

Birth trauma (not specified but including shoulder dystocia, bone fracture and/or nerve palsy) was reported in three trials (Garner 1997; Landon 2009; Yang 2014). Event rates were low with only the Landon 2009 trial reporting 3/964 (0.3\%) events in the lifestyle intervention group and $6 / 966(0.6 \%)$ in the control group (RR $0.48,95 \% \mathrm{Cl} 0.12$ to 1.90 ; three trials, $\mathrm{n}=1930$ infants) (Analysis 1.27). Event rates for bone fracture were very low with only one event being reported in the Crowther 2005 trial in the control group (1/885) compared with no events in the lifestyle intervention group (0/845). No events were reported by Yang 2014 (RR 0.35, $95 \% \mathrm{Cl} 0.01$ to 8.45 , two trials, $\mathrm{n}=1730$ infants) (Analysis 1.27). Nerve palsy was only reported in one trial (Crowther 2005) where there were no events in the lifestyle intervention group (0/506) and $3 / 524$ events in the control group. The difference was not statistically significant. Shoulder dystocia was reported in five trials (Bancroft 2000; Crowther 2005; Elnour 2008; Landon 2009; Yang 2014). Lifestyle interventions were associated with a significant decrease in the risk of shoulder dystocia (RR $0.38,95 \% \mathrm{Cl} 0.21$ to 0.66; five trials, 2894 infants; Analysis 1.27).

\subsection{Gestational age at birth}

There was no evidence of a difference for gestational age at birth between the lifestyle intervention and control groups reported in five trials (Bancroft 2000; Garner 1997; Gillen 2004; Landon 2009; Yang 2014) (MD 0.04 weeks, 95\% Cl -0.13 to 0.20; $\mathrm{n}=2057$ infants; five trials; $\mathrm{I}^{2}=31 \%$; Analysis 1.28). Two trials (Crowther 2005; Jovanovic-Peterson 1989) reported data in a format that could not be included in a meta-analysis (Table 9); their results concur with the meta-analysis indicating no evidence of a difference in gestational age at birth between infants exposed to the lifestyle intervention and control groups.

\subsection{Preterm birth (< 37 weeks' gestation; and < 32 weeks' gestation)}

Lifestyle interventions were associated with a reduction in the risk of preterm birth (<37 weeks' gestation) compared with the control group as reported in four trials (Elnour 2008; Landon 2009; Yang 2014) (RR 0.71, 95\% Cl 0.53 to 0.96; $n=1797$ infants; three trials; $\left.\right|^{2}$ = 27\%; Analysis 1.29).

\subsection{Five-minute Apgar less than seven}

There was no evidence of a difference between the lifestyle intervention and control groups for a five-minute Apgar score less than seven reported by Crowther 2005 (RR 0.56; $95 \% \mathrm{Cl} 0.21$ to 1.52 ; one trial, $\mathrm{n}=1030$ infants; Analysis 1.30).

\subsection{Birthweight and z score}

Birthweight was reported in six trials (Bancroft 2000; Crowther 2005; Garner 1997; Jovanovic-Peterson 1989; Landon 2009; Yang 2014). Lifestyle interventions were associated with a significant reduction in birthweight (MD $-109.64 \mathrm{~g}, 95 \% \mathrm{Cl}-149.77$ to -69.51 ; six trials, $\mathrm{n}=3074$ infants; Analysis 1.31) without a consequent increase in the risk of SGA as previously reported (Analysis 1.26). No data were reported for $z$ scores.

\subsection{Length and $z$ score}

Length at birth - one trial (Yang 2014) reported no evidence of a difference in infant length at birth between infants exposed to a lifestyle intervention or the control group (MD $-0.10 \mathrm{~cm}, 95 \% \mathrm{Cl}$ -0.37 to 0.17 ; one trial, $n=700$ infants; Analysis 1.32 ). No data were reported for $z$ scores.

1.33 Adiposity (including skinfold thickness measurements ( $\mathrm{mm}$ ); fat mass)

Neonatal fat mass - one trial (Landon 2009) reported that the infants exposed to the lifestyle intervention had a decreased whole-body fat mass (estimated from skinfold thickness) compared with the control group (MD $-37.30 \mathrm{~g}, 95 \% \mathrm{Cl}-63.97$ to -10.63 ; one trial, 958 infants; low-quality evidence; Analysis 1.33). The evidence was downgraded for risk of bias and imprecision as it was based on a single study. No data were reported for skinfold thickness.

\subsection{Neonatal hypoglycaemia}

Neonatal hypoglycaemia - six trials (Bancroft 2000; Crowther 2005; Elnour 2008; Garner 1997; Landon 2009; Yang 2014) found no evidence of a difference in the risk of neonatal hypoglycaemia between the infants exposed to a lifestyle intervention and those exposed to the control group (average RR 0.99, 95\% Cl 0.65 to 1.52; six trials, $\mathrm{n}=3000$ infants; $\mathrm{I}^{2}=48 \%$, Tau ${ }^{2}=0.12 ;$ moderate-quality evidence; Analysis 1.34). The evidence was downgraded for risk of bias.

\subsection{Respiratory distress syndrome}

Respiratory distress syndrome - four trials (Bancroft 2000; Crowther 2005; Elnour 2008; Landon 2009) found no evidence of a difference in the risk of respiratory distress syndrome between exposure to lifestyle intervention or control groups (average RR $0.79,95 \% \mathrm{Cl}$ 0.34 to 1.85 , four trials, $n=2195$ infants; $1^{2}=64 \%$, Tau ${ }^{2}=0.44$; Analysis 1.35).

\subsection{Neonatal jaundice (hyperbilirubinaemia)}

Neonatal jaundice (hyperbilirubinaemia) - four trials (Crowther 2005; Elnour 2008; Garner 1997; Landon 2009) found no evidence of a difference in the risk for hyperbilirubinaemia between infants exposed to the lifestyle intervention or the control group (average RR $0.76,95 \% \mathrm{Cl} 0.50$ to 1.16 ; four trials, $\mathrm{n}=2362 ; \mathrm{I}^{2}=47 \%$, $\mathrm{Tau}^{2}=$ 0.08; Analysis 1.36). 


\subsection{Hypocalcaemia}

Hypocalcaemia was reported in two trials (Elnour 2008; Garner 1997). Lifestyle interventions were associated with an increased risk for hypocalcaemia compared with the control groups (RR 1.38, $95 \% \mathrm{Cl} 1.01$ to 1.88 ; two trials, $\mathrm{n}=464$ infants; Analysis 1.37).

\section{38 Polycythaemia}

Polycythaemia was reported in one trial (Elnour 2008). There was no evidence of a difference between lifestyle intervention and control group for the risk for infant polycythaemia (RR 0.22, 95\% $\mathrm{Cl} 0.01$ to 5.40; one trial, $\mathrm{n}=165$ infants; Analysis 1.38). Caution is recommended in interpreting the results due to the low event rates (0/99 in the lifestyle group; $1 / 66$ in the control group).

No data were reported for head circumference, $z$ scores for anthropometric measures, ponderal index, skinfold thickness or relevant biochemical markers.

\section{Childhood follow-up}

Three trials reported follow-up data into childhood (Crowther 2005; Garner 1997; Landon 2009).

The Landon 2009 trial has reported on follow-up of children at ages five to 10 years. Seventy-four per cent $(666 / 905)$ of the original trial cohort were contacted and $500(55 \%)$ consented to enrol in the follow-up. Continuous data for BMI z score, cholesterol concentration, triglycerides and impaired glucose tolerance were reported as adjusted means with $95 \% \mathrm{Cls}$ and we have therefore not included these data in the meta-analysis.

Gillman 2010 reported on the follow-up at four to five years from $199(20 \%)$ children in Australia who were born to 1000 mothers who participated in the ACHOIS trial (Crowther 2005). This cohort of data is likely to be biased as it does not represent the entire trial population. The mean age at follow-up in this cohort was $4.7 \pm 0.2$ years in the intervention group and $4.7 \pm 0.4$ years in the control group.

The offspring of the Garner 1997 trial were followed up at seven to 11 years by Keely (2008) (for metabolic markers of insulin resistance).

\subsection{Childhood weight and $z$ score}

Childhood weight was reported in one trial (Crowther 2005) who found no evidence of a difference between the lifestyle intervention and control group exposed infants (MD $-0.30 \mathrm{~kg}, 95 \% \mathrm{Cl}-1.29$ to 0.69 ; one trial, $n=199$ children; Analysis 1.39). No data were reported for z scores.

\subsection{Childhood height and $z$ score}

Childhood height was reported in one trial (Crowther 2005) who found no evidence of a difference between the lifestyle intervention and control group exposed infants (MD $-0.60 \mathrm{~cm}, 95 \% \mathrm{Cl}-2.05$ to 0.85 ; one trial, $\mathrm{n}=199$ children; Analysis 1.39). No data were reported for $z$ scores.

\subsection{1 and 1.42 Adiposity (including BMI, skinfold thickness, fat mass)}

Childhood BMI was reported in three trials (Crowther 2005; Garner 1997; Landon 2009).
There was no evidence of a difference between groups for $\mathrm{BMI} \geq$ 85th percentile reported in the three trials (Crowther 2005; Garner 1997; Landon 2009) (RR 0.91, 95\% Cl 0.75 to 1.11 ; participants $=767 ; 1^{2}=4 \%$; Analysis 1.41; moderate-quality evidence). The evidence was downgraded for risk of bias. Childhood BMI z score was reported in one trial (Crowther 2005) which found no evidence of a difference between groups at four to five years of age (MD 0.08 , $95 \% \mathrm{Cl}-0.28$ to 0.44 ; one trial, $\mathrm{n}=199$ children). The Landon 2009 follow-up of children at five to 10 years reported an adjusted mean BMI z score of $0.33(95 \% \mathrm{Cl} 0.15$ to $0.51 ; \mathrm{n}=264)$ in the treated group and an adjusted mean BMI $\mathrm{z}$ score of $0.36(95 \% \mathrm{Cl} 0.17$ to $0.55, \mathrm{n}=$ $236)$ in the untreated group. These data could not be combined in a meta-analysis (Analysis 1.42).

\subsection{Impaired glucose tolerance}

One study (Garner 1997) reported no evidence of a difference between the treated and untreated groups for fasting blood glucose concentration at seven to 11 years of age (MD $0.10 \mathrm{mg} / \mathrm{dL}, 95 \%$ $\mathrm{Cl}-0.10$ to 0.30 ; one trial, $\mathrm{n}=68$ children). The follow-up of the Landon 2009 trial reported that 12/264 (5.4\%) of children from the treated group and $13 / 236(7.2 \%)$ of children from the untreated group had impaired fasting glucose concentration $\geq 5.6 \mathrm{mmol} / \mathrm{L}$ $(100 \mathrm{mg} / \mathrm{dL})$. An adjusted mean fasting blood glucose concentration of $88.41 \mathrm{mg} / \mathrm{dL}$ ( $95 \% \mathrm{Cl} 87.33$ to $89.50 ; \mathrm{n}=264$ ) was reported for the treated group and an adjusted mean blood glucose concentration of $88.67 \mathrm{mg} / \mathrm{dL}(95 \% \mathrm{Cl} 87.56$ to $89.78, \mathrm{n}=236)$ was reported for the untreated group. These data could not be combined in a meta-analysis. There was no evidence of a difference between the lifestyle intervention and control groups for child two-hour postprandial glucose concentration (MD $0.00 \mathrm{mg} / \mathrm{dL}, 95 \% \mathrm{Cl}-0.48$ to 0.48 ; one trial, $n=68$ children). See Analysis 1.43 .

\subsection{Dyslipidaemia or metabolic syndrome}

Dyslipidaemia or metabolic syndrome - in Garner 1997 there was no evidence of a difference between groups in total cholesterol concentration (MD $-0.20 \mathrm{mg} / \mathrm{dL}, 95 \% \mathrm{Cl}-0.55$ to 0.15 ; one trial, $\mathrm{n}=$ 68 children); HDL (MD $0.10 \mathrm{mg} / \mathrm{dL}, 95 \% \mathrm{Cl}-0.05$ to 0.25 ; one trial, $\mathrm{n}=$ 68 children) or LDL (MD $-0.12 \mathrm{mg} / \mathrm{dL}, 95 \% \mathrm{Cl}-0.50$ to 0.26 ; one trial, $\mathrm{n}=68$ children). The follow-up of the Landon 2009 trial reported low HDL cholesterol $(<40 \mathrm{mg} / \mathrm{dL})$ in $27 / 264(13 \%)$ of children in the treated group and $22 / 236(12 \%)$ in the untreated group. The adjusted mean for HDL cholesterol concentration for the treated group was $54.35 \mathrm{mg} / \mathrm{dL}(95 \% \mathrm{Cl} 52.42$ to $56.28 ; \mathrm{n}=264)$ and for the untreated group the adjusted mean $\mathrm{HDL}$ cholesterol concentration was $55.10 \mathrm{mg} / \mathrm{dL}$ ( $95 \% \mathrm{Cl} 53.16$ to $57.05 ; \mathrm{n}=236)$. These data could not be combined in a meta-analysis (Analysis 1.44).

The Landon 2009 follow-up also reported elevated triglyceride concentrations ( $\geq 100 \mathrm{mg} / \mathrm{dL}$ four to nine years, $\geq 130 \mathrm{mg} / \mathrm{dL} 10$ years) in 38/264 (18\%) of the treated group and 29/236 (16\%) in the untreated group. The adjusted mean triglyceride concentration was $58.91 \mathrm{mg} / \mathrm{dL}(95 \% \mathrm{Cl} 54.82$ to $63.30 ; \mathrm{n}=264)$ for the treated group and adjusted mean triglyceride concentration for the untreated group was $57.38 \mathrm{mg} / \mathrm{dL}$ (95\% Cl 53.33 to $61.73 ; \mathrm{n}=236$ ). These data could not be combined in a meta-analysis. Childhood data for triglyceride concentrations were reported by Garner 1997 who found a median value of $0.8 \mathrm{mmol} / \mathrm{L}$ (range 0.4 to 2.7 ) in 43 children followed up whose mothers had been in the lifestyle intervention group and a median (range) of $0.83 \mathrm{mmol} / \mathrm{L}$ (0.5 to 5.4) in 25 children whose mothers had been in the control group. 
Blood pressure - the follow-up of the Landon 2009 trial reported data for the number of children with hypertension $(\geq 95$ th percentile for age, sex and height) which occurred in 30/264 (11.5\%) children from the treated group and 23/236 (10\%) in the untreated group. The adjusted mean systolic blood pressure in the treated group was $100 \mathrm{~mm} / \mathrm{Hg}(95 \% \mathrm{Cl} 98$ to $101, \mathrm{n}=264)$ and for the untreated group the adjusted mean systolic blood pressure was 100 $\mathrm{mm} / \mathrm{Hg}(95 \% \mathrm{Cl} 98$ to $101, \mathrm{n}=236)$. The adjusted mean diastolic blood pressure in the treated group was $60 \mathrm{~mm} / \mathrm{Hg}(95 \% \mathrm{Cl} 59$ to $61, n=264)$ and for the untreated group the adjusted mean systolic blood pressure was $59 \mathrm{~mm} / \mathrm{Hg}(95 \% \mathrm{Cl} 58$ to $60, \mathrm{n}=236)$.

No data were reported for the following childhood outcomes: weight or height $\mathrm{z}$ scores, head circumference and z scores, educational attainment, type 1 diabetes or type 2 diabetes.

\section{Adult outcomes}

No data were reported for any of the pre-specified adult outcomes for this review (weight, height, adiposity, employment, education and social status/achievement, dyslipidaemia or metabolic syndrome, type 1 diabetes, type 2 diabetes, impaired glucose tolerance, cardiovascular health (as defined by trialists including blood pressure, hypertension, cardiovascular disease, metabolic syndrome)).

\section{Health service use}

\subsection{Number of antenatal visits or admissions}

There was no evidence of a difference between the lifestyle intervention and control groups for the number of antenatal visits or admissions - (RR 1.06, $95 \% \mathrm{Cl} 0.87$ to 1.29 ; one trial, $\mathrm{n}=1000$ women; Analysis 1.45) reported in one trial (Crowther 2005).

\subsection{6 and 1.47 Number of hospital or health professional visits (including midwife, obstetrician, physician, dietician, diabetic nurse)}

Number of hospital or health professional visits (during pregnancy) - the women randomised to the lifestyle intervention groups were more likely to have a visit with a dietitian compared with the control groups (RR 9.24, 95\% Cl 7.12 to 12.01; one trial, $\mathrm{n}=1000$ women; Analysis 1.46) or a visit with a diabetes care educator (RR 8.55 , $95 \% \mathrm{Cl} 6.67$ to 10.96; one trial, $\mathrm{n}=1000$ women; Analysis 1.46) than the control group. This is most likely due to the trial protocol requiring a visit with a dietician (Crowther 2005). One trial (Yang 2014) reported no evidence of a difference in the number of visits to an obstetrician between the lifestyle intervention and control groups (MD 0.20 visits, $95 \% \mathrm{Cl}-0.21$ to 0.61 ; one trial, $\mathrm{n}=700$ women; Analysis 1.47) and Ferrara 2011 reported no evidence of a difference between groups for the number of visits to an antenatal care provider (not specified) - (MD 0.10 visits, $95 \% \mathrm{Cl}-1.58$ to 1.78 ; one trial, 197 women; Analysis 1.47). Other data reported as median or mean without standard deviation are summarised in Table 10.

\subsection{Admission to neonatal intensive care unit/nursery}

There was no evidence of a difference in the admission to neonatal intensive care unit or special care baby unit between infants who had been exposed to the lifestyle intervention or the control groups (average RR $0.91,95 \% \mathrm{Cl} 0.59$ to 1.40 ; three trials, $\mathrm{n}=2030$ infants; $\mathrm{I}^{2}$ $=70 \%$, Tau $^{2}=0.09$; Analysis 1.48) reported in three trials (Bancroft 2000; Crowther 2005; Landon 2009).

Costs - only one trial (Crowther 2005) provided data for the economic impact of a lifestyle intervention compared with usual care. Table 11 illustrates the costs of gestational diabetes to the families and the health service for the lifestyle and control groups. Not surprisingly the costs were higher in the intervention group than the control group which is mainly due to increased surveillance and increased contact with health professionals.

No data were reported for duration of stay in neonatal intensive care or special care baby unit, or the duration of the mothers' stay in hospital (antenatal, neonatal, postnatal), extra use of healthcare services or women's view of treatment advice.

\section{DISCUSSION}

\section{Summary of main results}

Fifteen trials (in 45 reports) are included in this review (4501 women, 3768 infants).

The evidence suggests that for women diagnosed with gestational diabetes mellitus (GDM), a lifestyle intervention (two or more interventions including dietary advice, physical activity, education, self-monitoring of blood glucose), there is no clear difference in risk of developing hypertension in pregnancy or of having a caesarean birth (Summary of findings for the main comparison). There was no evidence of a difference between lifestyle intervention and control groups for the mother developing type 2 diabetes at follow-up ranging from 4.5 to 10 years. A lifestyle intervention was associated with a decrease in weight gain in pregnancy compared with a control group. The lifestyle intervention group did have more visits to health professionals and an increased use of additional pharmacological therapies. One small study ( $n=159$ women; Ferrara 2011) found that women in the lifestyle intervention group were more likely to meet postpartum weight goals at one year compared with the control group. Few trials reported on long-term maternal outcomes.

There was no evidence of a difference between infants exposed to lifestyle interventions or control for the risk of perinatal death or a composite of serious infant adverse events. Those infants exposed to the lifestyle intervention had a decreased risk of being born large-for-gestational age (LGA) (Summary of findings 2) compared with the infants whose mothers had been in the control group. None of the included trials reported on childhood neurodisability. Infants who had been exposed to a lifestyle intervention had a decreased risk of or having macrosomia, being born preterm ( $<37$ weeks') and had a lower birthweight compared with the infants whose mothers had been in the control group. There was also a reduced risk of shoulder dystocia associated with lifestyle interventions. No infant adverse effects or increased likelihood of admission to neonatal intensive care were associated with the interventions reviewed. Follow-up into childhood was poorly reported with only three of the 15 included trials contributing data (Crowther 2005; Garner 1997; Landon 2009). There was no evidence of a difference between groups for body mass index (BMI) greater or equal to the 85th percentile and no evidence of a difference in dyslipidaemia or blood pressure. None of the trials have yet reported data for the infant as an adult (Summary of findings 2).

\section{Overall completeness and applicability of evidence}

This review has focused on lifestyle interventions for the treatment of women with GDM that included a combination of interventions such as nutritional advice, physical activity, education, and selfmonitoring of blood glucose concentrations. Lifestyle interventions 
are used as the primary therapeutic strategy for women diagnosed with GDM. Some women who commence lifestyle interventions will require supplementary pharmacological interventions (insulin or oral anti-diabetic pharmacological therapies), and this is evident from this review with 10 of the included studies reporting an increase in the use of supplementary pharmacological therapy.

The evidence for treatment needs to be taken in context for the needs of the individual woman, and other Cochrane systematic reviews have examined or plan to examine different dietary advice for women with GDM (Han 2013), exercise (Ceysens 2016), insulin (Brown 2016) and oral anti-diabetic pharmacological therapies (Brown 2015b). This review does not include women with impaired glucose tolerance, not meeting criteria for diagnosis of GDM, which is covered by the Han 2012 Cochrane systematic review.

Due to insufficient data we are unable to make any judgements on lifestyle interventions as a sole intervention without any supplementary pharmacological therapy. Nor are we able to make any judgements on the effectiveness of treatment based on duration of treatment as gestational age at trial entry was poorly reported for the included trials. In the description of included studies we have listed all of the interventions described by the included trials. There is a wide variety and diversity of interventions that include exercise, diet, self-monitoring of blood glucose and education for example. We are unable to determine which if any of the interventions are more effective than another but most of the interventions include some dietary component.

\section{Quality of the evidence}

Fifteen trials (45 publications) are included in this review (4501 women and their infants). The main reasons for downgrading evidence was inconsistency, imprecision and risk of bias. Overall, the evidence was judged to be of unclear risk of bias due to inadequate reporting of allocation concealment and blinding of outcome assessors and selective outcome reporting. There is variation between the trials with regards to the content of the lifestyle interventions (see Characteristics of included studies). The evidence is dominated by two large trials (Crowther 2005; Landon 2009) that included 1000 women and 958 women, respectively. Both of these trials were judged to be at low risk of bias.

\section{Potential biases in the review process}

We believe that we have made every effort to minimise biases in the review process. We have conducted a systematic search of the literature for randomised controlled trial evidence, not restricted by language or date of publication. Where necessary we have attempted to make contact with authors of primary studies to obtain additional methodological and/or outcome data. We have adhered to Cochrane methodology for searching, data extraction and analysis.

\section{Agreements and disagreements with other studies or reviews}

A systematic review assessing the effect of treatment of GDM by Poolsup 2014 included 10 studies and reported a decreased risk of macrosomia, LGA, shoulder dystocia and gestational hypertension. Seven of the 10 studies included in the Poolsup 2014 were excluded from our review based on study design and the remaining three trials that they included were also included in our review (Crowther 2005; Garner 1997; Landon 2009). Another systematic review by
Hartling 2013 reported on the benefits and harms of treating GDM. The review found increased antenatal visits, reduced preeclampsia, shoulder dystocia and macrosomia in the treated group. No clear differences between intervention and control groups were found for neonatal hypoglycaemia, caesarean section, induction of labour or admission to neonatal intensive care. The evidence was based on five randomised trials (including quasi-randomised trials) and six cohort studies. Three of the studies were included in our review (Crowther 2005; Garner 1997; Landon 2009).

\section{AUTHORS' CONCLUSIONS}

\section{Implications for practice}

Lifestyle interventions are resource-intensive and require trained personnel to provide optimal education and management support.

Low-quality evidence suggests that women receiving lifestyle interventions are less likely to have postnatal depression and are more likely to achieve postpartum weight goals than women in usual care or diet-only groups.

For the infant, there is moderate-quality evidence of a reduced risk of being born large-for-gestational age (LGA) and low-quality evidence for reduced adiposity (neonatal fat mass) for infants exposed to lifestyle interventions compared with usual care or dietalone groups. The limited available moderate-quality evidence for longer-term follow-up suggests there is no clear difference between groups for adiposity in childhood (childhood BMI > 85th centile) and no trials reported data into adulthood for adiposity.

The value of lifestyle interventions in low- and middle-income countries or for different ethnicities remains unclear. The longerterm benefits or harms of lifestyle interventions remains unclear due to limited reporting. Lifestyle interventions are useful as the primary therapeutic strategy and most commonly includes components of healthy eating, physical activity and self-monitoring of blood glucose levels.

\section{Implications for research}

Future research should focus on which specific interventions are most useful, which health professionals should give them and the optimal format for providing the information. Evaluation of longterm outcomes for the mother and her child should be a priority when planning future trials. There has been no in-depth exploration of the costs 'saved' from reduction in risk of LGA/macrosomia and potential longer-term risks for the infants.

\section{ACKNOWLEDGEMENTS}

We acknowledge the valuable contributions from the authors of the original review "Treatments for gestational diabetes" of Nisreen Alwan, Jane West and Derek Tuffnell upon which this update is based (Alwan 2009).

We acknowledge the contribution of the authors of the other two reviews that were split from this original review in the preparation of the core background sections of the new review protocols:

Oral anti-diabetic pharmacological therapies for the treatment of women with gestational diabetes - Julie Brown, Ruth Martis, Brenda Hughes, Janet Rowan, Caroline Crowther. 
Insulin for the treatment of women with gestational diabetes Julie Brown, Luke Greskowiak, Michelle Downie, Kate Williamson, Caroline Crowther.

We acknowledge the contribution of Tineke Crawford who has assisted with data extraction and assessment of risk of bias.

We acknowledge the support from the Cochrane Pregnancy and Childbirth Review Group editorial team in Liverpool, the Australian and New Zealand Satellite of the Cochrane Pregnancy and Childbirth review Group and the Liggins Institute, University of Auckland, New Zealand.
This project was supported by the National Institute for Health Research, via Cochrane Infrastructure and Cochrane Programme Grant funding to Cochrane Pregnancy and Childbirth. The views and opinions expressed therein are those of the authors and do not necessarily reflect those of the Systematic Reviews Programme, NIHR, NHS or the Department of Health.

As part of the pre-publication editorial process, this review has been commented on by four peers (an editor and three referees who are external to the editorial team) and the Group's Statistical Adviser. 


\section{R E F E R E N C E S}

\section{References to studies included in this review}

Bancroft 2000 \{published data only\}

* Bancroft K, Tuffnell DJ, Mason GC, Rogerson LJ, Mansfield M. A randomised controlled pilot study of the management of gestational impaired glucose tolerance. BJOG: an international journal of obstetrics and gynaecology 2000;107(8):959-63.

Bancroft K, Tuffnell DJ, Mason GC, Rogerson LJ, Mansfield M. A randomised controlled study of the management of impaired glucose tolerance in pregnancy. British Journal of Obstetrics and Gynaecology 1998;105(Suppl 17):53-4.

\section{Bo 2014 \{published data only\}}

* Bo S, Rosato R, Ciccone G, Canil S, Gambino R, Poala CB, et al. Simple lifestyle recommendations and the outcomes of gestational diabetes. A $2 \times 2$ factorial randomized trial. Diabetes, Obesity and Metabolism 2014;16(10):1032-5.

NCT01506310. Efficacy of behavioural therapy and exercise in gestational diabetes mellitus. clinicaltrials.gov/show/ NCT01506310 Date first received: 26 December 2011.

\section{Crowther 2005 \{published data only\}}

ACTRN12606000294550. Australasian carbohydrate intolerance study in pregnancy. anzctr.org.au/Trial/Registration/ TrialReview.aspx?ACTRN=12606000294550 Date first received: 11 July 2006.

Crowther CA, Hiller JE, Moss JR, McPhee AJ, Jeffries WS, Robinson JS. Does antenatal treatment of screen detected impaired glucose tolerance improve health outcomes in women and their infants? The ACHOIS trial. 30th British Congress of Obstetrics and Gynaecology; 2004 July 7-9; Glasgow, UK. 2004:26.

* Crowther CA, Hiller JE, Moss JR, McPhee AJ, Jeffries WS, Robinson JS, et al. Effect of treatment of gestational diabetes mellitus on pregnancy outcomes. New England Journal of Medicine 2005;352(24):2477-86.

Gillman M, Oakey H, Baghurst P, Volkmer R, Robinson J, Cowther $\mathrm{C}$. Effect of treatment of gestational diabetes mellitus on obesity in the next generation. Diabetes Care 2010;33(5):964-8.

Moss JR, Crowther CA, Hiller JE, McPhee AJ, Jeffries WS, Willson $\mathrm{KJ}$. Costs and consequences of treatment of gestational diabetes mellitus - evaluation from the ACHOIS randomised trial [abstract]. Journal of Paediatrics and Child Health 2007;43(1):A28-A29.

Moss JR, Crowther CA, Hiller JE, Willson KJ, Robinson JS, for the Australian Carbohydrate Intolerance Study in Pregnant Women (ACHOIS) Trial Group. Costs and consequences of treatment for mild gestational diabetes mellitus - evaluation from the ACHOIS randomised trial. BMC Pregnancy and Childbirth 2007;7:27.

Pirc LK, Owens JA, Crowther CA, Willson K, De Blasio MJ, Robinson JS. Mild gestational diabetes in pregnancy and the adipoinsular axis in babies born to mothers in the ACHOIS randomised controlled trial. BMC Pediatrics 2007;7:18.

Elnour 2008 \{published data only\}

Elnour AA, El Mugammar IT, Jaber T, Revel T, McElnay JC. Pharmaceutical care of patients with gestational diabetes mellitus. Journal of Evaluation in Clinical Practice 2008;14(1):131-40.

\section{Ferrara 2011 \{published data only\}}

Erlich SF, Hedderson MM, Quesenberry CP, Feng J, Brown SD, Crites $\mathrm{Y}$, et al. Postpartum weight loss and glucose metabolism in women with gestational diabetes: the DEBI Study. Diabetic Medicine 2014;31:862-7.

* Ferrara A, Hedderson MM, Albright CL, Ehrlich SF, Quesenberry CP Jr, Peng T, et al. A pregnancy and postpartum lifestyle intervention in women with gestational diabetes mellitus reduces diabetes risk factors: a feasibility randomized control trial. Diabetes Care 2011;34(7):1519-25.

NCT00460018. Diet, exercise and breastfeeding intervention program for women with gestational diabetes (DEBI Trial). clinicaltrials.gov/show/NCT00460018 Date first received: 11 April 2007.

\section{Garner 1997 \{published data only\}}

* Garner P, Okun N, Keely E, Wells G, Perkins S, Sylvain J, et al. A randomized controlled trial of strict glycemic control and tertiary level obstetric care versus routine obstetric care in the management of gestational diabetes: a pilot study. American Journal of Obstetrics and Gynecology 1997;177(1):190-5.

Keely EJ, Malcolm JC, Hadjiyannakis S, Gaboury I, Lough G, Lawson ML. Prevalence of metabolic markers of insulin resistance in offspring of gestational diabetes pregnancies. Pediatric Diabetes 2008;9(1):53-9.

Okun N. Gestational Diabetes Study. Personal communication 1994.

Gillen 2004 \{published data only\}

Gillen LJ, Tapsell LC. Advice that includes food sources of unsaturated fat supports future risk management of gestational diabetes mellitus. Journal of the American Dietetic Association 2004;104:1863-7.

\section{Jovanovic-Peterson 1989 \{published data only\}} Jovanovic-Peterson L, Durak EP, Peterson CM. Randomized trial of diet vs diet plus cardiovascular conditioning on glucose levels in gestational diabetes. American Journal of Obstetrics and Gynecology 1989;161:415-9.

\section{Kaviani 2014 \{published data only\}}

IRCT2013091014612N1. The effect of relaxation on blood sugar and blood pressure in pregnant women with gestational diabetes mellitus referring to selective centers of Shiraz University of Medical Sciences. en.search.irct.ir/view/15019 Date first received: 21 November 2013. 
* Kaviani M, Bahoosh N, Azima S, Asadi N, Sharif F, Sayadi M. The effect of relaxation on blood sugar and blood pressure changes of women with gestational diabetes: a randomized control trial. Iranian Journal of Diabetes and Obesity 2014;6(1):14-22.

\section{Landon 2009 \{published data only\}}

Bahado-Singh R, Mele L, Landon M, Ramin S, Carpenter M, Casey $\mathrm{B}$, et al. Fetal male gender and the benefits of treatment of mild gestational diabetes. American Journal of Obstetrics and Gynecology 2012;206(5):422.e1-422.e5.

Bahado-Singh RO. The relationship between fetal gender and the effects of treatment of mild gestational diabetes. Reproductive Sciences 2011;18(3 Suppl 1):T239.

Berggren EK, Mele L, Landon MB, Spong CY, Ramin S, Casey B, et al. Perinatal outcomes in Hispanic and non-Hispanic white women with mild gestational diabetes. Obstetrics and Gynecology 2012;120(5):1099-104.

Casey B. Effect of treatment of mild gestational diabetes on long term maternal outcomes. American Journal of Obstetrics and Gynecology 2015;212(1 Suppl):S3.

Casey BM, Mele L, Landon MB, Spong CY, Ramin SM, Wapner RJ, et al. Does maternal BMI influence treatment effect in women with mild gestational diabetes?. American Journal of Perinatology 2015;32(1):93-100.

Durnwald CP, Mele L, Spong CY, Ramin SM, Varner MW, Rouse DJ, et al. Glycaemic characteristics and neonatal outcomes of women treated for mild gestational diabetes. Obstetrics \& Gynecology 2011;117(4):819-27.

Klebanoff M, for the Eunice Kennedy Shriver National Institute of Child Health and Human Development Maternal-Fetal Medicine Units Network. Treatment of gestational diabetes (GDM) weight gain and perinatal outcome - marginal structural model (MSM) analysis. American Journal of Epidemiology 2011;173(Suppl):S41.

Landon M, Rice M, Varner M, Casey B, Reddy U, Wapner R, et al. Mild gestational diabetes mellitus and long-term child health. Diabetes Care 2015;38(3):445-52. [DOI: 10.2337/dc14-2159]

Landon MB. A prospective multicenter randomized treatment trial of mild gestational diabetes. American Journal of Obstetrics and Gynecology 2008;199(6 Suppl 1):S2.

* Landon MB, Spong CY, Thom E, Carpenter MW, Ramin SM, Casey B, et al. A multicenter, randomized trial of treatment for mild gestational diabetes. New England Journal of Medicine 2009;361(14):1339-48.

Landon MB, Thom E, Spong CY, Carpenter M, Mele L, Johnson F, et al. The National Institute of Child Health and Human Development Maternal-Fetal Medicine Unit Network randomised clinical trial in progress: standard therapy versus no therapy for mild gestational diabetes. Diabetes Care 2007;30:S194-S199.

Landon MB, Thom E, Spong CY, Gabbe SG, Leindecker S, Johnson $\mathrm{F}$, et al. A planned randomized clinical trial of treatment for mild gestational diabetes mellitus. Journal of Maternal-Fetal \& Neonatal Medicine 2002;11(4):226-31.

Palatnik A. The association of timing of treatment initiation for mild gestational diabetes with perinatal outcomes. American Journal of Obsetrics and Gynecology 2015;212(1 Suppl 1):S302.

Palatnik A, Mele L, Landon M, Reddy U, Ramin S, Marshall W. Timing of treatment initiation for mild gestational diabetes mellitus and perinatal outcomes. American Journal of Obstetrics and Gynecology 2015;213:560.e1-560.e8.

Sutton AL, Mele L, Landon M, Ramin S, Varner MW, Thorp JM, et al. Delivery timing and cesarean delivery risk in women with mild gestational diabetes mellitus. American Journal of Obstetrics and Gynecology 2014;211(3):244.e1-244.e7.

Mendelson 2008 \{published data only\}

* Mendelson S, McNeese-Smith D, Koniak-Griffin D, Nyamathi A, Lu M. A community-based parish nurse intervention program for Mexican-American women with gestational diabetes. JOGNN: Journal of Obstetric, Gynecologic \& Neonatal Nursing 2008;37(4):415-25.

Mendleson SG. A Community-Based Parish Nurse Intervention Program for Mexican American Women with Gestational Diabetes [thesis]. Los Angeles: University of California, 2007.

Rahimikian 2014 \{published data only\}

IRCT2013031812840N1. A comparison of two teaching methods on pregnancy outcomes in discharge of patients with gestational diabetes. en.search.irct.ir/view/13022 Date first received: 12 April 2013.

* Rahimikian F, Dehghan Nayeri N, Mehran A, Shiraz M, Senobari M. A comparative study of two methods of discharge education on pregnancy outcomes in women with gestational diabetes. Journal of Urmia Nursing and Midwifery Faculty 2014;12(7):591-8.

\section{Yang 2003 \{published and unpublished data\}}

Yang X, Hsu-Hage B, Dong L, Shao P, Wang H, Tian H, et al. Intensive diabetes management may improve pregnancy: outcomes in Chinese gravidas with impaired glucose tolerance. Diabetes Care 2003;26:254-5.

* Yang X, Hsu-Hage BH, Dong L, Zhang H, Zhang C, Zhang Y. Postpartum glucose intolerance in Chinese women with gestational diabetes. Diabetic Medicine 2003;20(8):687-9.

\section{Yang 2014 \{published data only\}}

Yang X, Tian H, Zhang F, Zhang C, Li Y, Leng J, et al. A randomised translational trial of lifestyle intervention using a 3 tier shared care approach on pregnancy outcomes in Chinese women with gestational diabetes mellitus but without diabetes. Journal of Translational Medicine 2014;12:290.

\section{Youngwanichsetha 2014 \{published data only\}}

Youngwanichsetha S, Phumdoung S, Ingkathawornwong T. The effects of mindfulness eating and yoga exercise on blood sugar levels of pregnant women with gestational diabetes mellitus. Applied Nursing Nursing 2014;27:227-30. 


\section{References to studies excluded from this review}

\section{Abirami 2014 \{published data only\}}

Abirami P, Judie A. Reduction of risk on newly detected gestational diabetes mellitus by multi model intervention - A hospital based study. International Journal of Pharmaceutical and Clinical Research 2014;6(4):370-4.

\section{Adam 2014 \{published data only\}}

Adam C, L'Abbe C, Lachapelle J, Ourabah S, Rakel A, de Guise M, et al. Impact of an individualised counselling on physical activity in women with gestational diabetes: Interim analysis of a randomized control trial. Endocrine Society's 96th Annual Meeting and Expo; 2014, June 21-24; Chicago, USA. Chicago: Endocrine Society 96th Annual Meeting, 2014:Abstract no: SUN-1035.

\section{Bastani 2015 \{published data only\}}

Bastini F. Effect of acupressure on maternal anxiety in women with gestational diabetes mellitus: a randomised clinical trial. Clinical Nursing Research 2015;25(3):1-17.

\section{Berry 2013 \{published data only\}}

Berry DC, Neal M, Hall EG, Schwartz TA, Verbiest S, Bonuck K, et al. Rationale, design and methodology for the optimizing outcomes in women with gestational diabetes mellitus and their infants study. BMC Pregnancy and Childbirth 2013;13:184.

\section{Bevier 1999 \{published data only\}}

Bevier WC, Fischer R, Jovanovic L. Treatment of women with an abnormal glucose challenge test (but a normal oral glucose tolerance test) decreases the prevalence of macrosomia. American Journal of Perinatology 1999;16(6):269-75.

\section{Bonomo 2005 \{published data only\}}

Bonomo M, Corica D, Mion E, Gonçalves D, Motta G, Merati R, et al. Evaluating the therapeutic approach in pregnancies complicated by borderline glucose intolerance: a randomized clinical trial. Diabetic Medicine 2005;22:1536-41.

\section{Branch 2010 \{unpublished data only\}}

NCT01171456. Early intervention for gestational diabetes. clinicaltrials.gov/show/NCT01171456 Date first received: 13 July 2010.

\section{Fadl 2015 \{published data only\}}

* Fadl HE, Gardefors S, Hjertberg R, Nord E, Persson B, Schwarcz E, et al. Randomized controlled study in pregnancy on treatment of marked hyperglycemia that is short of overt diabetes. Acta Obstetricia et Gynecologica Scandinavica 2015;94(11):81-7.

NCT00625781. Treatment of impaired glucose tolerance in pregnancy. clinicaltrials.gov/show/NCT00625781 Date first received: 1 February 2008.

\section{Ford 1997 \{published data only\}}

Ford FA, Bruce CB, Fraser RB. Preliminary report of a randomised trial of dietary advice in women with mild abnormalities of glucose tolerance in pregnancy. Personal communication 1997.
Grant 2011 \{published data only\}

Grant SM, Wolever TMS, O'Connor DL, Nisenbaum R, Josse RG. Effect of a low glycaemic index diet on blood glucose in women with gestational hyperglycaemia. Diabetes Research and Clinical Practice 2011;91(1):15-22.

Holmes 2012 \{unpublished data only\} ISRCTN62685558. Gestational diabetes: things you need to know (but maybe don't) a DVD for women with gestational diabetes mellitus. isrctn.com/ISRCTN62685558 Date first received: 8 November 2012 .

\section{Homko 2002 \{published data only\}}

Homko CJ, Sivan E, Reece EA. The impact of self-monitoring of blood glucose on self-efficacy and pregnancy outcomes in women with diet controlled gestational diabetes. Diabetic Educator 2002;28(3):435-43.

\section{Kitzmiller 1990 \{published data only\}}

Kitzmiller JL. Trial of diet vs diet plus insulin for gestational diabetes. Personal communication 1990.

\section{Langer 1989 \{published data only\}}

Langer O, Anyaegbunam A, Brustman L, Divon M. A prospective randomized study: management of women with one abnormal value (OGTT) reduces adverse outcome in pregnancy. Proceedings of 9th Annual Meeting of the Society of Perinatal Obstetricians; 1989 Feb 1-4; New Orleans, Louisiana, USA. 1989:11.

* Langer O, Anyaegbunam A, Brustman L, Divon M. Management of women with one abnormal oral glucose tolerance test value reduces adverse outcome in pregnancy. American Journal of Obstetrics and Gynecology 1989;161:593-9.

\section{Li 1987 \{published data only\}}

Li DFH, Wong VCW, O'Hoy KMKY, Yeung CY, Ma HK. Is treatment needed for mild impairment of glucose tolerance in pregnancy? A randomized controlled trial. British Journal of Obstetrics and Gynaecology 1987;94:851-4.

\section{Mirzamoradi 2015 \{published data only\}}

Mirzamoradi M, Bakhtiyari M, Kimiaee P, Hosseini-Najarkolaei A, Mansournia MA. Investigating the effects of treatment based on single high blood glucose in gestational diabetes screening on maternal and neonatal complications. Achives in Gynecology and Obstetrics 2015;292:687-95.

\section{O'Sullivan 1971 \{published data only\}}

O'Sullivan JB. Prospective study of gestational diabetes and its treatment. In: Stowers JB, Sutherland HW editor(s). Carbohydrate metabolism in pregnancy and the newborn. London: Churchill Livingstone, 1975:195-204.

* O'Sullivan JB, Charles D, Dandrow RV. Treatment of verified prediabetics in pregnancy. Journal of Reproductive Medicine 1971;7:21-4.

O'Sullivan JB, Gellis SS, Dandrow RV, Tenney BO. The potential diabetic and her treatment in pregnancy. Obstetrics \& Gynecology 1966;27:683-9. 
O'Sullivan 1974 \{published data only\}

O'Sullivan JB, Mahan CM, Charles D, Dandrow RV. Medical treatment of the gestational diabetic. Obstetrics \& Gynecology 1974;43:817-21.

O'Sullivan 1980 \{published data only\}

O'Sullivan JB, Mahan CM. Insulin treatment and high risk groups. Diabetes Care 1980;3(3):482-5.

Osmundson 2015 \{published data only\}

Osmundson S, Norton M, El-Sayed Y, Faig J, Carter S, Kitzmiller J. Early treatment of women with prediabetes in pregnancy: a randomised controlled trial. American Journal of Obstetrics and Gynecology 2015;212(1 Suppl):S23-S24.

Perichart-Perera 2009 \{published data only\} Perichart-Perera O, Balas-Nakash M, Parra-Covarrubias A, Rodriguez-Cano A, Ramirez-Torres A, Ortega-Gonzalez C, et al. A medical nutrition therapy program improves perinatal outcomes in Mexican pregnant women with gestational diabetes and type 2 diabetes mellitus. Diabetes Educator 2009;35(6):1004-13.

\section{Reader 2006 \{published data only\}}

Reader D, Splett P, Gubderson EP, Diabetes Care and Education Dietetic Practice Group. Impact of gestational diabetes mellitus nutrition practice guidelines implemented by registered dieticians on pregnancy outcomes. Journal of the American Dietetic Association 2006;106(9):1426-33.

Rey 1997 \{published data only\}

Rey E. Gestational diabetes: who needs a tight follow-up?. American Journal of Obstetrics and Gynecology 1995;172:333.

* Rey E. Usefulness of a breakfast test in the management of women with gestational diabetes. Obstetrics \& Gynecology 1997;89(6):981-8.

\section{References to studies awaiting assessment}

Cao 2012 \{published data only\}

Cao X, Wang Z, Yang C, Mo X, Xiu L, Li Y, et al. Comprehensive intensive therapy for chinese gestational diabetes benefits both newborns and mothers. Diabetes Technology and Therapeutics 2012;14(11):1002-7.

\section{Kaveh 2012 \{published data only\}}

Kaveh M, Kiani A, Salehi M, Amouei S. Impact of education on nutrition and exercise on the level of knowledge and metabolic control indicators (FBS \& PPBS) of gestational diabetes mellitus (GDM) patients. Iranian Journal of Endocrinology and Metabolism 2012;13(5):541-8.

\section{Zhang 2012 \{published data only\}}

Zhang LX. Evaluation of the effect of health education on selfmanagement of patients with gestational diabetes mellitus. Maternal and Child Health Care of China 2012; Vol. 27, issue 31:4850-1.

\section{References to ongoing studies}

Durnwald NCT01858233 \{published data only\}

NCT01858233. The IBEP Study: an intervention for lifestyle modification in women with gestational diabetes. clinicaltrials.gov/show/NCT01858233 Date first received: 8 May 2013.

\section{Ferrara NCT01489163 \{unpublished data only\}}

NCT01489163. Lifestyle interventions program for women with gestational diabetes or gestational impaired glucose tolerance (APPLES). clinicaltrials.gov/show/NCT01489163 Date first received: 7 December 2011.

Hoseinzadeh IRCT2014080418682N1 \{published data only\} IRCT2014080418682N1. The effects of an educational intervention based on the theory of planned behavior on selfcare behavior and blood glucose levels in pregnant women with gestational diabetes treated with insulin. en.search.irct.ir/view/ IRCT2014080418682N1 Date first received: 13 March 2015.

Mirfeizi IRCT201406022892N3 \{published data only\} IRCT201406022892N3. The effect of self care education on quality of life in women with gestational diabetes. en.search.irct.ir/view/IRCT201406022892N3 Date first received: 26 June 2014.

\section{Roeder NCT01926457 \{published data only\}}

NCT01926457. Treating prediabetes in the first trimester. clinicaltrials.gov/show/NCT01926457 Date first received: 15 August 2013.

Sahnaz IRCT2014042017346N1 \{published data only\} IRCT2014042017346N1. Effectiveness of stress management with cognitive behavioural method on blood sugar levels and stress among patient with gestational diabetes. en.search.irct.ir/view/17875 Date first received: 27 April 2014.

\section{Ziegler DRKS00000465 \{published data only\}}

DRKS00000465. MuKiS- Mother-child sports - a study to evaluate the impact of exercise on maternal metabolism and fetal development in women with gestational diabetes. drks-neu.uniklinik-freiburg.de/drks_web/navigate.do? navigationId=trial.HTML\&TRIAL_ID=DRKS00000465 Date first received: 30 June 2010.

\section{Additional references}

\section{ACOG 2005}

ACOG Committee. ACOG Committee Opinion number 315, September 2005. Obesity in pregnancy. Obstetrics \& Gynecology 2005;106(3):671-5.

\section{ACOG 2013}

American College of Obstetricians and Gynecologists practice bulletin clinical management guidelines for obstetriciangynecologists. ACOG Practice Bulletin. Clinical management guidelines for obstetrician-gynecologists. Obstetrics \& Gynecology 2013;122(2 Pt 1):406-16. 


\section{ADA 2013}

American Diabetes Association. Diagnosis and classification of diabetes mellitus. Diabetes Care 2013;36(Suppl 1):567-74.

\section{ADA 2015a}

American Diabetes Association. Management of diabetes in pregnancy Sec.12. In Standards of Medical Care in Diabetes 2015. Diabetes Care 2015;38(Suppl 1):S77-S79.

\section{ADA 2015b}

American Diabetes Association. Classification and diagnosis of diabetes. Sec 2. In Standards of Medical Care in Diabetes - 2015. Diabetes Care 2015;38(Suppl 1):S8-S16.

\section{Anderberg 2010}

Anderberg E, Kallen K, Berntorp K. The impact of gestational diabetes mellitus on pregnancy outcome comparing different cut-off criteria for abnormal glucose tolerance. Acta Obstetricia et Gynecologica Scandinavica 2010;89(12):1532-7.

\section{Asano 2014}

Asano RY, Sales MM, Browne RA, Vila Nova Moraes JF, Coelho HJ Jr, Moraes MR, et al. Acute effects of physical exercise in type 2 diabetes: a review. World Journal of Diabetes 2014;5(5):659-65.

\section{Barbour 2007}

Barbour LA, McCurdy CE, Hernandez TL, Kirwan JP, Catalano PM, Friedman JE. Cellular mechanisms for insulin resistance in normal pregnancy and gestational diabetes. Diabetes Care 2007;30(Suppl 2):S111-S119.

\section{Barrett 2014}

Barrett H, Dekker Nitert M, McIntyre H, Callaway L. Normalizing metabolism in diabetic pregnancy: is it time to target lipids? Diabetes Care 2014;37(5):1484-93.

\section{Bellamy 2009}

Bellamy L, Casas JP, Hingorani AD, Williams D. Type 2 diabetes mellitus after gestational diabetes: a systematic review and meta-analysis. Lancet 2009;373(9677):1173-9.

\section{Bottalico 2007}

Bottalico JN. Recurrent gestational diabetes: risk factors, diagnosis, management, and implications. Seminars in Perinatology 2007;31(3):176-84.

\section{Boyadzhieva 2012}

Boyadzhieva MV, Atanasova I, Zacharieva S, Tankova T, Dimitrova V. Comparative analysis of current diagnostic criteria for gestational diabetes mellitus. Obstetric Medicine 2012;5:71-7.

\section{Brown 2015b}

Brown J, Martis R, Hughes B, Rowan J, Crowther CA. Oral antidiabetic pharmacological therapies for the treatment of women with gestational diabetes. Cochrane Database of Systematic Reviews 2015, Issue 11. [DOI: 10.1002/14651858.CD011967]

\section{Brown 2016}

Brown J, Grzeskowiak L, Williamson K, Downie MR, Crowther CA. Insulin for the treatment of women with gestational diabetes. Cochrane Database of Systematic Reviews 2016, Issue 1. [DOI: 10.1002/14651858.CD012037]

\section{Catalano 2003}

Catalano PMA, Huston-Presley TL, Amini SB. Increased fetal adiposity: a very sensitive marker of abnormal in utero development. American Journal of Obstetrics and Gynecology 2003;189(6):1698-704

\section{Ceysens 2006}

Ceysens G, Rouiller D, Boulvain M. Exercise for diabetic pregnant women. Cochrane Database of Systematic Reviews 2006, Issue 3. [DOI: 10.1002/14651858.CD004225.pub2]

\section{Ceysens 2016}

Ceysens G, Brown J, Boulvain M. Exercise for pregnant women with gestational diabetes for improving maternal and fetal outcomes. Cochrane Database of Systematic Reviews 2016, Issue 5. [DOI: 10.1002/14651858.CD012202]

\section{Chamberlain 2013}

Chamberlain C, McNamara B, Williams E, Yore D, Oldenburg B, Oats $\mathrm{J}$, et al. Diabetes in pregnancy among indigenous women in Australia, Canada, New Zealand and the United States. Diabetes/Metabolism Research and Reviews 2013;29(4):241-56.

\section{Chasan-Taber 2008}

Chasan-Taber L, Schmidt MD, Pekow P, Sternfeld B, Manson JE, Solomon CG, et al. Physical activity and gestational diabetes mellitus among Hispanic women. Journal of Women's Health 2008;17(6):999-1008.

\section{Cheung 2009}

Cheung NW. The management of gestational diabetes. Journal of Vascular Health and Risk Management 2009;5(1):153-64.

\section{Chibalin 2000}

Chibalin AV, Yu M, Ryder JW, Song XM, Galuska D, Krook A et al. Exercise-induced changes in expression and activity of proteins involved in insulin signal transduction in skeletal muscle: differential effects on insulin receptor substrates 1 and 2. Proceedings of the National Academy of Sciences of the United States of America 2000;97:38-43.

\section{Clapp 2006}

Clapp JF. Effects of diet and exercise on insulin resistance during pregnancy. Metabolic Syndrome and Related Disorders 2006;4(2):84-90.

\section{Coustan 2010}

Coustan DR, Lowe LP, Metzger BE, Dyer AR, International Association of Diabetes and Pregnancy Study Groups. The hyperglycemia and adverse pregnancy outcome (HAPO) study: paving the way for new diagnostic criteria for gestational diabetes mellitus. American Journal of Obstetrics and Gynecology 2010;202(6):654.e1-654.e6.

\section{Cundy 2014}

Cundy T, Ackermann E, Ryan EA. Gestational diabetes: new criteria may triple the prevalence but effect on outcomes is unclear. BMJ 2014;348:g1567. 


\section{Cypryk 2008}

Cypryk K, Szymczak W, Czupryniak L, Sobczak M, Lewinski A. Gestational diabetes mellitus - an analysis of risk factors. Endokrynologia Polska (Warszawa) 2008;59(5):393-7.

\section{Dabelea 2005}

Dabelea D, Snell-Bergeon JK, Hartsfield CL, Bischoff KJ, Hamman RF, McDuffie RS, et al. Increasing prevalence of gestational diabetes mellitus (GDM) over time and by birth cohort: Kaiser Permanente of Colorado GDM Screening Program. Diabetes Care 2005;28(3):579-84.

\section{de Veciana 1995}

de Veciana M, Major CA, Morgan MA, Asrat T, Toohey JS, Lien JM, et al. Postprandial versus preprandial blood glucose monitoring in women with gestational diabetes mellitus requiring insulin therapy. New England Journal of Medicine 1995;333(19):1237-41.

\section{Dela 1993}

Dela F, Handberg A, Mikines KJ, Vinten J, Galbo H. GLUT4 and insulin receptor binding and kinase activity in trained human muscle. Journal of Physiology 1993;469:615-24.

\section{Devlieger 2008}

Devlieger R, Casteels K, Van Assche FA. Reduced adaptation of the pancreatic $B$ cells during pregnancy is the major causal factor for gestational diabetes: current knowledge and metabolic effects on the offspring. Acta Obstetricia et Gynecologica Scandinavica 2008;87(12):1266-70.

\section{Dornhorst 2002}

Dornhorst A, Frost G. The principles of dietary management of gestational diabetes: reflection on current evidence. Journal of Human Nutrition and Dietetics 2002;15(2):145-56.

\section{Duran 2014}

Duran A, Saenz S, Torrejon M, Bordiu E, del Valle L, Galindo M, et al. Introduction of IADPSG criteria for the screening and diagnosis of gestational diabetes mellitus results in improved pregnancy outcomes at a lower cost in a large cohort of pregnant women: the St. Carlos gestational diabetes study. Diabetes Care 2014;37:2442-50.

\section{Esakoff 2009}

Esakoff TF, Cheng YW, Sparks TN, Caughey AB. The association between birthweight $4000 \mathrm{~g}$ or greater and perinatal outcomes in patients with and without gestational diabetes mellitus. American Journal of Obstetrics and Gynecology 2009;200(6):672.e1-672.e4.

\section{Ferrara 2007}

Ferrara A. Increasing prevalence of gestational diabetes mellitus: a public health perspective. Diabetes Care 2007;30(Suppl 2):S141-S146.

\section{Guerrero-Romero 2010}

Guerrero-Romero F, Aradillas-García C, Simental-Mendia LE, Monreal-Escalante E, de la Cruz Mendoza E, RodríguezMoran M. Birth weight, family history of diabetes, and metabolic syndrome in children and adolescents. Journal of Pediatrics 2010;156(5):719-23.

\section{Han 2012}

Han S, Crowther CA, Middleton P. Interventions for pregnant women with hyperglycaemia not meeting gestational diabetes and type 2 diabetes diagnostic criteria. Cochrane Database of Systematic Reviews 2012, Issue 1. [DOI: 10.1002/14651858.CD009037.pub2]

\section{Han 2013}

Han S, Crowther CA, Middleton P, Heatley E. Different types of dietary advice for women with gestational diabetes mellitus. Cochrane Database of Systematic Reviews 2013, Issue 3. [DOI: 10.1002/14651858.CD009275.pub2]

\section{HAPO 2008}

The HAPO Study Cooperative Research Group. Hyperglycemia and adverse pregnancy outcomes. New England Journal of Medicine 2008;358:1991-2002.

\section{Harder 2009}

Harder T, Roepke K, Diller N, Stechling Y, Dudenhausen JW, Plagemann A. Birth weight, early weight gain, and subsequent risk of type 1 diabetes: systematic review and meta-analysis. American Journal of Epidemiology 2009;169(12):1428-36.

\section{Harmon 2011}

Harmon KA, Gerard L, Jensen DR, Kealey EH, Hernandez TL, Reece MS, et al. Continuous glucose profiles in obese and normal-weight pregnant women on a controlled diet: metabolic determinants of fetal growth. Diabetes Care 2011;34(10):2198-204.

\section{Hartling 2013}

Hartling L, Dryden DM, Guthrie A, Muise M, Vandermeer B, Donovan L. Benefits and harms of treating gestational diabetes mellitus: A systematic review and meta-analysis for the U.S. Preventive Services Task Force and the National Institutes of Health Office of Medical Applications for Research. Annals of Internal Medicine 2013;159:123-9.

\section{Hedderson 2010}

Hedderson MM, Gunderson EP, Ferrara A. Gestational weight gain and risk of gestational diabetes mellitus. Obstetrics \& Gynecology 2010;115(3):597-604.

\section{Henriksen 2008}

Henriksen T. The macrosomic fetus: a challenge in current obstetrics. Acta Obstetricia et Gynecologica Scandinavica 2008;87(2):134-45.

\section{Higgins 2011}

Higgins JPT, Green S, editors. Cochrane Handbook for Systematic Reviews of Interventions Version 5.1.0 [updated March 2011]. The Cochrane Collaboration, 2011. Available from www.cochrane-handbook.org.

\section{Hillier 2007}

Hillier TA, Pedula KL, Schmidt MM, Mullen JA, Charles MA, Pettitt DJ. Childhood obesity and metabolic imprinting: the ongoing effects of maternal hyperglycemia. Diabetes Care 2007;30(9):2287-92. 


\section{Hjeltnes 1998}

Hjeltnes N, Galuska D, Bjornholm M, Aksnes AK, Lannem A, Zierath JR, et al. Exercise-induced overexpression of key regulatory proteins involved in glucose uptake and metabolism in tetraplegic persons: molecular mechanism for improved glucose homeostasis. FASEB Journal 1998;12:1701-12.

\section{Hoffman 1998}

Hoffman L, Nolan C, Wilson JD, Oats JJ, Simmons D. The Australasian Diabetes in Pregnancy Society. Gestational diabetes mellitus-management guidelines. Medical Journal of Australia 1998;169(2):93-7.

\section{IADPSG 2010}

ANonymous, International Association of Diabetes and Pregnancy Study Groups Consensus Panel. International association of diabetes and pregnancy study groups recommendations on the diagnosis and classification of hyperglycaemia in pregnancy. Diabetes Care 2010;33(3):676-82.

\section{Ilic 1999}

Ilic S, Jovanovic L, Pettitt DJ. Comparison of the effect of saturated and monounsaturated fat on postprandial plasma glucose and insulin concentration in women with gestational diabetes mellitus. American Journal of Perinatology 1999;16(9):489-95.

\section{IOM 2009}

Rasmussen KM, Yaktine AL, Institute of Medicine (US) and National Research Council (US) Committee to Reexamine IOM Pregnancy Weight Guidelines. Weight Gain During Pregnancy: Reexamining the Guidelines. Washington DC: National Academies Press, 2009.

\section{Jastrow 2010}

Jastrow N, Roberge S, Gauthier RJ, Laroche L, Duperron L, Brassard N, et al. Effect of birth weight on adverse obstetric outcomes in vaginal birth after cesarean delivery. Obstetrics \& Gynecology 2010;115(2 Pt 1):338-43.

\section{Jenkins 1981}

Jenkins DJ, Wolever TM, Taylor RH, Barker H, Fielden $\mathrm{H}$, Baldwin JM, et al. Glycemic index of foods: a physiological basis for carbohydrate exchange. American Journal of Clinical Nutrition 1981;34(3):362-6.

\section{Jensen 2004}

Jensen L, Bangsbo J, Hellsten Y. Effect of high intensity training on capillarization and presence of angiogenic factors in human skeletal muscle. Journal of Physiology 2004;557:571-82.

\section{Ju 2008}

Ju H, Rumbold AR, Willson KJ, Crowther CA. Effect of birth weight on adverse obstetric outcomes in vaginal birth after caesarean delivery. BMC Pregnancy and Childbirth 2008;8:31.

\section{Kim 2002}

Kim C, Newton KM, Knopp RH. Gestational diabetes and the incidence of type 2 diabetes: a systematic review. Diabetes Care 2002;25:1862-8.

\section{Kim 2010a}

Kim SY, England L, Wilson HG, Bish C, Satten GA, Dietz P. Percentage of gestational diabetes attributable to overweight and obesity. American Journal of Public Health 2010;100(6):1047-52.

\section{Kim 2010b}

Kim C. Gestational diabetes: risks, management, and treatment options. International Journal of Women's Health 2010;7(2):339-51.

\section{Kleinwechter 2014}

Kleinwechter H, Schäfer-Graf U, Bührer C, Hoesli I, Kainer F, Kautzky-Willer A, et al. Gestational diabetes mellitus (GDM) diagnosis, therapy and follow-up care: Practice Guideline of the German Diabetes Association(DDG) and the German Association for Gynaecologyand Obstetrics (DGGG). Experimental and Clinical Endocrinology \& Diabetes 2014;122(7):395-405.

\section{Knopp 1985}

Knopp RH, Bergelin RO, Wahl PW, Walden CE. Relationships of infant birth size to maternal lipoproteins, apoproteins, fuels, hormones, clinical chemistries, and body weight at 36 weeks gestation. Diabetes 1985;34(Suppl 2):71-7.

\section{Lain 2007}

Lain KY, Catalano PM. Metabolic changes in pregnancy. Clinical Obstetrics and Gynecology 2007;50(4):938-48.

\section{Langer 2005}

Langer O, Yogev Y, Most O, Xenakis EM. Gestational diabetes: the consequences of not treating. American Journal of Obstetrics and Gynecology 2005;192(4):989-97.

\section{Metzger 1998}

Metzger BE, Coustan DR. Summary and recommendations of the Fourth International Workshop-Conference on Gestational Diabetes Mellitus. Diabetes Care 1998;21(Suppl2):B161-B1 67.

\section{Metzger 2007}

Metzger BE, Buchanan TA, Coustan DR, De Leiva A, Dunger DB, Hadden DR. Summary and recommendations of the Fifth International Workshop-Conference on Gestational Diabetes Mellitus. Diabetes Care 2007;30(Suppl 2):S251-S260.

\section{Metzger 2008}

Metzger B. for The HAPO Study Cooperative Research Group. Hyperglycemia and adverse pregnancy outcomes. New England Journal of Medicine 2008;358:1991-2002.

\section{Ministry of Health 2014}

Ministry of Health. Screening, Diagnosis and Management of Gestational Diabetes in New Zealand: a clinical practice guideline. Wellington: Ministry of Health, 2014.

\section{Morisset 2010}

Morisset AS, St-Yves A, Veillette J, Weisnagel SJ, Tchernof A, Robitaille J. Prevention of gestational diabetes mellitus: a review of studies on weight management. Diabetes/Metabolism Research and Reviews 2010;26(1):17-25. 


\section{Morrison 2008}

Morrison JA, Friedman LA, Wang P, Glueck CJ. Metabolic syndrome in childhood predicts adult metabolic syndrome and type 2 diabetes mellitus 25 to 30 years late. Journal of Pediatrics 2008;152(2):201-6.

\section{Moses 2009}

Moses RG, Barker M, Winter M, Petocz P, Brand-Miller JC. Can a low-glycemic index diet reduce the need for insulin in gestational diabetes mellitus? A randomized trial. Diabetes Care 2009;32(6):996-1000.

\section{Muktabhant 2015}

Muktabhant B, Lawrie TA, Lumbiganon P, Laopaiboon M. Diet or exercise, or both, for preventing excessive weight gain in pregnancy. Cochrane Database of Systematic Reviews 2015, Issue 6. [DOI: 10.1002/14651858.CD007145.pub3]

\section{Mulla 2010}

Mulla WR, Henry TQ, Homko CJ. Gestational diabetes screening after HAPO: has anything changed?. Current Diabetes Reports 2010;10(3):224-8.

\section{Nankervis 2014}

Nankervis A, McIntyre HD, Moses R, Ross GP, Callaway L, Porter $C$, et al. ADIPS consensus guidelines for the testing and diagnosis of hyperglycaemia in pregnancy in Australia and New Zealand. http://adips.org/ downloads/2014ADIPSGDMGuidelinesV18.11.2014_000.pdf. ADIPS, (accessed 2014).

\section{NICE 2008}

National Institute for Health and Clinical Excellence (NICE). Diabetes in Pregnancy: Management of Diabetes and its Complications from Pre-conception to the Postnatal Period. NICE Clinical Guideline 63. London: NICE, 2008.

\section{NICE 2015}

National Institute for Health and Clinical Excellence (NICE). Diabetes in Pregnancy: Management of Diabetes and its Complications from Pre-conception to the Postnatal Period. NICE Clinical Guideline NG3. London: NICE, 2015.

\section{Petry 2010}

Petry CJ. Gestational diabetes: risk factors and recent advances in its genetics and treatment. British Journal of Nutrition 2010;104(6):775-87.

\section{Pettitt 1985}

Petitt DJ, Bennett PH, Knowler WC, Baird HR, Aleck KA. Gestational diabetes mellitus and impaired glucose tolerance during pregnancy. Long-term effects on obesity and glucose tolerance in the offspring. Diabetes 1985;34(Suppl 2):119-22.

\section{Pettitt 1993}

Pettitt DJ, Nelson RG, Saad MF, Bennett PH, Knowler WC. Diabetes and obesity in the offspring of Pima Indian women with diabetes during pregnancy. Diabetes Care 1993;16(1):310-4.

\section{Poolsup 2014}

Poolsup N, Suksomboon N, Amin M. Effect of treatment of gestational diabetes mellitus: A systematic review and metaanalysis. PLoS One 2014;9(3):e92485.

\section{Reader 2007}

Reader DM. Medical nutrition therapy and lifestyle interventions. Diabetes Care 2007;30(Suppl 2):S188-S193.

\section{Reece 2009}

Reece EA, Leguizamon G, Wiznitzer A. Gestational diabetes: the need for a common ground. Lancet 2009;373(9677):1789-97.

\section{RevMan 2014 [Computer program]}

The Nordic Cochrane Centre, The Cochrane Collaboration. Review Manager (RevMan). Version 5.3. Copenhagen: The Nordic Cochrane Centre, The Cochrane Collaboration, 2014.

\section{Richter 2001}

Richter EA, Derave W, Wojtaszewski JF. Glucose, exercise and insulin: emerging concepts. Journal of Physiology 2001;535(Pt 2):313-22

\section{Rowan 2011}

Rowan JA, Rush EC, Obolonkin V, Battin M, Wouldes T, Hague WM. Metformin in gestational diabetes: the offspring follow-up (MiG TOFU): body composition at 2 years of age. Diabetes Care 2011;34(10):2279-84.

\section{Schenk 2005}

Schenk S, Cook JN, Kaufman AE, Horowitz JF. Postexercise insulin sensitivity is not impaired after an overnight lipid infusion. American Journal of Physiology, Endocrinology and Metabolism 2005;288:E519-E525.

\section{Shah 2008}

Shah BR, Retnakaran R, Booth GL. Increased risk of cardiovascular disease in young women following gestational diabetes mellitus. Diabetes Care 2008;31(8):1668-9.

\section{Silva 2010}

Silva JC, Pacheco C, Bizato J, de Souza BV, Ribeiro TE, Bertini AM. Metformin compared with glyburide for the management of gestational diabetes. International Journal of Gynecology \& Obstetrics 2010;111(1):37-40.

\section{Simmons 2004}

Simmons D, Walters BN, Rowan JA, Mclntyre HD. Metformin therapy and diabetes in pregnancy. Medical Journal of Australia 2004;180(9):462-4.

\section{Solomon 1997}

Solomon CG, Willett WC, Carey VJ, Rich-Edwards J, Hunter DJ, Colditz $\mathrm{GA}$, et al. A prospective study of pregravid determinants of gestational diabetes mellitus. JAMA 1997;278(13):1078-83.

\section{Suman Rao 2013}

Suman Rao PN, Shashidhar A, Ashok C. In utero fuel homeostasis: Lessons for a clinician. Indian Journal of Endocrinology and Metabolism 2013;17(1):60-8. 


\section{Thomas 2010}

Thomas DE, Elliott EJ. The use of low-glycaemic index diets in diabetes control. British Journal of Nutrition 2010;104(6):797-802.

\section{Tran 2013}

Tran TS, Hirst JE, Do MA, Morris JM, Jeffrey HE. Early prediction of gestational diabetes mellitus in Vietnam: clinical impact of currently recommended diagnostic criteria. Diabetes Care 2013;36(3):618-24

\section{Tuomilehto 2001}

Tuomilehto J, Lindstrom J, Eriksson JG, Valle TT, Hamalainen H, Ilanne-Parikka $P$, et al. Prevention of type 2 diabetes mellitus by changes in lifestyle among subjects with impaired glucose tolerance. New England Journal of Medicine 2001;344(18):1343-50

\section{Tuomilehto 2011}

Tuomilehto J, Schwarz P, Lindström J. Long-term benefits from lifestyle interventions for type 2 diabetes prevention. Diabetes Care 2011;34(Suppl 2):S210-14.

\section{Vohr 2008}

Vohr BR, Boney CM. Gestational diabetes: the forerunner for the development of maternal and childhood obesity and metabolic syndrome?. Journal of Maternal-Fetal Medicine 2008;21(3):149-57.

\section{Weisz 2005}

Weisz B, Shrim A, Homko CJ, Schriff E, Epstein GS, Sivan E. One hour versus two hour postprandial glucose measurement in gestational diabetes: a prospective study. Journal of Perinatology 2005;25(4):241-4.

\section{Whincup 2008}

Whincup PH, Kaye SJ, Owen CG, Huxley R, Cook DG, Anazawa S, et al. Birth weight and risk of type 2 diabetes: a systematic review. JAMA 2008;300(24):2886-97.

\section{CHARACTERISTICS OF STUDIES}

Characteristics of included studies [ordered by study ID]

\section{WHO 1999}

World Health Organization. Definition, Diagnosis and Classification of Diabetes Mellitus and its Complications. Report of a WHO Consultation. Part 1. Geneva, Switzerland: WHO, 1999.

\section{WHO 2013}

World Health Organization. WHO Diagnostic Criteria and Classification of Hyperglycaemia First Detected in Pregnancy. Report WHO/NMH/MND/13.2. Geneva, Switzerland: WHO, 2013.

\section{Zhang 2006}

Zhang C, Liu S, Solomon CG, Hu FB. Dietary fiber intake, dietary glycemic load, and the risk for gestational diabetes mellitus. Diabetes Care 2006;29(10):2223-30.

\section{Zierath 2002}

Zierath JR. Invited review: exercise training-induced changes in insulin signalling in skeletal muscle. Journal of Applied Physiology 2002;93:773-81.

\section{References to other published versions of this review}

\section{Alwan 2009}

Alwan N, Tuffnell DJ, West J. Treatments for gestational diabetes. Cochrane Database of Systematic Reviews 2009, Issue 3. [DOI: 10.1002/14651858.CD003395.pub2]

\section{Brown 2015}

Brown J, Alwan NA, West J, Brown S, McKinlay CJD, Farrar D, et al. Lifestyle interventions for the treatment of women with gestational diabetes. Cochrane Database of Systematic Reviews 2015, Issue 11. [DOI: 10.1002/14651858.CD011970]

* Indicates the major publication for the study

\section{Bancroft 2000}

Methods Randomised controlled pilot study recruiting from 2 centres.

Participants

68 women.

Inclusion criteria: impaired glucose tolerance (Table 7).

Exclusion criteria: none stated.

Setting: specialist diabetic/antenatal clinics, Leeds, UK.

Timeframe: not specified.

Interventions

1) Intervention (Monitored) group women were given standard dietary advice about restricting carbohydrate intake to $185 \mathrm{~g}$ /day and a diet sheet listing calorific values of common foods. Glucose metabolism was monitored by capillary glucose series 5 days a week ( 1 to 2 hours postprandial), HbA1c was measured monthly (insulin was introduced if 5 or more capillary measurements $>7.0 \mathrm{mmol} / \mathrm{L}$ in 1 week), serial ultrasound for growth and amniotic fluid, Doppler studies, CTG monitoring $(n=32)$ 
Bancroft 2000 (Continued)

versus

2) Control (Unmonitored) group women received dietary advice, $\mathrm{HbAlc}$ monthly (but data not made available) but no capillary glucose measurements $(n=36)$.

Women cared for in a combined diabetic clinic run jointly by a diabetologist and an obstetrician. Birth was no later than 41 weeks' gestation.

\begin{tabular}{ll} 
Outcomes & $\begin{array}{l}\text { Primary outcome measure was admission to special care baby unit. } \\
\text { Secondary outcomes: perinatal morbidity (including birth trauma, metabolic disturbance, gestation at } \\
\text { birth, birthweight, stillbirth, neonatal hypoglycaemia, RDS), LGA, measures of maternal inconvenience, } \\
\text { number of capillary samples, number of antenatal clinic visits, mode of delivery, IOL, frequency of in- } \\
\text { sulin use, HbAlc. }\end{array}$ \\
\hline Notes & $\begin{array}{l}2 \text { women in the unmonitored group developed diabetes mellitus, both were diagnosed postnatally and } \\
\text { both delivered prematurely. }\end{array}$ \\
ITT analysis: not stated (but all women remained in their allocated groups). \\
Funding: not stated. \\
Sample size calculation: not stated. \\
Conflicts of interest: no declarations made in manuscript.
\end{tabular}

\section{Risk of bias}

\begin{tabular}{|c|c|c|}
\hline Bias & Authors' judgement & Support for judgement \\
\hline $\begin{array}{l}\text { Random sequence genera- } \\
\text { tion (selection bias) }\end{array}$ & Low risk & Computer-generated codes, telephone randomisation service used. \\
\hline $\begin{array}{l}\text { Allocation concealment } \\
\text { (selection bias) }\end{array}$ & Low risk & $\begin{array}{l}\text { Randomisation was controlled from a trial centre and administered by tele- } \\
\text { phone. }\end{array}$ \\
\hline $\begin{array}{l}\text { Blinding of participants } \\
\text { and personnel (perfor- } \\
\text { mance bias) } \\
\text { All outcomes }\end{array}$ & Low risk & $\begin{array}{l}\text { "the diabetologist was aware of the group to which each woman was ran- } \\
\text { domised but the obstetrician was blinded." }\end{array}$ \\
\hline $\begin{array}{l}\text { Blinding of outcome as- } \\
\text { sessment (detection bias) } \\
\text { All outcomes }\end{array}$ & Unclear risk & Not stated. \\
\hline $\begin{array}{l}\text { Incomplete outcome data } \\
\text { (attrition bias) } \\
\text { All outcomes }\end{array}$ & Unclear risk & No dropouts but 12 failed to attend follow-up postnatal measurements. \\
\hline $\begin{array}{l}\text { Selective reporting (re- } \\
\text { porting bias) }\end{array}$ & High risk & $\begin{array}{l}\text { The original protocol was not seen. Additional outcomes listed in the methods } \\
\text { section were reported in the results. }\end{array}$ \\
\hline Other bias & Low risk & No evidence of other bias; groups balanced at baseline. \\
\hline
\end{tabular}

Bo 2014

\begin{tabular}{ll}
\hline Methods & Randomised controlled trial. \\
\hline Participants & 200 women randomised.
\end{tabular}


Bo 2014 (Continued)

Inclusion criteria: age 18-50 years; 24-26 weeks' gestational age; GDM diagnosis based on a 75 g OGTT (Table 7); singleton pregnancy.

Exclusion criteria: $\mathrm{BMI}>40 \mathrm{~kg} / \mathrm{m}^{2}$; any known diseases, medications or obstetrical contraindications to exercise.

Setting: Sant'Anna Hospital, Turin, Italy.

Timing: July 2009 to February 2012.

Interventions

Intervention - Behavioural and exercise $(n=50)$ - advised to walk briskly at least $20 \mathrm{~min} /$ day every day (140 min/week; Borg's scale target rating 12-14) plus individually oral/written recommendations for helping with healthy dietary choices (i.e. lowering carbohydrate intake, strategies for out-of-home eating, healthy cooking and food shopping and related behavioural suggestions) and debunking false myths about diet in pregnancy.

Control - Diet $(n=50)$ - an individually-prescribed diet was given to each woman (carbohydrates $48 \%$ to $50 \%$, proteins $18 \%$ to $20 \%$, fats $30 \%$ to $35 \%$, fibre $20-25 \mathrm{~g} /$ day, no alcohol).

Exercise $(n=51)$ - advised to walk briskly at least $20 \mathrm{~min} /$ day every day (140 min/week; Borg's scale target rating 12-14).

Behavioural $(n=49)$ - individually oral/written recommendations for helping with healthy dietary choices (i.e. lowering carbohydrate intake, strategies for out-of-home eating, healthy cooking and food shopping and related behavioural suggestions) and debunking false myths about diet in pregnancy.

All women self-monitored blood glucose 4 to 6 times daily (preprandial and 2-hours postprandial).

For this review we used the diet only group as the control group and the combined behavioural and exercise intervention as the intervention group.

Outcomes

Maternal outcomes - pregnancy-induced hypertension, infectious diseases, caesarean section, cholestasis during pregnancy and peri- and postpartum complications. Metabolic equivalents, triglycerides, insulin, insulin resistance, CRP. Fasting and postprandial blood glucose, and HbA1c.

Neonatal outcomes - LGA; birthweight > 90th percentile), pre-term birth (gestational age at delivery < 37 weeks), and any neonatal conditions requiring a specific treatment or a prolonged in-hospital stay.

Notes

Treatment glycaemic targets were not detailed but insulin was started in the presence of fetal abdominal ultrasound $>70$ th percentile and or maternal hyperglycaemia (no details).

Power calculation: yes, based on an expected $10 \%$ reduction in fasting glucose by exercise.

ITT analysis: yes.

Funding: Regione Piemonte 2009.

Conflict of interest: the paper specifies that there authors report no conflicts of interest.

\section{Risk of bias}

\begin{tabular}{lll}
\hline Bias & Authors' judgement & Support for judgement \\
\hline $\begin{array}{l}\text { Random sequence genera- } \\
\text { tion (selection bias) }\end{array}$ & Unclear risk & $\begin{array}{l}\text { Randomisation was conducted through a website and is likely to be low risk of } \\
\text { bias but there are insufficient details to be sure. }\end{array}$ \\
\hline
\end{tabular}

\begin{tabular}{lll}
\hline $\begin{array}{l}\text { Allocation concealment } \\
\text { (selection bias) }\end{array}$ & Low risk & 'implemented through a website' - third person. \\
\hline $\begin{array}{l}\text { Blinding of participants } \\
\begin{array}{l}\text { and personnel (perfor- } \\
\text { mance bias) }\end{array}\end{array}$ & High risk & $\begin{array}{l}\text { No details, but due to the different interventions the research staff and partici- } \\
\text { pants are unlikely to have been blinded. }\end{array}$
\end{tabular}


Bo 2014 (Continued)

All outcomes

\begin{tabular}{|c|c|c|}
\hline $\begin{array}{l}\text { Blinding of outcome as- } \\
\text { sessment (detection bias) }\end{array}$ & Low risk & $\begin{array}{l}\text { "The dieticians, the obstetricians who reported maternal/neonatal complica- } \\
\text { tions and the laboratory personnel were blinded to the group assignment." }\end{array}$ \\
\hline
\end{tabular}

All outcomes

Incomplete outcome data Low risk All women randomised were analysed.
(attrition bias)

All outcomes

Selective reporting (re- High risk

porting bias)

Additional outcomes are reported that are not listed in the methods section. Outcomes listed are very generalised. Primary outcomes are not pre-specified. Birthweight is listed in the trial registration document but is not reported or listed in the manuscript.

Other bias Low risk Groups appeared balanced at baseline.

\section{Crowther 2005}

Methods Multi-centre randomised controlled trial ( $n=18$ centres; 14 in Australia and 4 in UK).

Participants 1000 women.

Inclusion criteria: singleton or twin pregnancy between 16 and 30 weeks' gestation, 1 or more risk factors on selective screening or impaired glucose tolerance (Table 7), and had an abnormal $75 \mathrm{~g}$ OGTT at 24 to 34 weeks' gestation (Table 7).

Exclusion criteria: women with previously treated GDM or active chronic systemic disease (except essential hypertension), more severe glucose impairment or less than 16 or more than 30 weeks' pregnant.

Setting: 18 centres in antenatal clinics in Australia and UK.

Timing: September 1993 to June 2003.

Interventions

1) Intervention group $(n=490)$ : care replicated clinical care in which universal screening and treatment for GDM was available, individualised dietary advice from a qualified dietician, instructions on how to self-monitor glucose levels 4 times a day until fasting glucose levels of at least $3.5 \mathrm{mmol} / \mathrm{L}$ [ $63 \mathrm{mg} / \mathrm{dL}$ ] and no more than $5.5 \mathrm{mmol} / \mathrm{L}$ [99 $\mathrm{mg} / \mathrm{dL}$ ], preprandial levels of no more than $5.5 \mathrm{mmol} / \mathrm{L}$, and levels 2 hours postprandially that were no more than $7.0 \mathrm{mmol} / \mathrm{L}[126 \mathrm{mg} / \mathrm{dL}]$, followed by daily monitoring at rotating times during the day; and insulin therapy, with the dose adjusted based on glucose levels, if there were 2 capillary-blood glucose results during the 2-week period in which the fasting level was at least $5.5 \mathrm{mmol} / \mathrm{L}$ or the postprandial level was at least $7.0 \mathrm{mmol} / \mathrm{L}$ at 35 weeks' gestation or less, if the postprandial level was at least $8.0 \mathrm{mmol} / \mathrm{L}(144 \mathrm{mg} / \mathrm{dL})$ at more than 35 weeks' gestation, or if 1 capillary-blood glucose results during the 2-week period was at least $9.0 \mathrm{mmol}$ per $\mathrm{L}(162 \mathrm{mg}$ per $\mathrm{dL}$ ).

2) Control group $(n=510)$ : care replicated clinical care in which screening for GDM was not available, women and caregivers were not aware of the diagnosis of glucose intolerance, at the discretion of the attending clinician, if indications arose that were suggestive of diabetes, further assessment for GDM was permitted, with treatment as considered appropriate.

Outcomes

Primary outcomes - infant: composite measures of serious perinatal complications (defined as 1 or more of death, shoulder dystocia, bone fracture, and nerve palsy), admission to neonatal nursery, and jaundice requiring phototherapy.

Primary outcomes - women: need for IOL and caesarean section, health status, and psychological outcomes.

Secondary outcomes - infant: gestational age at birth, birthweight, Apgar score of less than 7 at 5 mins, hypoglycaemia requiring IV therapy, convulsions, RDS, perinatal death, stillbirth, LGA, macrosomia, SGA. Childhood weight, BMI and height

Secondary outcomes - women: number of prenatal visits to a health professional, mode of birth, weight during pregnancy, number of antenatal admissions, presence or absence of pregnancy-induced 
hypertension ( $\mathrm{BP} \geq 140 / 90 \mathrm{mmHg}$ on 2 occasions 4 or more hours apart, perineal trauma, postpartum haemorrhage, postnatal infection, breastfeeding at hospital discharge, use of medication, postnatal depression.

Notes

$93 \%$ of the women had been found to be at risk of GDM on the basis of OGTT, and the remainder on the basis of risk factors.

5 perinatal deaths ( 3 stillbirths and 2 neonatal deaths) occurred in the control group: 2 stillbirths were unexplained intrauterine deaths at term of appropriately grown infants, and 1 at 35 weeks' gestation, was associated with pre-eclampsia and intrauterine growth restriction. 1 infant had a lethal congenital anomaly, and 1 infant died after an asphyxial condition during labour with antepartum haemorrhage. After consent had been obtained, a proportion of the women (not fewer than 1 in 5) who had normal OGTT results were assigned to the routine-care group to help maintain blinding.

Funding:National Health and Medical Research Council, Australia, Queen Victoria Hospital Research Foundation, Department of Obstetrics and Gynaecology- University of Adelaide.

ITT: yes.

Sample size calculation: yes based on the risk of serious perinatal outcome.

Conflicts of interest: conflicts of interested were not documented in the manuscript.

Gillman 2010 reports on 4-5 year follow-up from the ACHOIS trial (subgroup of 199 children from Australia).

Pirc 2007 reports on a subgroup of women and infants from the ACHOIS trial from a single centre in Australia ( $n=95$ women).

\section{Risk of bias}

\begin{tabular}{|c|c|c|}
\hline Bias & Authors' judgement & Support for judgement \\
\hline $\begin{array}{l}\text { Random sequence genera- } \\
\text { tion (selection bias) }\end{array}$ & Low risk & $\begin{array}{l}\text { Randomisation method used numbers generated by computer with variable } \\
\text { block sizes of } 6,8 \text {, and } 10 \text {. }\end{array}$ \\
\hline $\begin{array}{l}\text { Allocation concealment } \\
\text { (selection bias) }\end{array}$ & Low risk & Randomisation method was performed centrally. \\
\hline $\begin{array}{l}\text { Blinding of participants } \\
\text { and personnel (perfor- } \\
\text { mance bias) } \\
\text { All outcomes }\end{array}$ & Low risk & $\begin{array}{l}\text { Women and their health providers did not know the blood glucose results until } \\
\text { after the birth. }\end{array}$ \\
\hline $\begin{array}{l}\text { Blinding of outcome as- } \\
\text { sessment (detection bias) } \\
\text { All outcomes }\end{array}$ & Unclear risk & Not stated. \\
\hline $\begin{array}{l}\text { Incomplete outcome data } \\
\text { (attrition bias) } \\
\text { All outcomes }\end{array}$ & Low risk & $\begin{array}{l}\text { Dropouts: no losses to follow-up for primary and secondary clinical outcomes } \\
\text { for women at end of treatment. No losses to follow-up for primary and sec- } \\
\text { ondary clinical outcomes for infants at end of treatment. For maternal health } \\
\text { status outcomes of postnatal depression and quality of life } 68 \% \text { of women pro- } \\
\text { vided data for maternal health status. Overall data for clinical outcomes are } \\
\text { complete. }\end{array}$ \\
\hline $\begin{array}{l}\text { Selective reporting (re- } \\
\text { porting bias) }\end{array}$ & Low risk & Includes maternal and infant outcomes. \\
\hline Other bias & Low risk & No evidence of other bias, no differences in baseline. \\
\hline
\end{tabular}


Elnour 2008

\begin{tabular}{ll}
\hline Methods & Randomised controlled trial, stratified by age. \\
\hline Participants & 165 women randomised.
\end{tabular}

Participants

Inclusion criteria: UAE national, within 20 weeks' gestation, confirmed diagnosis of GDM (Table 7), age 20 to 39 years.

Exclusion criteria: abnormal renal or hepatic function, haemoglobinopathy.

Setting: out-patient and primary care clinics, United Arab Emirates.

Timeframe: not specified.

Interventions

1) Intervention group (structured pharmaceutical care) $(n=108) 10$ to 30 mins with a clinical pharmacist. Options of treatment explained and encouraged to participate in self management. Structured education on GDM and management provided (diet and exercise, glycaemic control, self-monitoring, review of treatment if glycaemic control inadequate). Received printed education booklet which contained general information on diabetes, aims of treatment, diet and exercise and action to take if hypoor hyperglycaemic. Asked to record plasma glucose at least 5 times per day for 3-4 days per week. Intervention took place at baseline and at monthly clinic visits. encourage to telephone pharmacist if any queries/concerns.

versus

2) Control group (usual care) $(n=72)$ - monthly clinic visits and self monitoring but no additional education or counselling or liaison between pharmacist and prescribing doctor.

Followed up to 6 months postpartum.

Knowledge, quality of life, maternal (hydramnios, severe hyperglycaemia, pre-eclampsia, gestational hypertension, lactation, postpartum haemorrhage, preterm labour, obstructed delivery, caesarean section, use of insulin, fasting blood glucose, $\mathrm{HbA1c}$ ) and neonatal (macrosomia $>4 \mathrm{~kg}$, hypoglycaemia, hyperbilirubinaemia, shoulder dystocia, congenital malformation, respiratory difficulties, SGA, LGA, polycythaemia, hypocalcaemia, preterm birth, admission to NICU) complications.

Notes No details on method of screening or diagnosing GDM. Authors contacted in September 2012. Authors responded immediately with additional information.

Power calculation: yes.

ITT analysis: yes.

Funding: not stated.

Conflicts of interest: no evidence of a declaration made in the manuscript.

\section{Risk of bias}

\begin{tabular}{lll}
\hline Bias & Authors' judgement & Support for judgement \\
\hline $\begin{array}{l}\text { Random sequence genera- } \\
\text { tion (selection bias) }\end{array}$ & Low risk & $\begin{array}{l}\text { Restricted randomisation method 'to ensure that the number of patients al- } \\
\text { located to control and intervention were in the same proportion in relation } \\
\text { to their subgroup classification' This additional information was obtained } \\
\text { through correspondence with the authors. }\end{array}$ \\
\hline $\begin{array}{l}\text { Allocation concealment } \\
\text { (selection bias) }\end{array}$ & Unclear risk & No details provided. \\
\hline
\end{tabular}


Elnour 2008 (Continued)

Blinding of participants High risk Participants and researchers were not blinded. and personnel (performance bias)

All outcomes

$\begin{array}{lll}\text { Blinding of outcome as- } & \text { Low risk } & \begin{array}{l}\text { In additional information received from the authors it was stated that "nursing } \\ \text { and pharmacy staff who assisted with the questionnaire administration were } \\ \text { blinded regarding group to which individual patients had been assigned". }\end{array} \\ \text { All outcomes } & \text { blection bias) }\end{array}$

Incomplete outcome data Low risk

(attrition bias)

165 patients completed the trial (99 intervention and 66 control). 9 were lost to

All outcomes follow-up in the intervention group due to abortion $(n=4)$ and withdrawal ( $n$ $=5$ ). 6 were lost in the control group ( $n=3$ abortion, $n=3$ withdrawal). Per-protocol analysis.

Selective reporting (re- Low risk Reported on maternal and infant outcomes of relevance.

porting bias)

Other bias Low risk No evidence of other risk of bias.

Ferrara 2011

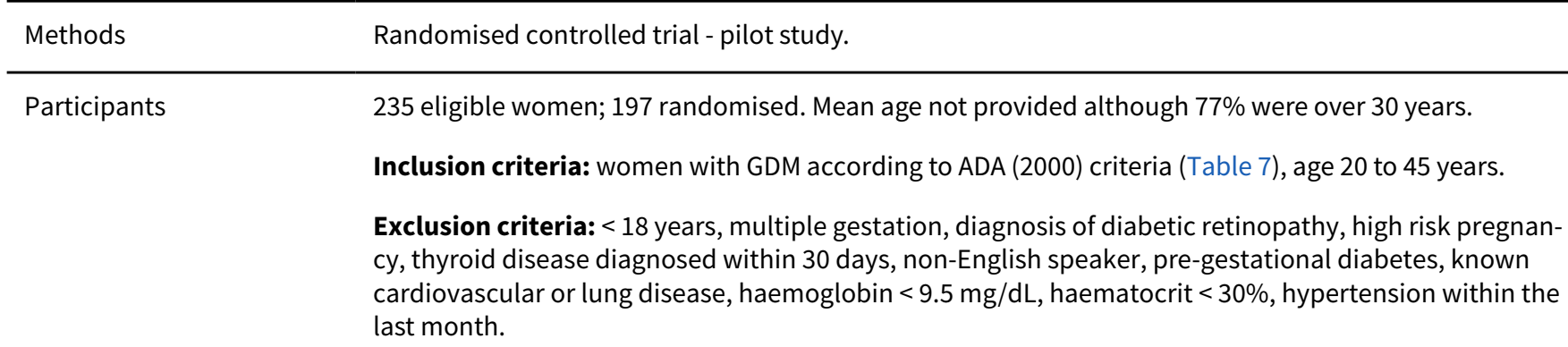

Setting: Northern California, USA.

Timing: October 2005 to May 2008.

Interventions

Intervention ( $\mathrm{n}=96$ ) Diet and exercise and breastfeeding intervention (DEBI). Delivered by a dietician using Social Cognitive Theory and Transtheoretical Model. Delivered prenatal, postpartum and maintenance based on 1-to-1 sessions and 2 individual telephone counselling sessions with a lifestyle coach. Advised not to exceed $11.4 \mathrm{~kg}$ for obese women and to follow ADA diet and moderate physical activity (150 $\mathrm{min} /$ week). Also had lactation consultant and contact maintained for 6 weeks postpartum.

versus

Control group (usual care) $(n=101)$ Printed material only in prenatal and postnatal period.

The maintenance phase continued for 6 months.

Outcomes

Primary outcome - meeting postpartum weight goal.

Secondary outcome - medication use, perinatal clinic visits, birthweight, macrosomia, physical activity, diet, breastfeeding, SGA.

Trials registration document also lists plasma glucose levels, plasma insulin levels, markers of insulin resistance and adiponectin as additional outcomes not reported in the published papers.

Notes

Power calculation: not stated.

ITT analysis: yes. 
Conflicts of interest: the authors report no potential conflicts of interest of relevance to the article in the Acknowledgements section of the manuscript.

Follow-up of 72 women postpartum is reported by Erlich 2014 for those women in the intervention group who lost weight or did maintained/gained weight postpartum.

\section{Risk of bias}

\begin{tabular}{|c|c|c|}
\hline Bias & Authors' judgement & Support for judgement \\
\hline $\begin{array}{l}\text { Random sequence genera- } \\
\text { tion (selection bias) }\end{array}$ & Low risk & $\begin{array}{l}\text { Randomly assigned. Computer-randomisation programme stratified for age, } \\
\text { pregravid BMI. }\end{array}$ \\
\hline $\begin{array}{l}\text { Allocation concealment } \\
\text { (selection bias) }\end{array}$ & Unclear risk & No details. \\
\hline $\begin{array}{l}\text { Blinding of participants } \\
\text { and personnel (perfor- } \\
\text { mance bias) } \\
\text { All outcomes }\end{array}$ & High risk & No blinding, open-label. \\
\hline $\begin{array}{l}\text { Blinding of outcome as- } \\
\text { sessment (detection bias) } \\
\text { All outcomes }\end{array}$ & Low risk & Trials registration document indicates that outcome assessors were blinded. \\
\hline $\begin{array}{l}\text { Incomplete outcome data } \\
\text { (attrition bias) } \\
\text { All outcomes }\end{array}$ & Low risk & $\begin{array}{l}97 \% \text { follow-up to postpartum in the usual care group and } 95 \% \text { in the interven- } \\
\text { tion group. }\end{array}$ \\
\hline $\begin{array}{l}\text { Selective reporting (re- } \\
\text { porting bias) }\end{array}$ & High risk & $\begin{array}{l}\text { The main outcome was meeting postpartum weight gain. This is a pilot study } \\
\text { and the full trial is yet to be reported on. There are very limited neonatal out- } \\
\text { comes and additional outcomes are listed in the trial registration document } \\
\text { that are not reported in the published papers. }\end{array}$ \\
\hline Other bias & Low risk & There was no evidence of other bias. \\
\hline
\end{tabular}

\section{Garner 1997}

\begin{tabular}{|c|c|}
\hline Methods & Randomised controlled pilot trial. \\
\hline \multirow[t]{3}{*}{ Participants } & 300 women from Canada. \\
\hline & $\begin{array}{l}\text { Inclusion criteria: diagnosis of gestational diabetes between } 24 \text { to } 32 \text { weeks' using } 75 \text { g glucose screen } \\
\text { with 1-hour cut-off level of } 8 \mathrm{mmol} / \mathrm{L} \text { (Table } 7 \text { ). }\end{array}$ \\
\hline & $\begin{array}{l}\text { Exclusion criteria: multiple gestation, maternal foetal blood group incompatibility, known congeni- } \\
\text { tal anomaly, prior evidence of planta praevia/abruptio, significant maternal disease (chronic hyperten- } \\
\text { sion, connective tissue disease, endocrine disorders, chronic hepatic disease), long-term medical ther- } \\
\text { apy affecting glucose metabolism such as steroids and beta-mimetic tocolytic agents, and imminent } \\
\text { delivery. }\end{array}$ \\
\hline
\end{tabular}

Setting: 2 teaching hospitals in Ottawa, Canada.

Timing: September 1991 to May 1994. 
1) Intervention group - Dietary counselling, calories restricted diet ( $35 \mathrm{kcal} / \mathrm{kg} / \mathrm{day}$ ), home glucose monitoring, if not controlled by diet alone then insulin supplementation, seen bi-weekly, ultrasound assessment of fetal growth, amniotic fluid volume and cardiac size. Aim to maintain blood glucose within the target range of $<4.4 \mathrm{mmol} / \mathrm{L}$ fasting and $<7.8 \mathrm{mmol} / \mathrm{L} 1$-hour post-prandial $(\mathrm{n}=149)$

versus

2) Control group ( $n=150$ ) - no dietary counselling but asked to continue unrestricted healthy diet for pregnancy as per Canada Food Guide. They were managed by the primary obstetric provider and were not seen again in the teaching unit. Treatment failures were transferred to the treatment arm of the trial and treated with diet/insulin/monitoring.

\section{Outcomes}

None were prespecified but reported on hyperbilirubinaemia, hypoglycaemia, fasting and postprandial blood glucose, hypocalcaemia, macrosomia, mortality, congenital anomaly, birth trauma, birthweight, weight gain in pregnancy and mode of delivery, gestational age at birth. Childhood BMI, cholesterol, blood glucose concentration.

Sample size calculation: yes.
ITT analysis: yes, treatment failures in the control group who were moved to the intervention group
were analysed in the control arm.
Funding: no details.
Conflicts of interest: there were no details on conflicts of interest published in the manuscript.
The trial was followed up at 7 to 11 years by Keely (2008) for metabolic markers of insulin resistance in
the offspring.

\section{Risk of bias}

\begin{tabular}{|c|c|c|}
\hline Bias & Authors' judgement & Support for judgement \\
\hline $\begin{array}{l}\text { Random sequence genera- } \\
\text { tion (selection bias) }\end{array}$ & Unclear risk & "randomly allocated" no other details. \\
\hline $\begin{array}{l}\text { Allocation concealment } \\
\text { (selection bias) }\end{array}$ & Unclear risk & No details. \\
\hline $\begin{array}{l}\text { Blinding of participants } \\
\text { and personnel (perfor- } \\
\text { mance bias) } \\
\text { All outcomes }\end{array}$ & Low risk & $\begin{array}{l}\text { "Health care workers in the control group were blinded to the blood glucose } \\
\text { group." }\end{array}$ \\
\hline $\begin{array}{l}\text { Blinding of outcome as- } \\
\text { sessment (detection bias) } \\
\text { All outcomes }\end{array}$ & Unclear risk & No details. \\
\hline $\begin{array}{l}\text { Incomplete outcome data } \\
\text { (attrition bias) } \\
\text { All outcomes }\end{array}$ & Low risk & 1 woman in the treatment arm of the trial was lost to follow-up. \\
\hline $\begin{array}{l}\text { Selective reporting (re- } \\
\text { porting bias) }\end{array}$ & High risk & Outcomes were not prespecified. An original protocol was not seen. \\
\hline Other bias & Low risk & There is no evidence of other bias. \\
\hline
\end{tabular}


Gillen 2004

\begin{tabular}{|c|c|}
\hline Methods & Single-centre randomised controlled trial. \\
\hline \multirow[t]{3}{*}{ Participants } & $\begin{array}{l}32 \text { women. No data provided on mean maternal age or ethnicity. } \\
\text { Inclusion criteria: GDM diagnosed at approximately } 28 \text { weeks' gestation (Table 7). }\end{array}$ \\
\hline & $\begin{array}{l}\text { Exclusion criteria: significant other health concerns, poor English language skills. } \\
\text { Setting: Diabetic clinic. Wollongong, Australia. }\end{array}$ \\
\hline & Timing: May to December 2002. \\
\hline \multirow[t]{2}{*}{ Interventions } & $\begin{array}{l}\text { 1) Intervention group: following a group session on management of GDM from a registered nurse dia- } \\
\text { betes educator and dietician the group received standard clinical practice plus advice for targeted in- } \\
\text { takes of foods rich in unsaturated fats based on meeting energy requirements. }\end{array}$ \\
\hline & $\begin{array}{l}\text { 2) Control group: following a group session on management of GDM from a registered nurse diabetes } \\
\text { educator and dietician the group received standard clinical practice (individualised carbohydrate por- } \\
\text { tion-controlled meal plan, with low-fat and low-glycaemic index dietary strategies and general advice } \\
\text { about meeting nutritional requirements of pregnancy). }\end{array}$ \\
\hline Outcomes & Outcomes: gestation at birth, mode of birth, changes in dietary intakes, use of insulin. \\
\hline \multirow[t]{4}{*}{ Notes } & ITT analysis was used. not stated. \\
\hline & Funding: not stated. \\
\hline & Sample size calculation: not stated. \\
\hline & Conflicts of interest: no details. \\
\hline
\end{tabular}

\section{Risk of bias}

Bias Authors' judgement Support for judgement

Random sequence genera- Low risk tion (selection bias)

Open table of random numbers constructed by an independent person and kept confidential from members of the study team. Women were matched consecutively to the next available number in the table and the study team informed of the result.

Allocation concealment $\quad$ Low risk
(selection bias)

\begin{tabular}{|c|c|c|}
\hline $\begin{array}{l}\text { Blinding of participants } \\
\text { and personnel (perfor- }\end{array}$ & Unclear risk & $\begin{array}{l}\text { Participants unaware of differences in advice between intervention and con- } \\
\text { trol groups, research staff were aware. }\end{array}$ \\
\hline
\end{tabular}

mance bias)

All outcomes

\begin{tabular}{lll}
\hline $\begin{array}{l}\text { Blinding of outcome as- } \\
\text { sessment (detection bias) } \\
\text { All outcomes }\end{array}$ & Unclear risk & Not stated. \\
\hline $\begin{array}{l}\text { Incomplete outcome data } \\
\text { (attrition bias) } \\
\text { All outcomes }\end{array}$ & Low risk & Dropouts: data not available for 1 woman from each group. \\
\hline $\begin{array}{l}\text { Selective reporting (re- } \\
\text { porting bias) }\end{array}$ & High risk & $\begin{array}{l}\text { An original protocol was not seen. The outcomes were not clearly prespecified. } \\
\text { The authors report that there were no differences in pregnancy outcomes or } \\
\text { nature of birth but they do not report any of this data in the paper. }\end{array}$
\end{tabular}

Other bias

Low risk

No evidence of other bias, no differences at baseline. 


\begin{tabular}{|c|c|}
\hline Methods & Randomised controlled trial. \\
\hline \multirow[t]{5}{*}{ Participants } & 19 women \\
\hline & Inclusion criteria: women diagnosed with GDM (Table 7). \\
\hline & Exclusion criteria: none detailed. \\
\hline & Setting: USA. \\
\hline & Timing: not specified. \\
\hline \multirow[t]{3}{*}{ Interventions } & $\begin{array}{l}\text { Intervention group - } 6 \text { week diet ( } 24 \text { to } 30 \mathrm{kcal} / \mathrm{kg} / 24 \text { hours; } 20 \% \text { protein, } 40 \% \text { carbohydrates, } 40 \% \text { fat } \\
\text { divided into } 3 \text { meals and } 3 \text { snacks) plus } 20 \text { mins of supervised aerobic exercise } 3 \text { times per week for the } \\
6 \text { weeks. An arm ergometer was used to maintain heart rate ( } 220 \text {-age in years) x } 70 \% \text { unless this heart } \\
\text { rate exceeded } 140 \mathrm{bpm} \text { and then } 140 \mathrm{bpm} \text { was the target heart rate. The exercise session never exceed } \\
\text { ed } 50 \% \text { maximal oxygen consumption. } 6 \text { women exercised between } 4 \mathrm{pm} \text { and } 5 \mathrm{pm} \text { and } 4 \text { women be- } \\
\text { tween } 10 \text { am and } 11 \mathrm{am} \text {. }\end{array}$ \\
\hline & $\begin{array}{l}\text { Control group - } 6 \text { week diet alone ( } 24 \text { to } 30 \mathrm{kcal} / \mathrm{kg} / 24 \text { hours; } 20 \% \text { protein, } 40 \% \text { carbohydrates, } 40 \% \text { fat } \\
\text { divided into } 3 \text { meals and } 3 \text { snacks). }\end{array}$ \\
\hline & $\begin{array}{l}\text { All women performed glucose self monitoring } 4 \text { times per day (before breakfast and } 1 \text { hour postpran- } \\
\text { dial). Seen weekly by a physician. Insulin was started if FPG }>5.8 \mathrm{mmol} / \mathrm{L} \text { or } 105 \mathrm{mg} / \mathrm{dL} \text { ) and/or } 1 \text { hour } \\
\text { postprandial plasma glucose was }>7.8 \mathrm{mmol} / \mathrm{L} \text { or } 140 \mathrm{mg} / \mathrm{dL} \text { ). }\end{array}$ \\
\hline
\end{tabular}

Outcomes HbA1c, fasting and 1-hour postprandial blood glucose, $50 \mathrm{~g}$ glucose challenge test, maternal hypoglycaemia, C-peptide, use of insulin, birthweight. No primary outcomes were pre-specified.

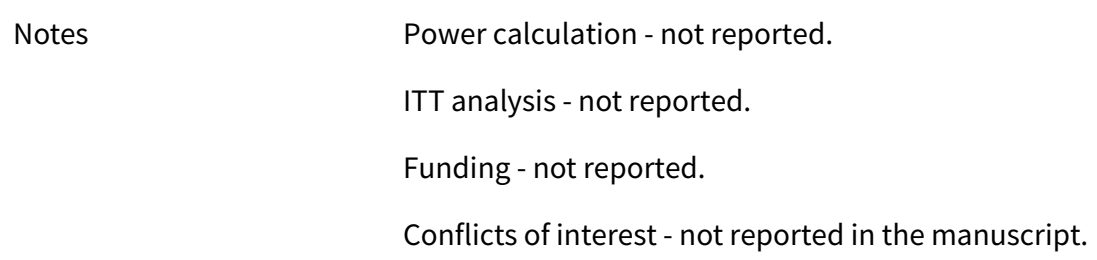

\section{Risk of bias}

\begin{tabular}{|c|c|c|}
\hline Bias & Authors' judgement & Support for judgement \\
\hline $\begin{array}{l}\text { Random sequence genera- } \\
\text { tion (selection bias) }\end{array}$ & Low risk & 'Randomized', by drawing a number. \\
\hline $\begin{array}{l}\text { Allocation concealment } \\
\text { (selection bias) }\end{array}$ & Unclear risk & No details. \\
\hline $\begin{array}{l}\text { Blinding of participants } \\
\text { and personnel (perfor- } \\
\text { mance bias) } \\
\text { All outcomes }\end{array}$ & High risk & No details but unlikely to have been blinded. \\
\hline $\begin{array}{l}\text { Blinding of outcome as- } \\
\text { sessment (detection bias) } \\
\text { All outcomes }\end{array}$ & Unclear risk & No details. \\
\hline $\begin{array}{l}\text { Incomplete outcome data } \\
\text { (attrition bias) }\end{array}$ & Low risk & Data reported for all 19 women randomised. \\
\hline
\end{tabular}


Jovanovic-Peterson 1989 (Continued)

All outcomes

\begin{tabular}{|c|c|c|}
\hline $\begin{array}{l}\text { Selective reporting (re- } \\
\text { porting bias) }\end{array}$ & High risk & $\begin{array}{l}\text { Additional outcomes are reported that were not listed a priori in the methods } \\
\text { section including gestational age at delivery and birthweight. }\end{array}$ \\
\hline
\end{tabular}

$\begin{array}{ll}\text { Other bias } \quad \text { High risk } & \begin{array}{l}\text { The women randomised to the exercise and diet intervention had a significant- } \\ \text { ly higher } 1 \text { hour plasma glucose in the diagnostic test at baseline. }\end{array}\end{array}$

Kaviani 2014

Methods Randomised controlled trial.

Participants 58 pregnant women with gestational diabetes (69 eligible).

Inclusion criteria: having gestational diabetes (Table 7), being in the pre-diabetic stage, not using insulin and psychiatric medications, no previous history of relaxation therapy, age 18 to 40 years, gestational age 24 to 30 weeks'.

Exclusion criteria: overt diabetes, unwillingness to co-operate at any stage of the study, being absent for more than 1 session of the training classes, not doing the relaxation exercises at home for more than 5 days, changing diet or physical activity during study, having pregnancy complications during study.

Setting: Shiraz, Iran.

Timing: February to April 2013.

Interventions

Intervention group (Relaxation training) $(n=29)$ over 10 weeks, five 45 min sessions - Session 1 Training on the nature and mechanism of diabetes, nature of stress and effect on body; Session 2 Different breathing techniques and body positions during relaxation; Session 3 How to relax muscles in various parts of the body after stress; Session 4 Relaxation through conditioning; Session 5 Training of differential relaxation and relaxation along with positive mental imagery (Based on the principles of Herbert Benson). Encouraged to practice relaxation at home for a month. Provided with a chart for recording relaxation exercises to evaluate their performance, $C D$ with soft music explaining how do perform the relaxation. Contacted by telephone by the researcher 3 times per week.

Control group $(\mathrm{n}=29)$ routine prenatal care (no details).

\begin{tabular}{ll}
\hline Outcomes & BP, fasting blood sugar, 2-hour postprandial blood sugar, use of insulin. \\
\hline Notes & Sample size calculation: yes but unclear on what outcome the calculation was based. \\
ITT analysis: yes. \\
Funding: University funding. \\
Conflicts of interest: not reported in the manuscript. \\
\hline
\end{tabular}

\section{Risk of bias}

\begin{tabular}{lll}
\hline Bias & Authors' judgement & Support for judgement \\
\hline $\begin{array}{l}\text { Random sequence genera- } \\
\text { tion (selection bias) }\end{array}$ & Low risk & 'random numbers' and 'permutation blocks.' \\
\hline $\begin{array}{l}\text { Allocation concealment } \\
\text { (selection bias) }\end{array}$ & Unclear risk & No details. \\
\hline
\end{tabular}


Kaviani 2014 (Continued)

Blinding of participants High risk No details but unlikely to be blinded due to nature of intervention. and personnel (performance bias)

All outcomes

\begin{tabular}{|c|c|}
\hline $\begin{array}{l}\text { Blinding of outcome as- } \\
\text { sessment (detection bias) }\end{array}$ & Unclear risk \\
\hline
\end{tabular}

All outcomes

Incomplete outcome data Low risk

58 women randomised and analysed.

(attrition bias)

All outcomes

\begin{tabular}{lll}
\hline $\begin{array}{l}\text { Selective reporting (re- } \\
\text { porting bias) }\end{array}$ & High risk & Very limited outcomes reported for mother, no neonatal outcomes reported. \\
\hline Other bias & Low risk & No differences at baseline. \\
\hline
\end{tabular}

Landon 2009

\begin{tabular}{ll}
\hline Methods & Randomised controlled trial. \\
\hline Participants & 958 women.
\end{tabular}

Participants

Inclusion criteria: abnormal result on glucose loading test (Table 7).

Between 24 and 30 weeks' gestation.

Exclusion criteria: pregestational diabetes, abnormal glucose screen before 24 weeks', previous GDM, history of stillbirth, multiple gestation, asthma, chronic hypertension, taking corticosteroids, known fetal anomaly or imminent preterm delivery. Fasting glucose $>5.3 \mathrm{mmol} / \mathrm{L}(95 \mathrm{mg} / \mathrm{dL})$.

Setting: Obstetric research centre, Washington, USA.

Timing: October 2002 to November 2007.

\begin{tabular}{|c|c|}
\hline \multirow[t]{4}{*}{ Interventions } & $\begin{array}{l}\text { 1) Intervention group - Formal nutrition counselling and diet therapy }+/ \text { - insulin and daily self monitor- } \\
\text { ing (fasting and } 2 \text { hour post-prandial) }(n=485)\end{array}$ \\
\hline & versus \\
\hline & 2) Control group - usual prenatal care $+/$ - insulin and self monitoring $(n=473)$. \\
\hline & $\begin{array}{l}\text { Insulin was commenced if fasting glucose levels were predominantly at } 5.3 \mathrm{mmol} / \mathrm{L} \text { or greater or post- } \\
\text { prandial glucose was } 6.7 \mathrm{mmol} / \mathrm{L} \text { or greater. }\end{array}$ \\
\hline
\end{tabular}

Outcomes

Primary outcome was a composite score (perinatal mortality, hyperglycaemia, hypoglycaemia, hyperbilirubinaemia, neonatal hyperinsulinaemia, birth trauma).

Secondary outcomes included individual components of the composite score, C-peptide, birthweight, preterm birth, macrosomia, LGA, SGA, neonatal glucose levels, neonatal hypoglycaemia, hyperbilirubinaemia, birth trauma, gestational age at birth, NICU admission, RDS, neonatal fat mass, adiposity, gestational weight gain, hypertension, pre-eclampsia, caesarean section, IOL, shoulder dystocia, maternal diabetes, use of insulin, metabolic syndrome. Childhood BMI.

Notes Sample size calculation: yes based on composite score.

ITT analysis: yes. 
Funding: Eunice Kennedy Shriver National Institute of Child Health and Human Development.

Conflicts of interest: the authors reported that there were no potential conflicts of interest relevant to this manuscript.

Casey 2015 reported on long-term maternal outcomes from this trial on 457 (50\%) of the eligible 905 women. 243 women were treated in the original trial and 214 untreated. 430 women had blood drawn for analysis.

Bahado-Singh 2012 reported on gender differences in fetal outcomes.

Durnwald 2011 reported on glycaemic characteristics and neonatal outcomes but do not report on differences between treatment and intervention groups.

Sutton 2014 reported on timing of delivery and caesarean section.

Landon 2015 reported on long-term follow-up of children at 5 to 10 years of age.

\section{Risk of bias}

\begin{tabular}{|c|c|c|}
\hline Bias & Authors' judgement & Support for judgement \\
\hline $\begin{array}{l}\text { Random sequence genera- } \\
\text { tion (selection bias) }\end{array}$ & Low risk & 'simple urn method.' \\
\hline $\begin{array}{l}\text { Allocation concealment } \\
\text { (selection bias) }\end{array}$ & Low risk & 'by the coordinating centre.' \\
\hline $\begin{array}{l}\text { Blinding of participants } \\
\text { and personnel (perfor- } \\
\text { mance bias) } \\
\text { All outcomes }\end{array}$ & High risk & Not possible to blind participants; staff were not blinded to allocation. \\
\hline $\begin{array}{l}\text { Blinding of outcome as- } \\
\text { sessment (detection bias) } \\
\text { All outcomes }\end{array}$ & Low risk & Outcome assessors were blinded for some outcomes. \\
\hline $\begin{array}{l}\text { Incomplete outcome data } \\
\text { (attrition bias) } \\
\text { All outcomes }\end{array}$ & Low risk & $\begin{array}{l}25 \text { women in the intervention group were lost to follow-up ( } 8 \text { had no delivery } \\
\text { data and } 17 \text { had missing laboratory data). } \\
33 \text { women in the control group were lost to follow-up ( } 18 \text { had no delivery data } \\
\text { and } 15 \text { had missing laboratory data). } \\
\text { ITT analysis was conducted. }\end{array}$ \\
\hline $\begin{array}{l}\text { Selective reporting (re- } \\
\text { porting bias) }\end{array}$ & Low risk & $\begin{array}{l}\text { The original protocol was not seen. All outcomes appear to be reported and in- } \\
\text { clude maternal and neonatal outcomes. Long-term maternal outcomes are re- } \\
\text { ported in abstract form by Casey } 2015 \text {. }\end{array}$ \\
\hline Other bias & Low risk & $\begin{array}{l}\text { No evidence of other bias, no differences in baseline measurements between } \\
\text { groups. }\end{array}$ \\
\hline
\end{tabular}

\section{Mendelson 2008}

\begin{tabular}{ll}
\hline Methods & Randomised trial. \\
\hline Participants & $\begin{array}{l}100 \text { Mexican-American women. Mean age in Parish nurse group was } 30.6 \pm 5.6 \text { years and in the usual } \\
\text { care group was } 31.5 \pm 5.2 \text { years. }\end{array}$
\end{tabular}


Inclusion criteria: diagnosed and referred for treatment for gestational diabetes (Table 7), self-reported Mexican descent, able to speak, read and write in English or Spanish, 18 to 40 years of age, between 12 and 32 weeks' gestation, singleton pregnancy.

Exclusion criteria: not specified.

Setting: outpatient clinic for women with gestational diabetes in a hospital in California, USA.

Timing: no details.

\begin{abstract}
Interventions
Intervention group (Parish nurse intervention program) $(n=49)$ Enhanced education and support provided by parish nurses fluent in Spanish. A supplemental 1-hour Parish nurse led discussion regarding medical recommendations for control of gestational diabetes to clarify areas of concern or misunderstanding. Also included spiritual principles such as encouragement of prayer and spiritual connection within the belief system of the women. Education included what is diabetes, types and risk factors; diabetes control with nutrition, activity, and medical treatment; and nutrition therapy (food groups and measurements).
\end{abstract}

Control group (Usual care) $(n=51)$ Education on diet, exercise, blood glucose testing and insulin administration if required in individual 1-hour sessions provided through handouts, demonstration and discussion.

\title{
Outcomes
}

Health promotions behaviour questionnaire, macrosomia, fasting blood glucose, random blood glucose, $\mathrm{HbA1c}$, duration of maternal and neonatal hospitalisation, caesarean section, use of insulin. Primary outcomes were not specified.

Notes

Power calculation: no data provided.

ITT analysis: not stated

Funding: Eugene Cota Robles Fellowship.

Conflicts of interest: not provided in the manuscript.

\section{Risk of bias}

\begin{tabular}{|c|c|c|}
\hline Bias & Authors' judgement & Support for judgement \\
\hline $\begin{array}{l}\text { Random sequence genera- } \\
\text { tion (selection bias) }\end{array}$ & Low risk & 'random number tables.' \\
\hline $\begin{array}{l}\text { Allocation concealment } \\
\text { (selection bias) }\end{array}$ & Unclear risk & No clear details provided despite contacting author. \\
\hline $\begin{array}{l}\text { Blinding of participants } \\
\text { and personnel (perfor- } \\
\text { mance bias) } \\
\text { All outcomes }\end{array}$ & Unclear risk & $\begin{array}{l}\text { Women were not blinded (information obtained from email), diabetes educa- } \\
\text { tors were blinded to allocation. }\end{array}$ \\
\hline $\begin{array}{l}\text { Blinding of outcome as- } \\
\text { sessment (detection bias) } \\
\text { All outcomes }\end{array}$ & Unclear risk & No details provided. \\
\hline $\begin{array}{l}\text { Incomplete outcome data } \\
\text { (attrition bias) } \\
\text { All outcomes }\end{array}$ & High risk & Not all women had an $\mathrm{HbA1C}$ at birth (27 out of 100 ). \\
\hline $\begin{array}{l}\text { Selective reporting (re- } \\
\text { porting bias) }\end{array}$ & Unclear risk & $\begin{array}{l}\text { The outcomes listed in the methods section were all reported in the results. } \\
\text { Caesarean section which was not prespecified was reported as an outcome in } \\
\text { the results. }\end{array}$ \\
\hline
\end{tabular}


Mendelson 2008 (Continued)

Other bias Low risk No differences between groups at baseline. No evidence of other bias.

Rahimikian 2014

\begin{tabular}{ll}
\hline Methods & Randomised controlled trial. \\
\hline Participants & 126 women with gestational diabetes (diagnostic criteria unclear). \\
& $\begin{array}{l}\text { Inclusion criteria: gestational age } 28 \text { to } 36 \text { weeks', hospitalised due to high blood sugar or gestational } \\
\text { diabetes (Table 7), not attending education sessions before, literate. }\end{array}$
\end{tabular}

Exclusion criteria: absent for 1 of the training sessions, not wanting to continue with the study.

Setting: Iran.

Timing: 2013.

\begin{tabular}{ll}
\hline Interventions & $\begin{array}{l}\text { Intervention group (Face-to-face education) ( } \mathrm{n}=42) 2 \text { sessions of } 40 \text { mins as individuals or in groups. } \\
\text { Session } 1 \text { definition of GDM, causes, symptoms, those at risk, management of GDM including training } \\
\text { on glycaemic control; session } 2 \text { nutrition, physical activity and exercise, insulin, pregnancy follow-up. }\end{array}$ \\
or (Instructional booklet education) $(\mathrm{n}=42)$ a booklet provided that includes all the information given \\
in the face-to-face sessions (not used in this review). \\
Control ( $\mathrm{n}=42$ ) routine hospital services (no details). \\
Maternal hospitalisation due to gestational diabetes and duration, type of delivery, use of insulin, birth- \\
weight, gestational age at birth, Apgar 1 and 5 mins, stillbirth. \\
Notes \\
Sample size calculation - no. \\
ITT analysis - no. \\
Funding - no details. \\
Conflicts of interest - no details.
\end{tabular}

\section{Risk of bias}

\begin{tabular}{lll}
\hline Bias & Authors' judgement & Support for judgement \\
\hline $\begin{array}{l}\text { Random sequence genera- } \\
\text { tion (selection bias) }\end{array}$ & Unclear risk & 'randomly assigned.' \\
\hline $\begin{array}{l}\text { Allocation concealment } \\
\text { (selection bias) }\end{array}$ & Unclear risk & No details. \\
\hline $\begin{array}{l}\text { Blinding of participants } \\
\text { and personnel (perfor- } \\
\text { mance bias) } \\
\text { All outcomes }\end{array}$ & High risk & No details but unlikely that participants or researchers were blinded. \\
\hline $\begin{array}{l}\text { Blinding of outcome as- } \\
\text { sessment (detection bias) } \\
\text { All outcomes }\end{array}$ & Unclear risk & No details. \\
\hline $\begin{array}{l}\text { Incomplete outcome data } \\
\text { (attrition bias) }\end{array}$ & Unclear risk & $\begin{array}{l}\text { Data appear to be missing for } 1 \text { of the intervention groups but no details pro- } \\
\text { vided. }\end{array}$ \\
\hline
\end{tabular}


Rahimikian 2014 (Continued)

All outcomes

\begin{tabular}{l}
$\begin{array}{l}\text { Selective reporting (re- } \\
\text { porting bias) }\end{array}$ High risk Raw data not reported for all outcomes. \\
\hline
\end{tabular}

Other bias Low risk No differences at baseline.

Yang 2003

\begin{tabular}{ll}
\hline Methods & Randomised controlled trial. \\
\hline Participants & 150 women randomised.
\end{tabular}

Participants

No details of inclusion or exclusion. Women were diagnosed with GDM after a $50 \mathrm{~g}, 1$-hour screen at 26 to 30 weeks (Table 7 ).

Setting: Tianjin, China.

Timing: no details of time that trial was conducted.

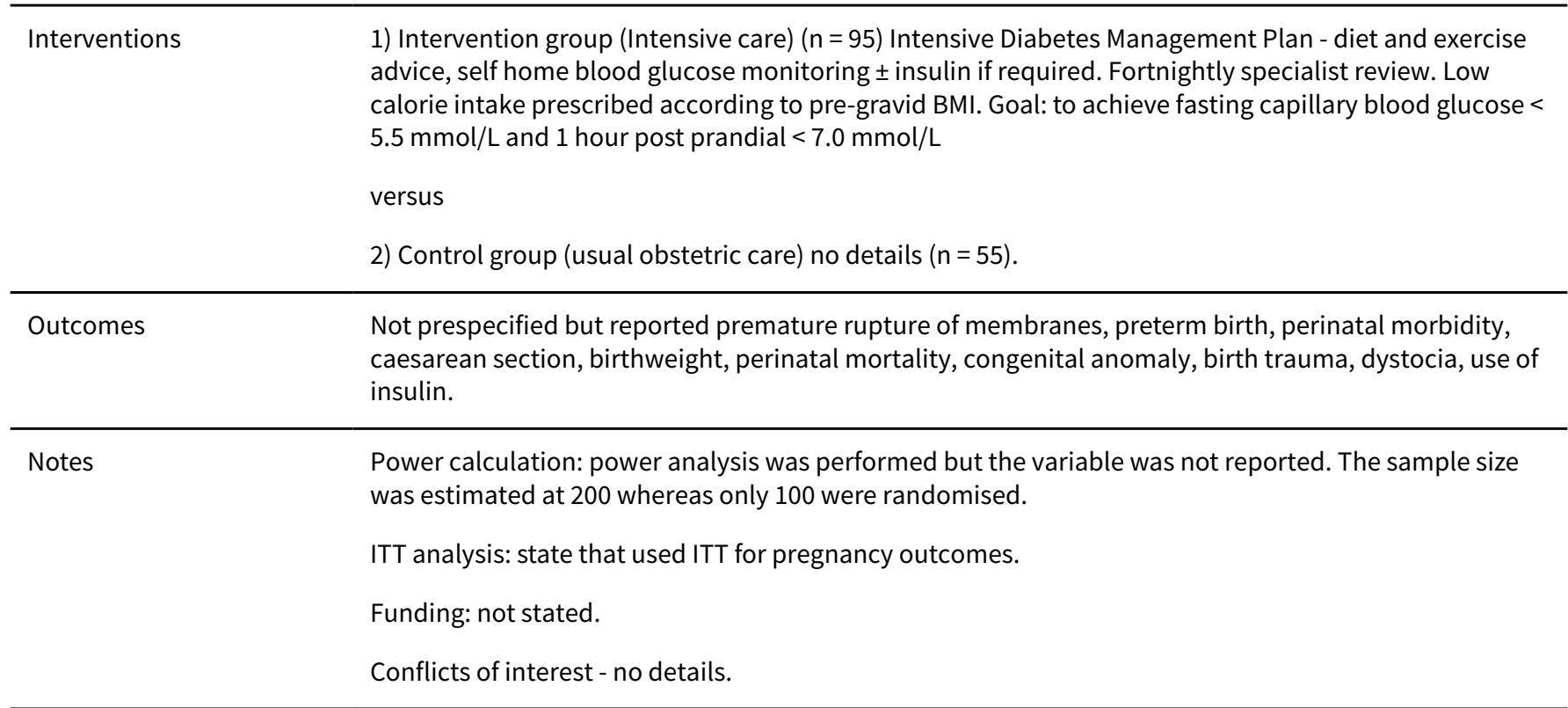

\section{Risk of bias}

\begin{tabular}{lll}
\hline Bias & Authors' judgement & Support for judgement \\
\hline $\begin{array}{l}\text { Random sequence genera- } \\
\text { tion (selection bias) }\end{array}$ & Unclear risk & 'randomized' no other details. \\
\hline $\begin{array}{l}\text { Allocation concealment } \\
\text { (selection bias) }\end{array}$ & Unclear risk & No details. \\
\hline $\begin{array}{l}\text { Blinding of participants } \\
\text { and personnel (perfor- } \\
\text { mance bias) } \\
\begin{array}{l}\text { All outcomes } \\
\hline\end{array}\end{array}$ & High risk & No details but unlikely that participants or researchers were blinded. \\
\hline
\end{tabular}


Yang 2003 (Continued)

Blinding of outcome as- $\quad$ Unclear risk Not reported.
sessment (detection bias)

All outcomes

\begin{tabular}{|c|c|c|}
\hline $\begin{array}{l}\text { Incomplete outcome data } \\
\text { (attrition bias) }\end{array}$ & High risk & $\begin{array}{l}\text { Of } 95 \text { women in the intervention group, only } 48 \text { completed the management } \\
\text { plan compared with } 55 / 55 \text { in the usual care group. }\end{array}$ \\
\hline
\end{tabular}

All outcomes plan compared with 55/55 in the usual care group.

\section{Selective reporting (re- High risk} porting bias)

Other bias

High risk
The study is reported as a letter only. There was no evidence of a full paper and only the data on caesarean section and PROM is reported.

Yang 2014

\begin{tabular}{ll}
\hline Methods & Randomised trial. \\
\hline Participants & $\begin{array}{l}948 \text { women randomised. Mean age of usual care group was } 29.7 \pm 3.2 \text { years and } 29.9 \pm 3.5 \text { years in the } \\
\text { shared care group. } 97 \% \text { were Han Chinese. }\end{array}$
\end{tabular}

GDM diagnosed by $50 \mathrm{~g}$ 1-hour glucose challenge test between 24 and 28 weeks' gestation (Table 7).

Exclusion criteria: OGTT meeting criteria for diabetes (FPG $\geq 7.0 \mathrm{mmol} / \mathrm{L}, 2 \mathrm{hour} \geq 11.1 \mathrm{mmol} / \mathrm{L}$ or $\mathrm{HbAlc} \geq 6.5 \% / 48 \mathrm{mmol} / \mathrm{mol}$ ); $<18$ years of age, multiple pregnancy, maternal fetal ABO blood type incompatibility, maternal diseases such as chronic hypertension, thyrotoxicosis, pre-pregnancy diabetes and long-term use of medications that might affect glucose metabolism.

Setting: Tianjin, China.

Timing: December 2010 to October 2012.

Interventions

Intervention group (Shared care) $(\mathrm{n}=344)$ - adapted from ACHOIS protocol. Intervention delivered by trained nurses and doctors. All women were offered individualised dietary advice and physical activity counselling. Different energy intakes were recommended based on prepregnancy BMI. All women were asked to engage in at least 30 mins of light to moderate physical activity daily. All women were offered a free glucose meter with memory function and free test strips. Asked to perform self-monitoring 4 times daily for first 2 weeks and then daily at different times in rotation. Glycaemic target was $\geq 3.5$ to $\leq 5.1 \mathrm{mmol} / \mathrm{L}$ for fasting capillary glucose and $\leq 7.0 \mathrm{mmol} / \mathrm{L}$ for 2-hour post-prandial capillary glucose up to 36 weeks' gestation and $\leq 8.0 \mathrm{mmol} / \mathrm{L}$ from 36 weeks' onwards. If target levels were exceeded 2 or more times during a 2-week interval or the 2-hour postprandial level exceed $9.0 \mathrm{mmol} / \mathrm{L}$ once during a 1 week period then insulin was recommended. At 30 and 34 weeks' gestation the group was offered 2 additional individualised counselling sessions to reinforce diet, physical activity and self monitoring. They were also offered group education sessions lasting 2 hours at 27, 29 and 33 weeks' gestation.

Control group (Usual care) ( $n=362$ ) - offered group education class lasting 30-40 mins delivered by a diabetes educator. Received advice on diet and physical activity but not specifically taught to self monitor blood glucose. Insulin treatment recommended if $\mathrm{HbA} 1 \mathrm{c} \geq 6.5 \%(48 \mathrm{~mol} / \mathrm{mol})$.

Outcomes $\quad$ Primary - macrosomia ( $\geq 4000 \mathrm{~g})$, LGA.

Secondary - pregnancy-induced hypertension.

Other outcomes included depression, caesarean section, use of insulin, weight gain in pregnancy, IOL, neonatal death, birth trauma, gestational age at birth, preterm birth, birthweight, birth length, neonatal hypoglycaemia, visits to health professional. Physical activity, food recall. Other outcomes were not reported a priori. 
Yang 2014 (Continued)

Notes
During Nov 2010 to July 2011 separate areas for intervention and follow-up in the 2 groups were unavailable due to building renovation and data collection for the usual care women was performed by the intervention staff members. The 242 women entering the trials during this period also received unintentional intervention. The authors excluded these women from the analysis.

Power calculation: yes based on a reduction in risk for pregnancy-induced hypertension.

ITT analysis: no, women wrongly allocated during a specific period were excluded from the analysis.

Funding: funding from BRIDGES an educational grant from Lilly Diabetes.

Conflicts of interest: a conflict was reported by 1 of the 12 authors: the author's institution had received research funding from Eli Lilly and the author is a member of advisory committee and speaker forum sponsored by Eli Lilly.

\section{Risk of bias}

\begin{tabular}{|c|c|c|}
\hline Bias & Authors' judgement & Support for judgement \\
\hline $\begin{array}{l}\text { Random sequence genera- } \\
\text { tion (selection bias) }\end{array}$ & Low risk & $\begin{array}{l}\text { 'simple randomization procedure without replacement' 'computer generated } \\
\text { random assignment' }\end{array}$ \\
\hline $\begin{array}{l}\text { Allocation concealment } \\
\text { (selection bias) }\end{array}$ & Unclear risk & No details provided. \\
\hline $\begin{array}{l}\text { Blinding of participants } \\
\text { and personnel (perfor- } \\
\text { mance bias) } \\
\text { All outcomes }\end{array}$ & Low risk & $\begin{array}{l}\text { 'The women with GDM in the trial but not the research team members were } \\
\text { masked to the random assignment.' }\end{array}$ \\
\hline $\begin{array}{l}\text { Blinding of outcome as- } \\
\text { sessment (detection bias) } \\
\text { All outcomes }\end{array}$ & Low risk & $\begin{array}{l}\text { Outcome assessors for pregnancy-induced hypertension were blinded to allo- } \\
\text { cation. }\end{array}$ \\
\hline $\begin{array}{l}\text { Incomplete outcome data } \\
\text { (attrition bias) } \\
\text { All outcomes }\end{array}$ & High risk & $\begin{array}{l}\text { During Nov } 2010 \text { to July } 2011 \text { separate areas for intervention and follow-up in } \\
\text { the } 2 \text { groups were unavailable due to building renovation and data collection } \\
\text { for the usual care women was performed by the intervention staff members. } \\
\text { The } 242 \text { women entering the trials during this period also received uninten- } \\
\text { tional intervention. The authors excluded these women from the analysis. } \\
\text { In addition to this } 1 \text { woman in the usual care group and } 5 \text { women in the shared } \\
\text { care group gave birth outside Tianjin. } 339 \text { women in the usual care and } 361 \\
\text { women in the shared care group were analysed. }\end{array}$ \\
\hline
\end{tabular}

Selective reporting (re- High risk
porting bias)

Additional outcomes are reported that were not pre-specified in the methods porting bias) section.

Other bias Low risk Groups were similar at baseline. No other risk of bias was identified.

\section{Youngwanichsetha 2014}

\begin{tabular}{ll}
\hline Methods & Randomised controlled trial. \\
\hline Participants & $\begin{array}{l}180 \text { women randomised. Mean maternal age in the intervention group was } 32.58 \pm 5.01 \text { years and for } \\
\text { the control group was } 31.24 \pm 4.54 \text { years. No ethnicity is reported but women were Thai. }\end{array}$
\end{tabular}


Youngwanichsetha 2014 (Continued)

Inclusion criteria: diagnosed with GDM A1 at 24 to 30 weeks' gestation (Table 7); not receiving insulin therapy for glycaemic control; having no serious complications such as gestational hypertension, preeclampsia, preterm labour or other serious health problems.

Exclusion criteria: none detailed.

Setting: tertiary hospital in Thailand.

Timing: not specified.

Interventions

Intervention ( $\mathrm{n}=90)$ Trained to perform mindfulness eating and yoga exercise in 250 -min sessions. Videos were used in classes and practicing manuals were offered for all the women to follow. Afterwards they were encouraged to continue with mindfulness eating and yoga at home 5 times a week for 8 weeks. Mindfulness eating involved setting a goal for blood glucose control, integrating medical nutrition therapy including carbohydrate choices and low glycaemic index food, considering portion size, being aware while consuming diabetic food, and eating slowly for 30 to 40 mins. The yoga that was used was yoga pranayama (deep breathing techniques) and asanas (posture and movements). it was designed for 15 to 20 mins daily practice for 5 days a week. The group were encouraged weekly by research staff.

Control group $(\mathrm{n}=90)$ Standard diabetes care (no details).

ITT analysis: no, they did not analyse the women who did not complete the study or who had been lost to follow-up.

Funding: no details provided in manuscript.

Conflicts of interest: no details provided in manuscript.

\section{Risk of bias}

\begin{tabular}{|c|c|c|}
\hline Bias & Authors' judgement & Support for judgement \\
\hline $\begin{array}{l}\text { Random sequence genera- } \\
\text { tion (selection bias) }\end{array}$ & Unclear risk & No details on method of randomisation. \\
\hline $\begin{array}{l}\text { Allocation concealment } \\
\text { (selection bias) }\end{array}$ & Unclear risk & $\begin{array}{l}\text { 'randomization was performed by a research assistant using opaque en- } \\
\text { velopes technique'. Not clear if this was sequential or not. }\end{array}$ \\
\hline $\begin{array}{l}\text { Blinding of participants } \\
\text { and personnel (perfor- } \\
\text { mance bias) } \\
\text { All outcomes }\end{array}$ & High risk & $\begin{array}{l}\text { No details provided but staff and participants are unlikely to have been blind- } \\
\text { ed. }\end{array}$ \\
\hline $\begin{array}{l}\text { Blinding of outcome as- } \\
\text { sessment (detection bias) } \\
\text { All outcomes }\end{array}$ & Low risk & $\begin{array}{l}\text { HbAlc testing was conducted by a laboratory and the personnel are likely to } \\
\text { have been blinded to allocation. }\end{array}$ \\
\hline $\begin{array}{l}\text { Incomplete outcome data } \\
\text { (attrition bias) } \\
\text { All outcomes }\end{array}$ & Low risk & $\begin{array}{l}3 \text { women in the intervention group moved to another town for work and did } \\
\text { not complete the study and another } 2 \text { were lost to follow-up for the same rea- } \\
\text { son, therefore } 85 \text { women were analysed. } \\
5 \text { women in the control group were lost to follow-up as they had moved to an- } \\
\text { other town for work, therefore } 85 \text { were analysed. }\end{array}$ \\
\hline
\end{tabular}


Youngwanichsetha 2014 (Continued)

\begin{tabular}{|c|c|c|}
\hline $\begin{array}{l}\text { Selective reporting (re- } \\
\text { porting bias) }\end{array}$ & High risk & $\begin{array}{l}\text { The trial only reports on the effects on glycaemic control and no neonatal or } \\
\text { other maternal outcomes are reported. }\end{array}$ \\
\hline
\end{tabular}

Other bias Low risk Groups appear balanced at baseline, no evidence of other bias.

BMI: body mass index

BP: blood pressure

BPM: beats per minute

CRP: C-reactive protein

CTG: cardiotocography

$\mathrm{dL}$ : decilitre

FPG: fasting plasma glucose

GDM: gestational diabetes mellitus

IOL: induction of labour

ITT: intention-to-treat

IV: intravenous

L: litre

LGA: large-for-gestational age

min: minute

NICU: neonatal intensive care unit

OGTT: oral glucose tolerance test

RDS: respiratory distress syndrome

SGA: small-for-gestational age

Characteristics of excluded studies [ordered by study ID]

\begin{tabular}{|c|c|}
\hline Study & Reason for exclusion \\
\hline Abirami 2014 & After contacting the authors it was clarified that this was not a randomised controlled trial. \\
\hline Adam 2014 & $\begin{array}{l}\text { This is a randomised controlled trial of exercise interventions and belongs in the exercise for preg- } \\
\text { nant diabetic women review. }\end{array}$ \\
\hline Bastani 2015 & $\begin{array}{l}\text { This is a randomised trial using acupressure to treat anxiety in women with GDM and not being } \\
\text { used for glycaemic control. }\end{array}$ \\
\hline Berry 2013 & $\begin{array}{l}\text { Although women are recruited in pregnancy with GDM, the main intervention starts at } 6 \text { weeks } \\
\text { postpartum. }\end{array}$ \\
\hline Bevier 1999 & $\begin{array}{l}\text { Women did not meet the criteria for GDM as they only had an elevated glucose challenge test and a } \\
\text { normal glucose tolerance test. }\end{array}$ \\
\hline Bonomo 2005 & $\begin{array}{l}\text { Women did not meet the criteria for GDM as they only had an elevated glucose challenge test and a } \\
\text { normal glucose tolerance test. }\end{array}$ \\
\hline Branch 2010 & This trial was registered but never started due to insufficient funding for enrolling participants. \\
\hline Fadl 2015 & Wrong comparison for this review - insulin versus no additional treatment. \\
\hline Ford 1997 & $\begin{array}{l}\text { Trial compared diet alone versus usual care. Does not meet the review criteria for a lifestyle inter- } \\
\text { vention. }\end{array}$ \\
\hline Grant 2011 & $\begin{array}{l}\text { Wrong comparison for this review. This trial is included in the Cochrane systematic review on differ- } \\
\text { ent types of dietary advice for women with GDM. }\end{array}$ \\
\hline Holmes 2012 & This is not a treatment trial for women with GDM. \\
\hline
\end{tabular}




\begin{tabular}{|c|c|}
\hline Study & Reason for exclusion \\
\hline Homko 2002 & Trial compared different types of monitoring of blood glucose - Wrong comparison. \\
\hline Kitzmiller 1990 & Informed by author that trial never started (March 2006). \\
\hline Langer 1989 & $\begin{array}{l}\text { Trial compared diet alone versus usual care. Not meeting the review criteria for a lifestyle interven- } \\
\text { tion. }\end{array}$ \\
\hline Li 1987 & This trial randomised women to 2 different screening/diagnosis strategies. Wrong comparison. \\
\hline Mirzamoradi 2015 & This trial randomised women to 2 different screening/diagnosis strategies. Wrong comparison. \\
\hline O'Sullivan 1971 & Quasi-randomised, alternate allocation. \\
\hline O'Sullivan 1974 & $\begin{array}{l}\text { Primary outcome death. Allocation used an alternate method, no intention-to-treat analysis. End- } \\
\text { points unclear. }\end{array}$ \\
\hline O'Sullivan 1980 & Not randomised. \\
\hline Osmundson 2015 & $\begin{array}{l}\text { Randomised trial of treating women with prediabetes, screened at }<14 \text { weeks' gestation. GDM was } \\
\text { confirmed by screening at } 26 \text { to } 28 \text { weeks' if not on insulin. Therefore not a trial treating women } \\
\text { with GDM. }\end{array}$ \\
\hline Perichart-Perera 2009 & Quasi-experimental design with an historical control group. \\
\hline Reader 2006 & This was an implementation trial for clinical practice guidelines rather than an intervention trial. \\
\hline Rey 1997 & Study compared home monitoring of blood glucose with clinic follow-up. Wrong comparison. \\
\hline
\end{tabular}

GDM: gestational diabetes mellitus

Characteristics of studies awaiting assessment [ordered by study ID]

\section{Cao 2012}

Methods

Participants

Interventions
States that groups were randomly allocated and also that the control group was age-matched to the intensive treatment group. Unclear if true randomisation took place.

Pregnant women with GDM.

A comprehensive intensive individualised therapy including education, dietary and exercise advice and instructions on self monitoring. Monitored by physician every 2 weeks.

Standard group received group education on diet and exercise, self-monitoring information given but not required at the same frequency as intensive group.

\begin{tabular}{ll}
\hline Outcomes & Caesarean section, pre-eclampsia, postpartum complications, birthweight, stillbirth, jaundice, \\
neonatal death, admission to NICU, preterm delivery, congenital malformation, neonatal hypogly- \\
caemia. Later follow-up maternal diabetes and metabolic syndrome.
\end{tabular}

Notes

Contact author emailed 20/01/2015. 
Kaveh 2012

\begin{tabular}{ll}
\hline Methods & Randomised controlled trial. \\
\hline Participants & Women with GDM. \\
\hline Interventions & Educational intervention with nutrition and exercise \\
& versus \\
control. \\
\hline Outcomes & Fasting and postprandial glucose levels; knowledge. \\
\hline Notes & $\begin{array}{l}\text { The article is in Persian and we are awaiting a translation to confirm inclusion/exclusion in this re- } \\
\text { view. }\end{array}$ \\
\hline
\end{tabular}

\section{Zhang 2012}

\begin{tabular}{ll}
\hline Methods & 'randomly divided.' \\
\hline Participants & Women with gestational diabetes. \\
\hline Interventions & Health education intervention with nutrition, exercise and foot care \\
& versus \\
& standard care. \\
\hline Outcomes & Self-efficacy, blood glucose levels. \\
\hline Notes & $\begin{array}{l}\text { Translation required to determine if true randomisation and if intervention and control groups } \\
\text { meet inclusion criteria for this review. }\end{array}$ \\
\hline
\end{tabular}

GDM: gestational diabetes mellitus

NICU: neonatal intensive care unit

Characteristics of ongoing studies [ordered by study ID]

\section{Durnwald NCT01858233}

\section{Trial name or title}

\begin{tabular}{ll}
\hline Methods & Randomised open-label trial. \\
\hline Participants & 120 women with GDM between 20 and 34 weeks' gestation. \\
\hline Interventions & Intensive behavioural modification, dietary counselling, lactation counselling \\
& versus \\
routine care and standard dietary counselling.
\end{tabular}

Primary outcomes: OGTT at 6 weeks postpartum.

Secondary outcomes: weight loss and lipid profiles. 
Durnwald NCT01858233 (Continued)

Contact information Valerie.armendariz@uphs.upenn.edu

\section{Notes}

\section{Ferrara NCT01489163}

Trial name or title Lifestyle intervention program for women with gestational diabetes or gestational impaired glucose tolerance (APPLES).

\begin{tabular}{ll}
\hline Methods & Randomised double-blind trial. \\
\hline Participants & 350 women with pregnancy complicated by high glucose levels. \\
\hline Interventions & Lifestyle counselling \\
& versus \\
& no intervention. \\
\hline
\end{tabular}

Outcomes

Primary - postpartum body weight.

Secondary - proportion of women reaching body weight goals, percent of calories from fat, time spent in physical activity, postpartum glycaemia.

Starting date December 2011.

Contact information

Assiamira Ferrara - Kaiser Permanente. USA.

Notes

\section{Hoseinzadeh IRCT2014080418682N1}

Trial name or title The effects of an educational intervention based on the theory of planned behavior on self-care behavior and blood glucose levels in pregnant women with gestational diabetes treated with insulin.

\begin{tabular}{ll}
\hline Methods & Randomised open-label trial ongoing in Iran. \\
\hline Participants & 60 pregnant women with gestational diabetes treated with insulin gestational age 20 to 24 weeks'. \\
\hline Interventions & $\begin{array}{l}\text { Education based on the theory of planned behaviour performed with } 4 \text { sessions of } 60 \text { minutes du- } \\
\text { ration }\end{array}$ \\
versus & routine prenatal care. \\
\hline
\end{tabular}

Outcomes Primary outcome - self-care behaviour.

Secondary outcomes - fasting and 2-hour post-prandial blood glucose level.

2014.


Hoseinzadeh IRCT2014080418682N1 (Continued)

Notes

Mirfeizi IRCT201406022892N3

\begin{tabular}{ll} 
Trial name or title & The effect of self-care education on quality of life in women with gestational diabetes. \\
\hline Methods & Randomised controlled trial. \\
\hline Participants & 240 women with gestational diabetes from Iran. Singleton pregnancy, 20 to 24 weeks' gestation. \\
\hline Interventions & $\begin{array}{l}4,45-\text { minute group education sessions for a month in self-care } \\
\text { versus } \\
\text { routine prenatal care. }\end{array}$ \\
\hline Outcomes & Primary outcome - quality of life. \\
\hline Starting date & 2014. \\
\hline Contact information & latibari@kiau.ac.ir; mani@kiau.ac.ir \\
\hline Notes &
\end{tabular}

Notes

Roeder NCT01926457

\begin{tabular}{ll}
\hline Trial name or title & Treating prediabetes in the first trimester. \\
\hline Methods & Randomised controlled trial, single-blind. \\
\hline Participants & 240 women from USA diagnosed with pre-diabetes < 15 weeks' gestational age. \\
\hline Interventions & $\begin{array}{l}\text { First trimester diabetes education, blood glucose monitoring, medication if required, growth ultra- } \\
\text { sounds, antenatal testing }\end{array}$ \\
& $\begin{array}{l}\text { versus } \\
\text { third trimester diabetes education, blood glucose monitoring, medication if required, growth ultra- } \\
\text { sounds, antenatal testing. }\end{array}$ \\
\hline Outcomes & $\begin{array}{l}\text { Primary outcomes - cord C-peptide. } \\
\text { Secondary outcomes - neonatal fat mass, gestational weight gain, return to pre-pregnancy weight, } \\
\text { maternal adiponectin, birthweight, LGA, ponderal index, admission to NICU, infant weight-for- } \\
\text { length, need for maternal pharmacotherapy, birth trauma, mode of birth, gestational weight gain, } \\
\text { postpartum weight retention, pre-eclampsia. }\end{array}$ \\
\hline Starting date & \begin{tabular}{l} 
2013. \\
\hline Notes
\end{tabular} \\
\hline haroeder@ucsd.edu
\end{tabular}




\begin{tabular}{ll}
\hline Trial name or title & $\begin{array}{l}\text { Effectiveness of stress management with cognitive behavioural method on blood sugar levels and } \\
\text { stress among patient with gestational diabetes. }\end{array}$ \\
\hline Methods & Randomised controlled trial. \\
\hline Participants & $\begin{array}{l}\text { Iranian trial in progress. Pregnant women with gestational diabetes, age } 18 \text { to } 45 \text { years, gestational } \\
\text { age } 24 \text { to } 32 \text { weeks'. }\end{array}$ \\
\hline Interventions & $\begin{array}{l}\text { Stress management training with 6, 2-hour sessions of cognitive-behavioural group-based treat- } \\
\text { ment }\end{array}$ \\
versus \\
routine prenatal care.
\end{tabular}

\begin{tabular}{ll}
\hline Outcomes & $\begin{array}{l}\text { Primary outcomes - fasting blood sugar, stress. } \\
\text { Secondary outcomes - anxiety, depression. }\end{array}$ \\
\hline Starting date & 2014. \\
\hline Contact information & najarshanaz@yahoo.com \\
\hline Notes & \\
\hline
\end{tabular}

\section{Ziegler DRKS00000465}

$\begin{array}{ll}\text { Trial name or title } & \text { MuKiS - Mother-child sports - a study to evaluate the impact of exercise on maternal metabolism } \\ \text { and fetal development in women with gestational diabetes. }\end{array}$
and fetal development in women with gestational diabetes.

\begin{tabular}{ll}
\hline Methods & Randomised controlled trial, open-label. \\
\hline Participants & 60 women with gestational diabetes in Munich, Germany. Age > 18 years, 24 to 30 weeks' gestation. \\
\hline Interventions & $\begin{array}{l}\text { Supervised physical activity twice a week for } 45 \text { minutes including walking and bicycle ergometry } \\
\text { plus diet as recommended by the German Diabetes Society } \\
\text { versus } \\
\text { diet therapy alone. }\end{array}$ \\
\hline Outcomes & $\begin{array}{l}\text { Participation rates, mood, cardiovascular measurements, maternal biomarkers, fetal abdominal } \\
\text { circumference, polyhydramnios, caesarean section rate, birthweight, macrosomia, cardiac hyper- } \\
\text { trophy. }\end{array}$ \\
\hline Starting date & 2009. \\
\hline Contact information & anziegler@lrz.uni-muenchen.de; Lydia.Henneberger@lrz.uni-muenchen.de \\
\hline Notes &
\end{tabular}

LGA: large-for-gestational age

OGTT: oral glucose tolerance test

GDM: gestational diabetes mellitus 
NICU: neonatal intensive care unit

\section{DATA AND ANALYSES}

\section{Comparison 1. Lifestyle intervention versus usual care/control}

\begin{tabular}{|c|c|c|c|c|}
\hline Outcome or subgroup title & No. of studies & $\begin{array}{l}\text { No. of partici- } \\
\text { pants }\end{array}$ & Statistical method & Effect size \\
\hline $\begin{array}{l}1 \text { Hypertensive disorders of preg- } \\
\text { nancy (including pre-eclampsia, } \\
\text { pregnancy-induced hypertension, } \\
\text { eclampsia) }\end{array}$ & 4 & 2796 & $\begin{array}{l}\text { Risk Ratio (M-H, Random, 95\% } \\
\mathrm{Cl} \text { ) }\end{array}$ & $0.70[0.40,1.22]$ \\
\hline 1.1 World Health Organization 1999 & 1 & 1000 & $\begin{array}{l}\text { Risk Ratio (M-H, Random, 95\% } \\
\text { Cl) }\end{array}$ & $0.65[0.48,0.88]$ \\
\hline 1.2 ADA 2013 & 2 & 1096 & $\begin{array}{l}\text { Risk Ratio (M-H, Random, 95\% } \\
\text { Cl) }\end{array}$ & $0.44[0.18,1.06]$ \\
\hline 1.3 IADPSG 2010 & 1 & 700 & $\begin{array}{l}\text { Risk Ratio (M-H, Random, 95\% } \\
\text { CI) }\end{array}$ & $2.40[1.06,5.44]$ \\
\hline 2 Caesarean section & 10 & 3545 & $\begin{array}{l}\text { Risk Ratio (M-H, Random, 95\% } \\
\text { Cl) }\end{array}$ & $0.90[0.78,1.05]$ \\
\hline 2.1 WHO 1999/ADIPS 1998 & 4 & 1250 & $\begin{array}{l}\text { Risk Ratio (M-H, Random, 95\% } \\
\text { Cl) }\end{array}$ & $0.89[0.78,1.02]$ \\
\hline 2.2 ADA 2013 & 2 & 1096 & $\begin{array}{l}\text { Risk Ratio (M-H, Random, 95\% } \\
\text { Cl) }\end{array}$ & $0.63[0.33,1.22]$ \\
\hline 2.3 IADPSG 2010 & 1 & 700 & $\begin{array}{l}\text { Risk Ratio (M-H, Random, 95\% } \\
\mathrm{Cl})\end{array}$ & $1.09[0.99,1.21]$ \\
\hline 2.4 Other/not specified & 3 & 499 & $\begin{array}{l}\text { Risk Ratio (M-H, Random, 95\% } \\
\mathrm{Cl})\end{array}$ & $0.94[0.65,1.38]$ \\
\hline 3 Development of type 2 diabetes & 2 & 486 & Risk Ratio (M-H, Fixed, 95\% Cl) & $0.98[0.54,1.76]$ \\
\hline $\begin{array}{l}4 \text { Perinatal (fetal and neonatal } \\
\text { death) and later infant mortality }\end{array}$ & 2 & 1988 & Risk Ratio (M-H, Fixed, 95\% Cl) & $0.09[0.01,1.70]$ \\
\hline 5 Large-for-gestational age & 6 & 2994 & Risk Ratio (M-H, Fixed, 95\% Cl) & $0.60[0.50,0.71]$ \\
\hline $\begin{array}{l}6 \text { Death or serious morbidity com- } \\
\text { posite (variously defined by trials, } \\
\text { e.g. perinatal or infant death, shoul- } \\
\text { der dystocia, bone fracture or nerve } \\
\text { palsy) }\end{array}$ & 2 & 1930 & $\begin{array}{l}\text { Risk Ratio (M-H, Random, 95\% } \\
\text { Cl) }\end{array}$ & $0.57[0.21,1.55]$ \\
\hline $\begin{array}{l}7 \text { Use of additional pharmacothera- } \\
\text { py }\end{array}$ & 9 & & $\begin{array}{l}\text { Risk Ratio (M-H, Random, 95\% } \\
\mathrm{Cl})\end{array}$ & Subtotals only \\
\hline $\begin{array}{l}7.1 \text { Use of anti-diabetic oral medica- } \\
\text { tion }\end{array}$ & 1 & 197 & $\begin{array}{l}\text { Risk Ratio (M-H, Random, 95\% } \\
\mathrm{Cl} \text { ) }\end{array}$ & $0.79[0.52,1.19]$ \\
\hline
\end{tabular}




\begin{tabular}{|c|c|c|c|c|}
\hline Outcome or subgroup title & No. of studies & $\begin{array}{l}\text { No. of partici- } \\
\text { pants }\end{array}$ & Statistical method & Effect size \\
\hline 7.2 Use of insulin treatment & 9 & 3254 & $\begin{array}{l}\text { Risk Ratio (M-H, Random, 95\% } \\
\mathrm{Cl})\end{array}$ & $2.54[1.19,5.42]$ \\
\hline 8 Maternal hypoglycaemia & 1 & 19 & Risk Ratio (M-H, Fixed, 95\% Cl) & $0.0[0.0,0.0]$ \\
\hline $\begin{array}{l}9 \text { Glycaemic control during/end } \\
\text { treatment }\end{array}$ & 7 & & $\begin{array}{l}\text { Mean Difference (IV, Random, } \\
95 \% \mathrm{CI} \text { ) }\end{array}$ & Subtotals only \\
\hline $\begin{array}{l}9.1 \text { Fasting blood glucose concen- } \\
\text { tration } \mathrm{mg} / \mathrm{dL}\end{array}$ & 6 & 853 & $\begin{array}{l}\text { Mean Difference (IV, Random, } \\
95 \% \mathrm{CI})\end{array}$ & $-3.10[-7.01,0.81]$ \\
\hline $\begin{array}{l}9.2 \text { Postprandial blood glucose con- } \\
\text { centration } \mathrm{mg} / \mathrm{dL}\end{array}$ & 4 & 588 & $\begin{array}{l}\text { Mean Difference (IV, Random, } \\
95 \% \mathrm{CI})\end{array}$ & $\begin{array}{l}-27.11[-44.62 \\
-9.61]\end{array}$ \\
\hline $9.3 \mathrm{HbA} 1 \mathrm{c} \mathrm{mmol} / \mathrm{mol}$ & 6 & 532 & $\begin{array}{l}\text { Mean Difference (IV, Random, } \\
95 \% \mathrm{Cl})\end{array}$ & $-0.33[-0.47,-0.19]$ \\
\hline 10 Weight gain in pregnancy $(\mathrm{kg})$ & 4 & 2930 & $\begin{array}{l}\text { Mean Difference (IV, Random, } \\
95 \% \mathrm{CI})\end{array}$ & $-1.30[-2.26,-0.35]$ \\
\hline 11 Induction of labour & 4 & 2699 & $\begin{array}{l}\text { Risk Ratio (M-H, Random, 95\% } \\
\text { Cl) }\end{array}$ & $1.20[0.99,1.46]$ \\
\hline 12 Postpartum haemorrhage & 2 & 1165 & $\begin{array}{l}\text { Risk Ratio (M-H, Random, 95\% } \\
\text { Cl) }\end{array}$ & $0.61[0.20,1.89]$ \\
\hline 13 Postnatal infection/pyrexia & 1 & 1000 & Risk Ratio (M-H, Fixed, 95\% Cl) & $0.61[0.34,1.10]$ \\
\hline 14 Perineal trauma/tear & 1 & 1000 & Risk Ratio (M-H, Fixed, 95\% Cl) & $1.04[0.93,1.18]$ \\
\hline $\begin{array}{l}15 \text { Breastfeeding at discharge, six } \\
\text { weeks postpartum, six months or } \\
\text { longer }\end{array}$ & 2 & & Risk Ratio (M-H, Fixed, 95\% Cl) & Subtotals only \\
\hline 15.1 At discharge & 1 & 1000 & Risk Ratio (M-H, Fixed, 95\% Cl) & $1.04[0.99,1.10]$ \\
\hline 15.2 At six months postpartum & 1 & 188 & Risk Ratio (M-H, Fixed, 95\% Cl) & $0.97[0.87,1.07]$ \\
\hline $\begin{array}{l}15.3 \text { Six months postpartum or } \\
\text { longer }\end{array}$ & 1 & 161 & Risk Ratio (M-H, Fixed, 95\% Cl) & $1.31[0.99,1.74]$ \\
\hline $\begin{array}{l}16 \text { Sense of well-being and quality } \\
\text { of lifeduring treatment }\end{array}$ & 2 & & $\begin{array}{l}\text { Mean Difference (IV, Fixed, 95\% } \\
\mathrm{CI} \text { ) }\end{array}$ & Subtotals only \\
\hline 16.1 Physical functioning & 2 & 847 & $\begin{array}{l}\text { Mean Difference (IV, Fixed, 95\% } \\
\mathrm{CI} \text { ) }\end{array}$ & $3.09[0.63,5.54]$ \\
\hline 16.2 Role physical & 2 & 847 & $\begin{array}{l}\text { Mean Difference (IV, Fixed, 95\% } \\
\mathrm{Cl})\end{array}$ & $7.94[3.29,12.59]$ \\
\hline 16.3 Bodily pain & 2 & 847 & $\begin{array}{l}\text { Mean Difference (IV, Fixed, 95\% } \\
\mathrm{Cl} \text { ) }\end{array}$ & $3.69[1.33,6.05]$ \\
\hline 16.4 General health & 2 & 847 & $\begin{array}{l}\text { Mean Difference (IV, Fixed, 95\% } \\
\mathrm{CI} \text { ) }\end{array}$ & $1.76[0.30,3.21]$ \\
\hline
\end{tabular}




\begin{tabular}{|c|c|c|c|c|}
\hline Outcome or subgroup title & No. of studies & $\begin{array}{l}\text { No. of partici- } \\
\text { pants }\end{array}$ & Statistical method & Effect size \\
\hline 16.5 Vitality & 2 & 847 & $\begin{array}{l}\text { Mean Difference (IV, Fixed, 95\% } \\
\mathrm{Cl})\end{array}$ & $2.71[0.88,4.54]$ \\
\hline 16.6 Social functioning & 2 & 847 & $\begin{array}{l}\text { Mean Difference (IV, Fixed, 95\% } \\
\mathrm{Cl})\end{array}$ & $3.27[0.81,5.74]$ \\
\hline 16.7 Role emotional & 2 & 847 & $\begin{array}{l}\text { Mean Difference (IV, Fixed, 95\% } \\
\mathrm{Cl})\end{array}$ & $9.08[4.49,13.67]$ \\
\hline 16.8 Mental health & 2 & 847 & $\begin{array}{l}\text { Mean Difference (IV, Fixed, 95\% } \\
\mathrm{CI} \text { ) }\end{array}$ & $0.90[-0.96,2.77]$ \\
\hline 16.9 Health state utility & 1 & 682 & $\begin{array}{l}\text { Mean Difference (IV, Fixed, 95\% } \\
\mathrm{Cl} \text { ) }\end{array}$ & $0.02[0.00,0.04]$ \\
\hline 16.10 Overall physical component & 1 & 682 & $\begin{array}{l}\text { Mean Difference (IV, Fixed, 95\% } \\
\mathrm{CI} \text { ) }\end{array}$ & $1.5[0.12,2.88]$ \\
\hline 16.11 Overall mental component & 1 & 682 & $\begin{array}{l}\text { Mean Difference (IV, Fixed, 95\% } \\
\mathrm{CI} \text { ) }\end{array}$ & $1.30[-0.17,2.77]$ \\
\hline 16.12 Anxiety & 1 & 682 & $\begin{array}{l}\text { Mean Difference (IV, Fixed, 95\% } \\
\mathrm{Cl} \text { ) }\end{array}$ & $-0.30[-0.88,0.28]$ \\
\hline $\begin{array}{l}17 \text { Sense of well-being and quality } \\
\text { of life three months postpartum }\end{array}$ & 2 & & $\begin{array}{l}\text { Mean Difference (IV, Random, } \\
95 \% \mathrm{CI})\end{array}$ & Subtotals only \\
\hline $\begin{array}{l}\text { 17.1 Physical functioning } 3 \text { months } \\
\text { postpartum }\end{array}$ & 2 & 738 & $\begin{array}{l}\text { Mean Difference (IV, Random, } \\
95 \% \mathrm{CI})\end{array}$ & $5.05[-0.91,11.02]$ \\
\hline $\begin{array}{l}17.2 \text { Physical role } 3 \text { months postpar- } \\
\text { tum }\end{array}$ & 2 & 738 & $\begin{array}{l}\text { Mean Difference (IV, Random, } \\
95 \% \mathrm{CI})\end{array}$ & $8.45[-3.21,20.12]$ \\
\hline $\begin{array}{l}17.3 \text { Bodily pain } 3 \text { months postpar- } \\
\text { tum }\end{array}$ & 2 & 738 & $\begin{array}{l}\text { Mean Difference (IV, Random, } \\
95 \% \mathrm{CI})\end{array}$ & $2.37[-1.03,5.77]$ \\
\hline $\begin{array}{l}17.4 \text { General health } 3 \text { months post- } \\
\text { partum }\end{array}$ & 2 & 738 & $\begin{array}{l}\text { Mean Difference (IV, Random, } \\
95 \% \mathrm{CI})\end{array}$ & $3.98[-0.46,8.43]$ \\
\hline 17.5 Vitality 3 months postpartum & 2 & 738 & $\begin{array}{l}\text { Mean Difference (IV, Random, } \\
95 \% \mathrm{Cl})\end{array}$ & $4.47[-1.67,10.62]$ \\
\hline 17.6 Social functioning 3 months & 2 & 738 & $\begin{array}{l}\text { Mean Difference (IV, Random, } \\
95 \% \mathrm{CI} \text { ) }\end{array}$ & $9.73[5.17,14.28]$ \\
\hline $\begin{array}{l}\text { 17.7 Role emotional } 3 \text { months post- } \\
\text { partum }\end{array}$ & 2 & 738 & $\begin{array}{l}\text { Mean Difference (IV, Random, } \\
95 \% \mathrm{CI} \text { ) }\end{array}$ & $6.92[-8.24,22.08]$ \\
\hline $\begin{array}{l}17.8 \text { Mental health } 3 \text { months post- } \\
\text { partum }\end{array}$ & 2 & 738 & $\begin{array}{l}\text { Mean Difference (IV, Random, } \\
95 \% \mathrm{CI} \text { ) }\end{array}$ & $-0.09[-2.58,2.40]$ \\
\hline $\begin{array}{l}17.9 \text { Health state utility } 3 \text { months } \\
\text { postpartum }\end{array}$ & 1 & 573 & $\begin{array}{l}\text { Mean Difference (IV, Random, } \\
95 \% \mathrm{Cl})\end{array}$ & $0.01[-0.01,0.03]$ \\
\hline
\end{tabular}




\begin{tabular}{|c|c|c|c|c|}
\hline Outcome or subgroup title & No. of studies & $\begin{array}{l}\text { No. of partici- } \\
\text { pants }\end{array}$ & Statistical method & Effect size \\
\hline $\begin{array}{l}17.10 \text { Overall physical component } 3 \\
\text { months postpartum }\end{array}$ & 1 & 573 & $\begin{array}{l}\text { Mean Difference (IV, Random, } \\
95 \% \mathrm{CI} \text { ) }\end{array}$ & $1.20[-0.19,2.59]$ \\
\hline $\begin{array}{l}17.11 \text { Overall mental component } 3 \\
\text { months postpartum }\end{array}$ & 1 & 573 & $\begin{array}{l}\text { Mean Difference (IV, Random, } \\
95 \% \mathrm{Cl} \text { ) }\end{array}$ & $0.20[-1.51,1.91]$ \\
\hline $\begin{array}{l}17.12 \text { Anxiety scores } 3 \text { months post- } \\
\text { partum }\end{array}$ & 1 & 573 & $\begin{array}{l}\text { Mean Difference (IV, Random, } \\
95 \% \mathrm{Cl} \text { ) }\end{array}$ & $-0.20[-0.83,0.43]$ \\
\hline 18 Postnatal depression & 1 & 573 & Risk Ratio (M-H, Fixed, 95\% Cl) & $0.49[0.31,0.78]$ \\
\hline $\begin{array}{l}19 \text { Postnatal weight retention or re- } \\
\text { turn to pre-pregnancy weight }\end{array}$ & 1 & & Risk Ratio (M-H, Fixed, 95\% Cl) & Subtotals only \\
\hline 19.1 Six weeks postpartum & 1 & 189 & Risk Ratio (M-H, Fixed, 95\% Cl) & $1.20[0.67,2.17]$ \\
\hline 19.2 Seven months postpartum & 1 & 159 & Risk Ratio (M-H, Fixed, 95\% Cl) & $1.59[0.99,2.57]$ \\
\hline 19.312 months postpartum & 1 & 156 & Risk Ratio (M-H, Fixed, 95\% Cl) & $1.75[1.05,2.90]$ \\
\hline $\begin{array}{l}20 \text { Fasting plasma glucose } 3 \text { months } \\
\text { postpartum } \mathrm{mmol} / \mathrm{L}\end{array}$ & 1 & & $\begin{array}{l}\text { Mean Difference (IV, Fixed, 95\% } \\
\mathrm{Cl} \text { ) }\end{array}$ & Subtotals only \\
\hline 20.1 Three months postpartum & 1 & 165 & $\begin{array}{l}\text { Mean Difference (IV, Fixed, 95\% } \\
\mathrm{CI})\end{array}$ & $-0.08[-0.16,0.00]$ \\
\hline 20.2 Six months postpartum & 1 & 165 & $\begin{array}{l}\text { Mean Difference (IV, Fixed, 95\% } \\
\mathrm{CI})\end{array}$ & $-0.14[-0.22,-0.06]$ \\
\hline $\begin{array}{l}21 \text { Maternal postnatal impaired glu- } \\
\text { cose tolerance }\end{array}$ & 1 & 56 & Risk Ratio (M-H, Fixed, 95\% Cl) & $0.67[0.12,3.69]$ \\
\hline $\begin{array}{l}22 \text { Maternal metabolic syndrome } \\
\text { (follow-up) }\end{array}$ & 1 & 430 & Risk Ratio (M-H, Fixed, 95\% Cl) & $0.93[0.71,1.22]$ \\
\hline 23 Stillbirth & 4 & 2355 & Risk Ratio (M-H, Fixed, 95\% Cl) & $0.15[0.01,2.86]$ \\
\hline 24 Neonatal death & 5 & 3055 & Risk Ratio (M-H, Fixed, 95\% Cl) & $0.73[0.22,2.42]$ \\
\hline 25 Macrosomia & 7 & 3422 & $\begin{array}{l}\text { Risk Ratio (M-H, Random, 95\% } \\
\text { Cl) }\end{array}$ & $0.64[0.48,0.87]$ \\
\hline 26 Small-for-gestational age & 4 & 2324 & Risk Ratio (M-H, Fixed, 95\% Cl) & $0.98[0.73,1.31]$ \\
\hline $\begin{array}{l}27 \text { Birth trauma (shoulder dystocia, } \\
\text { bone fracture, nerve palsy) }\end{array}$ & 6 & & Risk Ratio (M-H, Fixed, 95\% Cl) & Subtotals only \\
\hline 27.1 Birth trauma not specified & 3 & 1930 & Risk Ratio (M-H, Fixed, 95\% Cl) & $0.48[0.12,1.90]$ \\
\hline 27.2 Bone fracture & 2 & 1730 & Risk Ratio (M-H, Fixed, 95\% Cl) & $0.35[0.01,8.45]$ \\
\hline 27.3 Nerve palsy & 1 & 1030 & Risk Ratio (M-H, Fixed, 95\% Cl) & $0.15[0.01,2.86]$ \\
\hline 27.4 Shoulder dystocia & 5 & 2894 & Risk Ratio (M-H, Fixed, 95\% Cl) & $0.38[0.21,0.66]$ \\
\hline
\end{tabular}




\begin{tabular}{|c|c|c|c|c|}
\hline Outcome or subgroup title & No. of studies & $\begin{array}{l}\text { No. of partici- } \\
\text { pants }\end{array}$ & Statistical method & Effect size \\
\hline 28 Gestational age at birth (weeks) & 5 & 2057 & $\begin{array}{l}\text { Mean Difference (IV, Fixed, 95\% } \\
\mathrm{CI})\end{array}$ & $0.04[-0.13,0.20]$ \\
\hline $\begin{array}{l}29 \text { Preterm birth }(<37 \text { weeks' gesta- } \\
\text { tion; and }<32 \text { weeks' gestation) }\end{array}$ & 3 & 1797 & Risk Ratio (M-H, Fixed, 95\% Cl) & $0.71[0.53,0.96]$ \\
\hline $\begin{array}{l}30 \text { Five-minute Apgar less than sev- } \\
\text { en }\end{array}$ & 1 & 1030 & Risk Ratio (M-H, Fixed, 95\% Cl) & $0.56[0.21,1.52]$ \\
\hline 31 Birthweight (grams) & 6 & 3074 & $\begin{array}{l}\text { Mean Difference (IV, Fixed, 95\% } \\
\mathrm{CI} \text { ) }\end{array}$ & $\begin{array}{l}-109.64[-149.77 \\
-69.51]\end{array}$ \\
\hline 32 Length $(\mathrm{cm})$ & 1 & 700 & $\begin{array}{l}\text { Mean Difference (IV, Fixed, 95\% } \\
\mathrm{CI})\end{array}$ & $-0.10[-0.37,0.17]$ \\
\hline 33 Adiposity (Neonatal fat mass (g)) & 1 & 958 & $\begin{array}{l}\text { Mean Difference (IV, Fixed, 95\% } \\
\mathrm{CI})\end{array}$ & $\begin{array}{l}-37.30[-63.97 \\
-10.63]\end{array}$ \\
\hline 34 Neonatal hypoglycaemia & 6 & 3000 & $\begin{array}{l}\text { Risk Ratio (M-H, Random, 95\% } \\
\mathrm{Cl} \text { ) }\end{array}$ & $0.99[0.65,1.52]$ \\
\hline 35 Respiratory distress syndrome & 4 & 2195 & $\begin{array}{l}\text { Risk Ratio (M-H, Random, 95\% } \\
\mathrm{Cl} \text { ) }\end{array}$ & $0.79[0.34,1.85]$ \\
\hline $\begin{array}{l}36 \text { Neonatal jaundice (hyperbilirubi- } \\
\text { naemia) }\end{array}$ & 4 & 2362 & $\begin{array}{l}\text { Risk Ratio (M-H, Random, 95\% } \\
\text { Cl) }\end{array}$ & $0.76[0.50,1.16]$ \\
\hline 37 Hypocalcaemia & 2 & 464 & Risk Ratio (M-H, Fixed, 95\% Cl) & $1.38[1.01,1.88]$ \\
\hline 38 Polycythemia & 1 & 165 & Risk Ratio (M-H, Fixed, 95\% Cl) & $0.22[0.01,5.40]$ \\
\hline 39 Childhood weight (kg) & 1 & 199 & $\begin{array}{l}\text { Mean Difference (IV, Fixed, 95\% } \\
\mathrm{CI})\end{array}$ & $-0.30[-1.29,0.69]$ \\
\hline 40 Childhood height (cm) & 1 & 199 & $\begin{array}{l}\text { Mean Difference (IV, Fixed, 95\% } \\
\mathrm{Cl} \text { ) }\end{array}$ & $-0.60[-2.05,0.85]$ \\
\hline $\begin{array}{l}41 \text { Adiposity (Childhood BMI > 85th } \\
\text { percentile) }\end{array}$ & 3 & 767 & Risk Ratio (M-H, Fixed, 95\% Cl) & $0.91[0.75,1.11]$ \\
\hline 42 Adiposity (BMI Z score childhood) & 1 & 199 & $\begin{array}{l}\text { Mean Difference (IV, Fixed, 95\% } \\
\mathrm{CI} \text { ) }\end{array}$ & $0.08[-0.28,0.44]$ \\
\hline $\begin{array}{l}43 \text { Childhood glycaemic control } \\
\text { (mmol/L) }\end{array}$ & 1 & & $\begin{array}{l}\text { Mean Difference (IV, Fixed, 95\% } \\
\mathrm{CI})\end{array}$ & Subtotals only \\
\hline 43.1 Fasting blood glucose & 1 & 68 & $\begin{array}{l}\text { Mean Difference (IV, Fixed, 95\% } \\
\mathrm{CI})\end{array}$ & $0.10[-0.10,0.30]$ \\
\hline $\begin{array}{l}43.2 \text { Two-hour postprandial blood } \\
\text { glucose }\end{array}$ & 1 & 68 & $\begin{array}{l}\text { Mean Difference (IV, Fixed, 95\% } \\
\mathrm{CI} \text { ) }\end{array}$ & $0.0[-0.48,0.48]$ \\
\hline $\begin{array}{l}44 \text { Dyslipidaemia or metabolic syn- } \\
\text { drome (Childhood cholesterol (mg/ } \\
\text { dL)) }\end{array}$ & 1 & & $\begin{array}{l}\text { Mean Difference (IV, Fixed, 95\% } \\
\mathrm{CI})\end{array}$ & Subtotals only \\
\hline
\end{tabular}




\begin{tabular}{|c|c|c|c|c|}
\hline Outcome or subgroup title & No. of studies & $\begin{array}{l}\text { No. of partici- } \\
\text { pants }\end{array}$ & Statistical method & Effect size \\
\hline 44.1 Total cholesterol & 1 & 68 & $\begin{array}{l}\text { Mean Difference (IV, Fixed, 95\% } \\
\mathrm{CI} \text { ) }\end{array}$ & $-0.20[-0.55,0.15]$ \\
\hline 44.2 LDL cholesterol & 1 & 68 & $\begin{array}{l}\text { Mean Difference (IV, Fixed, 95\% } \\
\mathrm{CI} \text { ) }\end{array}$ & $-0.12[-0.50,0.26]$ \\
\hline 44.3 HDL cholesterol & 1 & 68 & $\begin{array}{l}\text { Mean Difference (IV, Fixed, 95\% } \\
\mathrm{CI})\end{array}$ & $0.10[-0.05,0.25]$ \\
\hline $\begin{array}{l}45 \text { Number of antenatal visits or ad- } \\
\text { missions }\end{array}$ & 1 & 1000 & Risk Ratio (M-H, Fixed, 95\% Cl) & $1.06[0.87,1.29]$ \\
\hline $\begin{array}{l}46 \text { Number of hospital or health pro- } \\
\text { fessional visits (including midwife, } \\
\text { obstetrician, physician, dietician, di- } \\
\text { abetic nurse) }\end{array}$ & 1 & & Risk Ratio (M-H, Fixed, 95\% Cl) & Subtotals only \\
\hline 46.1 Dietitian & 1 & 1000 & Risk Ratio (M-H, Fixed, 95\% Cl) & $9.24[7.12,12.01]$ \\
\hline 46.2 Diabetes educator & 1 & 1000 & Risk Ratio (M-H, Fixed, 95\% Cl) & $8.55[6.67,10.96]$ \\
\hline $\begin{array}{l}47 \text { Number of hospital or health pro- } \\
\text { fessional visits (including midwife, } \\
\text { obstetrician, physician, dietician, di- } \\
\text { abetic nurse)l }\end{array}$ & 2 & & $\begin{array}{l}\text { Mean Difference (IV, Fixed, 95\% } \\
\mathrm{CI} \text { ) }\end{array}$ & Subtotals only \\
\hline 47.1 Obstetrician & 1 & 700 & $\begin{array}{l}\text { Mean Difference (IV, Fixed, 95\% } \\
\mathrm{CI} \text { ) }\end{array}$ & $0.20[-0.21,0.61]$ \\
\hline $\begin{array}{l}47.2 \text { Healthcare provider (not speci- } \\
\text { fied) }\end{array}$ & 1 & 197 & $\begin{array}{l}\text { Mean Difference (IV, Fixed, 95\% } \\
\mathrm{Cl} \text { ) }\end{array}$ & $0.10[-1.58,1.78]$ \\
\hline $\begin{array}{l}48 \text { Admission to neonatal intensive } \\
\text { care unit/nursery }\end{array}$ & 3 & 2030 & $\begin{array}{l}\text { Risk Ratio (M-H, Random, 95\% } \\
\mathrm{Cl} \text { ) }\end{array}$ & $0.91[0.59,1.40]$ \\
\hline
\end{tabular}

\section{Analysis 1.1. Comparison 1 Lifestyle intervention versus usual care/control, Outcome 1 Hypertensive disorders of pregnancy (including pre-eclampsia, pregnancy-induced hypertension, eclampsia).}

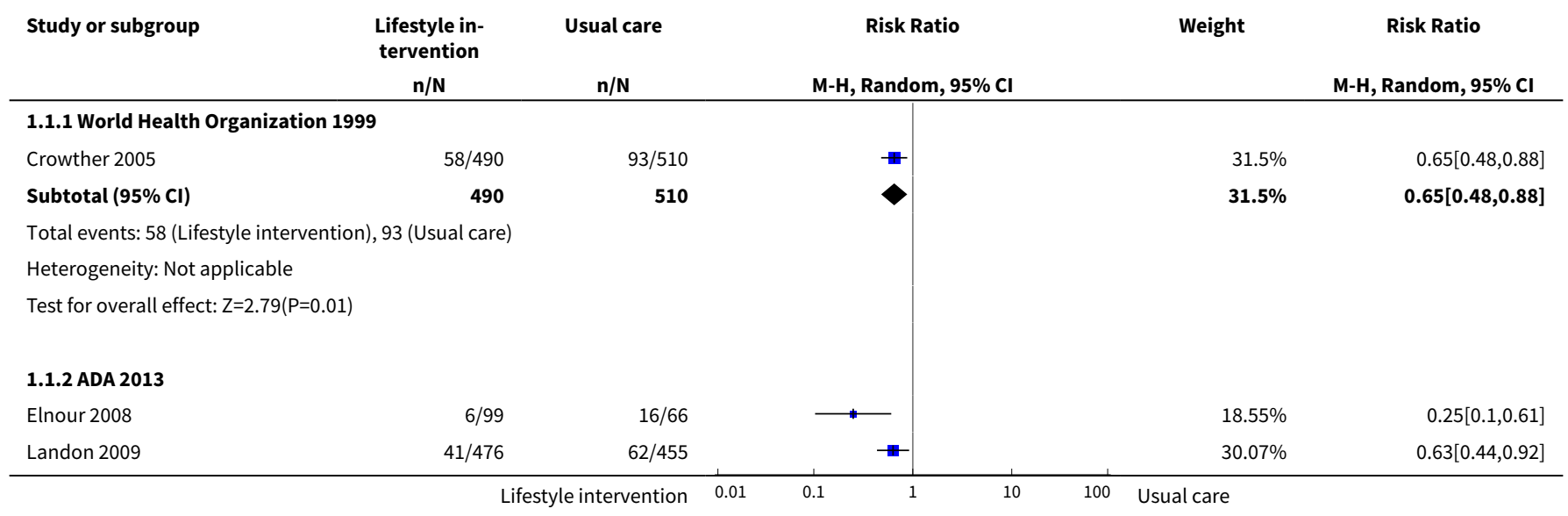




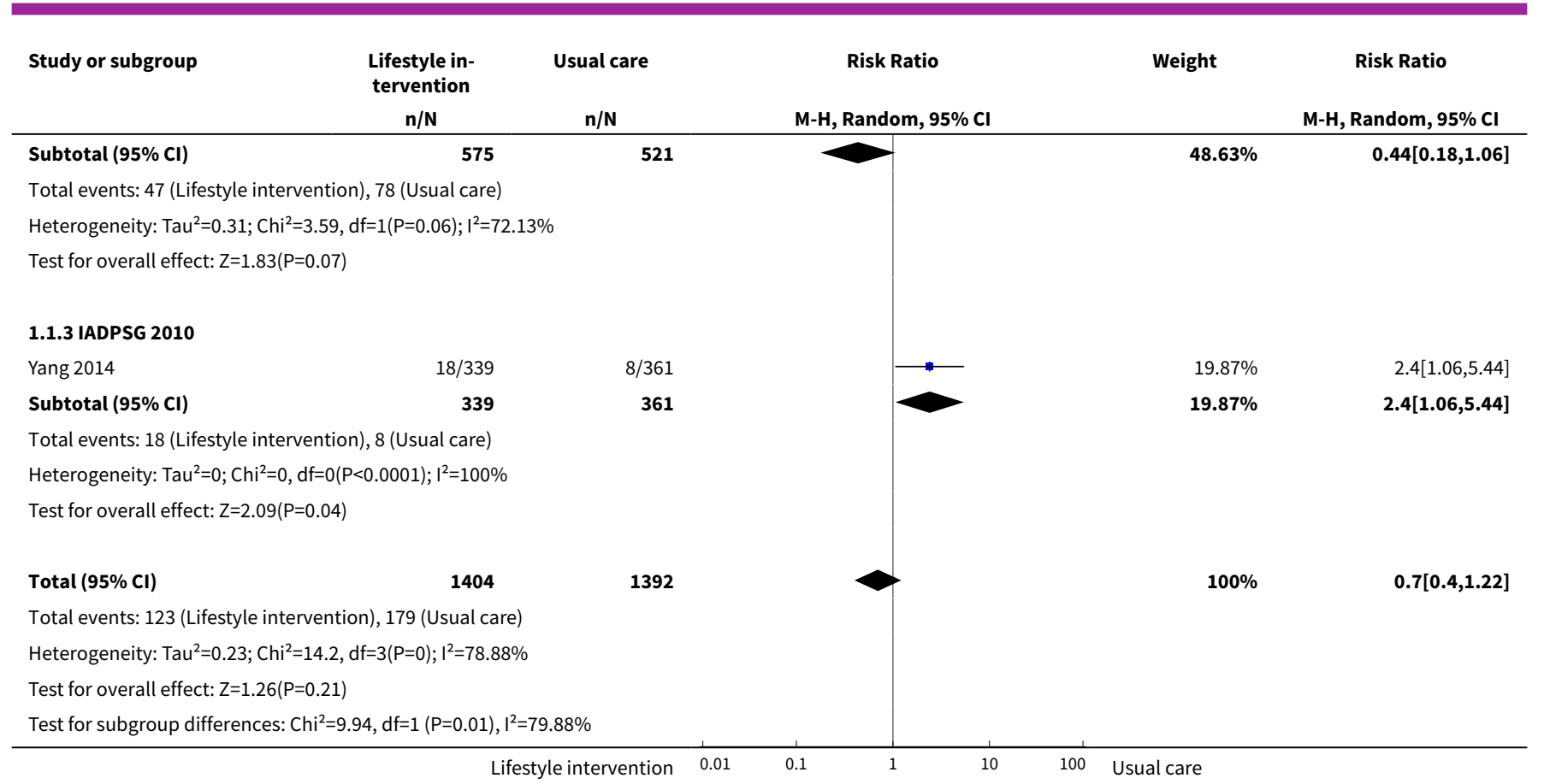

Analysis 1.2. Comparison 1 Lifestyle intervention versus usual care/control, Outcome 2 Caesarean section.

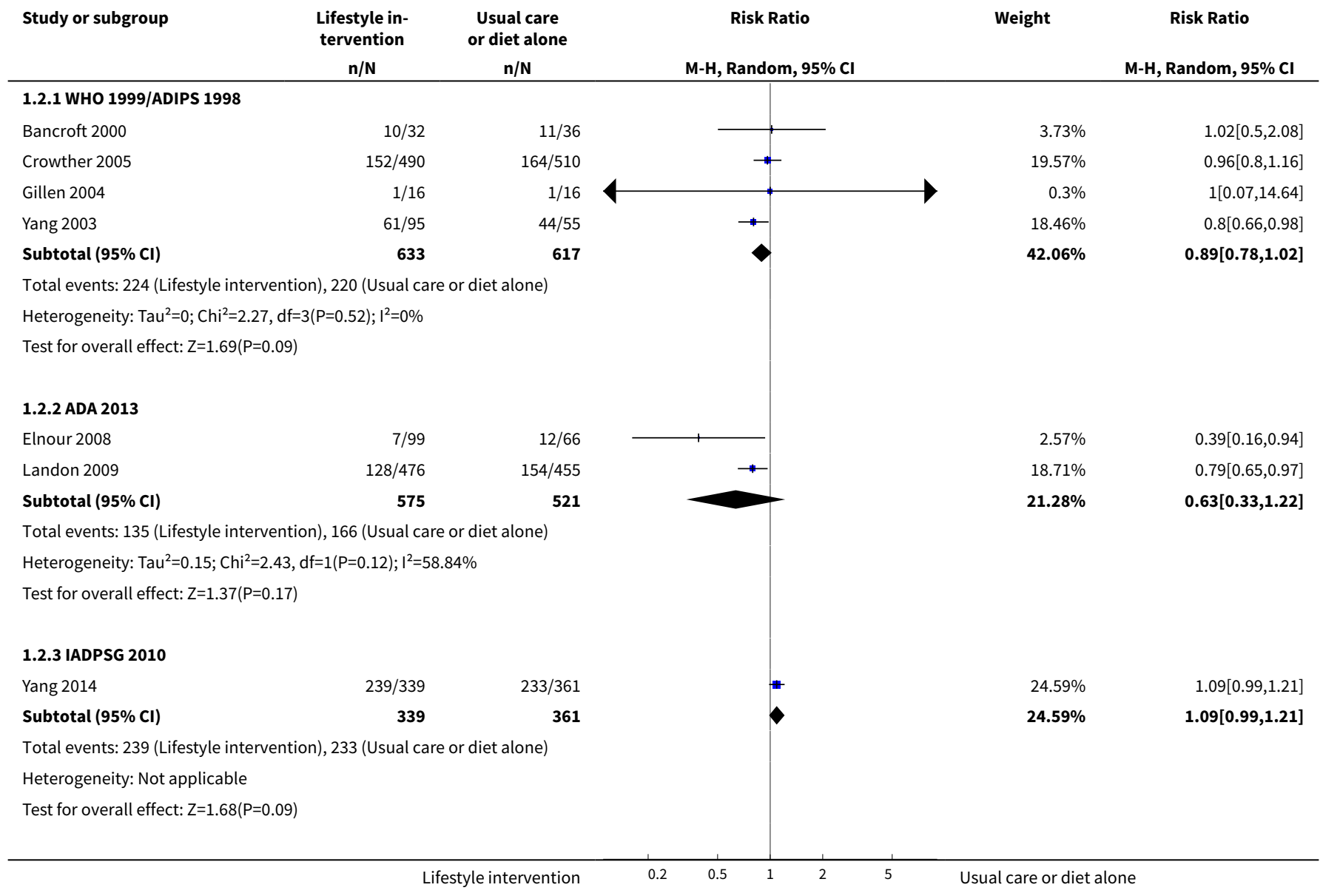




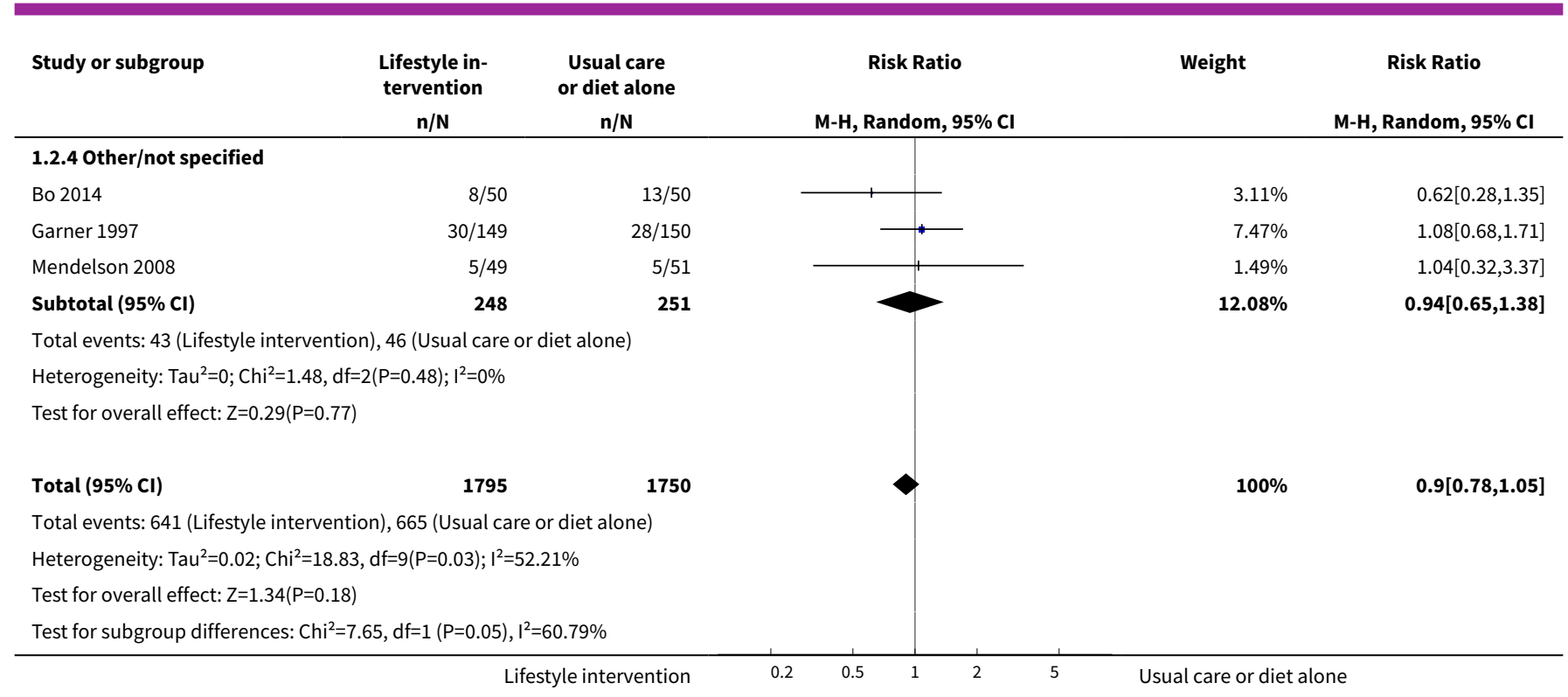

\section{Analysis 1.3. Comparison 1 Lifestyle intervention versus usual care/control, Outcome 3 Development of type 2 diabetes.}

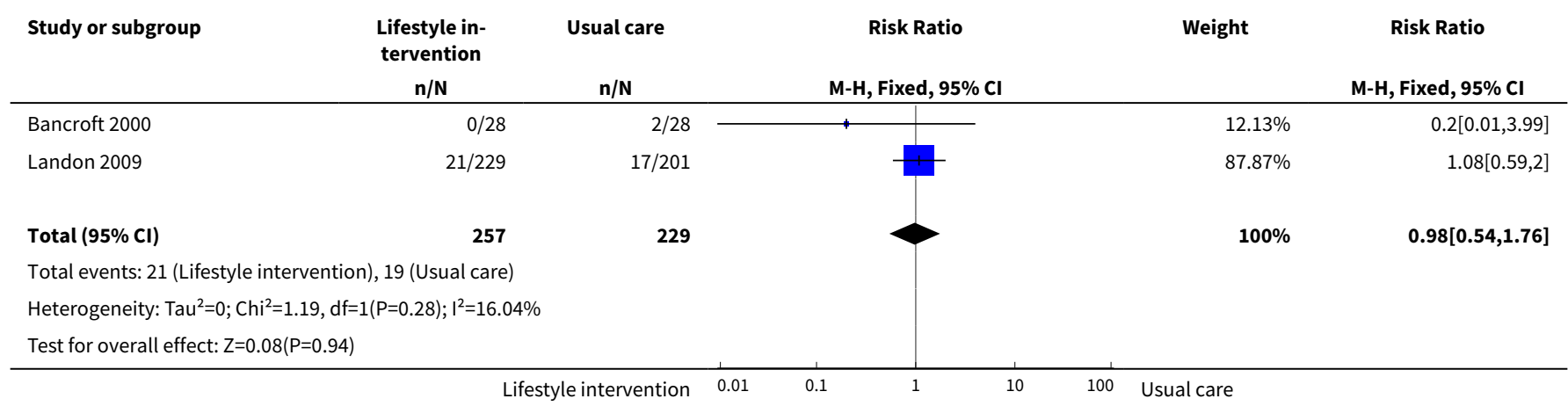

Analysis 1.4. Comparison 1 Lifestyle intervention versus usual care/control, Outcome 4 Perinatal (fetal and neonatal death) and later infant mortality.

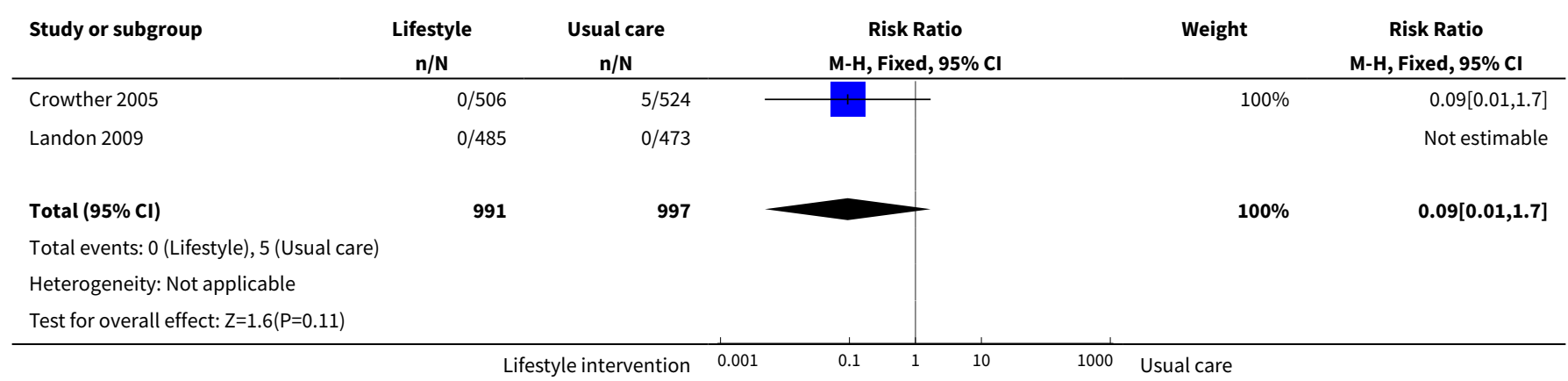


Analysis 1.5. Comparison 1 Lifestyle intervention versus usual care/control, Outcome 5 Large-for-gestational age.

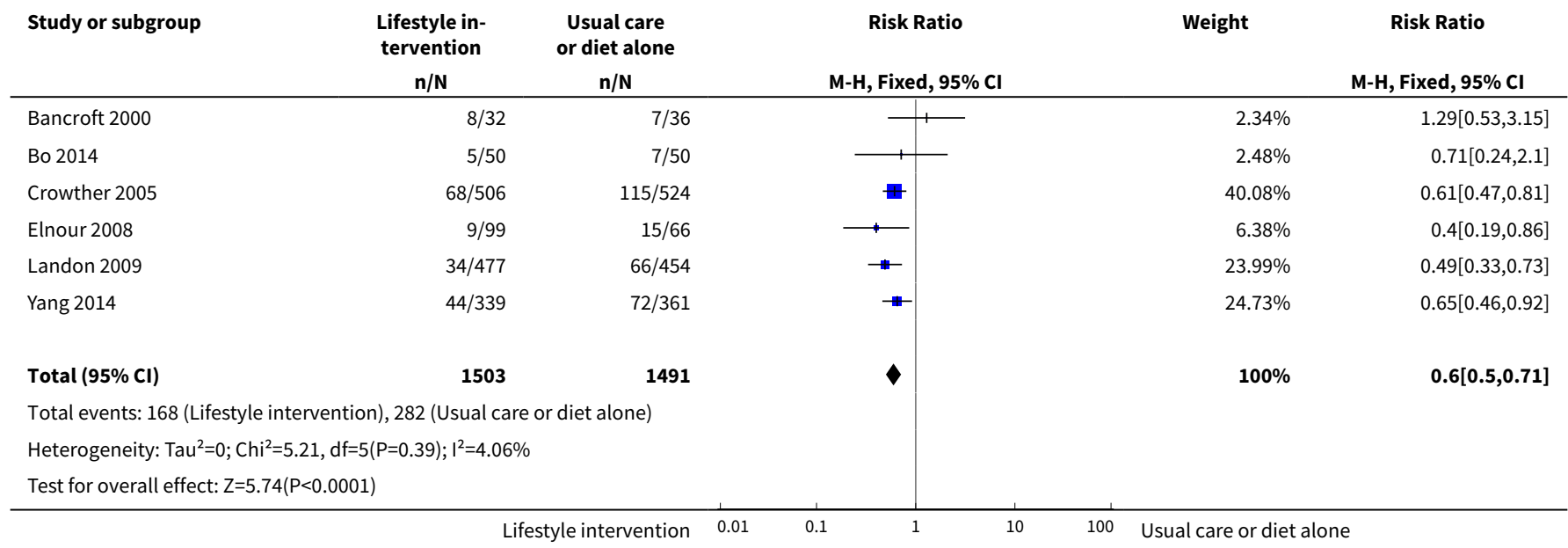

Analysis 1.6. Comparison 1 Lifestyle intervention versus usual care/control, Outcome 6 Death or serious morbidity composite (variously defined by trials, e.g. perinatal or infant death, shoulder dystocia, bone fracture or nerve palsy).

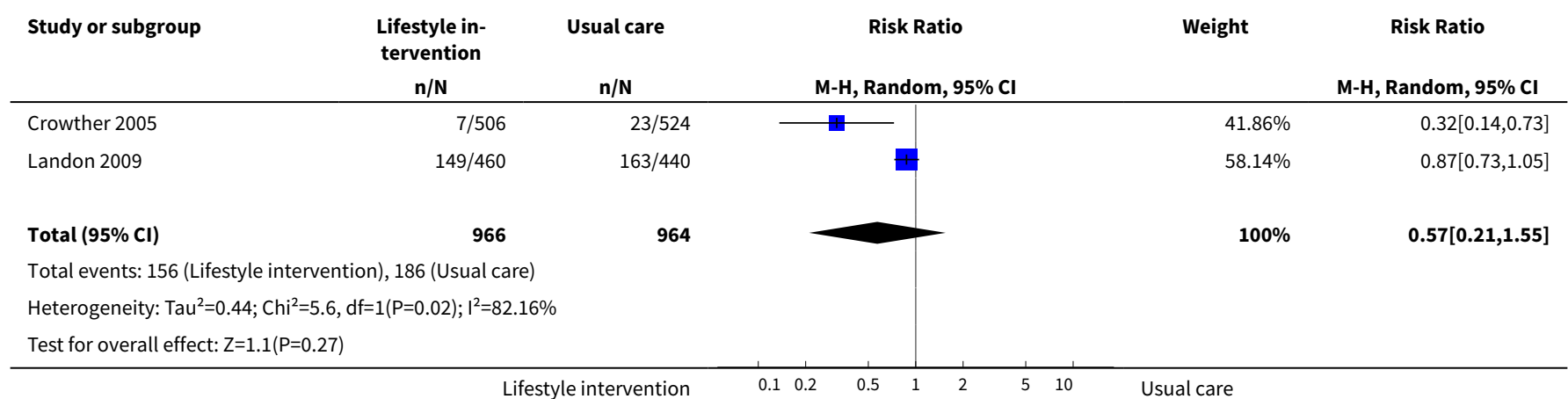

\section{Analysis 1.7. Comparison 1 Lifestyle intervention versus usual} care/control, Outcome 7 Use of additional pharmacotherapy.

$\begin{array}{ccccc}\text { Study or subgroup } & \begin{array}{c}\text { Lifestyle in- } \\ \text { tervention } \\ \mathrm{n} / \mathrm{N}\end{array} & \begin{array}{c}\text { Usual care } \\ \text { and diet alone } \\ \mathrm{n} / \mathrm{N}\end{array} & \text { Risk Ratio } & \text { Weight } \\ & \mathrm{M}-\mathrm{H}, \mathrm{Random}, 95 \% \mathrm{Cl} & \mathrm{M}-\mathrm{H}, \mathrm{Random}, 95 \% \mathrm{Cl}\end{array}$

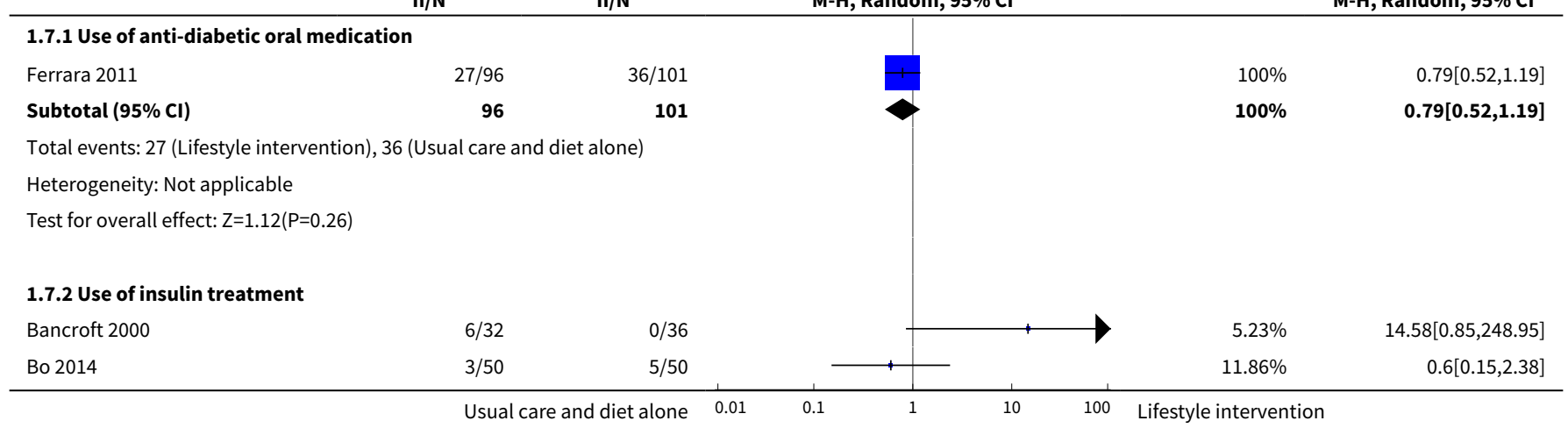




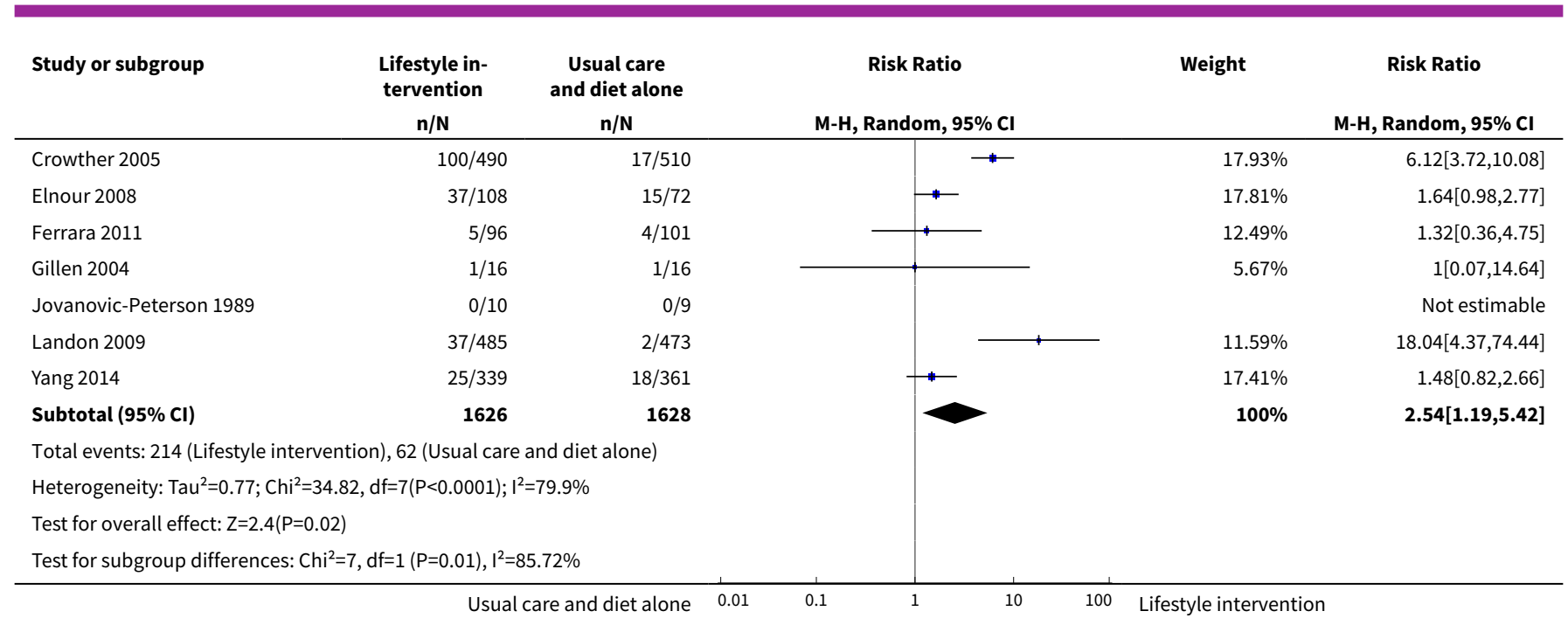

Analysis 1.8. Comparison 1 Lifestyle intervention versus usual care/control, Outcome 8 Maternal hypoglycaemia.

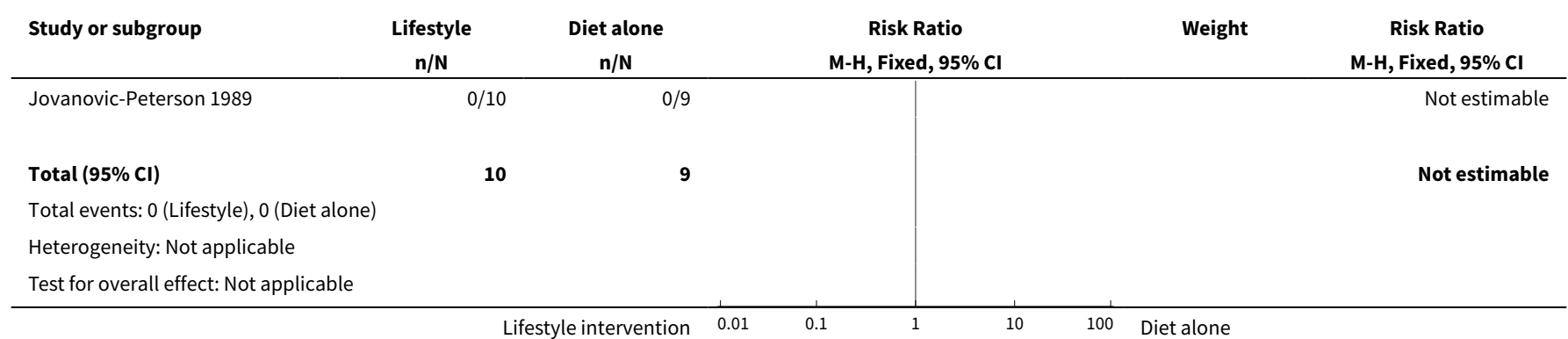

Analysis 1.9. Comparison 1 Lifestyle intervention versus usual care/control, Outcome 9 Glycaemic control during/end treatment.

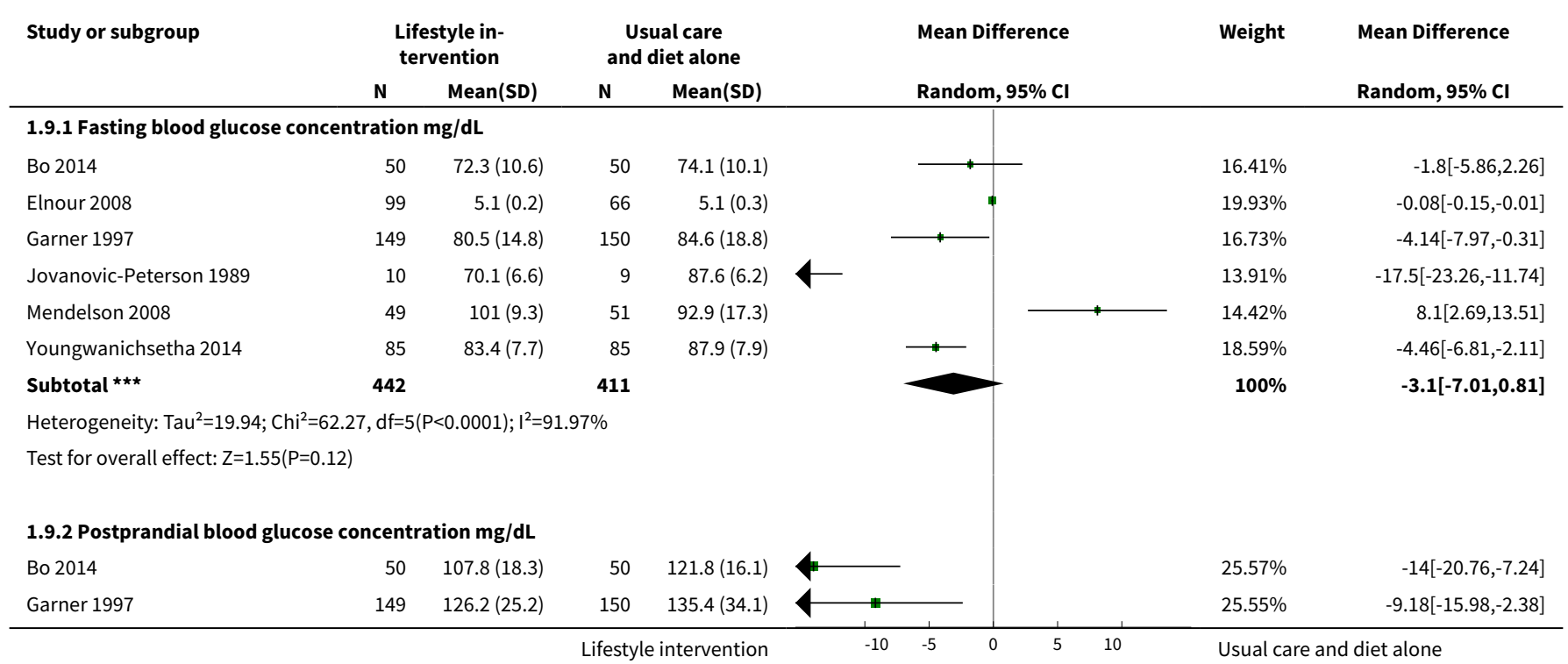




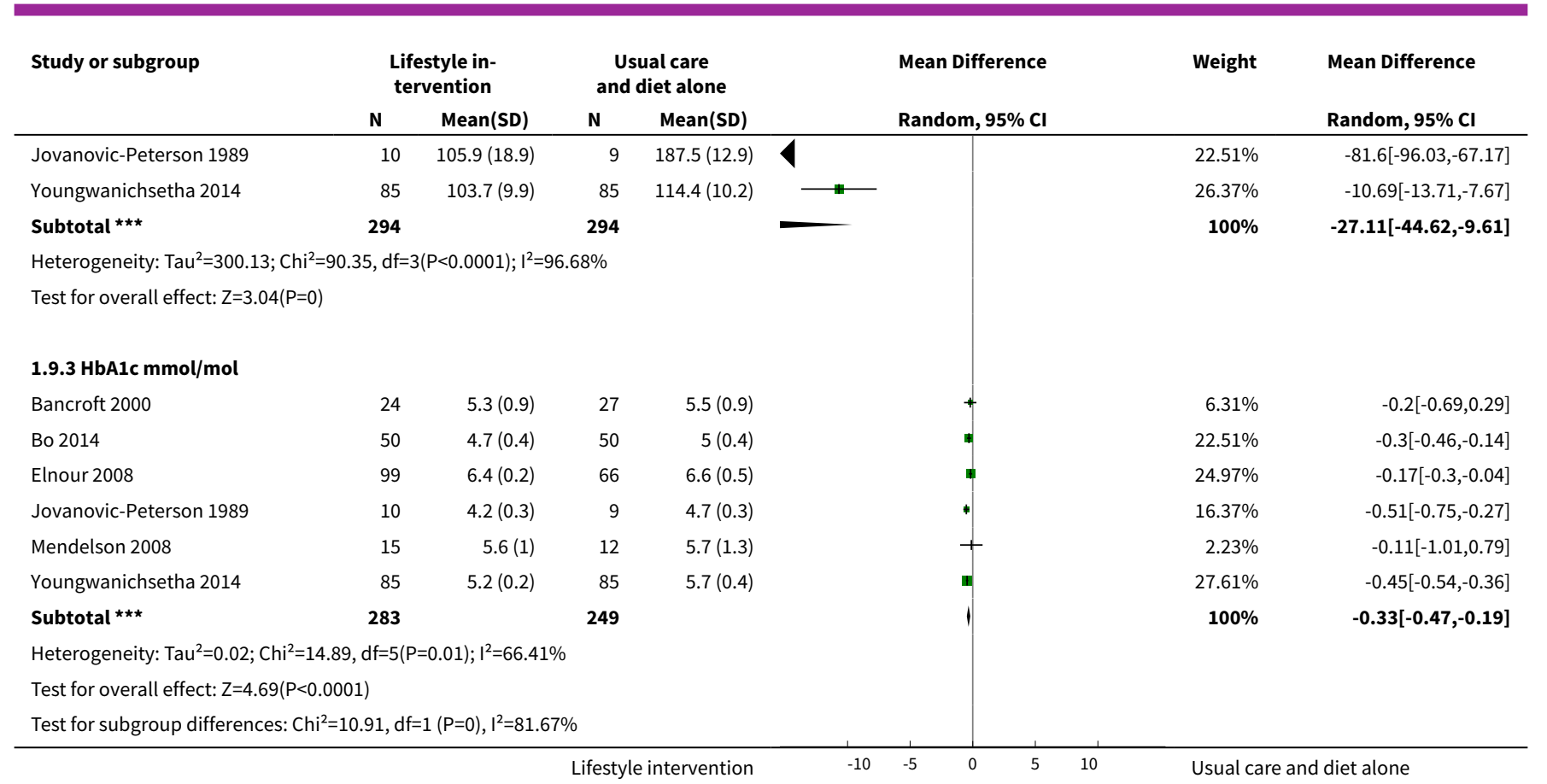

Analysis 1.10. Comparison 1 Lifestyle intervention versus usual care/control, Outcome 10 Weight gain in pregnancy (kg).

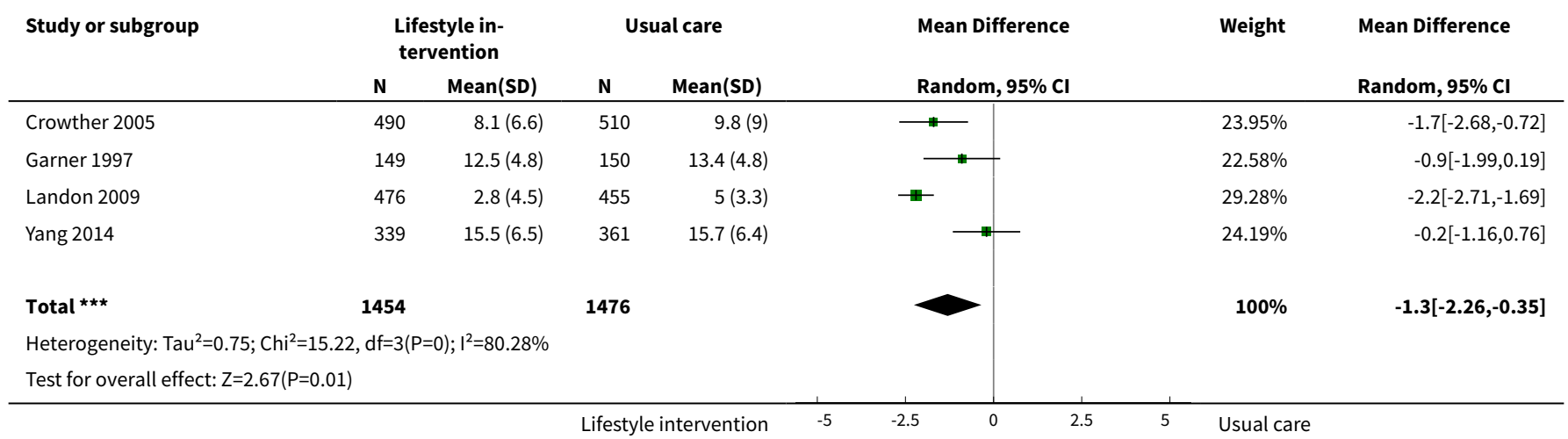

Analysis 1.11. Comparison 1 Lifestyle intervention versus usual care/control, Outcome 11 Induction of labour.

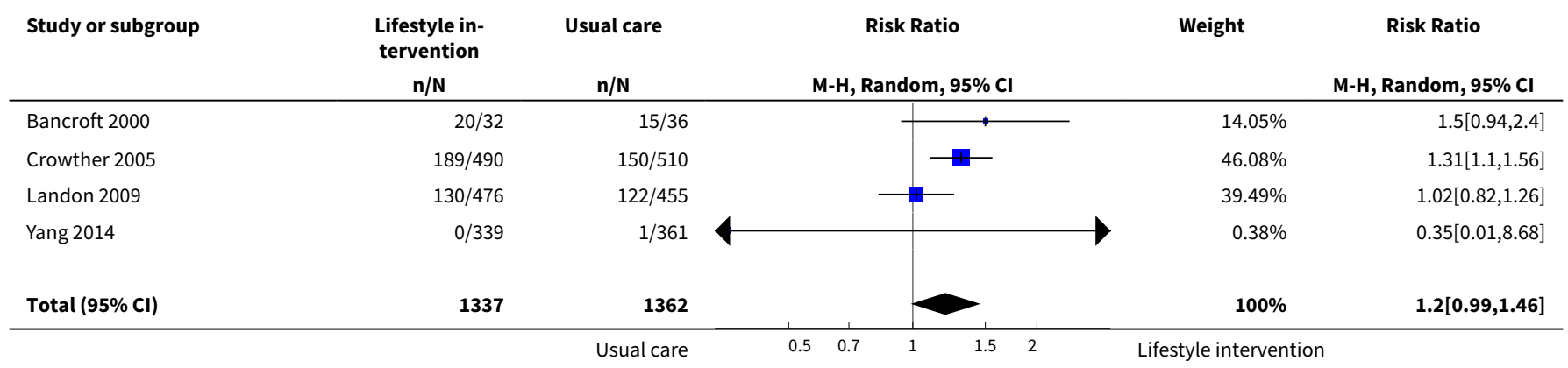




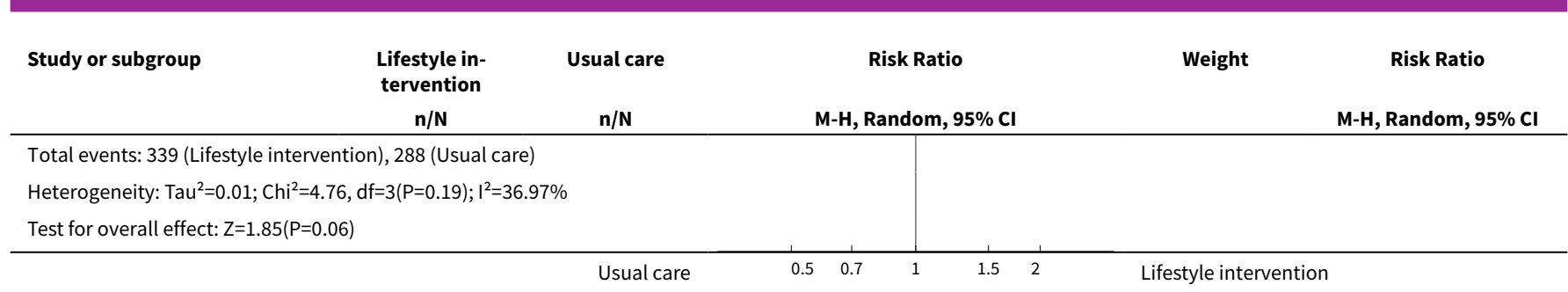

Analysis 1.12. Comparison 1 Lifestyle intervention versus usual care/control, Outcome 12 Postpartum haemorrhage.

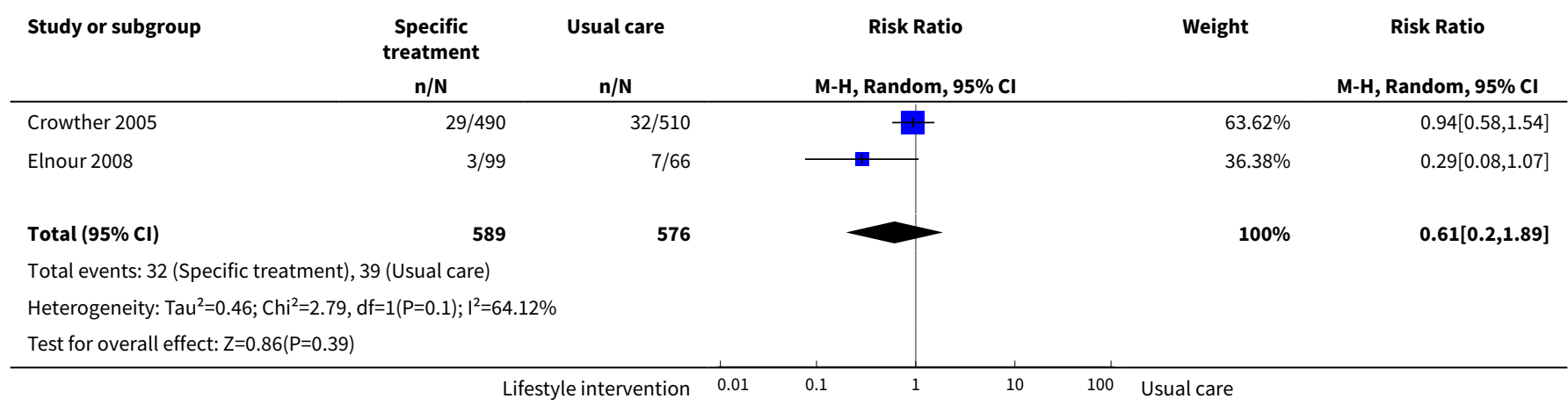

Analysis 1.13. Comparison 1 Lifestyle intervention versus usual care/control, Outcome 13 Postnatal infection/pyrexia.

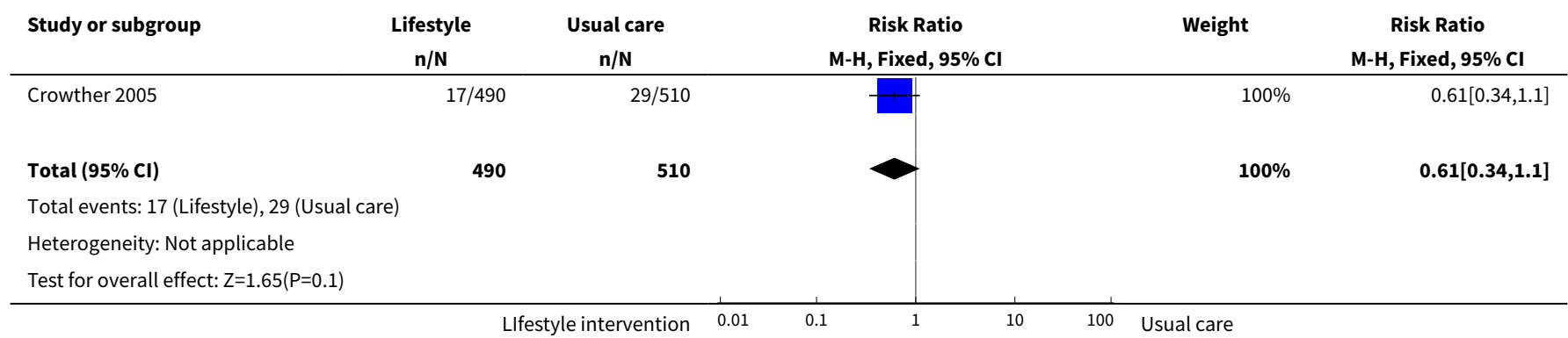

Analysis 1.14. Comparison 1 Lifestyle intervention versus usual care/control, Outcome 14 Perineal trauma/tear.

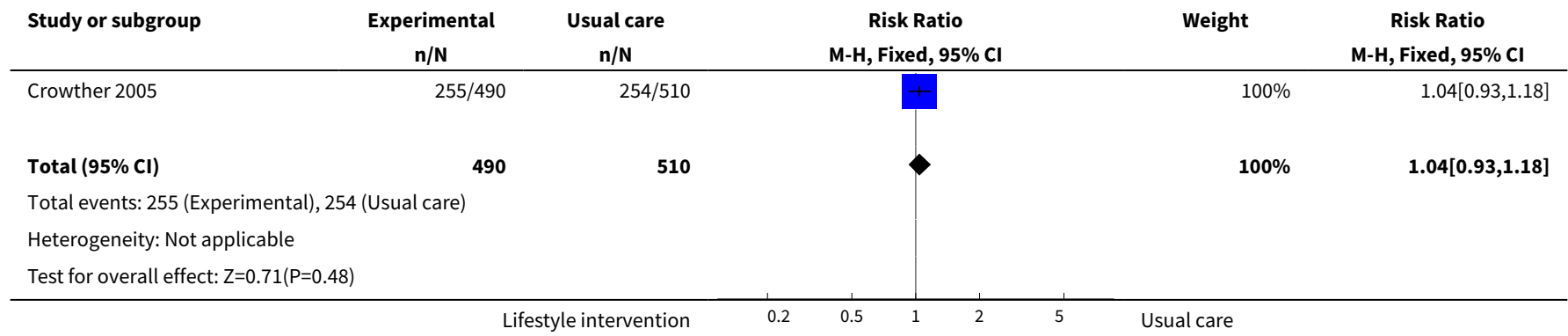


Analysis 1.15. Comparison 1 Lifestyle intervention versus usual care/control, Outcome 15 Breastfeeding at discharge, six weeks postpartum, six months or longer.

\begin{tabular}{|c|c|c|c|c|c|}
\hline Study or subgroup & $\begin{array}{c}\text { Lifestyle in- } \\
\text { tervention } \\
n / N \\
\end{array}$ & $\begin{array}{c}\text { Usual care } \\
\text { n/N } \\
\end{array}$ & $\begin{array}{c}\text { Risk Ratio } \\
\text { M-H, Fixed, 95\% Cl }\end{array}$ & Weight & $\begin{array}{c}\text { Risk Ratio } \\
\text { M-H, Fixed, 95\% CI }\end{array}$ \\
\hline \multicolumn{6}{|l|}{ 1.15.1 At discharge } \\
\hline Crowther 2005 & $413 / 490$ & $412 / 510$ & & $100 \%$ & $1.04[0.99,1.1]$ \\
\hline Subtotal $(95 \% \mathrm{Cl})$ & 490 & 510 & & $100 \%$ & $1.04[0.99,1.1]$ \\
\hline \multicolumn{6}{|c|}{ Total events: 413 (Lifestyle intervention), 412 (Usual care) } \\
\hline \multicolumn{6}{|c|}{ Test for overall effect: $Z=1.46(P=0.14)$} \\
\hline \multicolumn{6}{|c|}{ 1.15.2 At six months postpartum } \\
\hline Ferrara 2011 & $79 / 90$ & $89 / 98$ & - & $100 \%$ & $0.97[0.87,1.07]$ \\
\hline Subtotal $(95 \% \mathrm{Cl})$ & 90 & 98 & & $100 \%$ & $0.97[0.87,1.07]$ \\
\hline \multicolumn{6}{|c|}{ Total events: 79 (Lifestyle intervention), 89 (Usual care) } \\
\hline \multicolumn{6}{|c|}{ Test for overall effect: $Z=0.67(P=0.5)$} \\
\hline \multicolumn{6}{|c|}{ 1.15.3 Six months postpartum or longer } \\
\hline Ferrara 2011 & $47 / 75$ & $41 / 86$ & & $100 \%$ & $1.31[0.99,1.74]$ \\
\hline Subtotal $(95 \% \mathrm{Cl})$ & 75 & 86 & & $100 \%$ & $1.31[0.99,1.74]$ \\
\hline \multicolumn{6}{|c|}{ Total events: 47 (Lifestyle intervention), 41 (Usual care) } \\
\hline \multicolumn{6}{|c|}{ Heterogeneity: Not applicable } \\
\hline \multicolumn{6}{|c|}{ Test for overall effect: $\mathrm{Z}=1.9(\mathrm{P}=0.06)$} \\
\hline Test for subgroup dif & $3, d f=1(P=0.1), I$ & $83 \%$ & & & \\
\hline
\end{tabular}

Analysis 1.16. Comparison 1 Lifestyle intervention versus usual care/ control, Outcome 16 Sense of well-being and quality of lifeduring treatment.

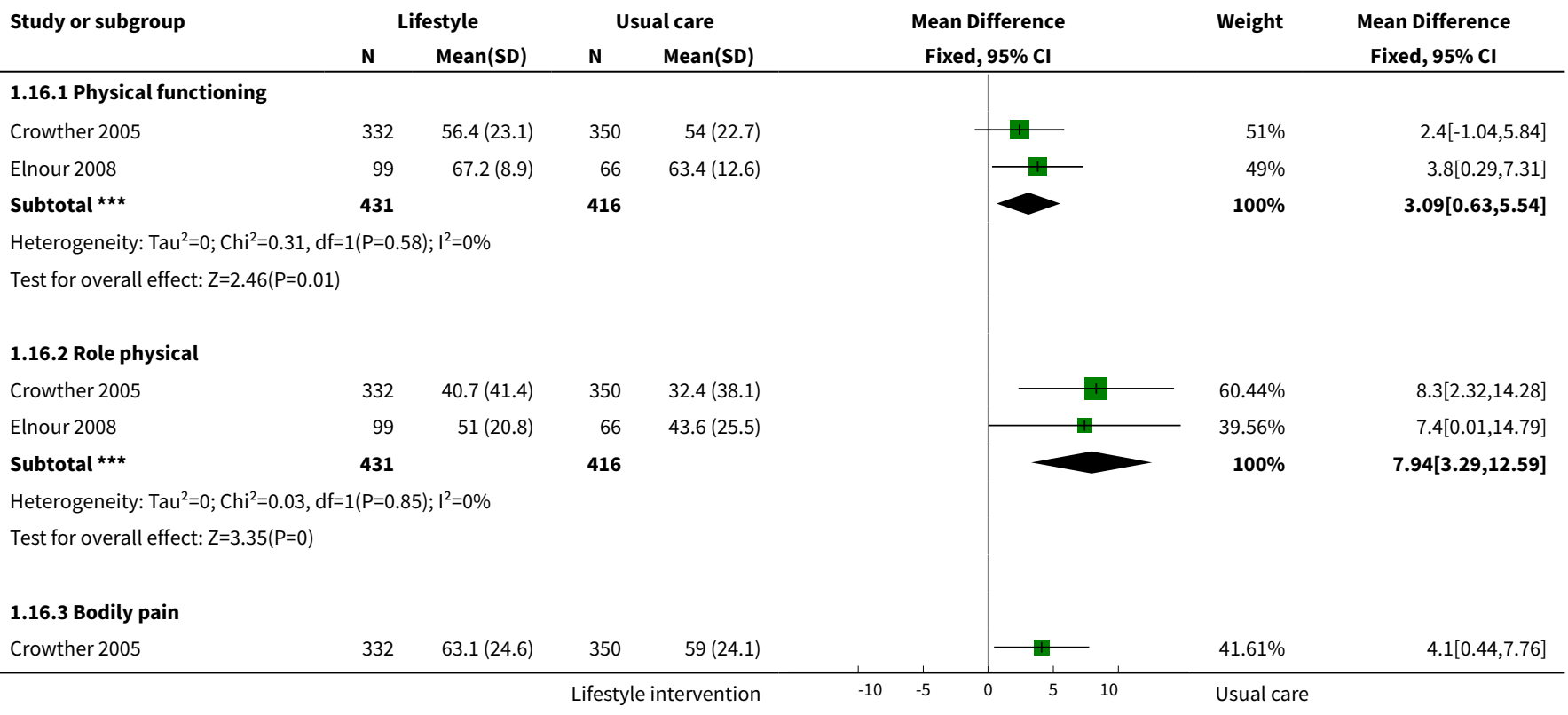




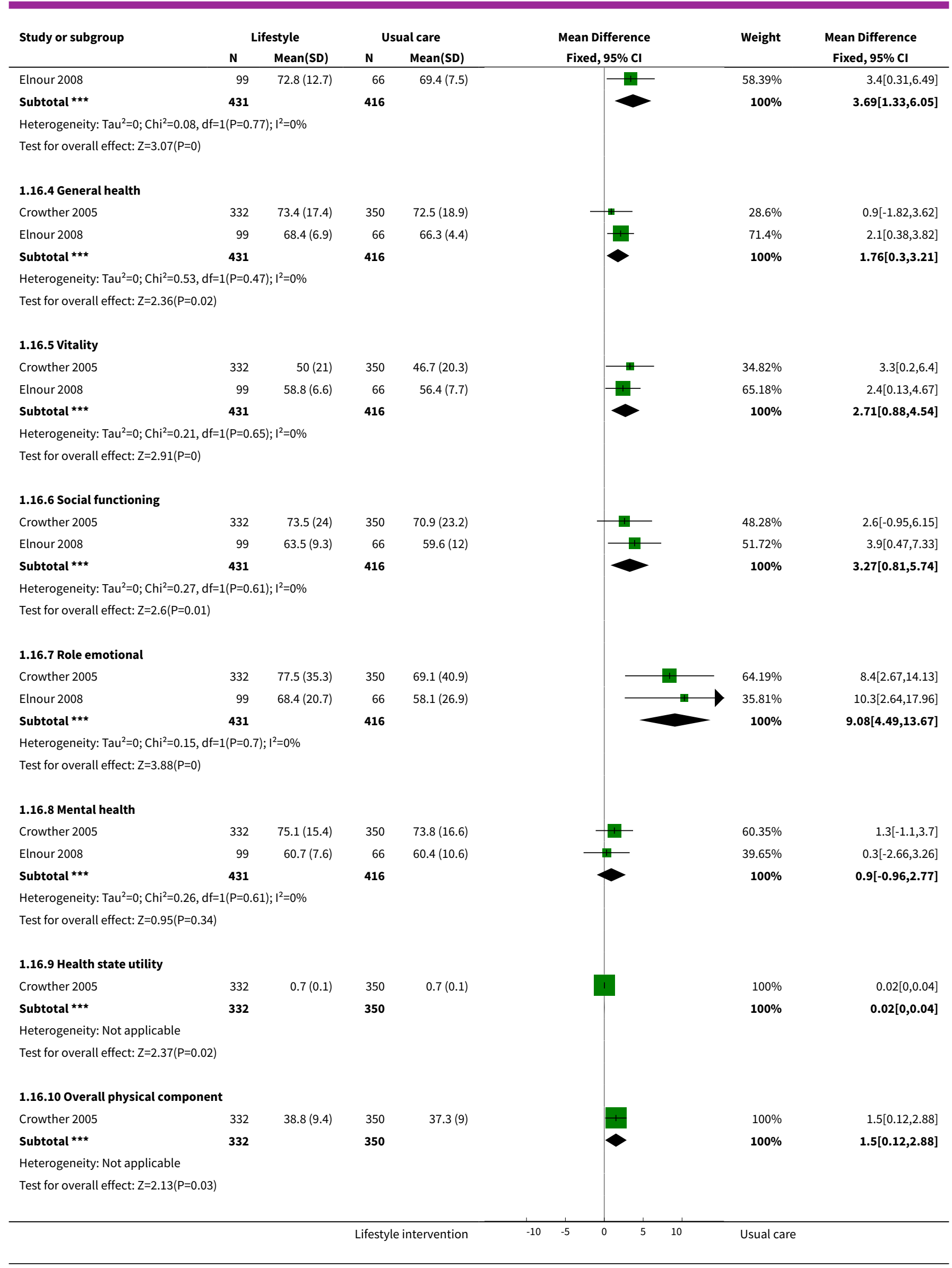




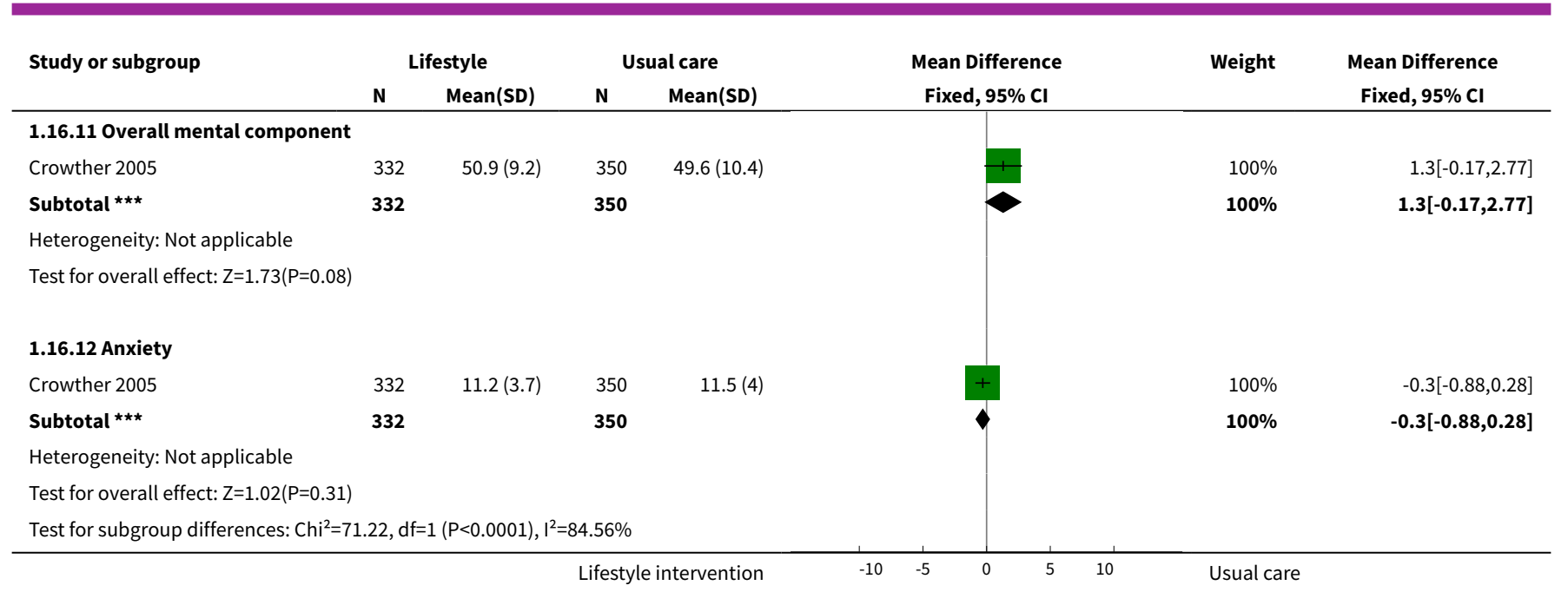

Analysis 1.17. Comparison 1 Lifestyle intervention versus usual care/control, Outcome 17 Sense of well-being and quality of life three months postpartum.

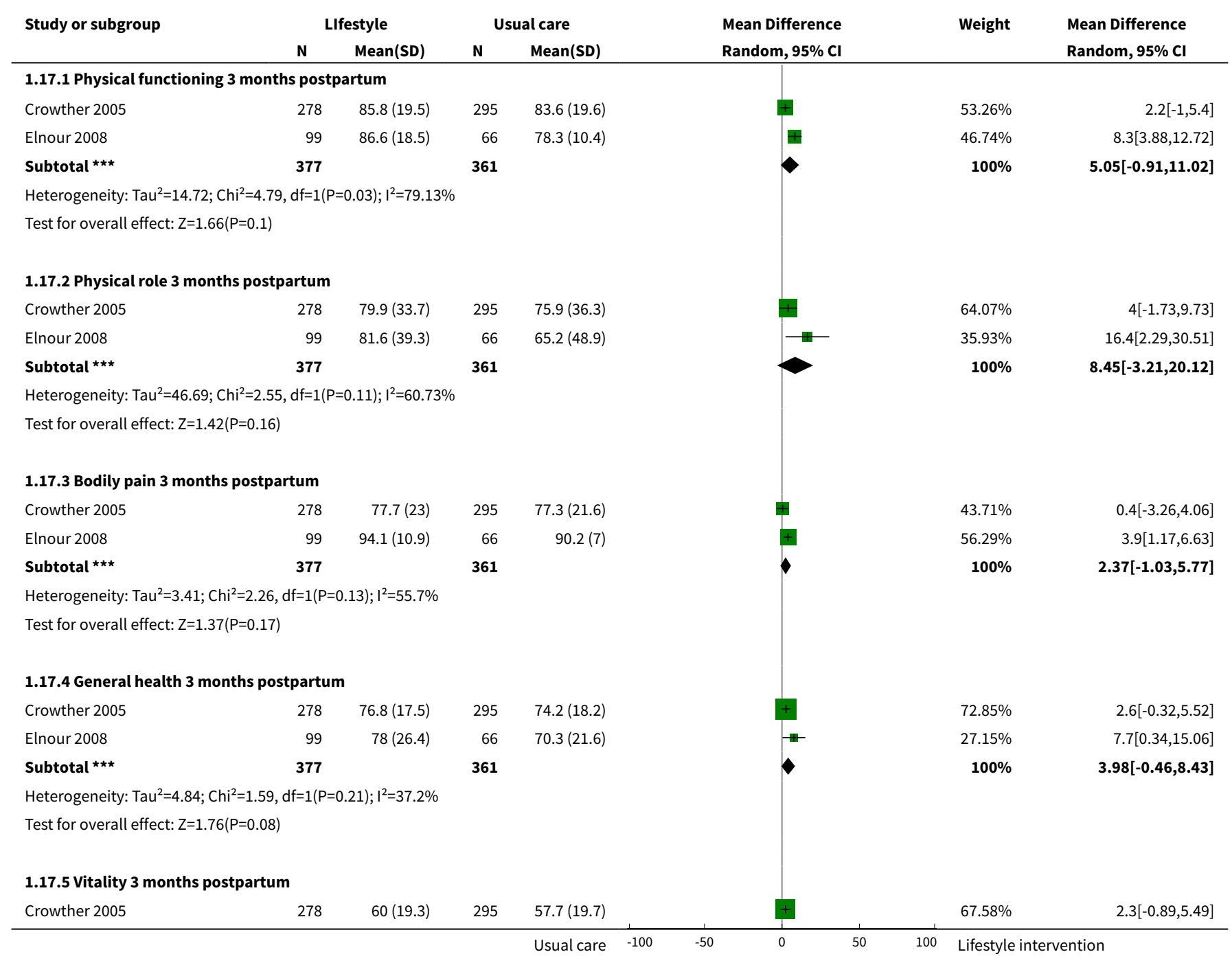




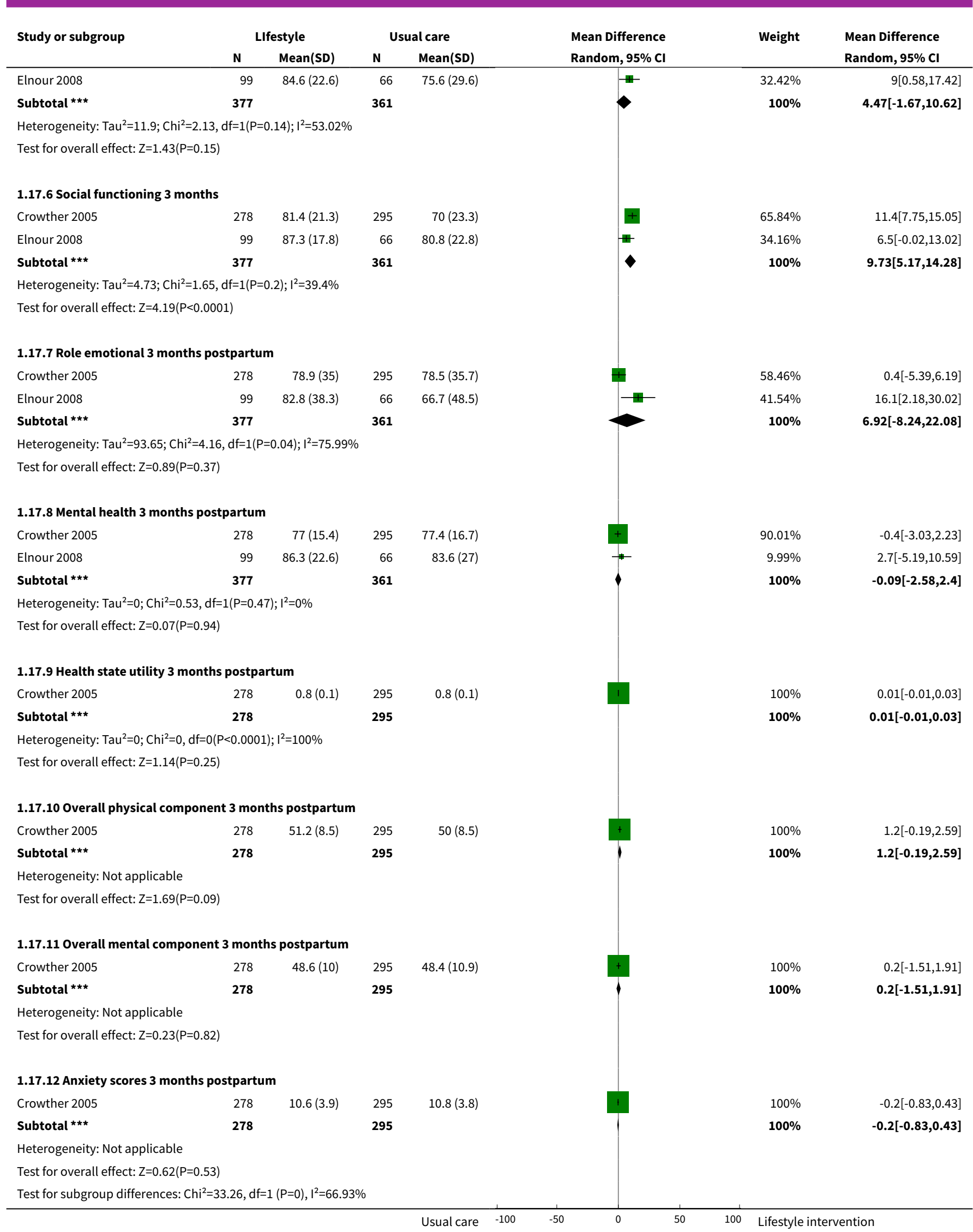


Analysis 1.18. Comparison 1 Lifestyle intervention versus usual care/control, Outcome 18 Postnatal depression.

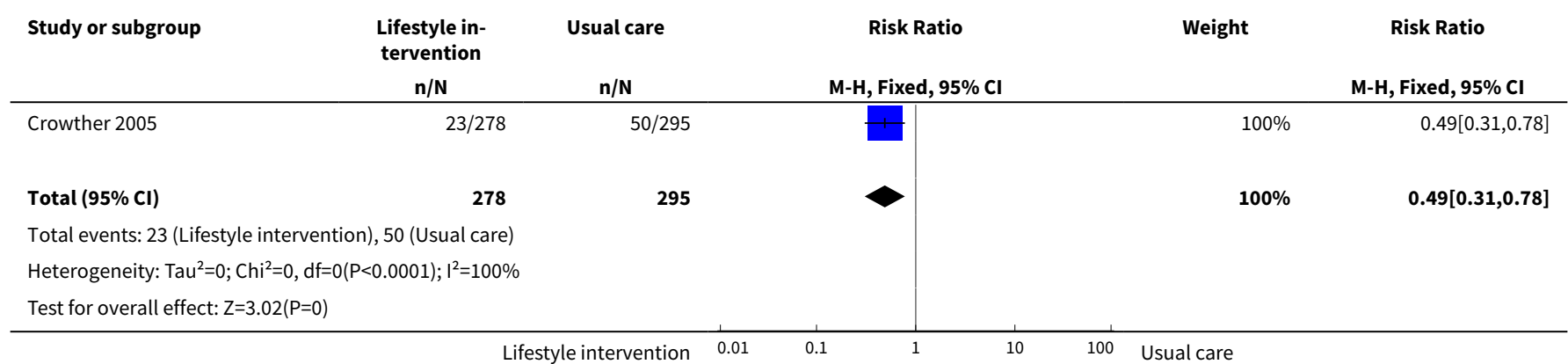

Analysis 1.19. Comparison 1 Lifestyle intervention versus usual care/control, Outcome 19 Postnatal weight retention or return to pre-pregnancy weight.

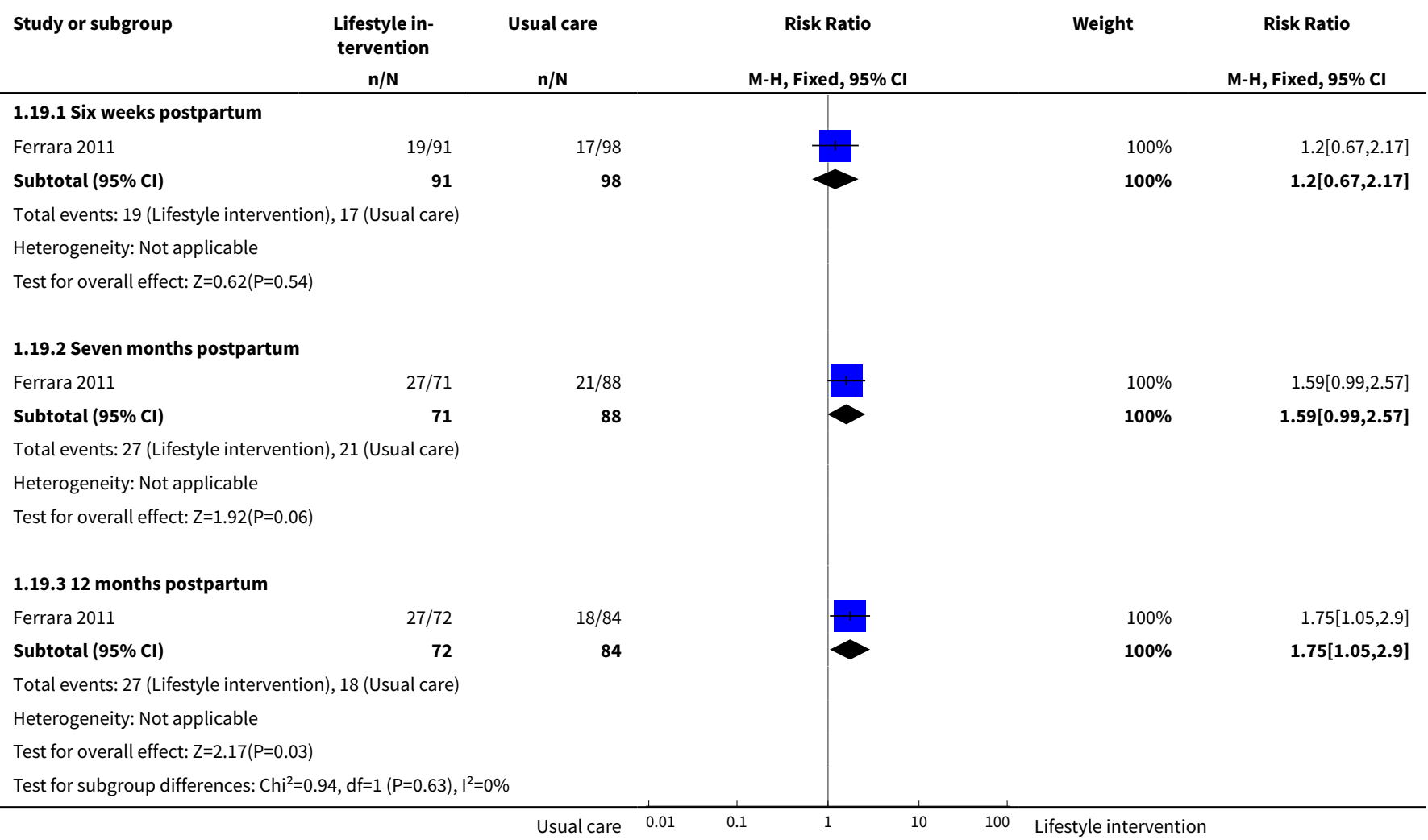


Analysis 1.20. Comparison 1 Lifestyle intervention versus usual care/ control, Outcome 20 Fasting plasma glucose 3 months postpartum mmol/L.

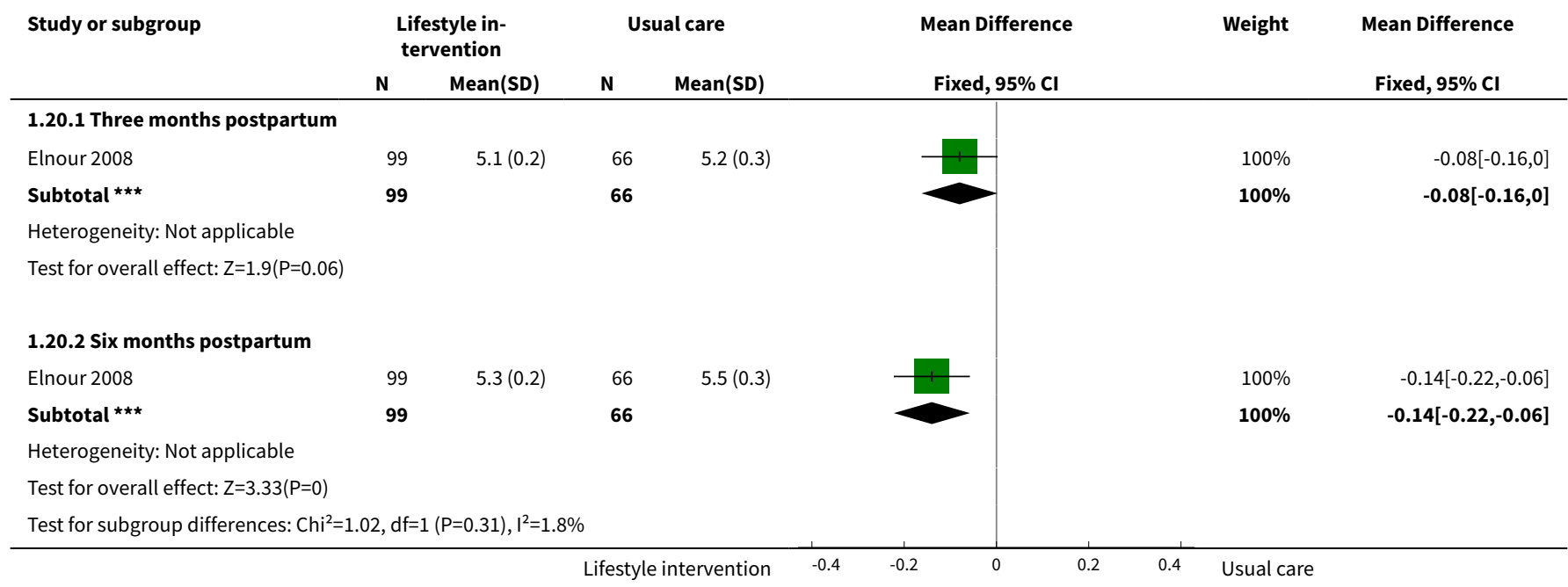

Analysis 1.21. Comparison 1 Lifestyle intervention versus usual care/ control, Outcome 21 Maternal postnatal impaired glucose tolerance.

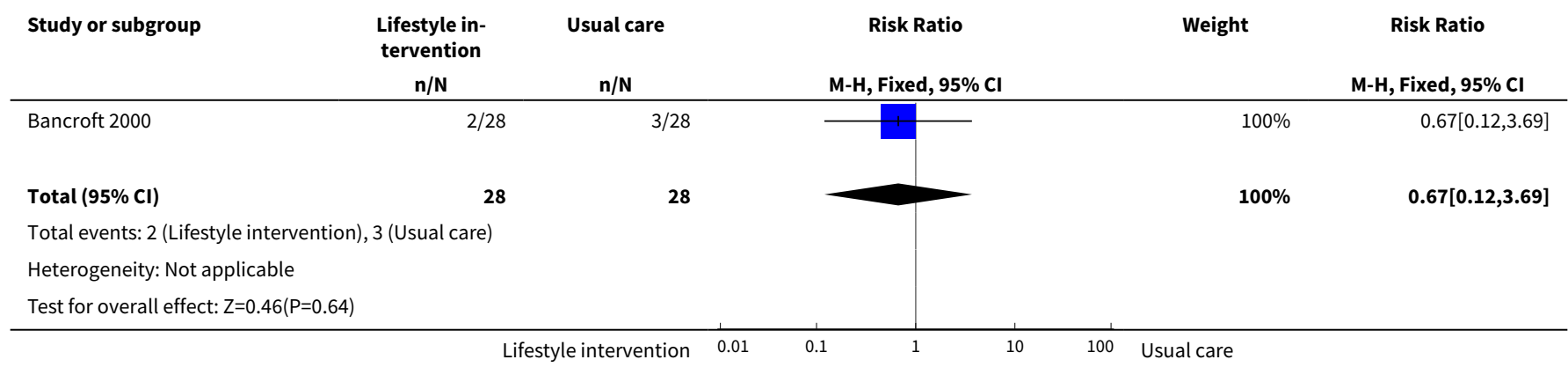

Analysis 1.22. Comparison 1 Lifestyle intervention versus usual care/ control, Outcome 22 Maternal metabolic syndrome (follow-up).

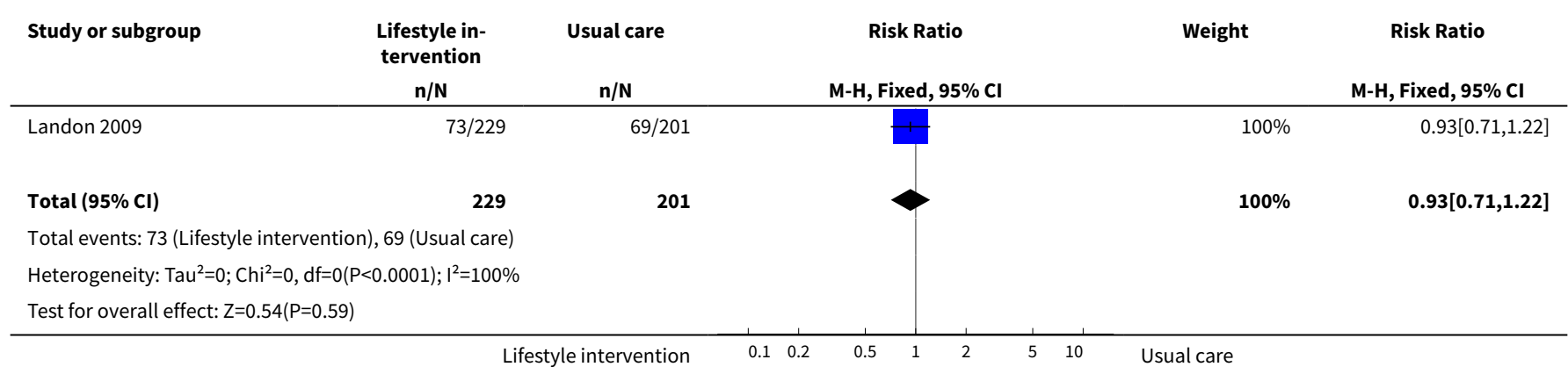


Analysis 1.23. Comparison 1 Lifestyle intervention versus usual care/control, Outcome 23 Stillbirth.

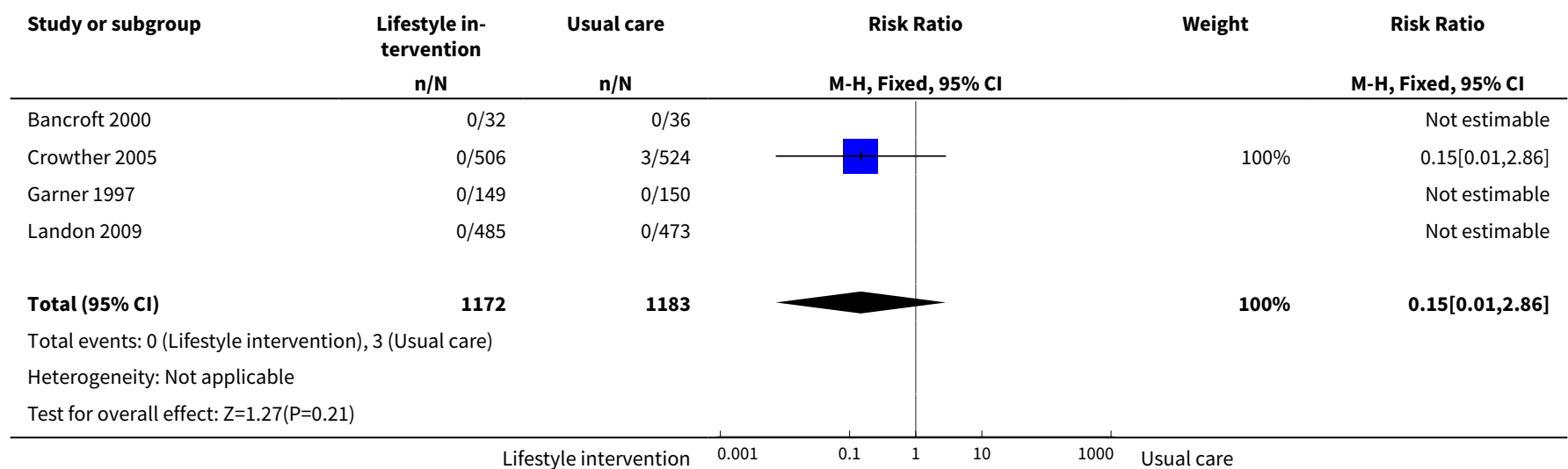

\section{Analysis 1.24. Comparison 1 Lifestyle intervention versus usual care/control, Outcome 24 Neonatal death.}

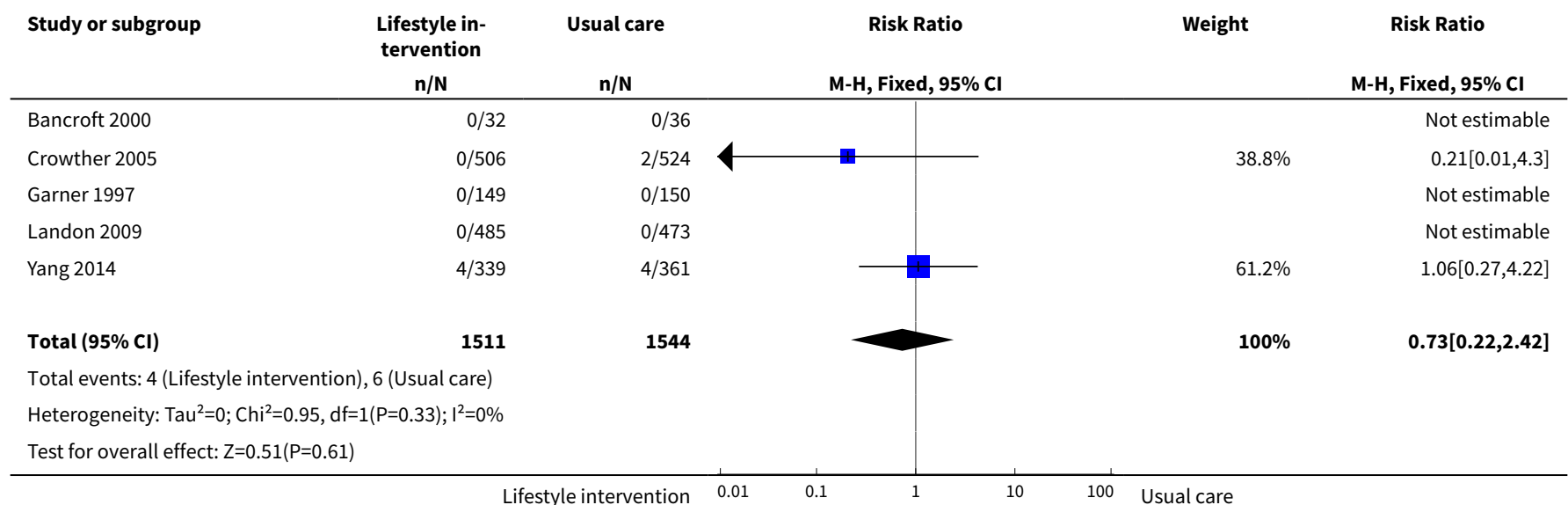

\section{Analysis 1.25. Comparison 1 Lifestyle intervention versus usual care/control, Outcome 25 Macrosomia.}

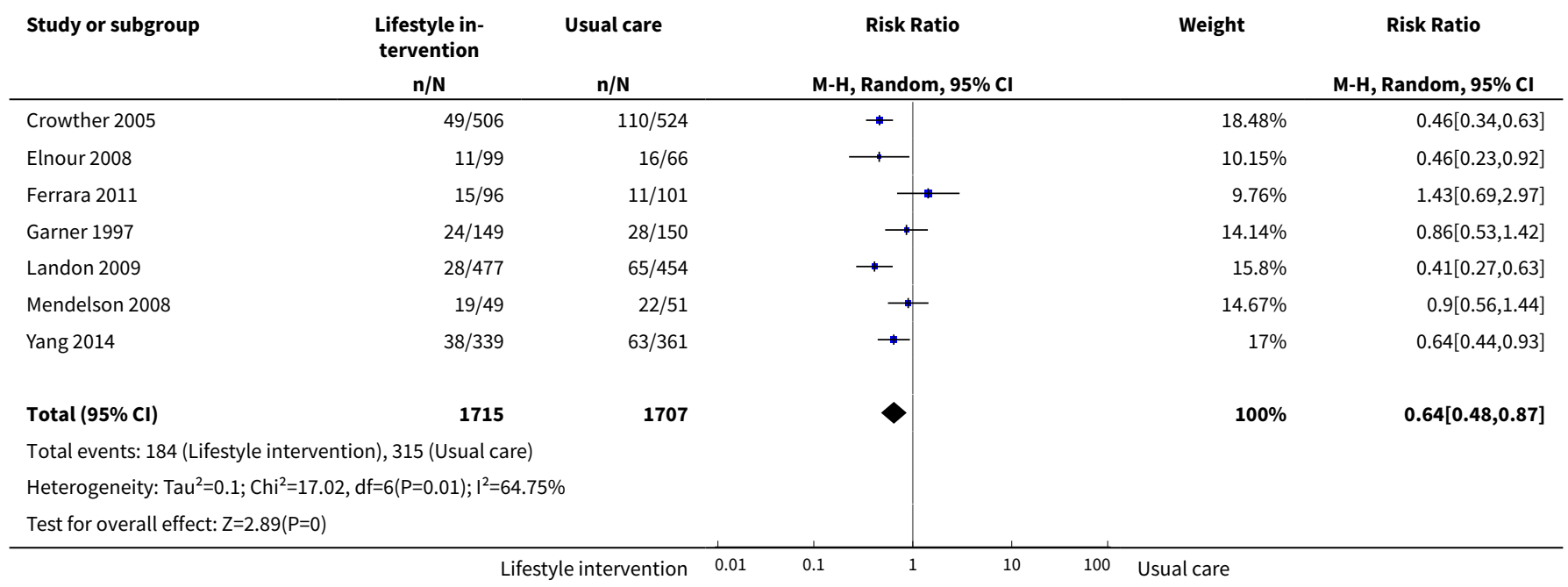


Analysis 1.26. Comparison 1 Lifestyle intervention versus usual care/control, Outcome 26 Small-for-gestational age.

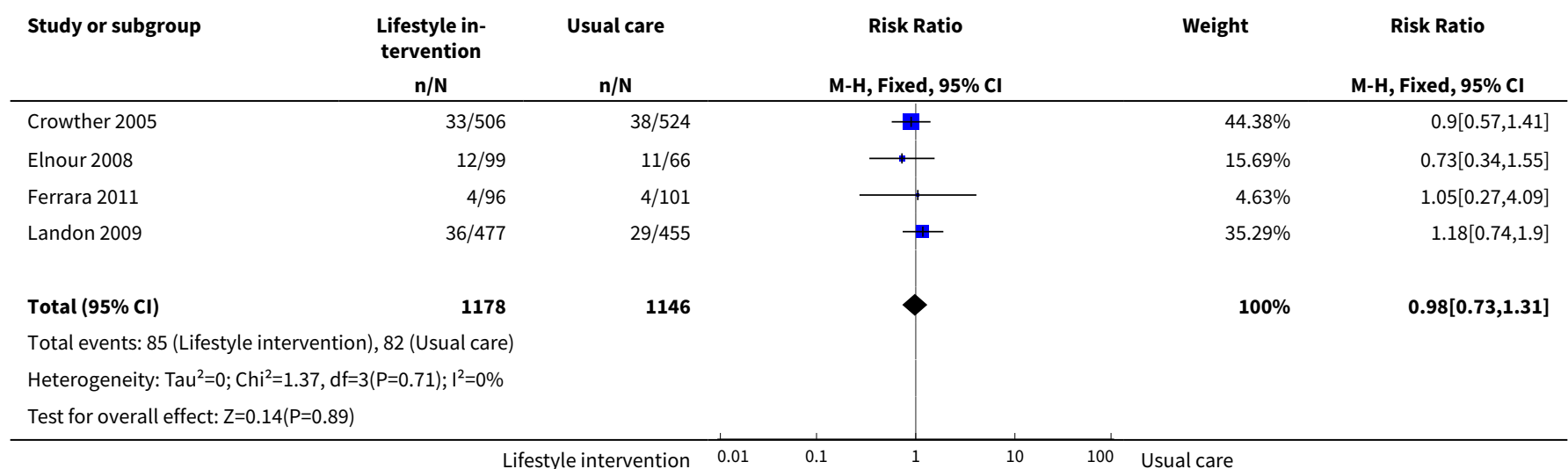

\section{Analysis 1.27. Comparison 1 Lifestyle intervention versus usual care/control, Outcome 27 Birth trauma (shoulder dystocia, bone fracture, nerve palsy).}

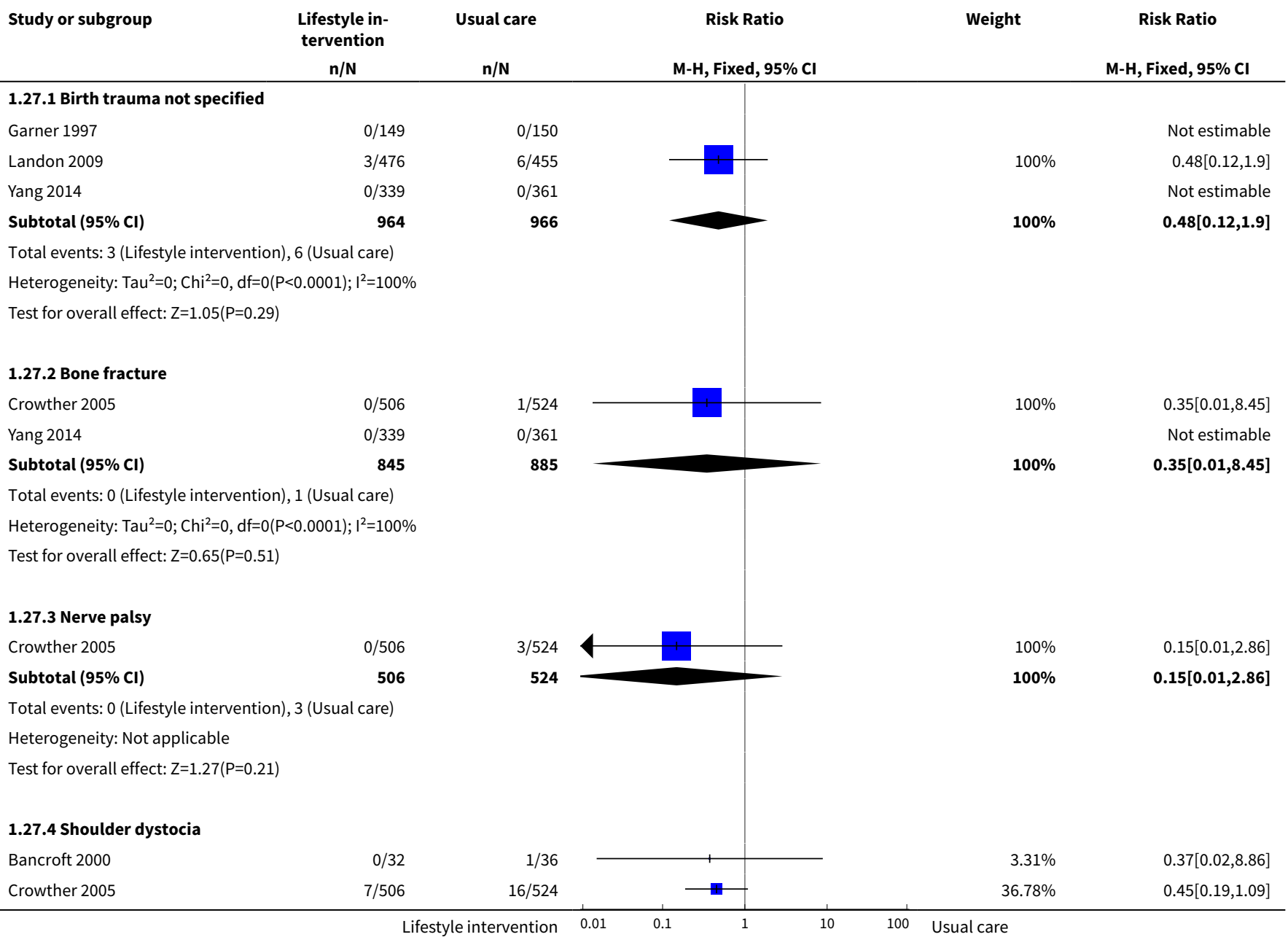




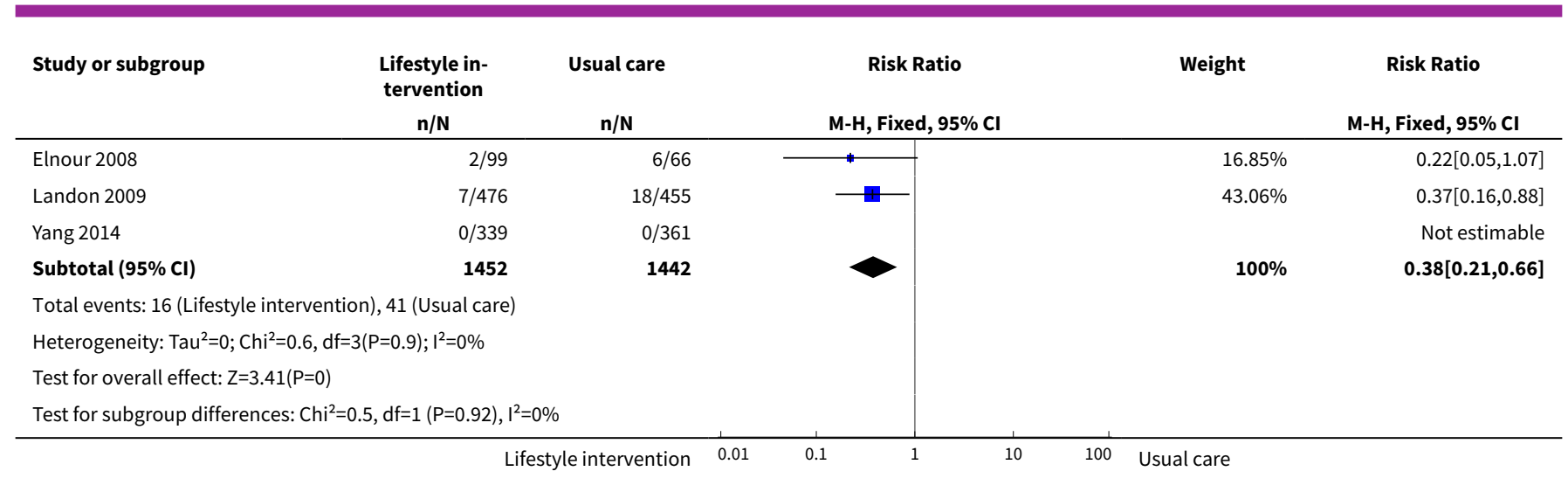

Analysis 1.28. Comparison 1 Lifestyle intervention versus usual care/control, Outcome 28 Gestational age at birth (weeks).

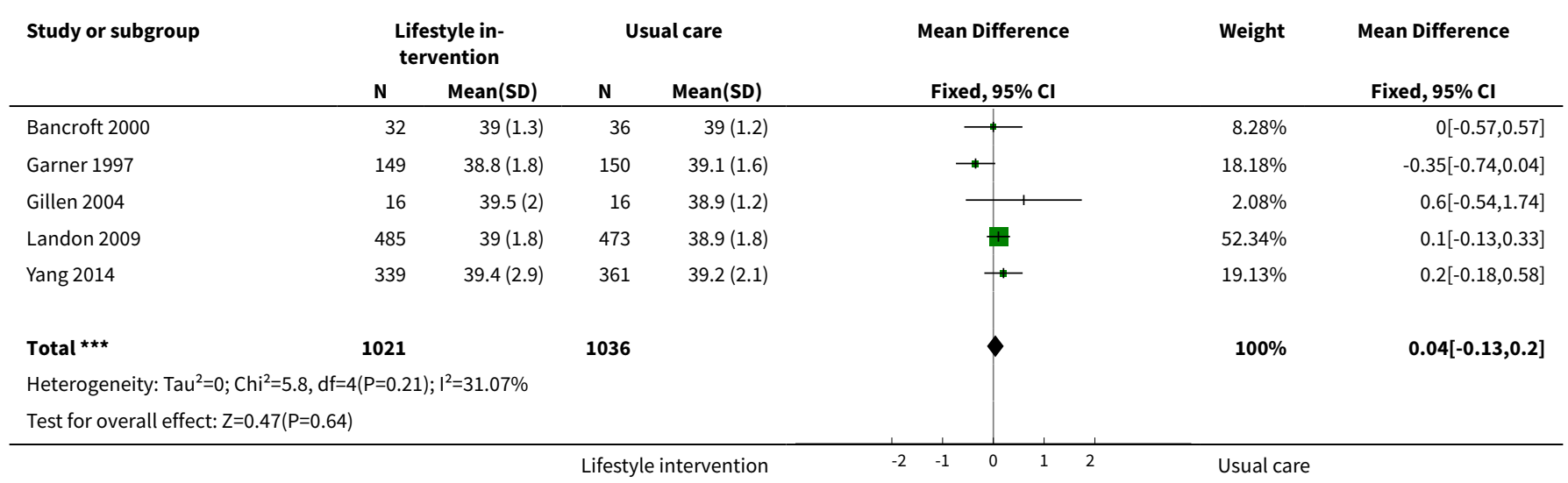

Analysis 1.29. Comparison 1 Lifestyle intervention versus usual care/control, Outcome 29 Preterm birth (<37 weeks' gestation; and < 32 weeks' gestation).

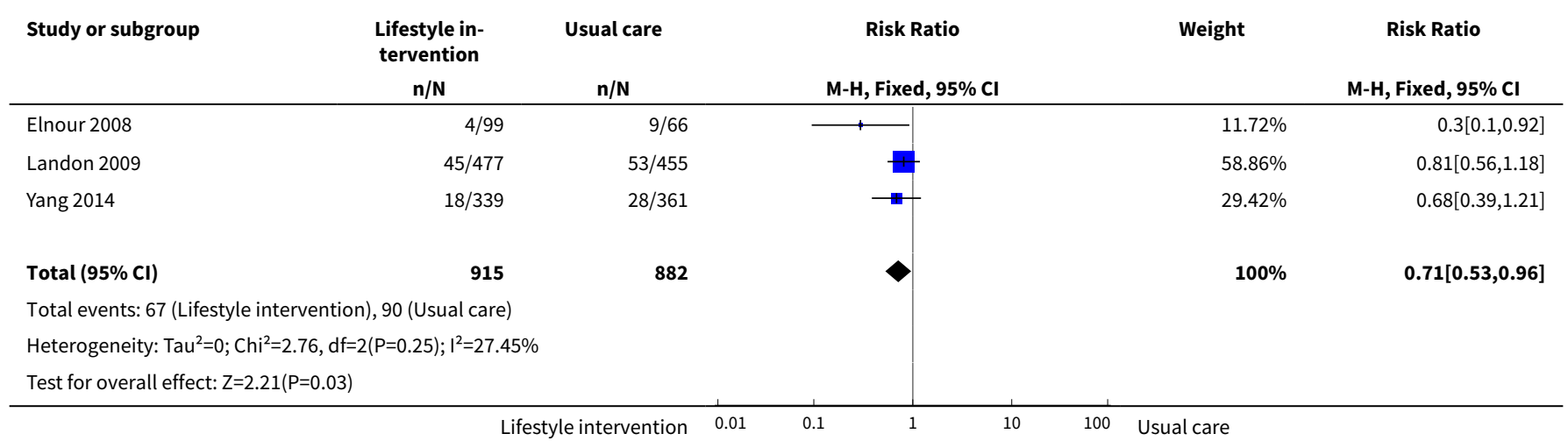


Analysis 1.30. Comparison 1 Lifestyle intervention versus usual care/control, Outcome 30 Five-minute Apgar less than seven.

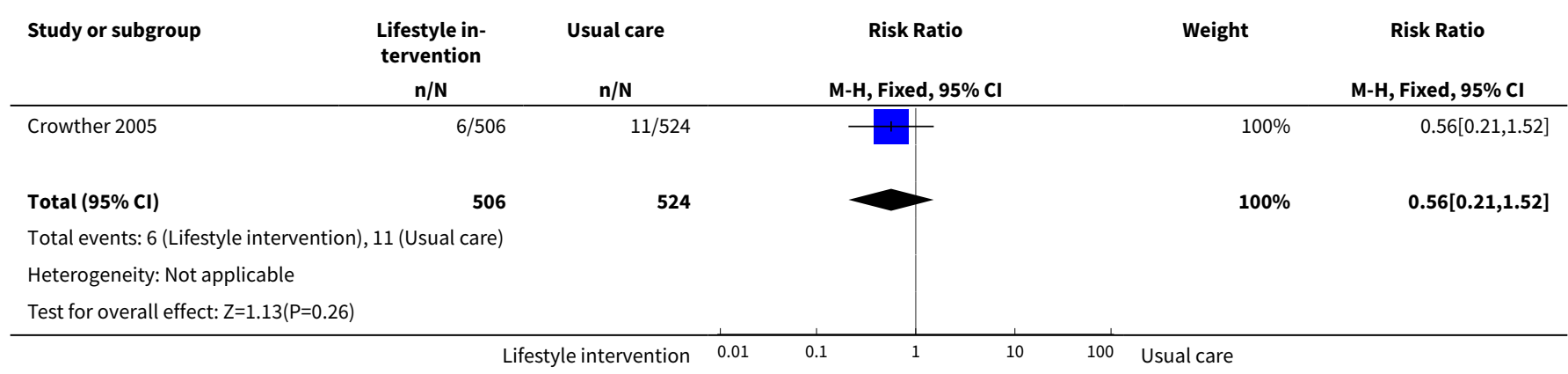

\section{Analysis 1.31. Comparison 1 Lifestyle intervention versus usual care/control, Outcome 31 Birthweight (grams).}

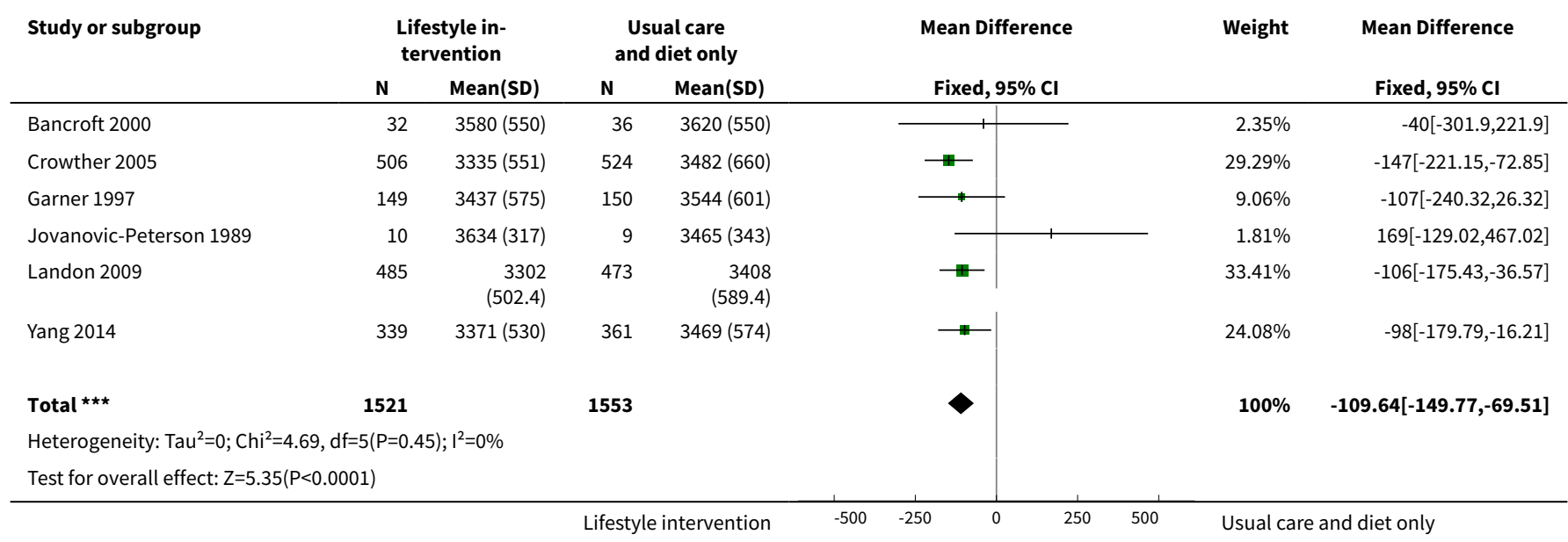

Analysis 1.32. Comparison 1 Lifestyle intervention versus usual care/control, Outcome 32 Length (cm).

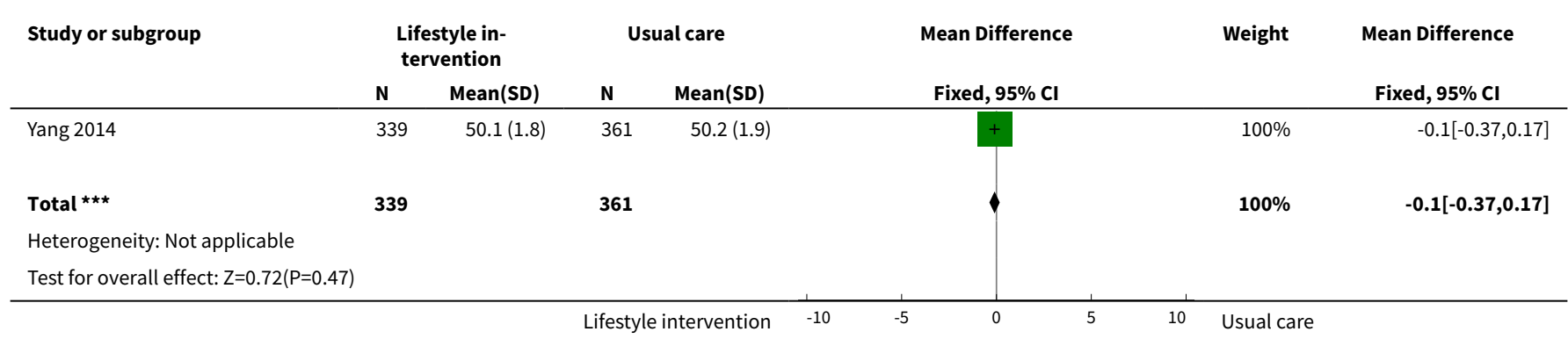




\section{Analysis 1.33. Comparison 1 Lifestyle intervention versus usual} care/control, Outcome 33 Adiposity (Neonatal fat mass (g)).

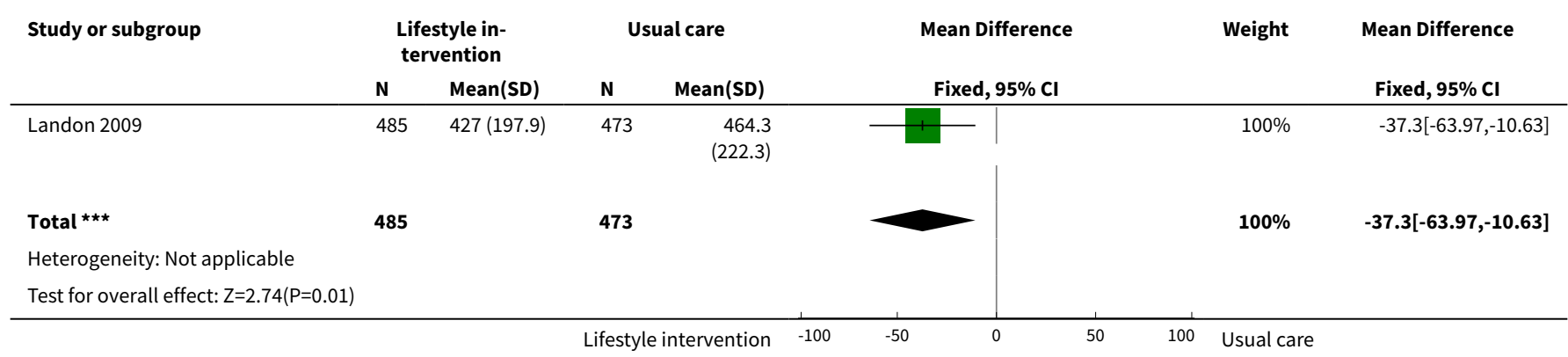

Analysis 1.34. Comparison 1 Lifestyle intervention versus usual care/control, Outcome 34 Neonatal hypoglycaemia.

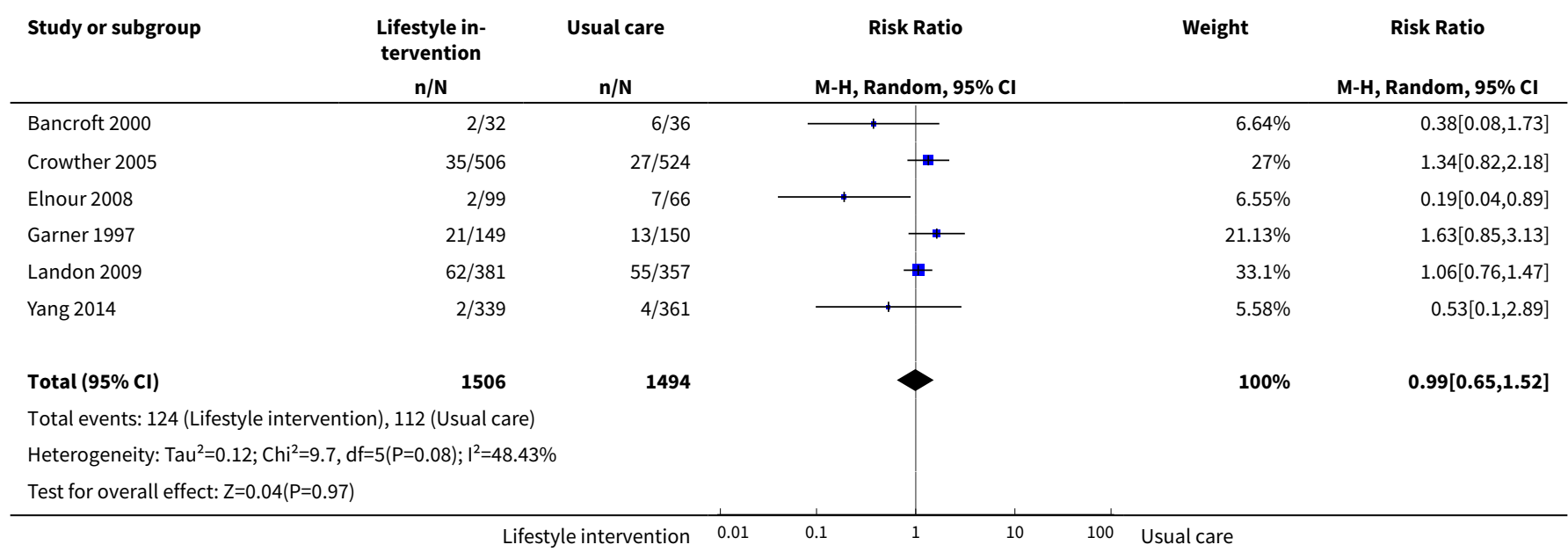

Analysis 1.35. Comparison 1 Lifestyle intervention versus usual care/control, Outcome 35 Respiratory distress syndrome.

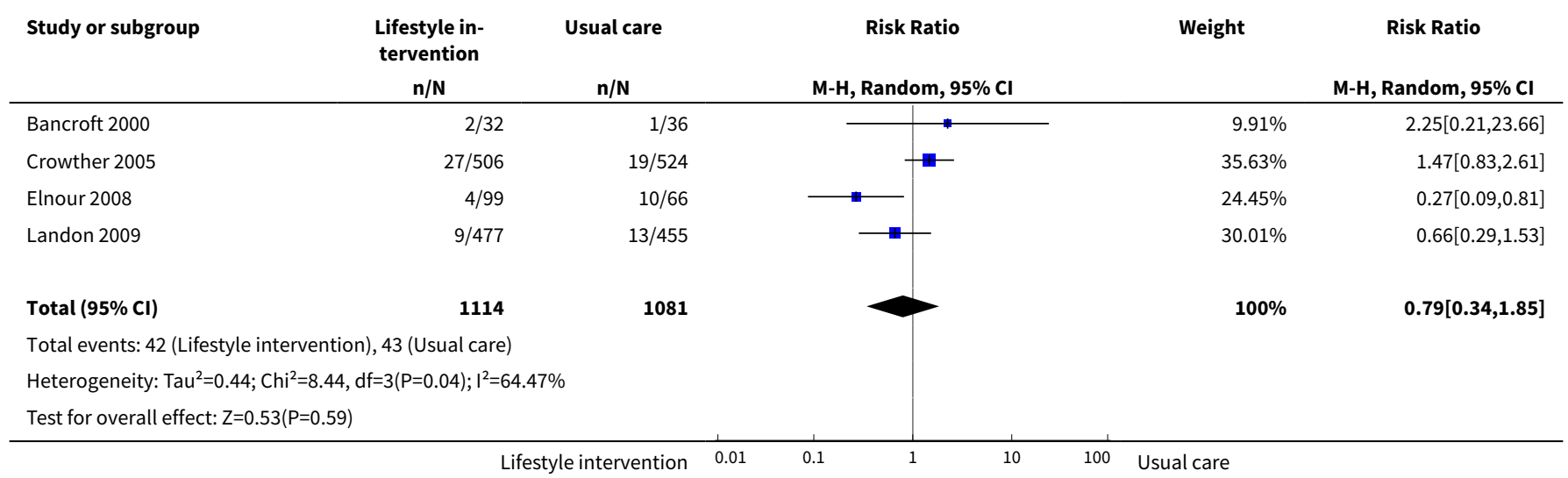


Analysis 1.36. Comparison 1 Lifestyle intervention versus usual care/ control, Outcome 36 Neonatal jaundice (hyperbilirubinaemia).

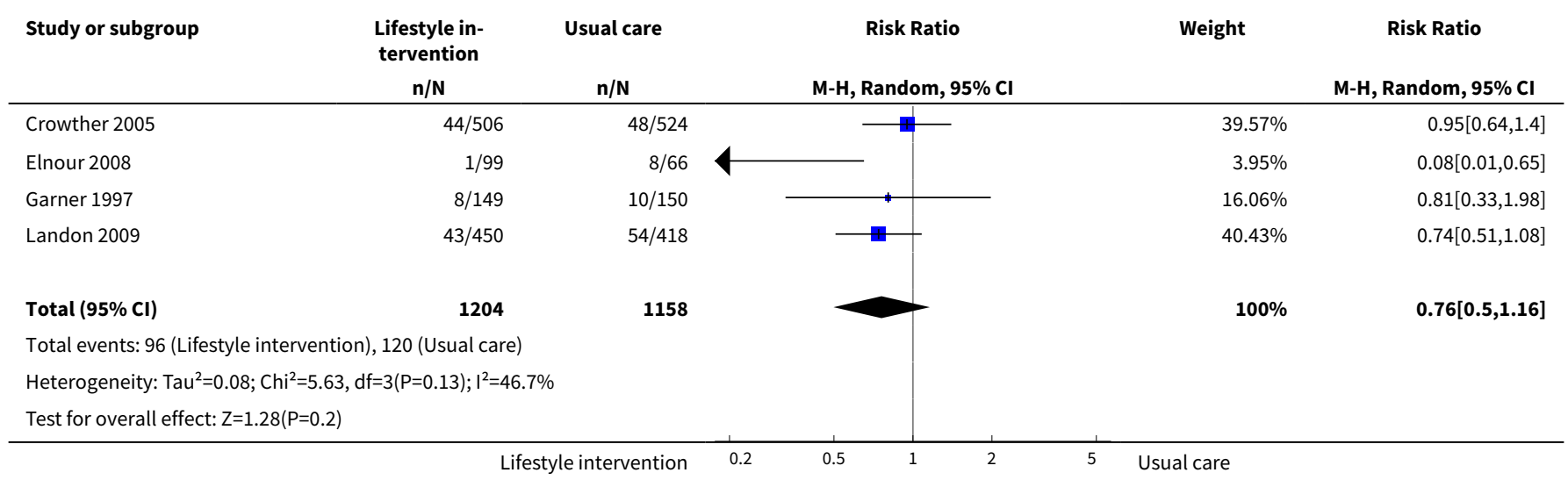

Analysis 1.37. Comparison 1 Lifestyle intervention versus usual care/control, Outcome 37 Hypocalcaemia.

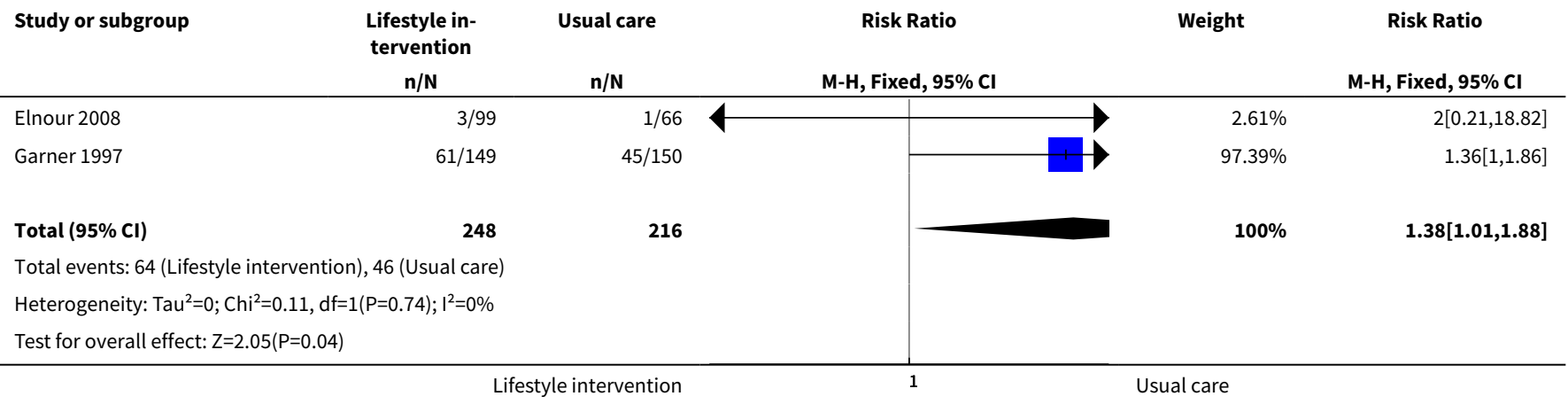

Analysis 1.38. Comparison 1 Lifestyle intervention versus usual care/control, Outcome 38 Polycythemia.

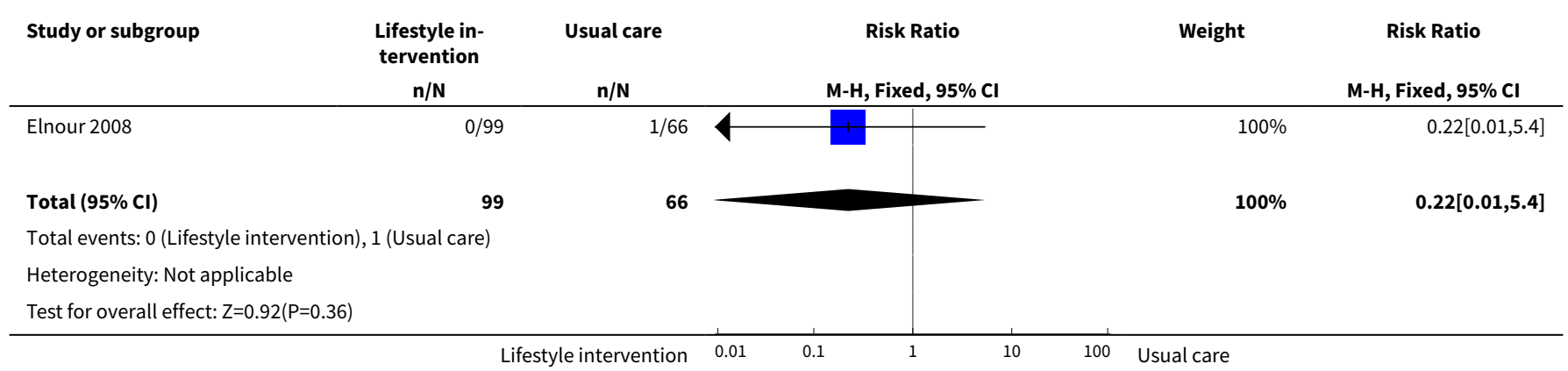


Analysis 1.39. Comparison 1 Lifestyle intervention versus usual care/control, Outcome 39 Childhood weight (kg).

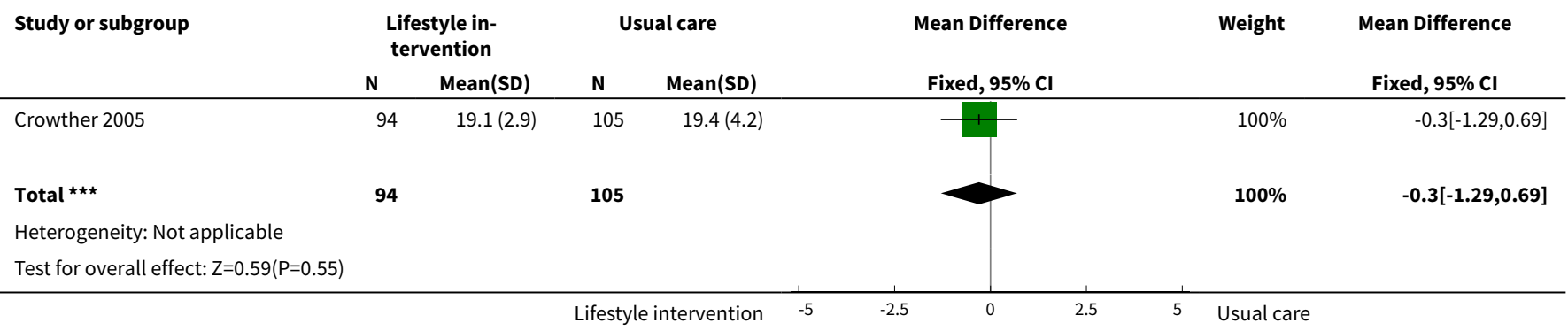

Analysis 1.40. Comparison 1 Lifestyle intervention versus usual care/control, Outcome 40 Childhood height (cm).

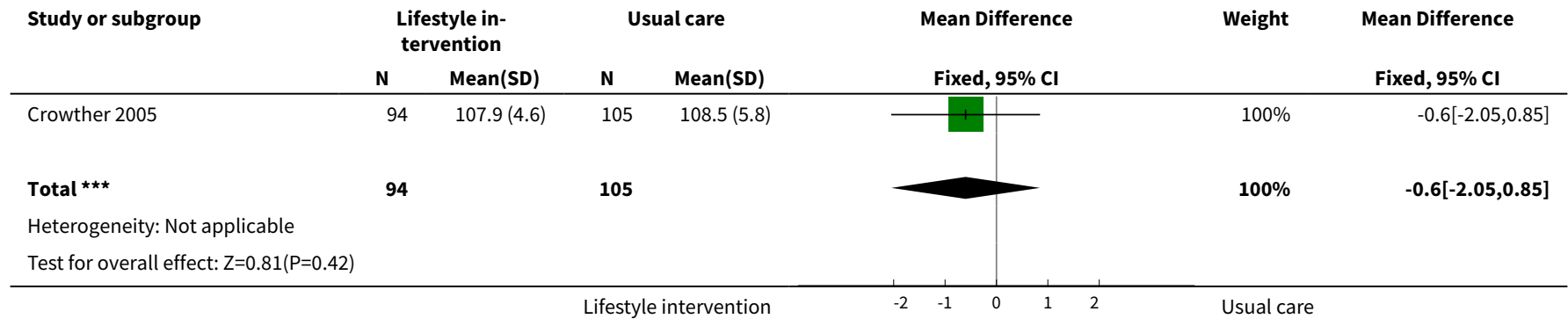

Analysis 1.41. Comparison 1 Lifestyle intervention versus usual care/ control, Outcome 41 Adiposity (Childhood BMI > 85th percentile).

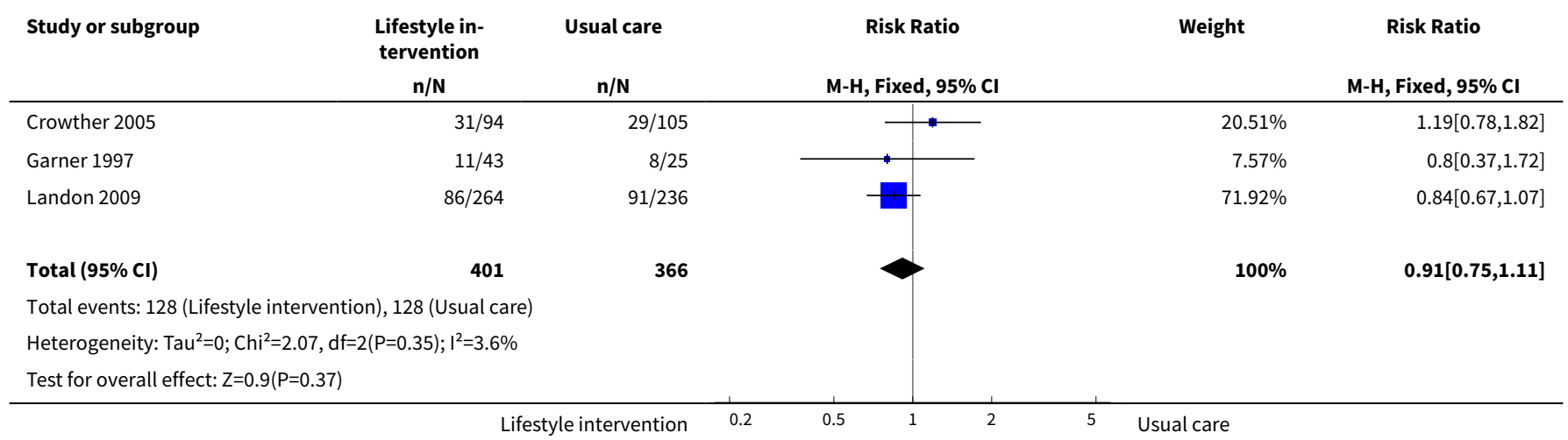

Analysis 1.42. Comparison 1 Lifestyle intervention versus usual care/control, Outcome 42 Adiposity (BMI Z score childhood).

\begin{tabular}{|c|c|c|c|c|c|c|c|c|}
\hline \multirow[t]{2}{*}{ Study or subgroup } & \multicolumn{2}{|c|}{$\begin{array}{l}\text { Lifestyle in- } \\
\text { tervention }\end{array}$} & \multicolumn{2}{|c|}{ Usual care } & \multirow{2}{*}{\multicolumn{2}{|c|}{$\begin{array}{c}\text { Mean Difference } \\
\text { Fixed, } 95 \% \mathrm{Cl} \\
\end{array}$}} & \multirow[t]{2}{*}{ Weight } & \multirow{2}{*}{$\begin{array}{c}\text { Mean Difference } \\
\text { Fixed, } 95 \% \mathrm{Cl}\end{array}$} \\
\hline & $\mathbf{N}$ & Mean(SD) & $\mathbf{N}$ & Mean(SD) & & & & \\
\hline Crowther 2005 & 94 & $0.5(1.2)$ & 105 & $0.4(1.4)$ & & & $100 \%$ & $0.08[-0.28,0.44]$ \\
\hline
\end{tabular}




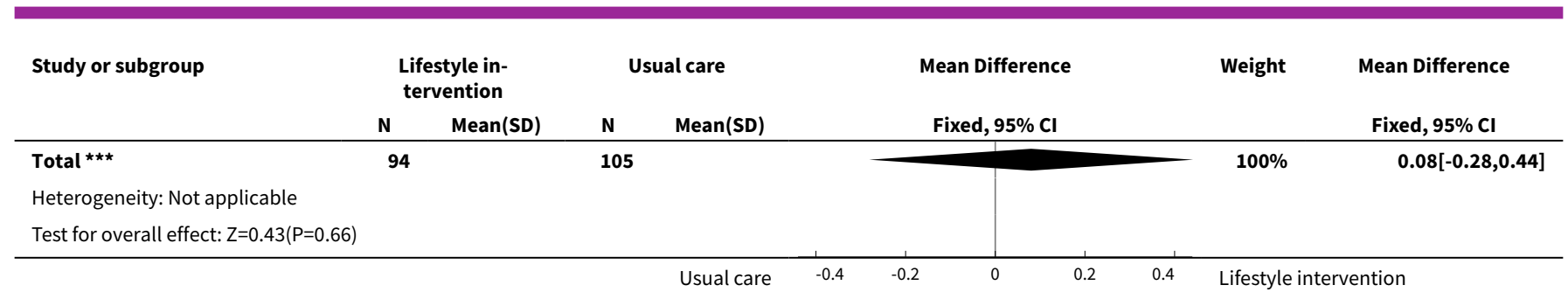

Analysis 1.43. Comparison 1 Lifestyle intervention versus usual care/control, Outcome 43 Childhood glycaemic control (mmol/L).

\begin{tabular}{|c|c|c|c|c|c|c|c|}
\hline \multirow[t]{2}{*}{ Study or subgroup } & \multicolumn{2}{|c|}{$\begin{array}{l}\text { Lifestyle in- } \\
\text { tervention }\end{array}$} & \multicolumn{2}{|c|}{ Usual care } & \multirow{2}{*}{$\begin{array}{c}\text { Mean Difference } \\
\text { Fixed, } 95 \% \mathrm{Cl} \\
\end{array}$} & \multirow[t]{2}{*}{ Weight } & \multirow{2}{*}{$\begin{array}{l}\text { Mean Difference } \\
\text { Fixed, } 95 \% \mathrm{Cl} \\
\end{array}$} \\
\hline & $\mathbf{N}$ & $\operatorname{Mean}(S D)$ & $\mathbf{N}$ & Mean(SD) & & & \\
\hline \multicolumn{8}{|c|}{ 1.43.1 Fasting blood glucose } \\
\hline Garner 1997 & 43 & $5(0.4)$ & 25 & $4.9(0.4)$ & & $100 \%$ & $0.1[-0.1,0.3]$ \\
\hline Subtotal $\star \star \star$ & 43 & & 25 & & & $100 \%$ & $0.1[-0.1,0.3]$ \\
\hline \multicolumn{8}{|c|}{ Heterogeneity: Not applicable } \\
\hline \multicolumn{8}{|c|}{ Test for overall effect: $Z=0.99(P=0.32)$} \\
\hline \multicolumn{8}{|c|}{ 1.43.2 Two-hour postprandial blood glucose } \\
\hline Garner 1997 & 43 & $5.9(1.2)$ & 25 & $5.9(0.8)$ & - & $100 \%$ & $0[-0.48,0.48]$ \\
\hline Subtotal $* \star \star$ & 43 & & 25 & & & $100 \%$ & $0[-0.48,0.48]$ \\
\hline \multicolumn{8}{|c|}{ Heterogeneity: Not applicable } \\
\hline \multicolumn{8}{|c|}{ Test for overall effect: Not applicable } \\
\hline & & & & Usual care & $-1 \quad-0.5$ & Lifestyl & ntion \\
\hline
\end{tabular}

Analysis 1.44. Comparison 1 Lifestyle intervention versus usual care/control, Outcome 44 Dyslipidaemia or metabolic syndrome (Childhood cholesterol (mg/dL)).

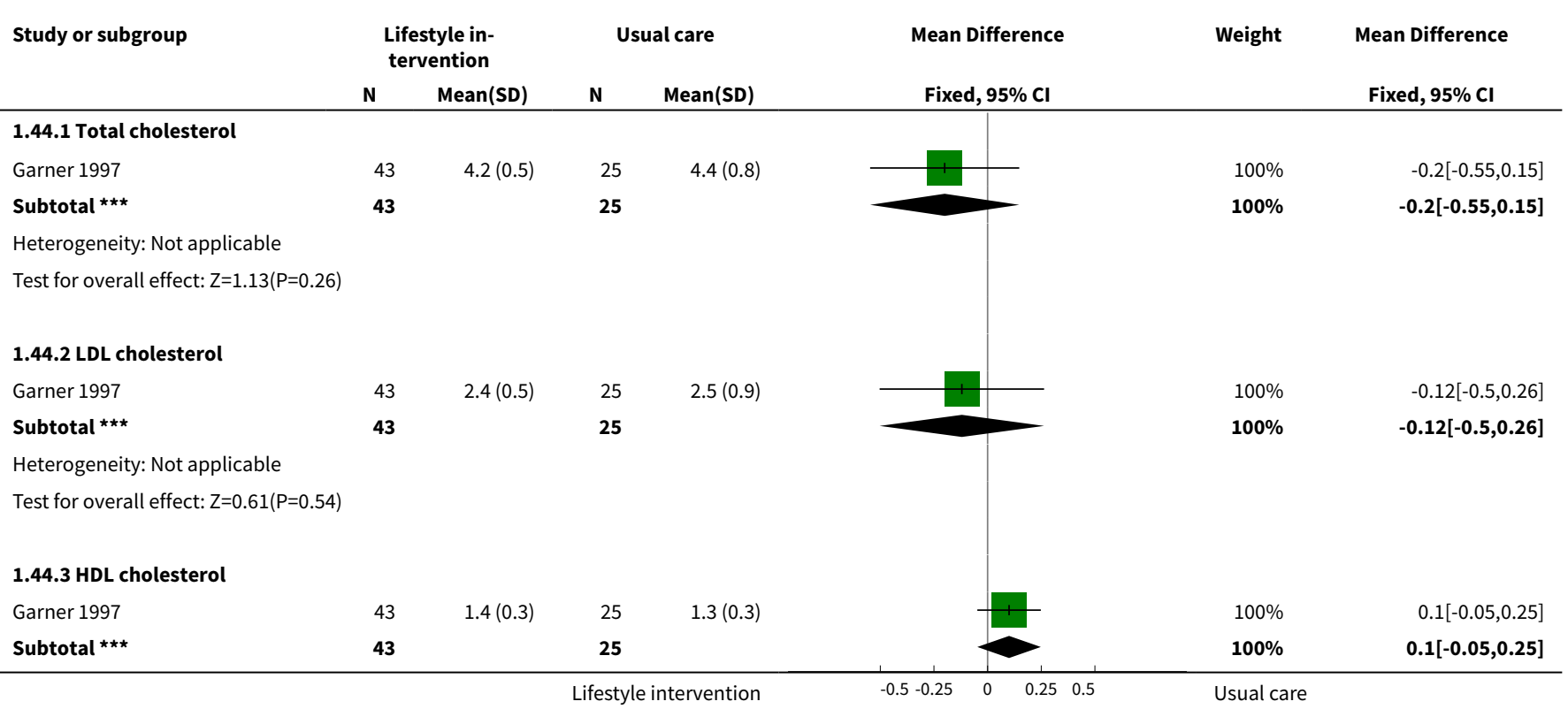




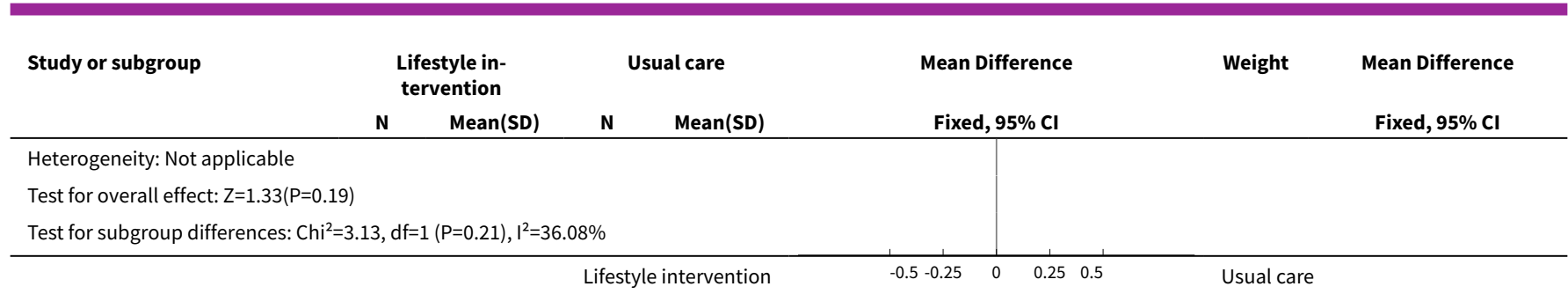

Analysis 1.45. Comparison 1 Lifestyle intervention versus usual care/ control, Outcome 45 Number of antenatal visits or admissions.

\begin{tabular}{|c|c|c|c|c|c|}
\hline Study or subgroup & $\begin{array}{c}\begin{array}{c}\text { Specific } \\
\text { treatment } \\
n / N\end{array} \\
\end{array}$ & $\begin{array}{c}\text { Routine ANC } \\
n / N \\
\end{array}$ & $\begin{array}{c}\text { Risk Ratio } \\
\text { M-H, Fixed, 95\% Cl }\end{array}$ & Weight & $\begin{array}{c}\text { Risk Ratio } \\
\text { M-H, Fixed, } 95 \% \mathrm{Cl}\end{array}$ \\
\hline Crowther 2005 & $141 / 490$ & $139 / 510$ & 2 & $100 \%$ & $1.06[0.87,1.29]$ \\
\hline Total $(95 \% \mathrm{Cl})$ & 490 & 510 & & $100 \%$ & $1.06[0.87,1.29]$ \\
\hline \multicolumn{6}{|c|}{ Total events: 141 (Specific treatment), 139 (Routine ANC) } \\
\hline \multicolumn{6}{|c|}{ Heterogeneity: Not applicable } \\
\hline \multicolumn{6}{|c|}{ Test for overall effect: $Z=0.54(P=0.59)$} \\
\hline
\end{tabular}

Analysis 1.46. Comparison 1 Lifestyle intervention versus usual care/control, Outcome 46 Number of hospital or health professional visits (including midwife, obstetrician, physician, dietician, diabetic nurse).

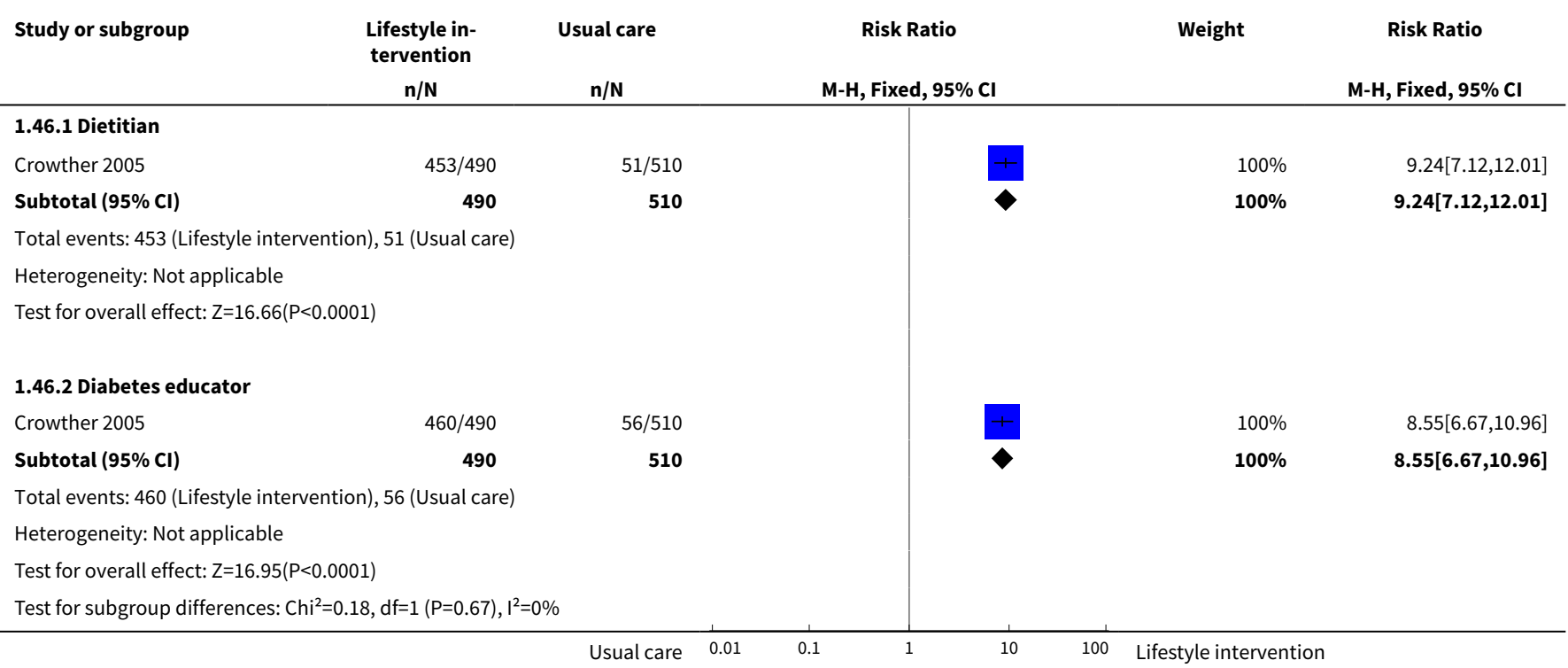


Analysis 1.47. Comparison 1 Lifestyle intervention versus usual care/control, Outcome 47 Number of hospital or health professional visits (including midwife, obstetrician, physician, dietician, diabetic nurse)l.

\begin{tabular}{|c|c|c|c|c|c|c|c|}
\hline \multirow[t]{2}{*}{ Study or subgroup } & \multicolumn{2}{|c|}{$\begin{array}{l}\text { Lifestyle in- } \\
\text { tervention }\end{array}$} & \multicolumn{2}{|c|}{ Usual care } & \multirow{2}{*}{$\begin{array}{c}\text { Mean Difference } \\
\text { Fixed, } 95 \% \mathrm{Cl} \\
\end{array}$} & \multirow[t]{2}{*}{ Weight } & \multirow{2}{*}{$\begin{array}{l}\text { Mean Difference } \\
\text { Fixed, } 95 \% \mathrm{Cl} \\
\end{array}$} \\
\hline & $\mathbf{N}$ & $\operatorname{Mean}(\mathrm{SD})$ & $\mathbf{N}$ & Mean(SD) & & & \\
\hline \multicolumn{8}{|l|}{ 1.47.1 Obstetrician } \\
\hline Yang 2014 & 339 & $7.8(3)$ & 361 & $7.6(2.5)$ & & $100 \%$ & $0.2[-0.21,0.61]$ \\
\hline 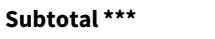 & 339 & & 361 & & & $100 \%$ & $0.2[-0.21,0.61]$ \\
\hline \multicolumn{8}{|c|}{ Heterogeneity: $\mathrm{Tau}^{2}=0 ; \mathrm{Chi}^{2}=0, \mathrm{df}=0(\mathrm{P}<0.0001) ; \mathrm{I}^{2}=100 \%$} \\
\hline \multicolumn{8}{|c|}{ 1.47.2 Healthcare provider (not specified) } \\
\hline Ferrara 2011 & 96 & $11.1(5.9)$ & 101 & $11(6.1)$ & & $100 \%$ & $0.1[-1.58,1.78]$ \\
\hline 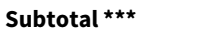 & 96 & & 101 & & & $100 \%$ & $0.1[-1.58,1.78]$ \\
\hline \multicolumn{8}{|c|}{ Heterogeneity: Not applicable } \\
\hline \multicolumn{8}{|c|}{ Test for overall effect: $Z=0.12(P=0.91)$} \\
\hline & & & fest & ervention & -0.5 & Usual car & \\
\hline
\end{tabular}

Analysis 1.48. Comparison 1 Lifestyle intervention versus usual care/ control, Outcome 48 Admission to neonatal intensive care unit/nursery.

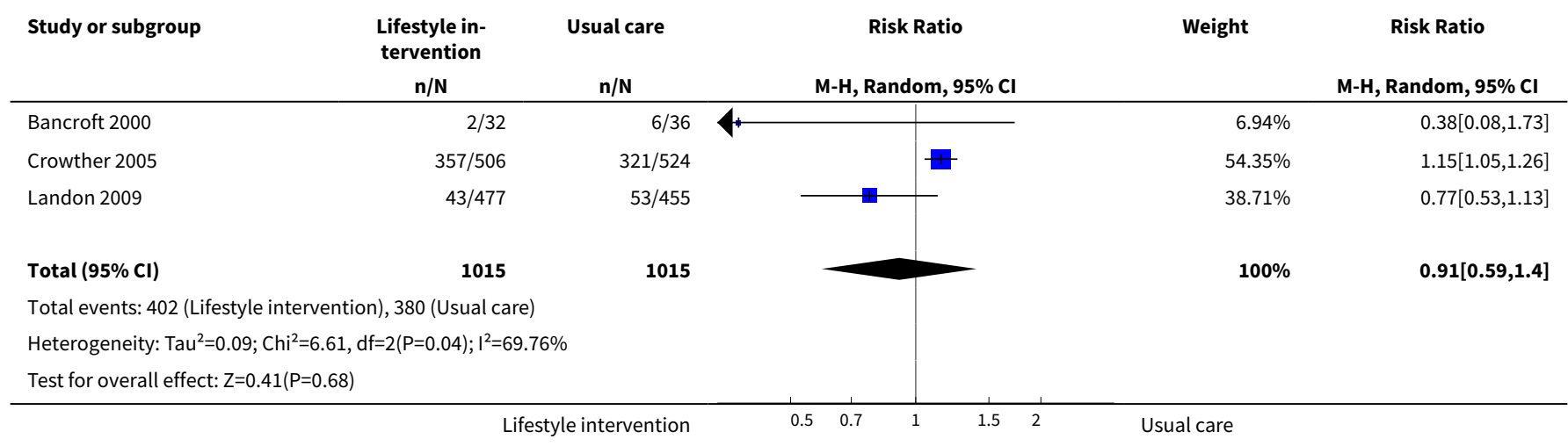

\section{ADDITIONAL TABLES}

Table 1. Examples of diagnostic criteria for gestational diabetes mellitus

\begin{tabular}{|c|c|c|c|c|c|c|}
\hline \multirow{2}{*}{$\begin{array}{l}\text { Organisation/pro- } \\
\text { fessional body }\end{array}$} & \multirow{2}{*}{$\begin{array}{l}\text { Screening crite- } \\
\text { ria } \\
\begin{array}{l}\text { 1-hour oral glu- } \\
\text { cose challenge } \\
\text { test }\end{array}\end{array}$} & \multicolumn{5}{|c|}{ Diagnostic criteria } \\
\hline & & $\begin{array}{l}\text { Oral glu- } \\
\text { cose toler- } \\
\text { ance test }\end{array}$ & Fasting & One hour & Two hour & Three hour \\
\hline $\begin{array}{l}\text { ADA 2015b*, IADPSG } \\
2010^{\star}, \text { ADIPS 2014* } \\
\text { (Nankervis 2014); }\end{array}$ & - & $75 \mathrm{~g}$ & $\begin{array}{l}\geq 5.1 \mathrm{mmol} / \mathrm{L}(\geq 92 \\
\mathrm{mg} / \mathrm{dL})\end{array}$ & $\begin{array}{l}\geq 10 \mathrm{mmol} / \\
\mathrm{L}(\geq 180 \\
\mathrm{mg} / \mathrm{dL})\end{array}$ & $\begin{array}{l}\geq 8.5 \mathrm{mmol} / \mathrm{L}(\geq 153 \\
\mathrm{mg} / \mathrm{dL})\end{array}$ & - \\
\hline
\end{tabular}


Table 1. Examples of diagnostic criteria for gestational diabetes mellitus (Continued)

\begin{tabular}{|c|c|c|c|c|c|c|}
\hline WHO 2013* & & $75 \mathrm{~g}$ & $\begin{array}{l}5.1-6.9 \mathrm{mmol} / \mathrm{L}(92 \\
-125 \mathrm{mg} / \mathrm{dl})\end{array}$ & $\begin{array}{l}\geq 10 \mathrm{mmol} / \\
\mathrm{L}(\geq 180 \\
\mathrm{mg} / \mathrm{dL})\end{array}$ & $\begin{array}{l}8.5-11.0 \mathrm{mmol} / \mathrm{L} \\
(153-199 \mathrm{mg} / \mathrm{dl})\end{array}$ & \\
\hline ADA 2015b & $\begin{array}{l}50 \mathrm{~g} \\
(\geq 7.8 \mathrm{mmol} / \mathrm{L} ; \\
\geq 140 \mathrm{mg} / \mathrm{dL})\end{array}$ & $75 \mathrm{~g}$ & $\begin{array}{l}\geq 5.1 \mathrm{mmol} / \mathrm{L}(\geq 92 \\
\mathrm{mg} / \mathrm{dL})\end{array}$ & $\begin{array}{l}\geq 10 \mathrm{mmol} / \\
\mathrm{L}(\geq 180 \\
\mathrm{mg} / \mathrm{dL})\end{array}$ & $\begin{array}{l}\geq 8.5 \mathrm{mmol} / \mathrm{L}(\geq 153 \\
\mathrm{mg} / \mathrm{dL})\end{array}$ & - \\
\hline $\begin{array}{l}\text { ACOG } 2013 \\
\text { Carpenter and } \\
\text { Coustan^^}\end{array}$ & $\begin{array}{l}50 \mathrm{~g} \\
(>7.2 \mathrm{mmol} / \mathrm{L} ; \\
>130 \mathrm{mg} / \mathrm{dL})\end{array}$ & $100 \mathrm{~g}$ & $\begin{array}{l}\geq 5.3 \mathrm{mmol} / \mathrm{L}(95 \\
\mathrm{mg} / \mathrm{dL})\end{array}$ & $\begin{array}{l}\geq 10 \mathrm{mmol} / \\
\mathrm{L}(180 \mathrm{mg} / \\
\mathrm{dL})\end{array}$ & $\begin{array}{l}\geq 8.6 \mathrm{mmol} / \mathrm{L}(155 \\
\mathrm{mg} / \mathrm{dL})\end{array}$ & $\begin{array}{l}\geq 7.8 \mathrm{mmol} / \\
\mathrm{L}(140 \mathrm{mg} / \\
\mathrm{dL})\end{array}$ \\
\hline Data Group^^ & $\begin{array}{l}50 \mathrm{~g} \\
(>7.8 \mathrm{mmol} / \mathrm{L} ;> \\
140 \mathrm{mg} / \mathrm{dL})\end{array}$ & $100 \mathrm{~g}$ & $\begin{array}{l}\geq 5.8 \mathrm{mmol} / \mathrm{L}(105 \\
\mathrm{mg} / \mathrm{dL})\end{array}$ & $\begin{array}{l}\geq 10.6 \\
\mathrm{mmol} / \mathrm{L} \\
(190 \mathrm{mg} / \\
\mathrm{dL})\end{array}$ & $\begin{array}{l}\geq 9.2 \mathrm{mmol} / \mathrm{L}(165 \\
\mathrm{mg} / \mathrm{dL})\end{array}$ & $\begin{array}{l}\geq 8.0 \mathrm{mmol} / \\
\mathrm{L}(145 \mathrm{mg} / \\
\mathrm{dL})\end{array}$ \\
\hline $\begin{array}{l}\text { ADIPS } 1998 \text { (Hoff- } \\
\text { man 1998) }\end{array}$ & & $75 \mathrm{~g}$ & $\begin{array}{l}\geq 5.5 \mathrm{mmol} / \mathrm{L}(\geq 99 \\
\mathrm{mg} / \mathrm{dL})\end{array}$ & & $\begin{array}{l}\geq 8.0 \mathrm{mmol} / \mathrm{L}(\geq 144 \\
\mathrm{mg} / \mathrm{dL})\end{array}$ & \\
\hline WHO 1999* & & $75 \mathrm{~g}$ & $\begin{array}{l}\geq 7.0 \mathrm{mmol} / \mathrm{L}(\geq 126 \\
\mathrm{mg} / \mathrm{dL})\end{array}$ & - & $\begin{array}{l}\geq 7.8 \mathrm{mmol} / \mathrm{L}(140 \\
\mathrm{mg} / \mathrm{dL})\end{array}$ & \\
\hline NICE 2015 & - & $75 \mathrm{~g}$ & $\begin{array}{l}\geq 5.6 \mathrm{mmol} / \mathrm{L}(\geq 101 \\
\mathrm{mg} / \mathrm{dL})\end{array}$ & - & $\begin{array}{l}\geq 7.8 \mathrm{mmol} / \mathrm{L}(140 \\
\mathrm{mg} / \mathrm{dL})\end{array}$ & - \\
\hline $\begin{array}{l}\text { New Zealand Min- } \\
\text { istry of Health 2014* }\end{array}$ & $\begin{array}{l}50 \mathrm{~g} \text { if } \mathrm{HbA} 1 \mathrm{c}<41 \\
\mathrm{mmol} / \mathrm{mol} \\
(\geq 7.8 \mathrm{mmol} / \mathrm{L} ; \\
\geq 140 \mathrm{mg} / \mathrm{dL})\end{array}$ & $75 \mathrm{~g}$ & $\begin{array}{l}\geq 5.5 \mathrm{mmol} / \mathrm{L}(\geq 99 \\
\mathrm{mg} / \mathrm{dL})\end{array}$ & - & $\begin{array}{l}\geq 9.0 \mathrm{mmol} / \mathrm{L}(\geq 162 \\
\mathrm{mg} / \mathrm{dL})\end{array}$ & - \\
\hline
\end{tabular}

ADA American Diabetes Association (recommends either the one step or two step strategy)

IADPSG International Association of the Diabetes and Pregnancy Study Groups

ADIPS Australasian Diabetes in Pregnancy Society

ACOG American College of Obstetrics and Gynecology

NICE National Institute for Health and Care Excellence

* 1 abnormal result required for diagnosis

$\wedge 2$ or more abnormal results required for diagnosis

Table 2. Maternal age (years)

\begin{tabular}{lll}
\hline Study ID & Lifestyle intervention & Usual care or diet alone \\
\hline Bancroft 2000 & Not stated & Not stated \\
\hline Bo 2014 & Exercise $35.9 \pm 4.8(n=51)$ & Diet $33.9 \pm 5.3(n=50)$ \\
& Behaviour 35.1 $\pm 4.4(n=49)$ & \\
& Behaviour/exercise/diet 35.5 $\pm 4.4(n=50)$ & $30.1 \pm 5.5(n=510)$ \\
\hline
\end{tabular}


Table 2. Maternal age (years) (Continued)

\begin{tabular}{lll} 
Elnour 2008 & $31.1(95 \% \mathrm{Cl} 30.2$ to 32.1) & $30.7(95 \% \mathrm{Cl} 29.4$ to 32) \\
\hline Ferrara 2011 & Not stated & Not stated \\
\hline Garner 1997 & $30.7 \pm 4.8(\mathrm{n}=149)$ & $30.7 \pm 4.6(\mathrm{n}=150)$ \\
\hline Gillen 2004 & Not stated & Not stated \\
\hline Jovanovic-Peterson 1989 & $31.1 \pm 2.8(\mathrm{n}=9)$ & $29.5 \pm 2.5(\mathrm{n}=10)$ \\
\hline Kaviani 2014 & Not stated & Not stated \\
\hline Landon 2009 & $29.2 \pm 5.7(\mathrm{n}=485)$ & $28.9 \pm 5.6(\mathrm{n}=473)$ \\
\hline Mendelson 2008 & $30.6 \pm 5.6(\mathrm{n}=49)$ & $31.5 \pm 5.2(\mathrm{n}=51)$ \\
\hline Rahimikian 2014 & $30.9 \pm 5.7(\mathrm{n}=42)$ face to face & $30.1 \pm 5.8(\mathrm{n}=42)$ \\
\hline Yang 2003 & $30.4 \pm 5.5(\mathrm{n}=42)$ booklet & Not stated \\
\hline Yang 2014 & Not stated & $29.73 \pm 3.2(\mathrm{n}=361)$ \\
\hline Youngwanichsetha 2014 & $32.58 \pm 5.01(\mathrm{n}=85)$ & $31.24 \pm 4.54(\mathrm{n}=85)$ \\
\hline
\end{tabular}

Bo 2014; Jovanovic-Peterson 1989 compared a lifestyle intervention with diet alone

Table 3. Maternal BMI at trial entry $(\mathrm{kg} / \mathrm{m} 2)$

\begin{tabular}{|c|c|c|}
\hline Study ID & Lifestyle intervention & Usual care or diet alone \\
\hline Bancroft 2000 & $31.2 \pm 6.7(n=32)$ & $27.5 \pm 6.1(n=36)$ \\
\hline \multirow[t]{3}{*}{ Bo 2014} & Exercise $27.7 \pm 4.3(n=49)$ & Diet $27.5 \pm 4.5(n=50)$ \\
\hline & Behaviour $27.5 \pm 4.4(n=49)$ & \\
\hline & Behaviour/exercise/diet $27.5 \pm 3.9(n=50)$ & \\
\hline Crowther 2005 & Median 26 (IQR 23.3 to 31.2) $(n=490)$ & Median $26($ IQR 22.9 to 30.9$)(n=510)$ \\
\hline Elnour 2008 & Not stated & Not stated \\
\hline Ferrara 2011 & Not stated but $57 \%$ had $\mathrm{BMI}>30$ & Not stated but $53 \%$ had $\mathrm{BMI}>30$ \\
\hline Garner 1997 & Not stated & Not stated \\
\hline Gillen 2004 & Not stated & Not stated \\
\hline Jovanovic-Peterson 1989 & Not stated & Not stated \\
\hline Kaviani 2014 & Not stated & Not stated \\
\hline Landon 2009 & $30.1 \pm 5.0(n=485)$ & $30.2 \pm 5.1(n=473)$ \\
\hline
\end{tabular}


Table 3. Maternal BMI at trial entry $(\mathrm{kg} / \mathrm{m} 2)$ (Continued)

\begin{tabular}{llc} 
Mendelson 2008 & Not stated & Not stated \\
\hline Rahimikian 2014 & Not stated & Not stated \\
\hline Yang 2003 & Not stated & Not stated \\
\hline Yang 2014 & $22.9 \pm 3.6(n=339)$ & $27.4 \pm 3.9(n=361)$ \\
\hline Youngwanichsetha 2014 & $27.09 \pm 3.56(n=85)$ & $275)$ \\
\hline
\end{tabular}

Bo 2014; Jovanovic-Peterson 1989 compared a lifestyle intervention with diet alone

Table 4. Ethnicity/Race

\begin{tabular}{|c|c|}
\hline Study ID & Ethnicity/Race \\
\hline Bancroft 2000 & $31 \%$ of women were Asian and $69 \%$ were Caucasian \\
\hline Bo 2014 & Not stated \\
\hline Crowther 2005 & $76 \%$ were Caucasian and $17 \%$ were Asian \\
\hline Elnour 2008 & UAE national \\
\hline Ferrara 2011 & $\begin{array}{l}52 \% \text { were Asian or Pacific Islander; } 19 \% \text { were non-Hispanic Caucasian and 19\% } \\
\text { were Hispanic }\end{array}$ \\
\hline Garner 1997 & Not stated \\
\hline Gillen 2004 & Not stated \\
\hline Jovanovic-Peterson 1989 & Not stated \\
\hline Kaviani 2014 & Persian \\
\hline Landon 2009 & 11.5\% Black, 25\% Caucasian, 5\% Asian, 56.5\% Hispanic \\
\hline Mendelson 2008 & Mexican \\
\hline Rahimikian 2014 & Not stated \\
\hline Yang 2003 & Not stated - probably Chinese \\
\hline Yang 2014 & 97\% Chinese Han \\
\hline Youngwanichsetha 2014 & Thai \\
\hline
\end{tabular}

Bo 2014; Jovanovic-Peterson 1989 compared a lifestyle intervention with diet alone

Table 5. Gestation at trial entry (weeks)

\begin{tabular}{lll}
\hline Study ID & Lifestyle intervention & Usual care or diet alone \\
\hline Bancroft 2000 & 31 (range 24 to 38) (n=32) & 32 (range 15 to 37) (n=36) \\
\hline \hline
\end{tabular}

Lifestyle interventions for the treatment of women with gestational diabetes (Review) 
Table 5. Gestation at trial entry (weeks) (Continued)

\begin{tabular}{|c|c|c|}
\hline Bo 2014 & Not stated & Not stated \\
\hline Crowther 2005 & Median 29.1 (IQR 28.2 to 30.0$)(n=490)$ & Median $29.2($ IQR 28.2 to 30.0$)(n=510)$ \\
\hline Elnour 2008 & $<20$ weeks' & $<20$ weeks' \\
\hline Ferrara 2011 & $31 \pm 5.6(n=96)$ & $31.0 \pm(n=6.1)$ \\
\hline Garner 1997 & Not stated & Not stated \\
\hline Gillen 2004 & Not stated & Not stated \\
\hline Jovanovic-Peterson 1989 & Not stated & Not stated \\
\hline Kaviani 2014 & Not stated & Not stated \\
\hline Landon 2009 & $28.8 \pm 1.6(n=485)$ & $28.9 \pm 1.5(n=473)$ \\
\hline Mendelson 2008 & Not stated & Not stated \\
\hline Rahimikian 2014 & Not stated & Not stated \\
\hline Yang 2003 & Not stated & Not stated \\
\hline Yang 2014 & Not stated & Not stated \\
\hline Youngwanichsetha 2014 & Not stated & Not stated \\
\hline
\end{tabular}

Bo 2014; Jovanovic-Peterson 1989 compared a lifestyle intervention with diet alone

Table 6. Treatment target

\begin{tabular}{ll}
\hline Study ID & Treatment target \\
\hline Bancroft 2000 & Insulin was introduced if 5 or more capillary measurements $>7.0 \mathrm{mmol} / \mathrm{L}(126 \mathrm{mg} / \mathrm{dL})$ in $1 \mathrm{week}$ \\
\hline Bo 2014 & $\begin{array}{l}\text { Treatment glycaemic targets were not detailed but insulin was started in the presence of fetal ab- } \\
\text { dominal ultrasound }>70 \text { th percentile and or maternal hyperglycaemia (no details) }\end{array}$ \\
\hline Crowther 2005 & $\begin{array}{l}\text { Fasting glucose levels } 3.5 \mathrm{mmol} / \mathrm{L}(63 \mathrm{mg} / \mathrm{dL}) \text { to } 5.5 \mathrm{mmol} / \mathrm{L}(99 \mathrm{mg} / \mathrm{dL}) \text {, pre-prandial levels of no } \\
\text { more than } 5.5 \mathrm{mmol} / \mathrm{L}(99 \mathrm{mg} / \mathrm{dL}), \text { and levels } 2 \text { hours post-prandially that were no more than } 7.0 \\
\text { mmol/L }(126 \mathrm{mg} / \mathrm{dL})\end{array}$ \\
\hline Elnour 2008 & Not stated \\
\hline Ferrara 2011 & Not stated \\
\hline Garner 1997 & Fasting glucose levels $<4.4 \mathrm{mmol} / \mathrm{L}(80 \mathrm{mg} / \mathrm{dL}) ; 1$-hour post-prandial $<7.8 \mathrm{mmol} / \mathrm{L}(140 \mathrm{mg} / \mathrm{dL})$ \\
\hline Gillen 2004 & Not stated \\
\hline Jovanovic-Peterson 1989 & $\begin{array}{l}\text { Fasting plasma glucose } \leq 5.8 \mathrm{mmol} / \mathrm{L} \text { or } 105 \mathrm{mg} / \mathrm{dL} \text { and/or 1-hour post-prandial plasma glucose } \\
\text { was } \leq 7.8 \mathrm{mmol} / \mathrm{L}(140 \mathrm{mg} / \mathrm{dL})\end{array}$ \\
\hline Kaviani 2014 & Not stated \\
\hline
\end{tabular}


Table 6. Treatment target (Continued)

\begin{tabular}{ll} 
Landon 2009 & Fasting glucose levels $<5.3 \mathrm{mmol} / \mathrm{L}, 2$-hour post-prandial glucose $<6.7 \mathrm{mmol} / \mathrm{L}$ \\
\hline Mendelson 2008 & Not stated \\
\hline Rahimikian 2014 & Not stated \\
\hline Yang 2003 & $<5.5 \mathrm{mmol} / \mathrm{L}(99 \mathrm{mg} / \mathrm{dL})$ fasting; $<7.0 \mathrm{mmol} / \mathrm{L}(126 \mathrm{mg} / \mathrm{dL}) 1.5$ hours postprandial \\
\hline Yang 2014 & $\geq 3.5$ to $\leq 5.1 \mathrm{mmol} / \mathrm{L}$ for fasting capillary glucose and $\leq 7.0 \mathrm{mmol} / \mathrm{L}(126 \mathrm{mg} / \mathrm{dL})$ for 2 -hour post- \\
& prandial capillary glucose up to 36 weeks' gestation and $\leq 8.0 \mathrm{mmol} / \mathrm{L}$ from 36 weeks' onwards \\
\hline Youngwanichsetha 2014 & Not stated
\end{tabular}

Bo 2014; Jovanovic-Peterson 1989 compared a lifestyle intervention with diet alone

Table 7. Details of diagnosis

\begin{tabular}{|c|c|c|c|c|}
\hline Study ID & Timing & Screening & Diagnosis & \\
\hline Bancroft 2000 & Not stated & Not stated & $\begin{array}{l}75 \mathrm{~g} \text { OGTT: fasting } \geq 7.0 \mathrm{mmol} / \mathrm{L} ; 2 \text { hour } 7.8 \\
\text { to } 11.0 \mathrm{mmol} / \mathrm{L}\end{array}$ & WHO 1999 \\
\hline Bo 2014 & 24 to 26 weeks' & Not stated & $75 \mathrm{~g}$ OGTT no further details & No details \\
\hline Crowther 2005 & 24 to 34 weeks' & $\begin{array}{l}50 \mathrm{~g} 1 \text {-hour glucose chal- } \\
\text { lenge at least } 7.8 \mathrm{mmol} / \mathrm{L} \\
(140 \mathrm{mg} / \mathrm{dL})\end{array}$ & $\begin{array}{l}75 \mathrm{~g} \text { OGTT plasma glucose level was less } \\
\text { than } 7.8 \mathrm{mmol} / \mathrm{L} \text { and } 2 \text {-hour value was } 7.8 \\
\text { to } 11.0 \mathrm{mmol} / \mathrm{L}(198 \mathrm{mg} / \mathrm{dL})\end{array}$ & WHO 1999 \\
\hline Elnour 2008 & 24 and 28 weeks' & $\begin{array}{l}50 \mathrm{~g} \text { 1-hour glucose chal- } \\
\text { lenge, serum value }>7.2 \\
\mathrm{mmol} / \mathrm{L} \text { or plasma value } \\
>7.8 \mathrm{mmol} / \mathrm{L} \text { or risk fac- } \\
\text { tors present }\end{array}$ & $\begin{array}{l}100 \mathrm{~g} \text { OGTT diagnosis if } 2 \text { or more values } \\
\text { are abnormal from fasting } \geq 5.3 \mathrm{mmol} / \mathrm{L}, 1 \text { - } \\
\text { hour value } \geq 10.0 \mathrm{mmol} / \mathrm{L}, 2 \text {-hour value } \geq \\
8.7 \mathrm{mmol} / \mathrm{L}, 3 \text {-hour value } \geq 7.8 \mathrm{mmol} / \mathrm{L}\end{array}$ & $\begin{array}{l}\text { Carpenter and } \\
\text { Coustan criteria }\end{array}$ \\
\hline Ferrara 2011 & Not stated & $\begin{array}{l}50 \mathrm{~g} \text { 1-hour glucose chal- } \\
\text { lenge }\end{array}$ & $100 \mathrm{~g}$ OGTT; 3-hour & $\begin{array}{l}\text { ADA (2000) crite- } \\
\text { ria }\end{array}$ \\
\hline Garner 1997 & 24 to 32 weeks' & $75 \mathrm{~g}$ 1-hour $>8 \mathrm{mmol} / \mathrm{L}$ & $\begin{array}{l}75 \mathrm{~g} \text { OGTT }>7.5 \mathrm{mmol} / \mathrm{L} \text { (2nd trimester) } \\
\text { and }>9.6 \mathrm{mmol} / \mathrm{L} \text { (3rd trimester) }\end{array}$ & Hatem 1988 \\
\hline Gillen 2004 & 28 weeks' & $\begin{array}{l}50 \mathrm{~g} \text { 1-hour venous plas- } \\
\text { ma glucose level } \geq 7.8 \\
\mathrm{mmol} / \mathrm{L} \text { or } \\
75 \mathrm{~g} \text { hour venous plasma } \\
\text { glucose level } \geq 8.0 \mathrm{mmol} / \\
\mathrm{L}\end{array}$ & $\begin{array}{l}75 \mathrm{~g} \text { OGTT plasma glucose level at fasting } \\
\text { of } \geq 5.5 \mathrm{mmol} / \mathrm{L} \text { and } / \text { or at } 2 \text { hours of } \geq 8.0 \\
\mathrm{mmol} / \mathrm{L}\end{array}$ & ADIPS 1998 \\
\hline $\begin{array}{l}\text { Jovanovic-Peter- } \\
\text { son } 1989\end{array}$ & Not stated & $\begin{array}{l}50 \mathrm{~g} \text { 1-hour glucose chal- } \\
\text { lenge }\end{array}$ & $\begin{array}{l}\text { Fasting and 1-hour tolerance test but no } \\
\text { other details provided }\end{array}$ & No details \\
\hline Kaviani 2014 & Not stated & Not stated & Not stated & Not stated \\
\hline Landon 2009 & 24 to 30 weeks' & $\begin{array}{l}50 \mathrm{~g} \text { 1-hour glucose chal- } \\
\text { lenge } 5.3 \text { to } 11 \mathrm{mmol} / \mathrm{L}\end{array}$ & $\begin{array}{l}100 \mathrm{~g} \text { OGTT; } 2 \text { or more of results was ab- } \\
\text { normal in addition to the abnormal chal- } \\
\text { lenge test (fasting }<5.3 \mathrm{mmol} / \mathrm{L}, 1 \text {-hour }\end{array}$ & $\begin{array}{l}\text { Carpenter and } \\
\text { Coustan criteria }\end{array}$ \\
\hline
\end{tabular}


Table 7. Details of diagnosis (Continued)

$>10.0 \mathrm{mmol} / \mathrm{L}, 2$-hours $>8.6 \mathrm{mmol} / \mathrm{L}, 3-$

hours $>7.8 \mathrm{mmol} / \mathrm{L}$

\begin{tabular}{lllll}
\hline Mendelson 2008 & Not stated & Not stated & Not stated & Not stated \\
\hline Rahimikian 2014 & Not stated & Not stated & Not stated & Not stated \\
\hline Yang 2003 & 26 to 30 weeks' & $\begin{array}{l}50 \text { g, 1-hour glucose chal- } \\
\text { lenge, } \geq 7.8 \mathrm{mmol} / \mathrm{L}\end{array}$ & $\begin{array}{l}\text { 75 g, 2-hour OGTT; fasting } \geq 7.0 \mathrm{mmol} / \mathrm{L}, \text { or } \\
\text { 2-hour glucose } \geq 7.8 \text { and } \leq 11.1 \mathrm{mmol} / \mathrm{L}\end{array}$ & WHO criteria \\
\hline Yang 2014 & 24 to 28 weeks' & $\begin{array}{l}50 \text { g, 1-hour glucose chal- } \\
\text { lenge, } \geq 7.8 \mathrm{mmol} / \mathrm{L}\end{array}$ & $\begin{array}{l}\text { 75 g, 2-hour OGTT; fasting } \geq 5.1 \mathrm{mmol} / \mathrm{L}, \\
\text { or 1-hour glucose } \geq 10.0 \mathrm{mmol} / \mathrm{L} \text { or 2-hour } \\
\text { glucose } \geq 8.5 \mathrm{mmol} / \mathrm{L}\end{array}$ & IADPSG criteria \\
\hline $\begin{array}{l}\text { Youngwanich- } \\
\text { setha 2014 }\end{array}$ & 24 to 30 weeks' & Not stated & Not stated & Not stated \\
\hline
\end{tabular}

OGTT: oral glucose tolerance test

Table 8. Other maternal outcomes

\begin{tabular}{|c|c|c|c|}
\hline Study ID & Outcome & Lifestyle & Usual care \\
\hline \multirow[t]{2}{*}{ Bancroft 2000} & $\begin{array}{l}\text { Postnatal fasting glucose } \\
(\mathrm{mmol} / \mathrm{L})\end{array}$ & Median 4.5 (range $2.7-5.9) n=28$ & Median 4.4 (range $2.4-8.8$ ) $n=28$ \\
\hline & $\begin{array}{l}\text { Postnatal post prandial 2-hour } \\
(\mathrm{mmol} / \mathrm{L})\end{array}$ & Median 5.1 (range 2.1-8.5) n = 28 & Median 5.5 (range $3.0-13.7) n=28$ \\
\hline Landon 2009 & $\begin{array}{l}\text { Maternal BMI }(\mathrm{kg} / \mathrm{m} 2) \text { at fol- } \\
\text { low-up }\end{array}$ & $\begin{array}{l}\text { Mean } 29.4(95 \% \mathrm{Cl} 28.6 \text { to } 30.3) n= \\
243\end{array}$ & $\begin{array}{l}\text { Mean } 29.1(95 \% \mathrm{Cl} 28.2 \text { to } 30.0) \mathrm{n} \\
=214\end{array}$ \\
\hline Garner 1997 & $\begin{array}{l}\text { Maternal BMI }(\mathrm{kg} / \mathrm{m} 2) \text { at fol- } \\
\text { low-up }\end{array}$ & BMI median 27.3 (range 19.4 to 50.5 ) & BMI median 29.6 (21.3 to 49.1 ) \\
\hline Garner 1997 & $\begin{array}{l}\text { Maternal fasting glucose at fol- } \\
\text { low-up }\end{array}$ & $\begin{array}{l}\text { Fasting glucose median } 5.4 \text { (range } 4.4 \\
\text { to } 7.8) \mathrm{mmol} / \mathrm{L}\end{array}$ & $\begin{array}{l}\text { Fasting glucose median } 5.5 \\
\text { (range } 4.8 \text { to } 17.6 \text { ) } \mathrm{mmol} / \mathrm{L}\end{array}$ \\
\hline
\end{tabular}

Table 9. Neonatal outcomes

\begin{tabular}{|c|c|c|c|}
\hline Study ID & Outcome & Lifestyle intervention & Ususal care or diet alone \\
\hline Crowther 2005 & $\begin{array}{l}\text { Gestational age at } \\
\text { birth }\end{array}$ & $\begin{array}{l}\text { Median } 39 \text { weeks (IQR } 38.1-40.0)(n= \\
\text { 490) }\end{array}$ & Median $39.3($ IQR $38.3-40.4)(n=510)$ \\
\hline $\begin{array}{l}\text { Jovanovic-Peterson } \\
1989\end{array}$ & $\begin{array}{l}\text { Gestational age at } \\
\text { birth }\end{array}$ & Range 39.5 to 40.5 weeks & Range 39.4 to 40.0 weeks \\
\hline
\end{tabular}

Jovanovic-Peterson 1989 compared a lifestyle intervention with diet alone 
Table 10. Health service use

\begin{tabular}{|c|c|c|c|}
\hline Study ID & Type of health service use & Lifestyle intervention & Usual care \\
\hline Bancroft 2000 & Number of capillary blood tests & Median 118 (range $0-520) ; \mathrm{n}=32$ & Median 0 (range 0$) ; \mathrm{n}=36$ \\
\hline Bancroft 2000 & Number of antenatal visits & Median 17 (range 2-28); $\mathrm{n}=32$ & Median 14 (range 6-33); $n=36$ \\
\hline Crowther 2005 & $\begin{array}{l}\text { Number of antenatal clinic visits after en- } \\
\text { rolment }\end{array}$ & Median $5.0($ IQR 1-7) n = 490 & Median $5.2($ IQR 3-7) n = 510 \\
\hline Crowther 2005 & $\begin{array}{l}\text { Number of physician clinic visits after en- } \\
\text { rolment }\end{array}$ & Median $3($ IQR 1-7) n = 490 & Median $0($ IQR $0-2) n=510$ \\
\hline Bancroft 2000 & Number of hospital admissions & Median 1 (range 0-6); $\mathrm{n}=32$ & Median 0 (range 0-8); $\mathrm{n}=36$ \\
\hline Crowther 2005 & Duration of stay in neonatal nursery & Median 1 day (IQR 1-2) $n=506$ & $\begin{array}{l}\text { Median } 1 \text { day (IQR 1-3) } n= \\
524\end{array}$ \\
\hline Crowther 2005 & Length of postnatal stay (mother) & Median 4 days (IQR 3-5) $n=490$ & $\begin{array}{l}\text { Median } 4 \text { days (IQR 3-5) } n= \\
510\end{array}$ \\
\hline Mendelson 2008 & Hospitalisation (days) (mother) & Mean 3.3, no SD provided & 3.3, no SD provided \\
\hline Mendelson 2008 & Hospitalisation (days) (infant) & Mean 3.4, no SD provided & 3.3, no SD provided \\
\hline
\end{tabular}

IQR: interquartile range

Table 11. Cost

\begin{tabular}{lll}
\hline Crowther 2005 & Lifestyle intervention & Usual care \\
\hline Package of treatment for mild GDM versus usual care & & \\
\hline $\begin{array}{l}\text { Direct costs per } 100 \text { women with a singleton pregnancy - including antenatal } \\
\text { clinic visits, specialist clinics, dietician, diabetes educator, insulin therapy }\end{array}$ & AUD67,432 & AUD33,681 \\
\hline In-patient costs - hospital costs & AUD545,125 & AUD524,891 \\
\hline Total direct health service costs & AUD612,557 & AUD558,572 \\
\hline Patient/family costs & AUD36,749 & AUD30,229
\end{tabular}

These data are in the publication by Moss (2007)

\section{APPEN DICES}

\section{Appendix 1. Clinical trial registry search strategy}

gestational diabetes OR GDM

diabetes AND pregnancy

\section{CONTRIBUTIONSOF AUTHORS}

Julie Brown guarantees this review. 
Julie Brown wrote the first version of this review and identified studies for inclusion along with Stephen Brown. She also was undertook data extraction and assessed risk of bias. She prepared the GRADE 'Summary of findings' tables.

The remaining authors Nisreen A Alwan; Jane West, Stephen Brown, Christopher JD McKinlay, Diane Farrar and Caroline Crowther have all contributed to interpretation of the data from clinical, paediatric and expert opinions and have provided significant feedback to draft versions, including the GRADE 'Summary of findings' tables.

\section{DECLARATIONS OF INTEREST}

Julie Brown: none known.

Nisreen A Alwan: received funding from the Wellcome Trust between Sep 2009-May 2014 for a Research Training Fellowship entitled: "The effect of maternal iron status and intake during pregnancy on cardiovascular disease risk in the offspring".

Jane West: none known.

Stephen Brown: none known.

Christopher JD McKinlay: none known.

Diane Farrar: none known.

Caroline A Crowther is the lead investigator for the ACHOIS trial that assessed treatment for women with mild gestational diabetes. This will be considered for inclusion in this review. However, Professor Crowther will not be involved in the decisions about inclusion of data or any data extraction from that trial.

\section{SOURCES OF SUPPORT}

\section{Internal sources}

- An internal University department grant, New Zealand.

An internal University of Auckland department grant from the Liggins Institiute has been awarded to Julie Brown to help with the preparation of several Cochrane systematic reviews as part of an Overview of Cochrane reviews for the treatment of women with gestational diabetes.

- Liggins Institute, New Zealand.

Support for infrastructure to support the preparation of this protocol is from the Liggins Institute, University of Auckland, New Zealand.

\section{External sources}

- Australian Satellite of the Cochrane Pregnancy and Childbirth Review Group, Australia.

Support for infrastructure from the Australian Satellite of the Cochrane Pregnancy and Childbirth

- National Institute for Health Research (NIHR), UKNIHR Cochrane Programme Grant Project: 13/89/05 - Pregnancy and childbirth systematic reviews to support clinical guidelines, UK.

\section{DIFFERENCES BETWEEN PROTOCOL AND REVIEW}

There are some differences between our published protocol (Brown 2015) and the full review, these are listed below.

Background - portions of the background have been amended for clarity following feedback from the authors of this review.

Objectives - this section has been edited to reflect that the intervention is about 'combined' lifestyle interventions which could be with or without pharmacotherapy.

\section{NOTES}

The original review (Alwan 2009) has been split into three new reviews due to the complexity of the included interventions. The following new review protocols have been published.

Lifestyle interventions for the treatment of women with gestational diabetes (this review)

Oral anti-diabetic pharmacological therapies for the treatment of women with gestational diabetes

Insulin for the treatment of women with gestational diabetes 
There will be similarities in the background, methods and outcomes between these three systematic reviews.

\section{N DEX TERMS}

\section{Medical Subject Headings (MeSH)}

*Life Style; Blood Glucose Self-Monitoring; Body Mass Index; Body Weight; Cesarean Section [statistics \& numerical data]; Depression, Postpartum [epidemiology]; Diabetes Mellitus, Type 2 [etiology]; Diabetes, Gestational [ ${ }^{\star}$ therapy]; Diet, Diabetic; Exercise; Infant, Postmature; Labor, Induced [statistics \& numerical data]; Patient Education as Topic; Perineum [injuries]; Pre-Eclampsia [epidemiology]; Randomized Controlled Trials as Topic

\section{MeSH check words}

Female; Humans; Infant, Newborn; Pregnancy 